\title{
REATOR ANAERÓBIO-AERÓBIO DE LEITO FIXO EM ESCALA PILOTO, COM RECIRCULAÇÃO DA FASE LÍQUIDA, APLICADO AO TRATAMENTO DE ESGOTO SANITÁRIO
}

\section{Antonio Pedro de Oliveira Netto}

\author{
Tese apresentada à Escola de Engenharia \\ de São Carlos, da Universidade de São \\ Paulo, como parte dos requisitos \\ necessários para obtenção do título de \\ Doutor em Ciências (Engenharia \\ Hidráulica e Saneamento).
}

Orientador: Prof. Dr. Marcelo Zaiat

Edição Revisada

SÃO CARLOS, SP 
AUTORIZO A REPRODUÇÃO E DIVULGAÇÃO TOTAL OU PARCIAL DESTE TRABALHO, POR QUALQUER MEIO CONVENCIONAL OU ELETRÔNICO, PARA FINS DE ESTUDO E PESQUISA, DESDE QUE CITADA A FONTE.

Ficha catalográfica preparada pela Seção de Tratamento da Informação do Serviço de Biblioteca - EESC/USP

$048 r$

Oliveira Netto, Antonio Pedro

Reator anaeróbio-aeróbio de leito fixo em escala piloto com recirculação da fase líquida, aplicado ao tratamento de esgoto sanitário / Antonio Pedro Oliveira Netto ; orientador Marcelo Zaiat. -- São Carlos, 2011.

Tese (Doutorado-Programa de Pós-Graduação e Área de Concentração em Hidráulica e Saneamento) -- Escola de Engenharia de São Carlos da Universidade de São Paulo, 2010 .

1. Tratamento anaeróbio-aeróbio. 2. Esgoto sanitário. 3. Biomassa imobilizada. 4. Recirculação da fase líquida. 5. Escala piloto I. Título. 


\section{FOLHA DE JULGAMENTO}

Candidato(a): Engenheiro ANTONIO PEDRO DE OLIVEIRA NETTO.

Tese defendida e julgada em 29/04/2011 perante a Comissão Julgadora:

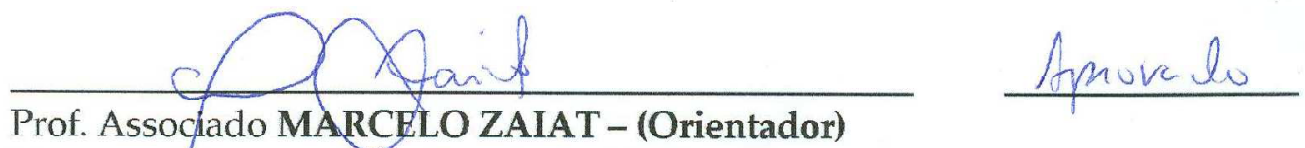

(Escola de/Engenharia de São Carlos/USP)

Wánie OrR Z Somiann'c

Prof ${ }^{a}$. Dr ${ }^{a}$. MÁRCIA HELENA RISSATO ZAMARIOLLI DAMIANOVIC

(Escola de Engenharia de São Carlos/USP)
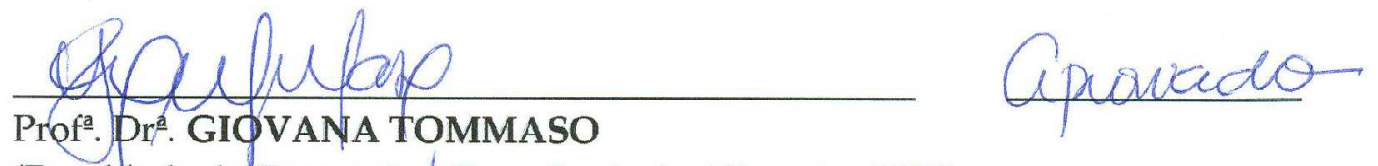

(Faculdade de Zootecnia é Engenharia de Alimentos/USP)

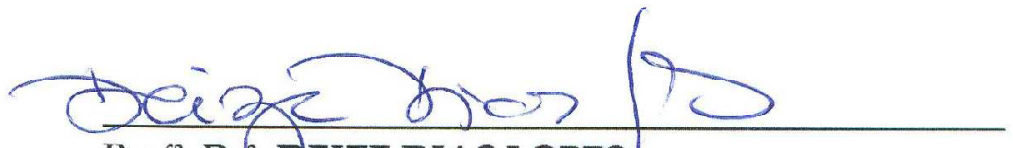

Prof ${ }^{a}$. Dre. DEIZE DIAS LOPES

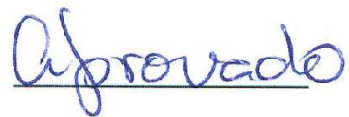

(Universidade Estadual de Londrina/UEL)

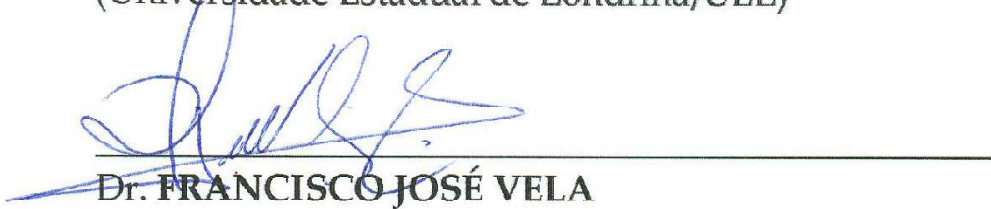

aprovedo

(Aquarum Saneamento Ambiental)

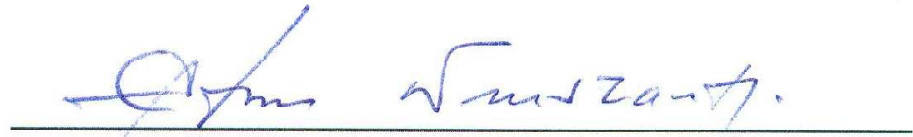

Prof. Titular EDSON CEZAR WENDLAND

Coordenador do Programa de Pós-Graduação em

EngenharjarHidráulica e Saneamento.

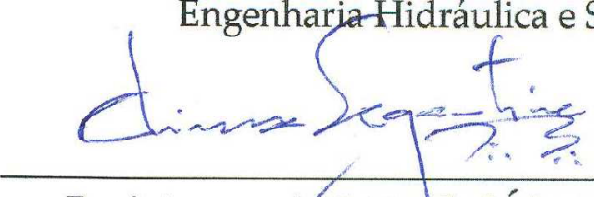

Prof. Associad6 PAULO CÉSAR LIMA SEGANTINE

Presidente dą Comissão da Pós-Graduação da EESC 
"A mais nobre alegria dos homens que pensam é haverem explorado o concebível e reverenciarem em paz o incognoscível" (Johann Goethe) 
À minha família, em especial aos meus pais José Mário Quintella e Suzana Maria pelo apoio e carinho incondicionais e à minha esposa Carla Rodrigues por todo incentivo e compreensão. 


\section{AGRADECIMENTOS}

Agradeço primeiramente a Deus, que é o maior responsável por todas as conquistas.

Meus pais, meu irmão e meu avô Antonio Oliveira que são a grande motivação de meu sucesso, pelas suas demonstrações de confiança e compreensão.

Agradeço a minha esposa Carla pelo incentivo e companheirismo durante todo o período de pós-graduação e pelo apoio nos momentos mais difíceis e cansativos de idas e vindas a São Paulo.

Ao professor Doutor e grande amigo Marcelo Zaiat pela excelente orientação que através de suas críticas e elogios procurou fazer sempre o melhor possível, contribuindo de forma decisiva para meu crescimento humano e profissional.

Aos meus amigos companheiros de turma do SHS, sou grato pelo convívio e disposição em ajudar nessa caminhada e ao aluno de iniciação científica Henrique Gamon Sonobe pelas realizações das análises durante grande parte do período experimental e por toda ajuda e amizade, os quais foram indispensáveis para conclusão desta pesquisa.

Às secretárias do Departamento de Hidráulica e Saneamento da EESC, Sá, Pavi e Rose pela disposição em ajudar no que fosse possível, e também à Flávia e Fernanda da contabilidade.

Ao Prof. Dr. Luiz Antonio Daniel e ao Eng. Civil Dr. Francisco José Vela pelas sugestões e avaliação do Plano de Qualificação.

Ao Prof. Titular Eugênio Foresti pela oportunidade de participar do Projeto Temático. 
Aos profissionais do Laboratório de Processos Biológicos (LPB), especialmente, Maria Ângela T. Adorno (Janja) pela permanente disposição em atender meus pedidos de ajuda durante a fase experimental desta pesquisa.

Aos colegas da área destinada aos estudos com esgoto sanitário do LPB, Jorge Pantoja, Theo Syrto, Adis Ivonne, Henrique Sonobe e principalmente ao grande amigo Eduardo Lucena pelo convívio, pela troca de idéias e ensinamentos durante a realização da pesquisa.

Aos amigos da colônia alagoana, Saulo José (Seu Boneco), Eduardo Lucena (Perereca), Valter Cléber (Clebinho), André Dória (Aliáasss), Walter Oliveira (Chimbinha), Gustavo Codá, Eduardo Toledo (Careca), Rafael Piatti, Rômulo Farias (Zoltan Clóoo), Pedro César, Wellison Gomes e Rafael pelos diversos momentos de descontração.

À General Water S/A pela iniciativa, ainda rara em nosso país, de financiar a pesquisa científica. Meus agradecimentos pela bolsa concedida, pelo apoio recebido e oportunidade de crescimento profissional.

À B\&F Dias pelo fornecimento dos difusores de ar utilizados na pesquisa e à FAPESP pelo apoio financeiro.

E a todos que de alguma maneira contribuíram para a realização deste trabalho. 


\section{SUMÁRIO}

LISTA DE FIGURAS i i

LISTA DE TABELAS vi

LISTA DE ABREVIATURAS E SIGLAS ix

LISTA DE SÍMBOLOS Xii

RESUMO XV XV

$\begin{array}{lll}\text { ABSTRACT } & \text { xvi }\end{array}$

$\begin{array}{ll}\text { 1. INTRODUÇÃO } & 01\end{array}$

$\begin{array}{ll}\text { 2. OBJETIVOS } & 05\end{array}$

$\begin{array}{ll}\text { 2.1 Objetivo Geral } & 05\end{array}$

$\begin{array}{ll}\text { 2.2 Objetivos Específicos } & 05\end{array}$

3. REVISÃO BIBLIOGRÁFICA 07

$\begin{array}{ll}3.1 \text { Tratamento de Esgoto Sanitário } & 07\end{array}$

$\begin{array}{ll}3.2 \text { Importância da remoção biológica de nitrogênio } & 13\end{array}$

3.3 Tratamento combinado anaeróbio-aeróbio de esgoto sanitário 21

3.4 Considerações Finais $\quad 32$

4. MATERIAL E MÉTODOS 37

4.1 Reator combinado anaeróbio-aeróbio de leito fixo em escala piloto 38

$\begin{array}{ll}\text { 4.2 Materiais Suporte } & 41\end{array}$

$\begin{array}{ll}4.3 \text { Esgoto Sanitário } & 43\end{array}$ 
4.4 Sistema de Aeração $\quad 46$

$\begin{array}{ll}\text { 4.5 Sistema de Sucção } & 49\end{array}$

$\begin{array}{lr}\text { 4.6 Métodos analíticos } & 50\end{array}$

4.7 Procedimento experimental $\quad 52$

4.8 Considerações para realização dos balanços de massa para 54 estimativa das constantes cinéticas

5. RESULTADOS E DISCUSSÕES

5.1 Caracterização da água residuária afluente ao sistema $\quad 59$

5.2 Avaliação do desempenho do reator 66

5.2.1 Avaliação do desempenho do reator combinado operado com 66 tempo de detenção hidráulica de 12 horas

5.2.2 Avaliação do desempenho do reator combinado operado com 85 tempo de detenção hidráulica de 10 horas

5.2.3 Avaliação do desempenho do reator combinado operado com 97 tempo de detenção hidráulica de 8 horas

5.2.4 Comparação entre as etapas estudadas

5.3 Aspectos construtivos e comparação com outras tecnologias 117

5.4 Balanço de massa para estimativa das constantes cinéticas 128

$\begin{array}{lr}\text { 5.4.1 Balanço para o carbono } & 129\end{array}$

5.4.1.1 Camada Acidogênica 129

5.4.1.2 Camada Anaeróbia/Anóxica/Aeróbia 132

$\begin{array}{ll}\text { 5.4.2 Balanço para o nitrogênio } & 137\end{array}$

5.4.2.1 Camada Acidogênica 137

5.4.2.2 Camada Anaeróbia/Anóxica 140 
5.4.3 Estimativa das constantes cinéticas

6. CONCLUSÕES

7.SUGESTÕES 


\section{LISTA DE FIGURAS}

Figura 3.1 Esquema da composição geral do esgoto doméstico.

Figura 3.2 Conversões biológicas do Nitrogênio.

Figura 4.1 Reator combinado anaeróbio-aeróbio em escala piloto.

Figura 4.2 Representação esquemática do reator combinado anaeróbio-aeróbio de 40 leito fixo em escala piloto.

Figura 4.3 Placa perfurada de fibra de vidro.

Figura 4.4 Materiais suporte utilizados no experimento. (a) Espuma de Poliuretano

$\left(\right.$ BioBob $\left.^{\circledR}\right)$; (b) Argila Expandida

Figura 4.5 Área de tratamento de esgoto do Laboratório de Processos Biológicos.

Figura 4.6 Bombas de alimentação e recirculação utilizadas na pesquisa.

Figura 4.7 Difusores tubulares de membrana de bolha fina.

Figura 4.8 Compressor de pistão para fornecimento de ar.

Figura 4.9 Filtro e medidor de vazão de ar.

Figura 4.10 Válvula de pé e crivo e cesto de aço inoxidável.

Figura 4.11 Sonda multiparâmetros.

Figura 4.12 Distribuição das camadas para realização do balanço de massa. 55

Figura 5.1 Perfil temporal de DQO bruta e filtrada para esgoto sanitário afluente, 60 realizado em abril de 2009.

Figura 5.2 Perfil temporal de da concentração de nitrogênio amoniacal para esgoto 60 sanitário afluente, realizado em abril de 2009.

Figura 5.3 Perfil temporal de concentração de sulfato para esgoto sanitário afluente, 61 realizado em abril de 2009.

Figura 5.4 Perfil temporal de DQO bruta e filtrada para esgoto sanitário afluente, 62 
realizado em julho de 2009.

Figura 5.5 Perfil temporal da concentração de nitrogênio amoniacal para esgoto 62 sanitário afluente, realizado em julho de 2009.

Figura 5.6 Perfil temporal de concentração de sulfato para esgoto sanitário afluente, 63 realizado em julho de 2009.

Figura 5.7 Perfil temporal de DQO bruta e filtrada para esgoto sanitário afluente, 64 realizado em novembro de 2009.

Figura 5.8 Perfil temporal da concentração de nitrogênio amoniacal para esgoto 65 sanitário afluente, realizado em novembro de 2009.

Figura 5.9 Perfil temporal de concentração de sulfato para esgoto sanitário afluente, 65 realizado em novembro de 2009.

Figura 5.10 Variação temporal da DQO para o reator de leito fixo operado de modo 71 contínuo com TDH de 12 horas.

Figura 5.11 Eficiências de remoção de DQO ao longo do tempo para o reator de leito 72 fixo operado de modo contínuo com TDH de 12 horas.

Figura 5.12 Variação temporal da Alcalinidade a Bicarbonato afluente e efluente para 73 o reator de leito fixo operado de modo contínuo com TDH de 12 horas.

Figura 5.13 Variação temporal da concentração das formas de Nitrogênio para o 75 reator de leito fixo operado de modo contínuo com TDH de 12 horas.

Figura 5.14 Variação temporal das concentrações efluentes das formas de Nitrogênio 75 para o reator de leito fixo operado de modo contínuo com TDH de 12 horas.

Figura 5.15 Variação temporal das concentrações efluentes de Nitrito, Nitrato e 77 alcalinidade para o reator de leito fixo operado de modo contínuo com TDH de 12 horas. 
Figura 5.16 Variação temporal do pH afluente e efluente para o reator de leito fixo 78 operado de modo contínuo com TDH de 12 horas.

Figura 5.17 Variação temporal da concentração de AVT afluente e efluente para o 79 reator de leito fixo operado de modo contínuo com TDH de 12 horas.

Figura 5.18 Variação temporal da concentração de SST afluente e efluente para o 80 reator de leito fixo operado de modo contínuo com TDH de 12 horas.

Figura 5.19 Variação temporal da concentração de SSV afluente e efluente para o 81 reator de leito fixo operado de modo contínuo com TDH de 12 horas.

Figura 5.20 Perfil temporal de DQO, para esgoto doméstico afluente e efluente para o 82 reator de leito fixo operado de modo contínuo com TDH de 12 horas e $r=3,0$.

Figura 5.21 Perfil temporal de Nitrogênio Amoniacal, para esgoto doméstico afluente 83 e efluente para o reator de leito fixo operado de modo contínuo com TDH de 12 horas e $\mathrm{r}=3,0$.

Figura 5.22 Perfil espacial de DQO para o reator de leito fixo operado de modo 83 contínuo com TDH de 12 horas e $\mathrm{r}=3,0$.

Figura 5.23 Perfil espacial de Nitrogênio Amoniacal para o reator de leito fixo 84 operado de modo contínuo com TDH de 12 horas e $r=3,0$.

Figura 5.24 Variação temporal da DQO para o reator de leito fixo operado de modo 88 contínuo com TDH de 10 horas.

Figura 5.25 Eficiências de remoção de DQO ao longo do tempo para o reator de leito 88 fixo operado de modo contínuo com TDH de 10 horas.

Figura 5.26 Variação temporal da Alcalinidade a Bicarbonato afluente e efluente para 89 o reator de leito fixo operado de modo contínuo com TDH de 10 horas.

Figura 5.27 Variação temporal da concentração das formas de Nitrogênio para o 91 
reator de leito fixo operado de modo contínuo com TDH de 10 horas.

Figura 5.28 Variação temporal das concentrações efluentes das formas de Nitrogênio 91 para o reator de leito fixo operado de modo contínuo com TDH de 10 horas.

Figura 5.29 Variação temporal das concentrações efluentes de Nitrito, Nitrato e 92 alcalinidade para o reator de leito fixo operado de modo contínuo com TDH de 10 horas.

Figura 5.30 Variação temporal do pH afluente e efluente para o reator de leito fixo 93 operado de modo contínuo com TDH de 10 horas.

Figura 5.31 Variação temporal da concentração de AVT afluente e efluente para o 94 reator de leito fixo operado de modo contínuo com TDH de 10 horas.

Figura 5.32 Variação temporal da concentração de SST afluente e efluente para o 95 reator de leito fixo operado de modo contínuo com TDH de 10 horas.

Figura 5.33 Variação temporal da concentração de SSV afluente e efluente para o 95 reator de leito fixo operado de modo contínuo com TDH de 10 horas.

Figura 5.34 Variação temporal da DQO para o reator de leito fixo operado de modo 101 contínuo com TDH de 8 horas.

Figura 5.35 Eficiências de remoção de DQO ao longo do tempo para o reator de leito 102 fixo operado de modo contínuo com TDH de 8 horas.

Figura 5.36 Variação temporal da Alcalinidade a Bicarbonato afluente e efluente para 103 o reator de leito fixo operado de modo contínuo com TDH de 8 horas.

Figura 5.37 Variação temporal da concentração das formas de Nitrogênio para o 104 reator de leito fixo operado de modo contínuo com TDH de 8 horas.

Figura 5.38 Variação temporal das concentrações efluentes das formas de Nitrogênio 105 para o reator de leito fixo operado de modo contínuo com TDH de 8 
horas.

Figura 5.39 Variação temporal das concentrações efluentes de Nitrito, Nitrato e 105 alcalinidade para o reator de leito fixo operado de modo contínuo com TDH de 8 horas.

Figura 5.40 Variação temporal do pH afluente e efluente para o reator de leito fixo 106 operado de modo contínuo com TDH de 8 horas.

Figura 5.41 Variação temporal da concentração de AVT afluente e efluente para o 107 reator de leito fixo operado de modo contínuo com TDH de 8 horas.

Figura 5.42 Variação temporal da concentração de SST afluente e efluente para o 108 reator de leito fixo operado de modo contínuo com TDH de 8 horas.

Figura 5.43 Variação temporal da concentração de SSV afluente e efluente para o 108 reator de leito fixo operado de modo contínuo com TDH de 8 horas.

Figura 5.44 Perfil temporal de DQO, para esgoto doméstico afluente e efluente para o 109 reator de leito fixo operado de modo contínuo com TDH de 8 horas e $r=3,0$.

Figura 5.45 Perfil temporal de Nitrogênio Amoniacal, para esgoto doméstico afluente 110 e efluente para o reator de leito fixo operado de modo contínuo com TDH de 8 horas e $\mathrm{r}=3,0$.

Figura 5.46 Perfil espacial de DQO para o reator de leito fixo operado de modo 110 contínuo com TDH de 8 horas e $r=3,0$.

Figura 5.47 Perfil espacial de Nitrogênio Amoniacal para o reator de leito fixo 111 operado de modo contínuo com TDH de 8 horas e $\mathrm{r}=3,0$.

Figura 5.48 Perfil temporal de 24 horas para esgoto doméstico efluente para o reator 112 de leito fixo operado de modo contínuo ao final da operação com TDH de 8 horas e $\mathrm{r}=3,0$. 
Figura 5.49 Volume de controle da camada anaeróbia-anóxica-aeróbia do reator 133 combinado para o balanço de carbono.

Figura 5.50 Perfil espacial de Nitrogênio Amoniacal, para esgoto doméstico no reator 139 de leito fixo operado de modo contínuo com TDH de 12 horas.

Figura 5.51 Volume de controle para camada anaeróbia-anóxica do reator combinado 142 para o balanço de nitrogênio.

Figura 5.52 Volume de controle para camada aeróbia do reator combinado para o 145 balanço de nitrogênio. 


\section{LISTA DE TABELAS}

Tabela 3.1 Valores típicos para caracterização de esgotos domésticos. 08

Tabela 3.2 Déficit na oferta de saneamento básico no Brasil. 10

Tabela 3.3 Doenças e outras conseqüências da ausência de tratamento do esgoto 11 sanitário.

Tabela 3.4 Transformações biológicas do nitrogênio.

Tabela 3.5 Dados operacionais das 4 fases na operação do reator de lodo ativado 30 operado em bateladas seqüenciais (RBS).

Tabela 4.1 Parâmetros analisados, método utilizado e freqüência de amostragem. 51

Tabela 4.2 Procedimento experimental utilizado durante a operação do sistema. 53

Tabela 5.1 Comparação entre os valores afluentes e efluentes da primeira etapa 68 operacional $(\mathrm{TDH}=12 \mathrm{~h})$.

Tabela 5.2 Comparação entre os valores afluentes e efluentes da segunda etapa 86 operacional $(\mathrm{TDH}=10 \mathrm{~h})$.

Tabela 5.3 Comparação entre os valores afluentes e efluentes da terceira etapa 98 operacional $(\mathrm{TDH}=8 \mathrm{~h})$.

Tabela 5.4 Comparação entre os valores efluentes das três etapas estudadas.

Tabela 5.5 Comparação entre os parâmetros operacionais das três etapas estudadas. 115

Tabela 5.6 Comparação entre diversos estudos com sistemas combinados tratando 119 esgoto sanitário.

Tabela 5.7 Composição média do biogás utilizado como fonte de doadores de 122 elétrons na pesquisa de Rodríguez (2006). 
Tabela 5.8 Comparação entre os parâmetros operacionais de sistemas de tratamento convencionais e reator combinado anaeróbio-aeróbio vertical de leito fixo.

Tabela 5.9 Constantes cinéticas aparentes para o reator combinado anaeróbio- 149 aeróbio de leito fixo.

Tabela 5.10 Comparação entre as constantes cinéticas de alguns estudos com 151 sistemas combinados tratando esgoto sanitário. 


\section{LISTA DE ABREVIATURAS E SIGLAS}

ADE Atividade Desnitrificante Específica.

AGV Ácido Graxos Voláteis.

AHR Anaerobic Hybrid Reactor.

AME Atividade Metanogênica Específica.

ANAMMOX Anaerobic Ammonium Oxidation.

APHA American Public Halph Association.

ASBBR Anaerobic Sequencing Bath Biofilm Reactor.

ASC Aerobic Solids Contact.

BF Biofiltro.

BFCW Batch-Fed Constructed Wetland.

CANON Completely Autotrophic Nitrogen Removal Over Nitrito.

CDC Compartimento de Decantação e Coleta.

C/N Relação Carbono/Nitrogênio.

CONAMA Conselho Nacional do Meio Ambiente.

COV Carga Orgânica Volumétrica.

CVN Carga Volumétrica de Nitrogênio.

DBO Demanda bioquímica de oxigênio.

DHS Down-flow Hanging Sponge.

DQO Demanda química de oxigênio.

DTR Curva de Distribuição do Tempo de Residência.

EESC/USP Escola de Engenharia de São Carlos da Universidade de São Paulo.

EGSB Expanded Granular Sludge Bed.

EPA Enviromment Protetion Agent. 
ETE Estação de Tratamento de Esgoto.

FAS Filtro Aeróbio Submerso.

FBAA Filtro Biológico Anaeróbio-Aeróbio.

FB Filtro Biológico.

IBGE Instituto Brasileiro de Geografia e Estatística.

LA Lodos Ativados.

LMFFAe Leito Móvel e Filme Fixo Aeróbio

LMFFAn Leito Móvel e Filme Fixo Anóxico

LPB Laboratório de Processos Biológicos.

NDS Nitrificação e Desnitrificação Simultâneas.

OLAND Oxygen Limited Autotrophic Nitrification Denitrification.

PNAD Pesquisa Nacional por Amostra de Domicílios.

PRFV Plástico Reforçado com Fibra de Vidro.

PROSAB Programa de Pesquisas em Saneamento Básico.

PVC Cloro polivinil ou Cloreto de polivinila.

RAAHLF Reator Aeróbio-Anaeróbio Horizontal de Leito Fixo.

RAALE $_{X} \quad$ Reator Anaeróbio-Aeróbio de Leito Expandido.

RAHLF Reator Anaeróbio Horizontal de Leito Fixo.

RARLF Reator Aeróbio Radial de Leito Fixo.

RBC Rotating Biological Contactor

RCLF Reator Combinado de Leito Fixo

RDNA Redução Dissimilatória do Nitrato a Amônia.

RMRLF Reator Misto Radial de Leito Fixo.

RRLF Reator Radial de Leito Fixo.

RSB Reator Seqüencial em Batelada. 
SANEPAR Companhia de Saneamento do Paraná.

SC Secondary Clarifier.

SHARON Single Reactor High Activity Ammonia Removal Over Nitrite.

SND Simultaneous Nitrification/Denitrification.

TDH Tempo de Detenção Hidráulica.

UASB Reator Anaeróbio de Fluxo Ascendente e Manta de Lodo (Upflow Anaerobic Sludge Blanket). 


\section{LISTA DE SÍMBOLOS}

\begin{tabular}{|c|c|c|}
\hline$\Delta$ Alc & Variação da Alcalinidade. & $\left(\mathrm{mgCaCO}_{3}\right)$ \\
\hline$\Delta \mathrm{x}$ & Espessura de Seção transversal. & \\
\hline $\bar{\theta}_{\mathrm{h}}$ & Tempo médio de detenção hidráulica. & (h) \\
\hline$\sigma^{2}$ & Variância dos pontos experimentais. & $\left(h^{2}\right)$ \\
\hline$( \pm r)$ & Velocidade de Reação. & \\
\hline AI & Alcalinidade intermediária. & $\left(\mathrm{mgCaCO}_{3} / \mathrm{L}\right)$ \\
\hline AP & Alcalinidade parcial. & $\left(\mathrm{mgCaCO}_{3} / \mathrm{L}\right)$ \\
\hline AVT & Concentração de ácidos voláteis totais. & $(\mathrm{mgHAc} / \mathrm{L})$ \\
\hline $\mathrm{CaCO}_{3}$ & Carbonato de Cálcio. & \\
\hline $\mathrm{CH}_{2} \mathrm{O}$ & Formaldeído. & \\
\hline $\mathrm{CH}_{4}$ & Metano. & \\
\hline $\mathrm{CO}_{2}$ & Dióxido de Carbônico. & \\
\hline $\mathrm{E}_{\mathrm{DN}}$ & Eficiência de Desnitrificação. & $(\%)$ \\
\hline $\mathrm{H}_{2} \mathrm{O}$ & Água. & \\
\hline $\mathrm{H}_{2} \mathrm{~S}$ & Gás Sulfídrico. & \\
\hline HAc & Ácido acético. & \\
\hline $\mathrm{HCO}_{3}^{-}$ & Íon Bicarbonato. & \\
\hline $\mathrm{HNO}_{2}$ & Ácido Nitroso. & \\
\hline $\mathrm{HNO}_{3}$ & Ácido Nítrico. & \\
\hline $\mathrm{k}$ & Constante Cinética. & \\
\hline Q & Vazão Afluente. & \\
\hline $\mathrm{Q}_{\mathrm{r}}$ & Vazão de Recirculação. & \\
\hline $\mathrm{N}_{2}$ & Gás nitrogênio. & \\
\hline
\end{tabular}


$\mathrm{NH}_{2} \mathrm{OH} \quad$ Hidroxilamina.

$\mathrm{N}_{2} \mathrm{H}_{4} \quad$ Hidrazina.

$\mathrm{N}_{2} \mathrm{O} \quad$ Óxido Nitroso.

NO Óxido Nítrico.

$\mathrm{NaCl} \quad$ Cloreto de Sódio.

$\mathrm{NH}_{3} \quad$ Amônia. $\quad(\mathrm{mg} / \mathrm{L})$

N-Amon Concentração de Nitrogênio Amoniacal. (mg/L)

N-NTK Concentração de Nitrogênio Total Kjeldahl. (mg/L)

$\mathrm{N}-\mathrm{NO}_{2}{ }^{-} \quad$ Concentração de Nitrito. $\quad(\mathrm{mg} / \mathrm{L})$

$\mathrm{N}_{-} \mathrm{NO}_{3}{ }^{-} \quad$ Concentração de Nitrato. $\quad(\mathrm{mg} / \mathrm{L})$

N-Org Concentração de Nitrogênio Orgânico. ～(mg/L)

NT Concentração de Nitrogênio Total (mg/L)

$\mathrm{O}_{2} \quad$ Oxigênio.

OD Concentração de Oxigênio Dissolvido. (mg/L)

pH Potencial hidrogeniônico.

$P_{\text {total }} \quad$ Concentração de fósforo total. (mg/L)

$P_{\text {solúvel }} \quad$ Concentração de fósforo solúvel. $\quad(\mathrm{mg} / \mathrm{L})$

r Razão de recirculação.

R Relação (AI/AP).

$\mathrm{SO}_{4}{ }^{2-} \quad$ Sulfato.

SSF Concentração de sólidos suspensos fixos. $\quad(\mathrm{mg} / \mathrm{L})$

SST Concentração de sólidos suspensos totais. $\quad(\mathrm{mg} / \mathrm{L})$

SSV Concentração de sólido suspensos voláteis. (mg/L)

ST Concentração de sólidos totais. $\quad(\mathrm{mg} / \mathrm{L})$

STF Concentração de sólidos totais fixos. (mg/L) 
STV Concentração de sólidos totais voláteis. $\quad(\mathrm{mg} / \mathrm{L})$

TDH Tempo de detenção hidráulica.

(h)

V

Volume. 


\section{RESUMO}

OLIVEIRA NETTO, A. P. (2011). Reator anaeróbio-aeróbio de leito fixo em escala piloto, com recirculação da fase líquida, aplicado ao tratamento de esgoto sanitário. São Carlos, Tese (Doutorado) - Departamento de Hidráulica e Saneamento, Escola de Engenharia de São Carlos, Universidade de São Paulo.

Este trabalho fundamentou-se na concepção, desenvolvimento tecnológico, ampliação de escala e avaliação do comportamento de sistema combinado anaeróbio-aeróbio de leito fixo e fluxo ascendente, com recirculação da fase líquida, para tratamento de esgoto sanitário. O reator, em escala piloto, foi construído em formato cilíndrico e confeccionado em fibra de vidro com volume total de aproximadamente $2,5 \mathrm{~m}^{3}$, com intuito de desenvolver um sistema capaz de operar como única unidade de tratamento para remoção de matéria orgânica e nitrogênio, reduzindo a geração de lodo e o consumo de energia pela combinação dos processos anaeróbio e aeróbio, possibilitando o aproveitamento das vantagens de cada um e minimizando seus aspectos negativos. Os melhores resultados operacionais foram encontrados para a etapa com tempo de detenção hidráulica total (TDH) de 12 horas e razão de recirculação (r) igual a 3,0, apresentando eficiências médias de remoção de DQO, N-NTK e SST de $92 \pm 3 \%$; $68 \pm 11 \%$ e $75 \pm 7 \%$, respectivamente, com valores médios efluentes de $54 \pm 22 \mathrm{mgDQO} / \mathrm{L}, 14 \pm 10 \mathrm{mgN}-\mathrm{NTK} / \mathrm{L}$ e $70 \pm 42 \mathrm{mgSST} / \mathrm{L}$. Os valores médios de carga orgânica volumétrica (COV) e carga volumétrica de nitrogênio $(\mathrm{CVN})$ removidas

foram de $1,08 \pm 0,04 \mathrm{kgDQO} / \mathrm{m}^{3}$.dia e $0,06 \pm 0,02 \mathrm{kgNTK} / \mathrm{m}^{3}$.dia para esta etapa. A estabilidade operacional durante a etapa com TDH de $12 \mathrm{~h}$, a alta remoção de matéria orgânica e nitrogênio, sem a necessidade de adição de fonte exógena de carbono, para promover o processo de desnitrificação, e de suplementação de alcalinidade consumida durante a nitrificação, e a reduzida necessidade de manutenção devido à tecnologia de fabricação adotada, comprovam a viabilidade técnica de utilização do reator combinado de leito fixo como unidade compacta para pequenas comunidades ou vazões afluentes, para tratamento de esgoto sanitário.

Palavras-chave: tratamento anaeróbio-aeróbio; esgoto sanitário; biomassa imobilizada; recirculação da fase líquida; escala piloto. 


\begin{abstract}
OLIVEIRA NETTO, A. P. (2011). Anaerobic-aerobic pilot-scale fixed-bed reactor, with recycle of the liquid phase, applied to the treatment of domestic sewage. São Carlos, Thesis - Escola de Engenharia de São Carlos, Universidade de São Paulo.

This work was based on design, technology development, scale up and performance evaluation of an up-flow combined anaerobic-aerobic fixed bed system, with recycle of the liquid phase, for treatment of domestic sewage. The pilot scale reactor was built in a fiberglass cylindrical shape with a total volume of approximately $2.5 \mathrm{~m}^{3}$, aiming at the development of a system capable of operate as a single treatment unit for organic matter and nitrogen removal, with low sludge production and energy consumption by the advantages of combination of anaerobic and aerobic processes. The improved operating results were found for the condition with overall hydraulic retention time (HRT) of 12 hours and recycle ratio (r) equal to 3.0, with average removal efficiencies of COD, TKN and TSS of $92 \pm 3 \%, 68 \pm 11 \%$ and $75 \pm 7 \%$, respectively, with average effluent values of $54 \pm 22 \mathrm{mgCOD} / \mathrm{L}, 14 \pm 10 \mathrm{mgTKN} / \mathrm{L}$ and $70 \pm 42 \mathrm{mgTSS} / \mathrm{L}$. The average values of removed organic loading rate (OLR) and nitrogen volumetric loading (NVL) reached $1.06 \pm 0.04 \mathrm{kgCOD} / \mathrm{m}^{3} . \mathrm{d}$ and $0.06 \pm 0.02 \mathrm{kgTKN} / \mathrm{m}^{3} . \mathrm{d}$ for this phase. The operational stability during the stage with HRT of $12 \mathrm{~h}$, the high organic matter and nitrogen removal, without addition of exogenous carbon source (electron donor) to promote the denitrification process, with no supplementation of alkalinity consumed during nitrification, and the reduced maintenance due to manufacturing technology adopted, proved the technical feasibility of the combined fixed-bed reactor as a compact unit for small communities or low inflow rates, for treatment of domestic sewage.
\end{abstract}

Keywords: anaerobic-aerobic treatment; domestic sewage; immobilized biomass; recycle of the liquid phase; pilot scale. 


\section{INTRODUÇÃO}

O Brasil apresenta elevado déficit no que diz respeito ao tratamento de seus esgotos domésticos, e o atendimento dessa demanda, sob o ponto de vista tecnológico, traduz-se na busca de alternativas sustentáveis para a realidade sócio-ambiental brasileira e que contemplem baixos custos de implantação, operação e manutenção.

O aumento populacional progressivo das cidades, o aumento da intensidade das atividades agrícolas e agropecuárias, para atender à demanda crescente de alimentos para a população, o crescimento industrial e agroindustrial são as principais causas do lançamento de resíduos brutos - líquidos e sólidos - no solo, nos rios, lagos e mares, destruindo a flora, a fauna, o equilíbrio dos ecossistemas, resultando no rompimento da harmonia entre o homem e o ambiente e na redução da qualidade de vida.

A característica do ser humano de se aglomerar de forma desorganizada em núcleos urbanos, cuja localização geralmente coincide com áreas onde a disponibilidade de água é maior, tem originado a poluição e contaminação dos recursos hídricos pelo lançamento de seus próprios efluentes. Assim, os cursos d’água são ao mesmo tempo a fonte para abastecimento e também o veículo natural de escoamento do esgoto doméstico e das águas residuárias industriais e agrícolas geradas pelo Ser Humano (LEME, 2008).

O lançamento de água residuária sem tratamento nos recursos hídricos, causa a decomposição de materiais orgânicos nela contidos e pode levar à queda da concentração de oxigênio dissolvido no meio, produção de gases mal cheirosos e corrosivos. Além do mais, águas residuárias de origem sanitária não tratadas contêm numerosos agentes patogênicos, ou causadores de doenças, que se alojam no trato intestinal humano. Águas 
residuárias também contêm nutrientes, principalmente nitrogênio e fósforo, os quais podem acelerar a eutrofização em reservatórios. A remoção de matéria orgânica, microrganismos patogênicos e nutrientes das águas residuárias, seguido de tratamento e disposição adequada, não é somente desejável, mas absolutamente necessária.

Recentemente, vários pesquisadores têm proposto sistemas biológicos combinando os reatores anaeróbios, numa primeira etapa, seguidos de unidades de póstratamento, com bons resultados no polimento de efluentes e remoção de nutrientes. No âmbito do Programa de Pesquisas em Saneamento Básico (PROSAB), várias alternativas de pós-tratamento foram desenvolvidas, entre elas, reatores aeróbios, disposição no solo, tratamento físico-químico e lagoas de estabilização. Quando se deseja a remoção de nutrientes, especialmente o nitrogênio, os sistemas combinados anaeróbio-aeróbios têm sido os mais empregados.

O interesse desses pesquisadores por essa configuração de reator, que combina os processos anaeróbio e aeróbio, deve-se a fatores como: menor exigência de área requerida para implantação, menores custos operacionais, baixa geração de lodo, remoção de nutrientes e, sobretudo, a retenção elevada de microrganismos nessa unidade - a qual é uma das condições necessárias ao tratamento de esgoto sanitário, especialmente quando se trabalha com velocidade baixa de crescimento microbiana como, por exemplo, as apresentadas pelas archaeas metanogênicas e bactérias nitrificantes.

Nos esgotos sanitários em geral, as concentrações dos compostos nitrogenados são baixas, com a predominância de nitrogênio amoniacal - N-Amon (60\%) e nitrogênio orgânico (40\%), sendo que a fração de nitritos e nitratos corresponde a menos de $1 \%$ (BARNES e BLISS, 1983; SEDLAK, 1991). Os nutrientes podem ser removidos através 
de processos físico-químicos e biológicos, sendo que os primeiros são mais dispendiosos, exigem manutenção mais intensiva e podem ter impactos ambientais secundários significativos (tais como a liberação de amônia no processo de stripping). Por isso, os processos biológicos têm sido a melhor alternativa para remoção de tais compostos, com o uso de sistemas físico-químicos para o polimento do efluente (SEDLAK, 1991).

A remoção biológica de nitrogênio pode ser conseguida através dos processos de nitrificação e desnitrificação, sendo o nitrogênio amoniacal (N-Amon) oxidado a nitrito, sob condições aeróbias (nitritação) e, seqüencialmente, a nitrato (nitratação). Este é, subsequentemente, reduzido a gás nitrogênio $\left(\mathrm{N}_{2}\right)$ sob condições anóxicas (desnitrificação). Essas condições podem ser atingidas em sequência espacial (sistema de dois estágios) ou temporal das fases anaeróbia, anóxica e aeróbia.

A etapa de nitrificação pode resultar na oxidação não apenas do nitrogênio amoniacal a nitrito, mas também na oxidação da matéria orgânica. Tal fato pode levar à necessidade de adição de fonte de carbono exógena na etapa de desnitrificação.

Entretanto, a utilização de fontes externas de carbono pode inviabilizar aplicações em grande escala, devido ao alto custo, sendo necessária a utilização de fontes mais simples e facilmente biodegradáveis, que podem tornar o processo mais econômico, além de mais eficiente (COSTA et al., 2000).

Reatores operados de forma combinada (anaeróbio/aeróbio) e com recirculação da fase líquida podem permitir o melhor aproveitamento das fontes de carbono nas etapas de desnitrificação, não havendo necessidade de adição de alcalinidade nem de fonte exógena de fonte de carbono para promover a desnitrificação em níveis substanciais, como ficou comprovado por Oliveira Netto (2007) tratando esgoto sanitário. A economia resultante 
da diminuição, ou até mesmo da eliminação da quantidade de fonte de carbono exógena necessária pode ser bastante significativa.

A imobilização celular é outro fator importante, tendo em vista que a biomassa agregada no interior de um reator aumenta a capacidade de tratamento, devido ao aumento da velocidade global de conversão de substrato pela elevada concentração de microrganismos; redução do tempo e volume de tratamento; redução da susceptibilidade as condições de choque ou transientes, assim como, possibilidade de eliminação de clarificação final (KATO et al. 1999).

A escolha do tema levou em consideração as adversidades dos efeitos de escala, taxa de transferência de oxigênio e setorização das regiões anaeróbia e aeróbia, que segundo a literatura técnica são relativamente mais controláveis em reatores de bancada, e raramente abordados em reatores de filme fixo de escala plena. Neste trabalho foi avaliado sistema combinado anaeróbio-aeróbio para tratamento de esgoto sanitário, em escala piloto, com foco principal na remoção de matéria orgânica e macronutrientes, em especial o nitrogênio, levando-se em consideração as configurações e os resultados encontrados nos estudos de Araújo Jr. (2006) e Oliveira Netto (2007).

Com esta pesquisa, procurou-se desenvolver um sistema de tratamento de esgoto sanitário confiável e eficiente, em escala piloto, baseado nos princípios do tratamento de efluentes por via biológica, com sistemas combinados, em estações compactas que não necessitem de alcalinização ou suplementação de fontes exógenas de carbono para a desnitrificação. 


\section{OBJETIVOS}

\subsection{Objetivo geral}

Avaliar o desempenho de um reator anaeróbio-aeróbio, em escala piloto, de escoamento ascendente e leito fixo, operado de modo contínuo, com recirculação da fase líquida aplicado ao tratamento de esgoto sanitário, contendo biomassa imobilizada em suporte inerte de diferentes tipos (espuma de poliuretano e argila expandida).

\subsection{Objetivos específicos}

Os objetivos específicos desse projeto foram:

- Avaliar a influência da carga orgânica aplicada sobre a remoção de matéria orgânica;

- Avaliar a influência da recirculação do efluente do reator aeróbio para o reator anaeróbio sobre a remoção de matéria orgânica e nitrogênio;

- Avaliar a influência do aumento de escala sobre a remoção de matéria orgânica e nitrogênio;

- Estimar as constantes cinéticas para o reator combinado anaeróbio-aeróbio de leito fixo;

- Comparar o sistema atual com outras tecnologias similares em relação a aspectos construtivos e de engenharia. 


\section{REVISÃO BIBLIOGRÁFICA}

\subsection{Tratamento de Esgoto Sanitário}

Dentre as prioridades de extrema importância numa administração municipal, encontra-se a de se ter um sistema de esgotamento sanitário configurado com rede coletora atendendo a totalidade das residências, emissários e interceptores devidamente executados e sistema de tratamento para as águas residuárias domésticas.

O planejamento e a construção de um sistema eficiente de esgotamento sanitário em uma cidade, seja ela de pequeno, médio ou grande porte é um desafio para os administradores, porém um desafio necessário e urgente que aponta para estatísticas de extremo impacto social, já que em curto espaço de tempo se alcançam índices favoráveis, fundamentalmente no que tange à melhoria da qualidade de vida da população atendida.

Ressalte-se ainda que um dos objetivos principais a serem atingidos é evitar que a interferência do homem com a geração de despejos domésticos ou industriais possa contribuir na introdução de compostos na água dos rios e córregos, afetando a sua qualidade.

Os esgotos domésticos contêm aproximadamente $99,99 \%$ de água. A fração restante inclui sólidos orgânicos e inorgânicos, em suspensão e dissolvidos, bem como microrganismos. Portanto, é devido a essa fração de $0,01 \%$ que há a necessidade de se tratar os esgotos (VON SPERLING, 1996).

A característica dos esgotos é função dos usos aos quais a água foi submetida. Esses usos e a forma com que são exercidos variam com o clima, a situação social e econômica e hábitos da população (VON SPERLING, 1996). Exemplo de valores típicos 
para parâmetros da caracterização de esgotos domésticos e representação de sua composição é mostrado na Tabela 3.1 e Figura 3.1, respectivamente.

Tabela 3.1 - Valores típicos para caracterização de esgotos domésticos. (Fonte: Adaptado de JORDÃO \& PESSOA, 2005).

\begin{tabular}{cccc}
\hline Parâmetro (mg/L) & Esgoto Forte & Esgoto Médio & Esgoto Fraco \\
\hline DBO $_{5,20}$ & 400 & 200 & 100 \\
DQO & 800 & 400 & 200 \\
SST & 360 & 230 & 120 \\
SSV & 280 & 175 & 90 \\
NTK & 85 & 40 & 20 \\
N-Amon & 50 & 20 & 10 \\
$\mathrm{~N}^{-O r g}$ & 35 & 20 & 10 \\
$\mathrm{~N}^{-N^{-}}{ }_{2}^{-}$ & 0,10 & 0,05 & 0 \\
$\mathrm{~N}^{-} \mathrm{NO}_{3}^{-}$ & 0,40 & 0,20 & 0,10 \\
$\mathrm{P}_{\text {total }}$ & 20 & 10 & 5 \\
$\mathrm{P}_{\text {solúvel }}$ & 13 & 6 & 3 \\
\hline
\end{tabular}




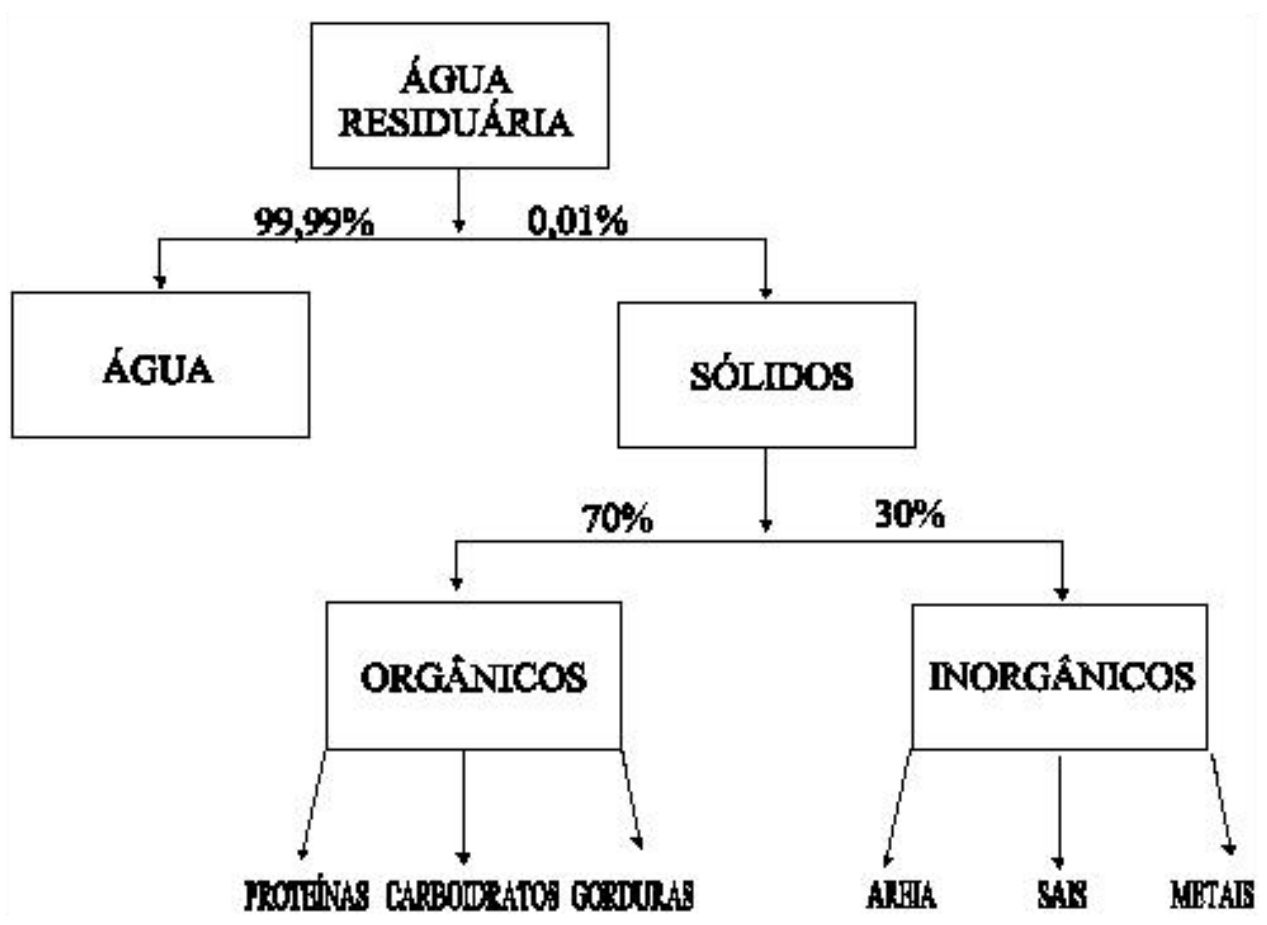

Figura 3.1 - Esquema da composição geral do esgoto doméstico (Fonte: SANEPAR, 1997).

A situação do setor de saneamento no Brasil pode ser expressa pelos números mostrados na Tabela 3.2. Esse panorama revela graves consequiências para a qualidade de vida da população, principalmente aquela mais pobre, residente na periferia das grandes cidades ou nas pequenas e médias cidades do interior. Outros países, principalmente os subdesenvolvidos, também sofrem com este problema. A falta de saneamento básico ainda atinge parcela expressiva da população mundial, com consequiências gravíssimas principalmente para as crianças. A Tabela 3.3 mostra algumas conseqüências da ausência de tratamento do esgoto sanitário. 
Tabela 3.2 - Déficit na oferta de saneamento básico no Brasil. (Fonte: PNAD 2003, IBGE)

\begin{tabular}{|c|c|c|c|c|c|}
\hline \multirow{3}{*}{ Área } & \multirow{3}{*}{$\begin{array}{l}\text { Número de } \\
\text { Domicílios } \\
\text { (em milhões) }\end{array}$} & \multicolumn{2}{|c|}{ Domicílios não atendidos por } & \multicolumn{2}{|c|}{ Domicílios não atendidos por } \\
\hline & & \multicolumn{2}{|c|}{ rede geral de água } & \multicolumn{2}{|c|}{ coleta de esgoto sanitário } \\
\hline & & (em milhões) & $\%$ & (em milhões) & $\%$ \\
\hline Urbana & 42,107 & 3,369 & 8,0 & 18,822 & 44,7 \\
\hline Rural & 7,035 & 5,231 & 74,4 & 6,754 & 96,0 \\
\hline Total & 49,142 & 8,600 & 17,5 & 25,576 & 52,0 \\
\hline
\end{tabular}


Tabela 3.3 - Doenças e outras conseqüências da ausência de tratamento do esgoto sanitário. (Fonte: PNAD 2003, IBGE)

\begin{tabular}{|c|c|c|c|}
\hline Poluentes & Parâmetros de caracterização & Tipos de esgoto & Conseqüências \\
\hline Patogênicos & Coliformes & Domésticos & Doenças de veiculação hídrica \\
\hline Sólidos em suspensão & Sólidos em suspensão totais & $\begin{array}{l}\text { - Domésticos; } \\
\text { - Industriais. }\end{array}$ & $\begin{array}{l}\text { - Problemas estéticos; } \\
\text { - Depósitos de lodo; } \\
\text { - Absorção de poluentes; } \\
\text { - Proteção de patogênicos. }\end{array}$ \\
\hline Matéria orgânica biodegradável & Demanda bioquímica de oxigênio & $\begin{array}{l}\text { - Domésticos; } \\
\text { - Industriais. }\end{array}$ & $\begin{array}{l}\text { - Consumo de oxigênio; } \\
\text { - Condições sépticas; } \\
\text { - Mortandade de peixes. }\end{array}$ \\
\hline Nutrientes & $\begin{array}{l}\text { - Nitrogênio; } \\
\text { - Fósforo. }\end{array}$ & $\begin{array}{l}\text { - Domésticos; } \\
\text { - Industriais. }\end{array}$ & $\begin{array}{l}\text { - Crescimento excessivo de algas; } \\
\text { - Toxicidade aos peixes; } \\
\text { - Doenças em recém-nascidos (nitratos). }\end{array}$ \\
\hline Compostos não biodegradáveis & $\begin{array}{l}\text { - Pesticidas; } \\
\text { - Detergentes; } \\
\text { - Outros. }\end{array}$ & $\begin{array}{l}\text { - Industriais; } \\
\text { - Agrícolas. }\end{array}$ & $\begin{array}{c}\text { - Toxicidade; } \\
\text { - Espumas; } \\
\text { - Redução da transferência de oxigênio; } \\
\text { - Não biodegradabilidade; } \\
\text { - Maus odores. }\end{array}$ \\
\hline
\end{tabular}


Existem várias formas e alternativas para se tratar águas residuárias. Confrontos entre essas alternativas são comumente encontrados tanto na literatura quanto na prática. O primeiro confronto refere-se à escolha entre tratamentos que utilizam processos físico-químicos e biológicos. Uma vez escolhido o tratamento biológico depara-se com um segundo confronto: utilizar tecnologias aeróbias ou anaeróbias. Não existe uma solução definitiva e única para todos os casos. Para cada situação, estudos de viabilidade econômica e técnica devem ser realizados para a solução do problema. Concluída esta etapa, ainda resta a conscientização política e social que muitas vezes por interesses diversos, resultam na etapa limitante de um procedimento cujo objetivo final nada mais é que a melhoria da qualidade de vida.

Pesquisas envolvendo tratamento de esgoto por processo biológico têm buscado utilizar tecnologias inovadoras para atingir eficiência elevada de remoção de poluentes. Dentre os reatores com potencialidade para uso no tratamento de esgoto sanitário e de efluentes industriais, pode-se citar: digestor anaeróbio de contato, filtro anaeróbio ou aeróbio, reator anaeróbio de fluxo ascendente com manta de lodo (UASB - Upflow Anaerobic Sludge Blanket) e reatores de leito expandido e fluidificado (anaeróbios, aeróbios e anóxicos).

Então, torna-se lógico considerar a melhor tecnologia disponível para tratamento dos efluentes, que reduza o investimento inicial e os custos de operação, visando devolver para a natureza os insumos utilizados, em qualidade pelo menos equivalente, minimizando os possíveis impactos ambientais. 


\subsection{Importância da remoção biológica de nitrogênio}

Existem muitas alternativas tecnicamente viáveis para o tratamento de águas residuárias visando a remoção de nitrogênio. Segundo Metcalf \& Eddy (1991), entre os processos e operações existentes, os mais usuais são: nitrificação e desnitrificação biológicas, cloração ao "break-point", troca iônica seletiva de amônia e "stripping" de amônia. Dentre esses, há ainda uma grande tendência para se usar processos biológicos para a remoção de nitrogênio, ou seja, a escolha dos processos de nitrificação e desnitrificação.

Os compostos nitrogenados são encontrados em altas concentrações nas águas residuárias industriais (processamento de alimentos: fabricação de pectina, farinha de peixe, carnes e embutidos, refinarias de petróleo, processos metalúrgicos, tintas, fertilizantes). Nos esgotos sanitários em geral, as concentrações são baixas, com a predominância de nitrogênio amoniacal - N-Amon (60\%) e nitrogênio orgânico - N-Org (40\%), sendo que a fração de nitritos e nitratos corresponde a menos de 1\% (SEDLAK, 1991).

As vias metabólicas envolvidas no ciclo do nitrogênio inorgânico têm sido conduzidas tanto por microrganismos amplamente descritos na literatura, bem como por alguns ainda pouco conhecidos. Os possíveis caminhos para obtenção de energia e as enzimas envolvidas, estão relacionadas com a adaptação e sobrevivência destes microrganismos sob uma variedade de condições ambientais (YE \& THOMAS, 2001).

A atividade microbiana combinada completa o ciclo do nitrogênio na natureza. No entanto, a entrada de altas cargas de nitrogênio devido à atividade humana, seja na forma de esgoto doméstico ou efluentes industriais, causa grande desequilíbrio no sistema. Neste contexto, conhecer o metabolismo microbiano do nitrogênio é de grande importância para o tratamento destes compostos. 
Em relação ao ciclo do nitrogênio, a reação mais recentemente descoberta é a oxidação anaeróbia do íon amônio, via nitrito, possibilidade encontrada pelo metabolismo microbiano para converter amônio em nitrogênio gasoso na ausência de oxigênio e de matéria orgânica. As atividades microbianas de oxidação anaeróbia do amônio e desnitrificação são os mecanismos majoritários na conversão de nitrogênio combinado a nitrogênio gasoso, completando o ciclo do nitrogênio (YE \& THOMAS, 2001).

Com o auxilio dos avanços na microbiologia, estudos recentes mostram que novos processos microbianos envolvendo as transformações de compostos de nitrogênio podem ocorrer em estações de tratamento de esgotos (ETE). Existe grande quantidade de compostos de nitrogênio envolvida nos processos de tratamento das águas residuárias, fazendo com que numerosas reações bioquímicas possam ocorrer devido a presença de diversos grupos microbianos. No entanto, a maioria dessas populações apresenta baixas velocidades de crescimento, o que dificulta o estudo dessas reações. $\mathrm{Na}$ Figura 3.2 são apresentadas algumas vias de conversão biológica do Nitrogênio. 


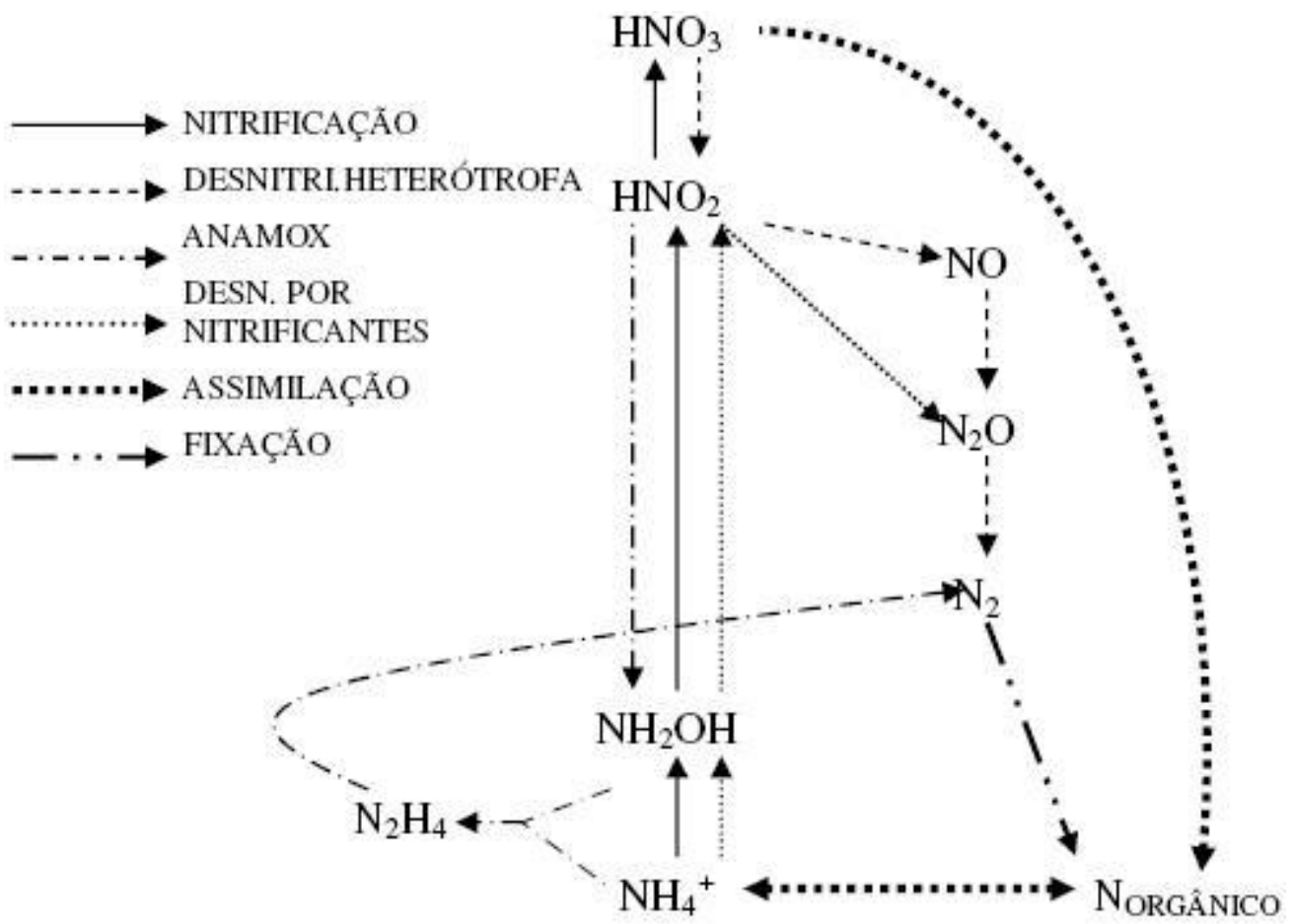

Figura 3.2 - Conversões biológicas do Nitrogênio (Fonte: Van LOOSDRECHT \& JETTEN, 1998).

A remoção biológica de nitrogênio é possível por meio dos processos seqüenciais de nitrificação e desnitrificação. O primeiro processo é a oxidação biológica de amônia para nitrato através do nitrito, enquanto que o segundo processo é a redução biológica de nitrato para nitrogênio molecular como último produto, usando-se material orgânico como redutor de elétrons.

As bactérias nitrificantes apresentam crescimento lento (grande tempo de geração), pois o baixo rendimento energético das reações de oxidação resulta em baixo rendimento celular. Assim sendo, faz-se necessário que o tempo de retenção celular seja muito superior ao mínimo para garantir a permanência da biomassa no reator (VIEIRA, 2000).

Com o desenvolvimento de consórcios microbianos auto-imobilizados ou aderidos a um material suporte em processos óxicos-anóxicos, todo o tratamento é 
acelerado, uma vez que esses consórcios trabalham combinando as vantagens tanto dos reatores de lodo ativado, quanto dos de biomassa aderida, resultando em sistema compacto.

A nitrificação pode ser definida, em termos gerais, como a transformação biológica de compostos nitrogenados orgânicos e inorgânicos de um estado reduzido a um estado mais oxidado (WETZEL, 1975). Na nitrificação, o íon amônio $\left(\mathrm{NH}_{4}{ }^{+}\right)$é transformado em nitratos, o que requer a mediação de bactérias específicas, principalmente autótrofos ou mixotróficas, e se realiza em dois passos seqüenciais: a oxidação de $\mathrm{N}-\mathrm{NH}_{4}{ }^{+}$a nitrito $\left(\mathrm{N}-\mathrm{NO}_{2}{ }^{-}\right)$, conhecido como nitritação; e a oxidação de $\mathrm{N}-\mathrm{NO}_{2}{ }^{-}$a nitrato $\left(\mathrm{N}^{-\mathrm{NO}_{3}}{ }^{-}\right)$, conhecido como nitratação.

A oxidação de N-Amon geralmente é atribuída a Nitrosomonas (principalmente N. europea e N. monocella) e Nitrosospira. Enquanto que a oxidação do nitrito é feita por Nitrobacter (N. agilis e N. winogradskyi) e Nitrospira (Van LOOSDRECHT \& JETTEN, 1998).

Quando se utiliza processo combinado anaeróbio/aeróbio, a nitrificação é facilitada devido a pouca quantidade de matéria orgânica presente no reator aeróbio após ter sido oxidada pelo processo anaeróbio precedente. Com isso, o consumo de oxigênio para a remoção de matéria orgânica é reduzido, bem como o tempo de detenção necessário para completar o processo de nitrificação, pois, para os autótrofos (nitrificantes), há maior disponibilidade de oxigênio, que é na maioria das vezes o composto limitante na nitrificação.

Outro limitante para a nitrificação é o consumo alcalinidade do meio neste processo. A alcalinidade pode ser fornecida por fontes externas, ou ser retirada da combinação da nitrificação com outros processos biológicos, como a amonificação e a desnitrificação, os quais fornecem alcalinidade ao meio. 
Com a imobilização da biomassa nitrificante no interior do reator, promove-se maior possibilidade de contato entre as nitrificantes e o N-Amon, especialmente em sistemas combinados anaeróbio/aeróbio, em que os compostos nitrogenados já se encontram quase que totalmente amonificados na entrada do reator aeróbio.

A desnitrificação biológica é um processo de redução do nitrato para óxido nitroso $\left(\mathrm{N}_{2} \mathrm{O}\right)$ e para nitrogênio gasoso $\left(\mathrm{N}_{2}\right)$, catalisada por microrganismos heterótrofos e autótrofos. Ocorre em condições anóxicas e na presença de doadores de elétrons específicos, como matéria orgânica, compostos reduzidos de enxofre ou hidrogênio molecular, sendo seus elétrons transferidos para os compostos de nitrogênio oxidados em vez de serem transferidos para o oxigênio.

A desnitrificação pode ocorrer devido a atividade de diversas espécies de bactérias desnitrificantes ou desnitrificantes parciais, comumente encontradas nos sistemas de tratamento de esgotos, como: Pseudomonas, Alcaligenes, Flavobacterium, Achromobacter, Bacillus, Miocrococcus, Acinetobacter (EISENTRAEGER et al., 2001).

Nem todos os microrganismos, classificados como desnitrificantes, podem executar toda a rota metabólica, desde nitrito até o $\mathrm{N}_{2}$. Alguns microrganismos são capazes de executar apenas uma parte do metabolismo, a partir de um dos compostos iônicos de nitrogênio (nitrito ou nitrato) para um dos compostos gasosos $\left(\mathrm{NO}, \mathrm{N}_{2} \mathrm{O}\right.$ ou $\mathrm{N}_{2}$ ), sendo estes organismos identificados como desnitrificantes parciais. Além disso, alguns organismos são capazes, apenas, de reduzir nitrato para nitrito, sendo referidos como redutores de nitrato (BOTHE et al., 2000).

O último passo para a remoção do nitrogênio por vias biológicas é a desnitrificação e, portanto, em sistemas combinados, esse processo pode ser prejudicado pela ausência de fonte de carbono para as bactérias desnitrificantes, pois a quase 
totalidade do carbono afluente ao sistema é removida nas etapas anteriores à desnitrificação.

Nestes sistemas combinados para tratamento terciário, pode ser necessária a introdução de fonte externa de carbono para a desnitrificação. Existem diversas fontes externas de carbono que podem ser utilizadas para a desnitrificação, como descrito no trabalho de Santos et. al. (2003), que estudou a utilização de metanol, etanol e metano como fonte de carbono para a desnitrificação em frascos em batelada. No entanto, devese dar preferência a fontes de baixo, ou nenhum custo, como o próprio esgoto, ou o gás metano produzido nos reatores anaeróbios.

A remoção biológica de nitrogênio tem incorporado novos processos microbianos: SHARON ("Single reactor system for High Ammonium Removal Over Nitrite”), ANAMMOX (“Anaerobic Ammonium Oxidation”), CANON (“Completely Autotrophic Nitrogen removal Over Nitrite"), desamonificação, OLAND (“Oxygen Limited Autotrophic Nitrification Denitrification") e nitrificação/desnitrificação por metanotróficas. Isso foi possível devido aos novos conceitos como desnitrificação aeróbia e nitrificação heterotrófica, também chamado de nitrificação e desnitrificação simultâneas (NDS), oxidação anaeróbia de N-Amon ou desnitrificação por nitrificantes autotróficas. 
Na Tabela 3.4 estão representadas as estequiometrias de cada processo de transformação biológica do nitrogênio (reações e produtos), bem como a variação de energia livre envolvida. Como pode ser observado, constam tanto as equações químicas fundamentais quanto conjuntos de equações sugeridas por vários autores para os processos de remoção de nitrogênio. 
Tabela 3.4 - Transformações biológicas do nitrogênio.

\begin{tabular}{ll}
\hline Processos, reações e produtos & $\Delta \mathrm{G}^{0}\left(\mathrm{~kJ} \cdot \mathrm{mol}^{-1}\right)$ \\
\hline Fixação do Nitrogênio & $-39,4$ \\
1) $0,5 \mathrm{~N}_{2}+1,5 \mathrm{H}_{2}+\mathrm{H}^{+} \rightarrow \mathrm{NH}_{4}^{+}{ }^{(1)}$ & \\
\hline Nitrificação e Desnitrificação convencionais & $-290,4$ \\
2) $\mathrm{NH}_{4}^{+}+1,5 \mathrm{O}_{2} \rightarrow \mathrm{NO}_{2}^{-}+2 \mathrm{H}^{+}+\mathrm{H}_{2} \mathrm{O}(1)$ & $-72,1$ \\
3) $\mathrm{NO}_{2}^{-}+0,5 \mathrm{O}_{2} \rightarrow \mathrm{NO}_{3}^{-(1)}$ & \\
$\mathrm{NO}_{3}^{-}+1,5\left\{\mathrm{CH}_{2} \mathrm{O}\right\}+H^{+} \rightarrow{ }_{(1)}$ & $-594,6$ \\
$0,5 \mathrm{~N}_{2}+1,75 \mathrm{H}_{2} \mathrm{O}+1,25 \mathrm{CO}_{2}$ &
\end{tabular}

\section{Desnitrificação Autotrófica}

5) $3 \mathrm{NO}_{3}^{-}+5 \mathrm{NH}_{4}^{+} \rightarrow 4 \mathrm{~N}_{2}+9 \mathrm{H}_{2} \mathrm{O}+2 \mathrm{H}^{+}{ }^{(2)} \quad-297,0$

\begin{tabular}{ll}
\hline ANAMMOX & $-358,0$ \\
6) $\mathrm{NO}_{2}^{-}+\mathrm{NH}_{4}^{+} \rightarrow \mathrm{N}_{2}+\mathrm{H}_{2} \mathrm{O}^{(3)}$ & \\
7) $\mathrm{NH}_{4}^{+}+1,32 \mathrm{NO}_{2}^{-}+0,066 \mathrm{HCO}_{3}^{-}+0,13 \mathrm{H}^{+} \rightarrow$ & \\
$1,02 \mathrm{~N}_{2}+0,26 \mathrm{NO}_{3}^{-}+0,066 \mathrm{CH}_{2} \mathrm{O}_{0,5} \mathrm{~N}_{0,15}+2,03 \mathrm{H}_{2} \mathrm{O}$ & \\
\hline $\mathrm{SHARON}$ & $-290,4$ \\
8) $\mathrm{NH}_{4}^{+}+1,5 \mathrm{O}_{2} \rightarrow \mathrm{NO}_{2}^{-}+\mathrm{H}_{2} \mathrm{O}+2 \mathrm{H}^{+}{ }^{(3)}$ & $-271,0$ \\
\hline OLAND & \\
9) $0,5 \mathrm{NH}_{4}^{+}+0,75 \mathrm{O}_{2} \rightarrow 0,5 \mathrm{NO}_{2}^{-}+0,5 \mathrm{H}_{2} \mathrm{O}+\mathrm{H}^{+}$ & \\
10) $0,5 \mathrm{NH}_{4}^{+}+0,5 \mathrm{NO}_{2}^{-} \rightarrow 0,5 \mathrm{~N}_{2}+\mathrm{H}_{2} \mathrm{O}$ & \\
\hline
\end{tabular}

CANON

11) $\mathrm{NH}_{4}^{+}+1,5 \mathrm{O}_{2} \rightarrow \mathrm{NO}_{2}^{-}+\mathrm{H}_{2} \mathrm{O}+2 \mathrm{H}^{+(3)}-290,4$

12) $\mathrm{NH}_{4}^{+}+1,32 \mathrm{NO}_{2}^{-}+\mathrm{H}^{+} \rightarrow 1,02 \mathrm{~N}_{2}+0,26 \mathrm{NO}_{3}^{-}+2 \mathrm{H}_{2} \mathrm{O}^{(3)}$

RDNA (redução dissimilatória do nitrato a amônia)

13) $\mathrm{NO}_{3}^{-}+2\left\{\mathrm{CH}_{2} \mathrm{O}\right\}+2 \mathrm{H}^{+} \rightarrow \mathrm{NH}_{4}^{+}+2 \mathrm{CO}_{2}+\mathrm{H}_{2} \mathrm{O}^{(3)} \quad-655,0$

Fonte: (1) SEDLAK (1991)

(2) SHU-GUANG XIE et. al. (2003)

(3) SCHMIDT et al. (2003) 
Segundo Callado \& Foresti (2001), com relação à disponibilidade de carbono orgânico, em baixa relação carbono/nitrogênio $(\mathrm{C} / \mathrm{N})$, as bactérias heterótrofas, limitadas pelo carbono, deixam excesso de amônia disponível para a nitrificação. Em alta relação $\mathrm{C} / \mathrm{N}$, o processo de nitrificação é inibido, não ocorrendo a oxidação da amônia. Por isso, existe uma vantagem aparente em separar a nitrificação do processo de remoção de matéria orgânica.

Sistemas biológicos similares podem ter diferentes relações $\mathrm{C} / \mathrm{N}$ ótimas se usadas para tratar diferentes águas residuárias sob condições ambientais e em reatores distintos. Por isso, relação $\mathrm{C} / \mathrm{N}$ ótima para sistemas desnitrificantes biológicos para tratar águas residuárias específicas deve ser determinada experimentalmente.

Há interesse, portanto, em dispor de sistemas que, na primeira etapa (anaeróbia), promovam o processo de amonificação em que o nitrogênio orgânico é convertido a nitrogênio amoniacal e, na segunda etapa (aeróbia), promovam a nitrificação por meio da oxidação da amônia, de maneira a resultar em baixas concentrações de nitrogênio amoniacal no efluente. Embora essas duas etapas sejam importantes, é indispensável a remoção do nitrato resultante por meio da desnitrificação para que a concentração de compostos nitrogenados no efluente seja baixa.

\subsection{Tratamento combinado anaeróbio-aeróbio de esgoto sanitário}

A utilização de sistemas de tratamento de esgoto que aplicam processos anaeróbios como unidades principais para remoção da matéria orgânica é uma prática relativamente recente. Anteriormente, tais processos eram aplicados quase que exclusivamente na etapa de digestão de lodo (primário e secundário) em estações de tratamento que utilizavam processos aeróbios convencionais, como lodos ativados e filtros aeróbios. Foresti et al. (2006) citam que a sustentabilidade em sistemas de 
tratamento de efluentes baseia-se em três conceitos principais: proteção à saúde pública; conservação ambiental; e recuperação (reciclagem) de recursos. Adicionalmente, devem-se considerar os aspectos econômicos envolvidos, que limitam os países em desenvolvimento na obtenção da sustentabilidade, obrigando-os a desenvolver tecnologias alternativas àquelas de altos custos de construção e manutenção, aplicadas em países desenvolvidos.

As vantagens relacionadas à aplicação de processos anaeróbios em sistemas de tratamento de esgotos são bem conhecidas e permitem a redução de custos operacionais no que diz respeito, principalmente, a economia de energia e a produção de lodo, além da produção de biogás, uma potencial fonte alternativa de energia. No entanto, também é conhecido o fato de que os reatores anaeróbios, aplicados ao tratamento de esgotos domésticos, produzem efluentes que, geralmente, não atendem aos padrões de emissão em corpos hídricos receptores. Conseqüentemente, os reatores anaeróbios devem ser combinados com outras tecnologias de forma a se atingir uma situação ideal para um determinado sistema de tratamento de esgoto.

Embora eficiente em termos de remoção de matéria orgânica, o tratamento anaeróbio apresenta alguns problemas, entre outros, relacionados com o conteúdo de fósforo e nitrogênio no seu efluente que acarretam problemas para a sua disposição final em corpos d'água. Como uma das alternativas tecnológicas capazes de proporcionar as variações das condições ambientais necessárias para a ocorrência dos processos acima mencionados está a utilização de reatores combinados anaeróbio-aeróbio como uma das possíveis alternativas tecnológicas (SILVA \& NOUR, 2004).

De acordo com Chernicharo (2006), a utilização de processos combinados anaeróbio-aeróbio propicia uma série de vantagens perante as estações de tratamento aeróbias convencionais, tais como baixa potência de aeração requerida na fase aeróbia, 
menor produção de lodo biológico e menores custos de implantação e operação. Em sistemas combinados UASB / lodos ativados ou UASB / reator de biofilme aerado, o excesso de lodo gerado no reator aeróbio pode ser direcionado para o reator UASB, onde é digerido e adensado juntamente com o lodo anaeróbio, dispensando unidades de digestão e adensamento adicionais.

Em Minas Gerais já existem vários sistemas compostos com reator anaeróbio de manta de lodo seguido de pós-tratamento, construídos em ferrocimento, alguns em operação desde 1997. Esses sistemas atendem populações que variam da ordem de 2.000 habitantes até mais de 15.000 habitantes, e tiveram custos de construção variando desde $\mathrm{R}$ \$ 9,00 por habitante até $\mathrm{R} \$ 55,00$ por habitante atendido (BONIFÁCIO, 2001). Segundo o autor citado, essa tecnologia, com numerosas unidades já construídas e em implantação, deve seu sucesso à execução simples, ao baixo custo e ao fato da eficiência do tratamento estar dentro das exigências técnicas dos órgãos de Meio Ambiente.

Com o objetivo de alcançar melhor estabilidade e maior eficiência no processo, foram propostas diversas combinações de tratamento anaeróbio e aeróbio. No entanto, o grande problema da aplicação do tratamento anaeróbio-aeróbio é encontrar a condição ótima para cada sistema (BODIK et al., 2003).

Dos Santos et al. (1997) apresentaram estudo comparativo do comportamento e dos resultados obtidos com sistemas de laboratório e escala real, fazendo referência a um filtro anaeróbio híbrido, parcialmente preenchido com tubos de PVC cortados para tratamento de águas residuais de uma fábrica de lacticínios.

A comparação do comportamento e estabilidade do filtro anaeróbio em escala real e de laboratório permitiu realçar que as condições operacionais do sistema em escala real são muito mais desfavoráveis e bem distantes em relação àquelas que são proporcionadas em laboratório, fato este que dá origem a períodos mais prolongados de 
estabilização do sistema. Contudo, o sistema de escala real consegue atingir uma situação de estabilidade e eficiência bem elevada, devido à progressiva adaptação das populações bacterianas às condições reais de alimentação. A eficiência de remoção da DQO (em média 72\%) se aproximou muito das eficiências encontradas para o reator em escala de laboratório.

Kato et al. (2001) avaliaram desempenho de dois reatores EGSB ("expanded granular sludge bed") em escala piloto (volume total de $401 \mathrm{~L}$ para cada reator), um anaeróbio e outro aeróbio, para tratamento de esgotos sanitários. O reator anaeróbio operou com tempo de detenção hidráulica (TDH) de 4 horas. Valores médios de DQO bruta de $93 \mathrm{mg} / \mathrm{L}$ e de DQO filtrada de $53 \mathrm{mg} / \mathrm{L}$ foram obtidos no efluente. Isso significou eficiências de $58 \%$ e $76 \%$, respectivamente, para uma carga orgânica aplicada $\left(\mathrm{C}_{\mathrm{v}}\right)$ de 1,23 g DQO/L.d. As concentrações de sólidos em suspensão totais (SST) estiveram sempre abaixo de $30 \mathrm{mg} / \mathrm{L}$, obtendo-se até $15 \mathrm{mg} / \mathrm{L}$. O reator aeróbio operou com um TDH de 8 h e apresentou, no efluente, valores médios de DQO bruta de $84 \mathrm{mg} / \mathrm{L}$ e de DQO filtrada de $51 \mathrm{mg} / \mathrm{L}$. A eficiência de remoção de DQO bruta foi de $59 \%$ e de DQO filtrada de $75 \%$, para uma $\mathrm{C}_{\mathrm{v}}$ de $0,64 \mathrm{~g}$ DQO/L.d. A concentração de SST foi de $20 \mathrm{mg} / \mathrm{L}$ no efluente. A nitrificação resultou em concentrações de nitrato da ordem de até $30 \mathrm{mg} \mathrm{N} / \mathrm{L}$, porém tal processo ocorreu por curtos períodos alternados. A posterior remoção completa de nitrogênio por desnitrificação, no reator anaeróbio, ficou prejudicada devido a problemas operacionais no reator aeróbio.

Callado \& Foresti (2001), operando um sistema anaeróbio-aeróbio composto por reatores operados em bateladas seqüenciais (RSB) em série, alcançaram altas eficiências de remoção de DQO, nitrogênio e fósforo de esgoto sanitário com tempo de ciclo de 24 h, 12 h e 6 h. A nitrificação, desnitrificação e a remoção biológica de fósforo ocorriam no segundo RSB, operado sob ciclos aeróbio e anóxico, tratando efluente do 
reator anaeróbio. Para a efetiva desnitrificação e remoção de fósforo, foi necessária a suplementação de carbono com acetato.

Bodik et al. (2002), operando um sistema combinado anaeróbio-aeróbio em escala piloto, constituído por biofiltro biológico anaeróbio seguido de sistema de lodos ativados tratando esgoto sanitário em condições reais, atingiram altas eficiências na remoção de matéria orgânica $(78,6 \%-83,0 \%)$ e SST $(80,9 \%-92,7 \%)$. O TDH das zonas anaeróbia e aeróbia foram de 15 h e 4 h, respectivamente. A média de remoção de nitrogênio amoniacal variou de 46,4\% a 87,3\% durante a operação do sistema. Também foi observado a efetiva desnitrificação do efluente. Foi possível concluir que, em condições reais de operação, é possível operar o sistema por um longo período de tempo sem necessidade de remoção do lodo produzido.

Gaspar (2003) operou uma unidade piloto de lodos ativados para o tratamento de esgoto doméstico, pré-tratado anaerobiamente em reator UASB, visando a remoção de nitrogênio e fósforo. O sistema piloto era constituído de reator anóxico, reator aeróbio e decantador. O sistema de lodos ativados, como pós-tratamento de efluentes de reatores anaeróbios não foi eficiente na remoção de nitrogênio devido a pouca disponibilidade de matéria orgânica para os organismos que realizam a desnitrificação; Em se tratando da remoção de amônia, o sistema de lodos ativados se mostrou eficaz, com eficiências médias de remoção sempre acima de 95\%; e o sistema se mostrou eficiente na remoção de matéria orgânica. As eficiências de remoção de matéria orgânica, em termos de DQO $_{\text {total }}$, atingiram $88 \%$.

Santos (2004) avaliou desempenho de configuração de unidade para tratamento biológico de esgoto sanitário por processo combinado, visando à remoção de nutrientes, especialmente nitrogênio. $\mathrm{O}$ sistema construído em escala piloto teve volume útil igual a 71,48 litros. Nesta nova configuração de reatores para tratamento terciário de esgoto 
sanitário, utilizaram-se três reatores sobrepostos, sendo: um reator UASB; um reator de leito móvel e filme fixo aeróbio (com aplicação de oxigênio puro), além de um reator de leito móvel e filme fixo com ambiente anóxico. Foram obtidos resultados de remoção de DQO e de nitrogênio bastante satisfatórios, sobretudo quando o tempo de detenção hidráulica total esteve próximo a 20 horas (94,6\% para DQO e 96,7\% para N-NTK, com formação de nitrato em concentrações inferiores a $10,0 \mathrm{mgN}-\mathrm{NO}_{3}{ }^{-} / \mathrm{L}$ ). A idealização desta configuração teve como finalidade realização de tratamento de esgoto sanitário até nível terciário em planta compacta, podendo ser utilizada por pequenas e grandes comunidades, devido à possibilidade de se construir diversos módulos do sistema proposto.

Mendonça (2004) avaliou desempenho de um reator anaeróbio-aeróbio de leito expandido (RAALE $)_{X}$ em escala plena $\left(159 \mathrm{~m}^{3}\right)$ para o tratamento de esgoto sanitário. Na condição anaeróbia, após inoculação e 60 dias de operação o RAALE X $_{X}$ tratando cerca de 3,40 kg.DQO/m³ .dia para TDH de 2,69 h, obteve-se eficiência média de remoção de $76 \%$ para DBO, 72\% para DQO, e $80 \%$ para SST, quando então o efluente passou a apresentar valores médios, de $225 \mathrm{mg} / \mathrm{L}$ de DQO, $98 \mathrm{mg} / \mathrm{L}$ de $\mathrm{DBO}$ e $35 \mathrm{mg} / \mathrm{L}$ de SST. Nestas condições, para carga nitrogenada de $0,27 \mathrm{~kg} . \mathrm{N} / \mathrm{m}^{3}$.dia, gerou efluente com concentrações médias de nitrogênio orgânico de 8 mg/L e N-Amon de 37 mg/L, com remoção média de NTK de $4 \%$, contudo demonstrando elevada eficiência no potencial de amonificação (82\%). Para a condição anaeróbia-aeróbia, o tempo de operação do RAALE $_{X}$, foi inferior a dois meses, sem alcançar regime de equilíbrio dinâmico. Face aos resultados obtidos, o autor confirmou que esse reator configura-se como alternativa adequada para o tratamento de esgoto sanitário, pois sua instalação ocupa pouca área relativa e exige tempo de detenção total de cerca de $10 \mathrm{~h}$. 
Rodríguez (2006) avaliou o desempenho de uma nova configuração de filtro biológico percolador (FB), constituído por dois compartimentos superpostos, um para a nitrificação e outro para a desnitrificação. Para a taxa de carregamento hidráulica média aplicada de $5,6 \mathrm{~m}^{3} / \mathrm{m}^{2}$.dia e taxa de carregamento orgânica média aplicada de $0,26 \mathrm{kgDQO} / \mathrm{m}^{3}$.dia, a nitrificação ocorreu de forma eficiente, obtendo-se entre $60 \% \mathrm{e}$ 74\% de conversão de N-Amon, sendo que o efluente final apresentou, em média, concentração abaixo de $10 \mathrm{mg} / \mathrm{L}$. A desnitrificação ocorreu de forma bastante satisfatória mesmo na presença de OD. Obtiveram-se concentrações de nitrato menores que 10 mg/L. Contudo, Rodríguez (2006) acredita ser possível a obtenção de maiores eficiências de remoção desde que as condições anóxicas no compartimento desnitrificante sejam mantidas.

Araújo Jr. (2006) avaliou o desempenho do reator combinado anaeróbio-aeróbio vertical de leito fixo para o tratamento de água residuária de indústria produtora de lisina, visando a remoção de matéria orgânica e nitrogênio. A melhor condição operacional do reator foi conseguida aplicando-se tempo de detenção hidráulica (TDH) de 35 h ( 21 h na zona anaeróbia e 14 h na zona aeróbia), com base no volume útil do reator, e razão de recirculação $(\mathrm{R})$ igual a 3,5, apresentando eficiências na remoção de DQO, NTK e NT de 97\%, 94\% e 77\%, respectivamente, com concentrações efluentes médias de $36 \pm 10 \mathrm{mg}$ DQO/L, $2 \pm 1 \mathrm{mg} \mathrm{N}-\mathrm{NH}_{4} / \mathrm{L}, 8 \pm 3 \mathrm{mg} \mathrm{N}-\mathrm{Org} / \mathrm{L}$,

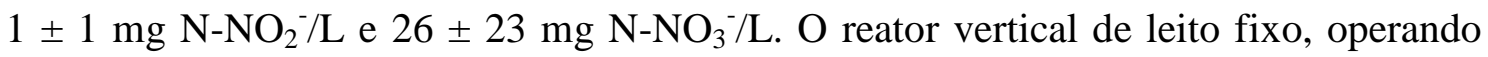
unicamente em condição anaeróbia, apresentou eficiências médias na remoção de DQO de $43 \pm 9 \%, 60 \pm 9 \%$ e $70 \pm 6 \%$, respectivamente para TDH aplicados de $11 \mathrm{~h}, 17 \mathrm{~h}$ e $21 \mathrm{~h}$.

Tandukar et al. (2006a) desenvolveram um sistema de tratamento de esgoto, que consiste num reator UASB com pós-tratamento DHS (down-flow hanging sponge). O 
sistema foi instalado numa estação de tratamento e continuamente avaliado por mais de 3 anos com esgoto bruto como afluente, à temperatura de $25 \pm 3^{\circ} \mathrm{C}$. Poluentes orgânicos foram apenas parcialmente removidos na etapa anaeróbia. A matéria orgânica remanescente, assim como os compostos nitrogenados, foram quase completamente removidos pela unidade de pós-tratamento DHS. O sistema demonstrou eficiência de remoção maior que 95\% para demanda bioquímica de oxigênio (DBO) não-filtrada, 80\% para demanda química de oxigênio (DQO) não-filtrada e $70 \%$ para sólidos suspensos. A qualidade do efluente obtido foi excelente, com apenas 4 - $9 \mathrm{mg} / \mathrm{L}$ de DBO não-filtrada; a quantidade de oxigênio dissolvido no efluente final foi de 5 - $7 \mathrm{mg} / \mathrm{L}$. Além disso, a produção de lodo pode ser considerada desprezível. O sistema também exibiu estabilidade a altas cargas hidráulicas e orgânicas aplicadas.

Oliveira Netto (2007) avaliou o desempenho de um sistema que combina os processos anaeróbio e aeróbio, para tratamento de esgoto sanitário, operado de modo contínuo sem e com recirculação da fase líquida. Essa configuração de reator foi a mesma utilizada por Araújo Jr. (2006). O desempenho do sistema foi avaliado em três diferentes tempos de detenção hidráulica (TDH), 6, 8 e 10 horas, na fase anaeróbia, nos quais os melhores valores de remoção de matéria orgânica chegaram a 80\% para TDH de 10 h, com valores de DQO efluente abaixo de $150 \mathrm{mg} / \mathrm{L}$. Com a inserção da fase aeróbia ao sistema (TDH de aproximadamente 11 horas, sendo 8 horas para a fase anaeróbia e 3 horas para a fase aeróbia), a eficiência subiu para mais de 90\% com DQO efluente abaixo dos $50 \mathrm{mg} / \mathrm{L}$. Foram obtidos ganhos quando feita recirculação do efluente tratado, principalmente em relação à remoção de matéria orgânica (95\%) e remoção de nitrogênio total que foi de $75 \%$ para razão de recirculação (r) de 1,5 . O reator avaliado apresentou estabilidade operacional, alta remoção de matéria orgânica e nitrogênio sem a necessidade de adição de fonte exógena de carbono e de 
suplementação de alcalinidade.

Hoffmann et al. (2007) apresentaram estudo do tratamento biológico de efluente sanitário em reator de lodo ativado operado em bateladas seqüenciais (RBS) em escala real, a fim de alcançar a nitrificação e desnitrificação na mesma fase, realizada por limitação de oxigênio. $\mathrm{O}$ reator possibilitou o tratamento de $250 \mathrm{~m}^{3}$ de esgoto por ciclo. Durante todas as fases, apresentadas na Tabela 3.5, o tratamento apresentou eficiências relativamente estáveis da remoção de $\mathrm{DQO}_{\text {total }}$ entre $80 \%-90 \%$ e $90 \%-95 \%$ de remoção para $\mathrm{DBO}_{5}$. Entretanto, a eficiência de nitrificação variou, foi melhor nas $1^{\mathrm{a}} \mathrm{e}$ $4^{a}$ fases $(94 \%$ e $96 \%)$, na $3^{a}$ fase ficou com $89 \%$ e na $2^{a}$ fase com concentrações de oxigênio abaixo de $0,6 \mathrm{mg} \mathrm{O}_{2} / \mathrm{L}$ a nitrificação somente chegou a $63 \%$. A desnitrificação nesta fase ( $2^{\mathrm{a}}$ fase) foi a mais eficiente, com $95 \%$, nas $1^{\mathrm{a}}$ e $3^{\mathrm{a}}$ fases ficou em $87 \%$ e $72 \%$ respectivamente e na $4^{\text {a }}$ fase, com elevadas concentrações de oxigênio, só alcançou 55\%. O pior resultado da remoção de Nitrogênio (nitrificação + desnitrificação) foi na $4^{\mathrm{a}}$ fase (53\%), quando as altas concentrações de oxigênio evitaram a remoção do nitrato formado pela nitrificação eficiente, que provocou também a redução da alcalinidade. A mais alta remoção de nitrogênio foi de $77 \%$ na $3^{\mathrm{a}}$ fase, na qual, pela microscopia, também se observaram as melhores condições operacionais, já que a maioria das bactérias filamentosas, que anteriormente dominavam o lodo, desapareceu, e os protozoários se desenvolveram novamente com grande variedade. 
Tabela 3.5 - Dados operacionais das 4 fases na operação do reator de lodo ativado operado em bateladas seqüenciais (RBS). (Fonte: HOFFMANN et al. 2007)

\begin{tabular}{cccccc}
\hline DADOS OPERACIONAIS & UNIDADE & FASE 1 & FASE 2 & FASE 3 & FASE 4 \\
\hline Tempo de estudo & dias & 28 & 21 & 45 & 28 \\
Número de ciclos por dia & - & $3 \times 8 \mathrm{~h}$ & $3 \times 8 \mathrm{~h}$ & $2 \times 12 \mathrm{~h}$ & $2 \times 12 \mathrm{~h}$ \\
Concentração $\mathrm{O}_{2}$ durante a & & & & $<0,1$ & $>0,6$ \\
fase biológica & $\mathrm{mg} \mathrm{O}_{2} / \mathrm{L}$ & $<0,6$ & $>0,1$ & $<0,6$ & $<2,0$ \\
& & $<1,0$ & $<0,6$ & + uma vez/d $>2,0$ & \\
\hline
\end{tabular}

Chan et al. (2007) estudaram um sistema em escala piloto constituído de tanques de $5 \mathrm{~m}$ x $3 \mathrm{~m} \times 1,8 \mathrm{~m}$ (comprimento x largura $\times$ profundidade), funcionando em batelada, tratando esgoto de uma pequena comunidade no interior da China. O sistema possuía um TDH total de 18 horas, atingindo eficiência média de $60 \%$ de remoção da matéria carbonácea. A remoção de N-Amon e fósforo foi de $50 \%$ e $40 \%$, respectivamente, enquanto que a remoção de SST foi de aproximadamente $80 \%$.

La Motta et al. (2007) investigaram o comportamento de um sistema combinado UASB seguido de ASC (“Aerobic Solids Contact”) para tratamento de esgoto sanitário. O reator UASB possuía um volume total de 396 L e o ASC tinha um volume de 240 L. Os resultados indicaram que o reator UASB obteve eficiência de remoção média de 34\% em relação a DQO e 36\% para SST, evidenciando seu mau funcionamento. Após passagem pelo ASC, o efluente atingiu baixos valores de DQO, na ordem de $30 \mathrm{mg} / \mathrm{L}$ para um TDH total de 5 horas.

Fontana et al. (2007) avaliaram desempenho de biofiltro aerado submerso (BF) preenchido com carvão granular, empregado no pós-tratamento de efluente proveniente de reator UASB, que operava com TDH de 8 h. Os biofiltros BF1 e BF2 (em PVC, 
volume total de $53 \mathrm{~L}$ e volume de armazenamento de 18,9 L) operaram com TDH de $4 \mathrm{~h}$ e 6 h, respectivamente. O UASB apresentou eficiência média de $64 \%$ na remoção de DQO filtrada $\left(\mathrm{DQO}_{\mathrm{f}}\right)$, tratando esgoto doméstico. O efluente obtido na saída do UASB, com valores médios de $70 \pm 25 \mathrm{mg} \mathrm{DQO} / \mathrm{L}, 73 \pm 38 \mathrm{mg} \mathrm{DBO} / \mathrm{L}, 31 \pm 6 \mathrm{mg} \mathrm{NH} / \mathrm{L} \mathrm{e}$ $35 \pm 6 \mathrm{mg}$ NTK/L, foi utilizado como afluente aos biofiltros. O BF1 apresentou eficiências médias na remoção de $\mathrm{DQO}_{\mathrm{f}}, \mathrm{DBO}_{5}, \mathrm{~N}$-Amon e NTK de 62\%, 46\%, 89\% e $84 \%$, respectivamente, com valores médios de $25 \pm 11 \mathrm{mg} \mathrm{DQO}_{\mathrm{f}} / \mathrm{L}$, $36 \pm 29 \mathrm{mg} \mathrm{DBO}_{5} / \mathrm{L}, 4 \pm 9 \mathrm{mg} \mathrm{NH} / \mathrm{L}$ e $6 \pm 12 \mathrm{mg} \mathrm{NTK} / \mathrm{L}$. Por outro lado, o BF2, apresentou eficiências médias na remoção de $68 \%, 95 \%, 89 \%$ e $80 \%$ respectivamente, com valores médios de $21 \pm 12 \mathrm{mg} \mathrm{DQO} / \mathrm{L}, 3 \pm 3 \mathrm{mg} \mathrm{DBO} / \mathrm{L}, 6 \pm 12 \mathrm{mg} \mathrm{NH} \mathrm{NH}_{3} / \mathrm{L} \mathrm{e}$ $8 \pm 13 \mathrm{mg}$ NTK/L. Os sistemas combinados apresentaram eficiências globais de remoção de $\mathrm{DQO}_{\mathrm{f}}$ de $87 \%$ e $90 \%$ para o UASB + BF1 e UASB + BF2, respectivamente. Verificou-se, também, a ocorrência de nitrificação, com eficiência média de remoção de $\mathrm{N}$-Amon e de NT superiores a $89 \%$ e $80 \%$, respectivamente. Comparativamente, o BF2, operando com uma carga orgânica volumétrica inferior ao BF1, mostrou-se mais estável às variações dos fatores operacionais, apresentando eficiências ligeiramente superiores, exceto em relação à remoção de DBO.

Yilmaz (2008) obteve bons resultados operando um sistema UASB com póstratamento em reator operado em bateladas seqüenciais (RBS), tratando esgoto doméstico, à temperatura ambiente $\left(14-28^{\circ} \mathrm{C}\right)$, durante 6 meses. As eficiências do sistema foram de $86 \%$ para remoção de DQO, $100 \%$ para N-NH${ }_{4}^{+}$e $60 \%$ para $\mathrm{P}_{-} \mathrm{PO}_{4}{ }^{-3}$. As principais vantagens do pré-tratamento anaeróbio foram melhora na eficiência de nitrificação e não produção de lodo em excesso no sistema. Por outro lado, o sistema UASB-RBS não pôde remover eficientemente fósforo. 
Mahmoud et al. (2009) avaliaram um sistema combinado anaeróbio-aeróbio, composto por um reator anaeróbio híbrido (AHR) e seguido por sistema DHS (downflow hanging sponge). O sistema combinado foi operado constantemente com tempo de detenção hidráulica $(\mathrm{TDH})$ de 8 horas $(\mathrm{AHR}=6$ horas e DHS $=2$ horas $)$ e carga orgânica média de $1,9 \mathrm{~kg} \mathrm{DQO} / \mathrm{m}^{3}$.d para o AHR e 2,1 kg DQO $/ \mathrm{m}^{3} . \mathrm{d}$ para o DHS. O sistema combinado foi capaz de remover $95 \%$ e $89 \%$ da $\mathrm{DBO}_{5}$ total e DQOtotal, atingindo valores residuais no efluente final de apenas 10 e $49 \mathrm{mg} / \mathrm{L}$, respectivamente. A concentração de amônia foi reduzida em $83 \%$ e a concentração média de biomassa aderida à esponja atingiu 20 g SSV/L. Análise de amostras do efluente coletada na saída de cada segmento ao longo do DHS revelou que a maior parte da matéria orgânica, expressa em frações de DQO, é removida no $1^{\circ}$ e $2^{\circ}$ segmentos do sistema DHS. Este foi seguido por nitrificação nos próximos dois segmentos.

Das opções de tratamento de efluentes líquidos, os sistemas combinados anaeróbio-aeróbios mostram-se promissores, principalmente quando, além da redução da matéria orgânica, deseja-se a remoção de nutrientes, em particular o nitrogênio. A comparação de todos os resultados obtidos, nos trabalhos pesquisados, evidenciou a importância do pós-tratamento aeróbio na remoção de parcela de matéria orgânica não removida em tratamento unicamente anaeróbio. Os resultados demonstram o potencial destes reatores como alternativa para o tratamento e pós-tratamento de esgoto sanitário, com resultados promissores de remoção de matéria orgânica e nitrogênio.

\subsection{Considerações Finais}

No tratamento de águas residuárias em sistemas em grande escala, com freqüência não são considerados aspectos básicos dos processos biológicos envolvidos na remoção de nitrogênio, o que pode afetar seu desenvolvimento normal, resultando 
em tecnologias não sustentáveis. Apesar disso, quando se tem conhecimento suficiente dos processos biológicos, é provável a aplicação de projetos tecnológicos inovadores (combinação de processos, compactos, mais eficientes, mais simples) que permitam o reuso de água e o melhoramento ambiental.

Os resultados obtidos pelas pesquisas já realizadas e apresentadas nessa revisão, quanto à remoção de matéria orgânica e nitrogênio, utilizando-se de sistemas combinados de filme fixo são bastante encorajadores, para que se utilize mais dessa tecnologia em sistemas de tratamento, sobretudo em regiões nas quais há pouca disponibilidade de espaço para a construção de estação de tratamento.

É de fundamental importância, a busca por alternativas que minimizem custos. Quando a tecnologia permite a ciclagem interna das fontes de carbono para a desnitrificação e a recuperação da alcalinidade, as vantagens obtidas são grandiosas, visto que não será necessário a adição de alcalinizante no afluente, para suprir a demanda de alcalinidade consumida no processo de nitrificação.

Já a ciclagem interna das fontes de carbono e doadores de elétrons para promover o processo de desnitrificação, é possível através da recirculação do efluente tratado, proporcionando mistura e homogeneização do meio líquido, não sendo necessário adição de uma fonte exógena de fonte de carbono, necessária quando são operados reatores combinados anaeróbio-aeróbio-anóxico com a finalidade de remoção de matéria orgânica e de nitrogênio, confirmado pela operação do reator combinado anaeróbio-aeróbio de leito fixo, em escala de bancada, por Oliveira Netto (2007) e por Araújo Jr. (2006) que concluiu que o sistema combinado se mostra promissor para o tratamento de águas residuárias com altas concentrações de matéria orgânica e nitrogênio, tendo algumas vantagens sobre os sistemas convencionais de tratamento por 
lodos ativados, tais como, menor área de implantação, pequena geração de lodo e simplicidade operacional.

A bibliografia consultada forneceu base para que a parte experimental da pesquisa pudesse ser realizada, tendo sido utilizados muitos dos conceitos já estabelecidos no projeto e na realização dos experimentos e, principalmente, no entendimento dos fenômenos ocorridos durante a operação no sistema.

A experiência transmitida por outros pesquisadores permitiu que se desenvolvesse conhecimento mais aprofundado dos processos de tratamento, podendose utilizar dessa experiência para inferir se o comportamento do sistema vinha ocorrendo de forma adequada, e quais as medidas necessárias para correção de eventuais problemas.

Conforme se pode observar pela revisão da literatura, são muitas as variáveis determinantes a serem consideradas na obtenção da remoção biológica de nitrogênio. Reatores com biofilme apresentam-se como uma alternativa viável e efetiva, embora certas condições ambientais e hidráulicas devam ser mantidas para evitar inibição dos processos bioquímicos.

Por meio dos trabalhos da revisão é possível observar que sistemas com biofilme têm, entre outras vantagens, a habilidade de sustentar uma grande variedade de populações microbianas, em diferentes locais do biofilme, o que permite a ocorrência simultânea de diferentes processos biológicos. Esta habilidade torna esse tipo de sistema bastante atraente, quando se querem propor alternativas de tratamento compactas e efetivas.

O estudo de uma nova configuração de reator que incorpore um compartimento para a nitrificação e outro para a desnitrificação configura-se como uma alternativa 
bastante interessante, para alcançar a remoção completa de nitrogênio em uma única unidade. 


\section{MATERIAL E MÉTODOS}

Esse item contempla o material que foi utilizado para realização do experimento, assim como o protocolo experimental adotado para desenvolvimento do mesmo.

O reator utilizado foi de leito fixo de fluxo ascendente em escala piloto, operado de modo contínuo, com argila expandida e espuma de poliuretano como suportes de imobilização da biomassa. O leito do reator foi dividido em seis compartimentos com volumes diferentes. A argila expandida foi escolhida para o primeiro compartimento pelo fato deste tipo de suporte permitir a aderência prioritária de organismos acidogênicos (ORTEGA et al., 2001), que produzem compostos intermediários servindo de substrato para a comunidade microbiana mista aderida à espuma de poliuretano, suporte que permite aderência de biomassa anaeróbia com grande diversidade (RIBEIRO et al., 2005), comprovada pela operação do reator combinado anaeróbioaeróbio vertical de leito fixo por Araújo Jr. (2006) e Oliveira Netto (2007).

O reator de leito fixo foi operado como anaeróbio-aeróbio, com fluxo ascendente. $\mathrm{O}$ efluente do reator, após passar por zona aeróbia, retornava para o leito anaeróbio, acima do compartimento contendo argila expandida e na base do compartimento contendo espuma de poliuretano. Com esse procedimento, o efluente aeróbio nitrificado passa por processo de desnitrificação no leito anaeróbio/anóxico, utilizando como fonte de carbono e energia (doador de elétrons) os compostos orgânicos intermediários da degradação anaeróbia, provenientes do leito contendo argila expandida. Assim, a intenção com essa configuração é evitar a adição de fonte externa de carbono e de alcalinizante em operação combinada (anaeróbia-aeróbia-anóxica), com a finalidade de remoção de matéria orgânica e de nitrogênio. 


\subsection{Reator combinado anaeróbio-aeróbio de leito fixo em escala piloto}

Para realização dos experimentos foi utilizado reator de leito fixo e escoamento ascendente, apresentado na Figura 4.1, o qual operou como combinado anaeróbioaeróbio e com recirculação da fase líquida. A Figura 4.1 mostra montagem do reator e a Figura 4.2 apresenta o desenho esquemático do sistema.

O reator foi construído em tubo de fibra de vidro com diâmetro interno de 100 $\mathrm{cm}$ e $350 \mathrm{~cm}$ de comprimento, com volume total de aproximadamente $2,5 \mathrm{~m}^{3}$.

O leito foi dividido em seis compartimentos de diferentes volumes, separados por placas perfuradas de fibra de vidro (Figura 4.3), sendo estas reforçadas, para garantir a sustentação do leito.

O aumento de escala deve ser analisado já que com base nos experimentos e resultados encontrados para o reator em escala de bancada (OLIVEIRA NETTO, 2007), essa configuração de reator pode ser alternativa viável para remoção de matéria orgânica e nitrogênio de esgoto sanitário, além de poder permitir a operação do sistema sem necessidade de adição de alcalinidade nem de fonte exógena de fonte de carbono para promover a desnitrificação em níveis substanciais. 


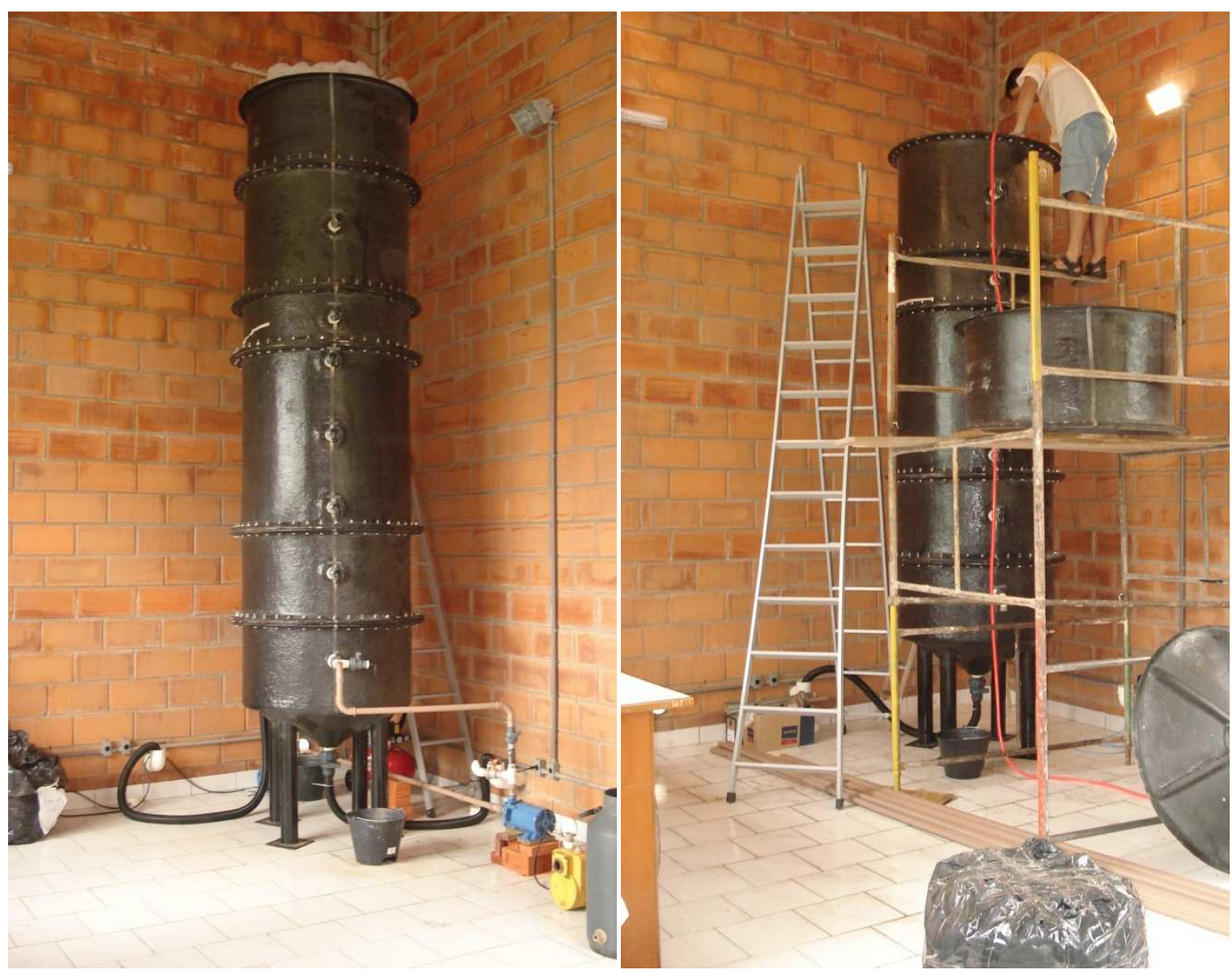

Figura 4.1 - Reator combinado anaeróbio-aeróbio em escala piloto 


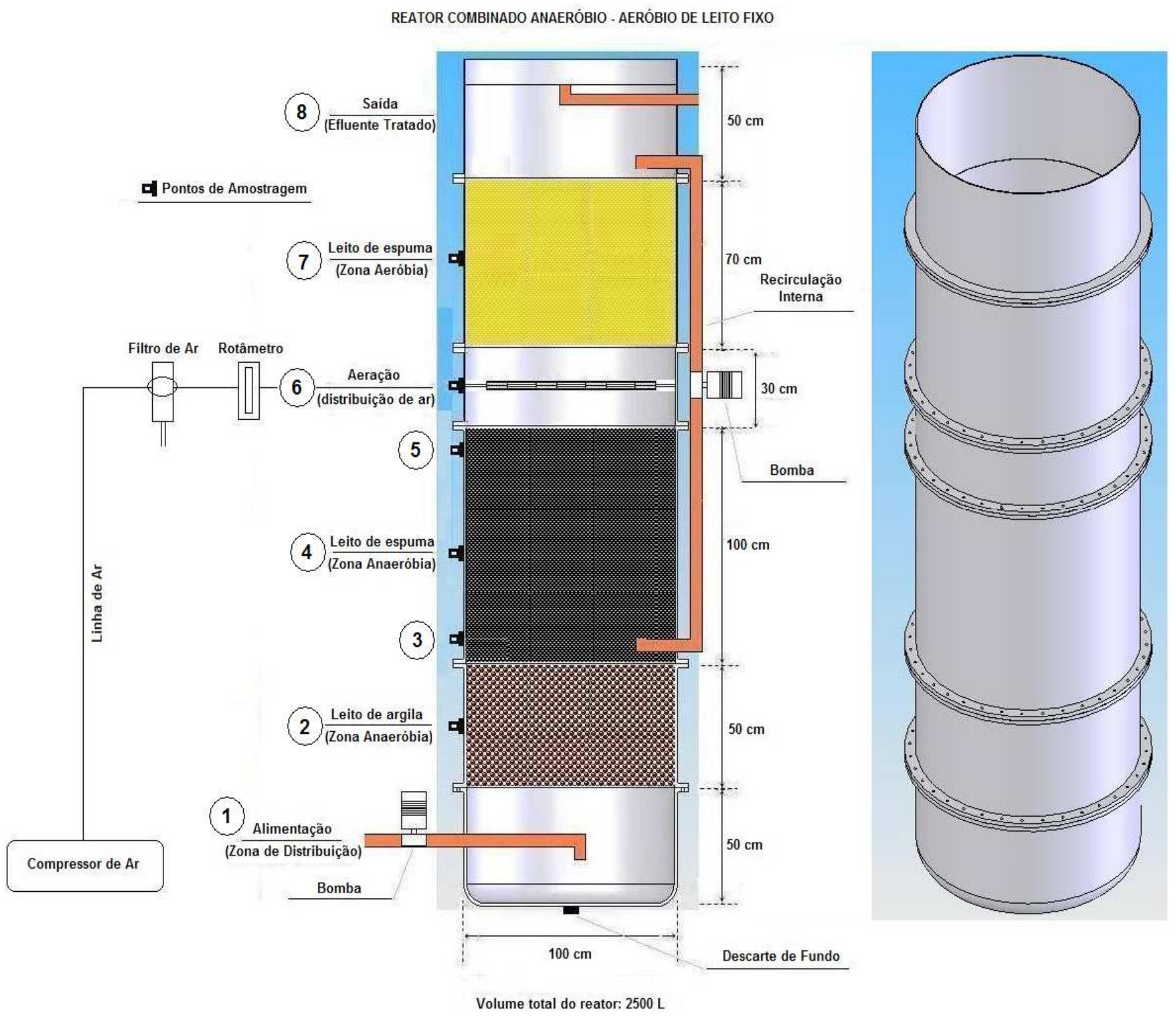

Figura 4.2 - Representação esquemática do reator combinado anaeróbio-aeróbio de leito fixo em escala piloto 


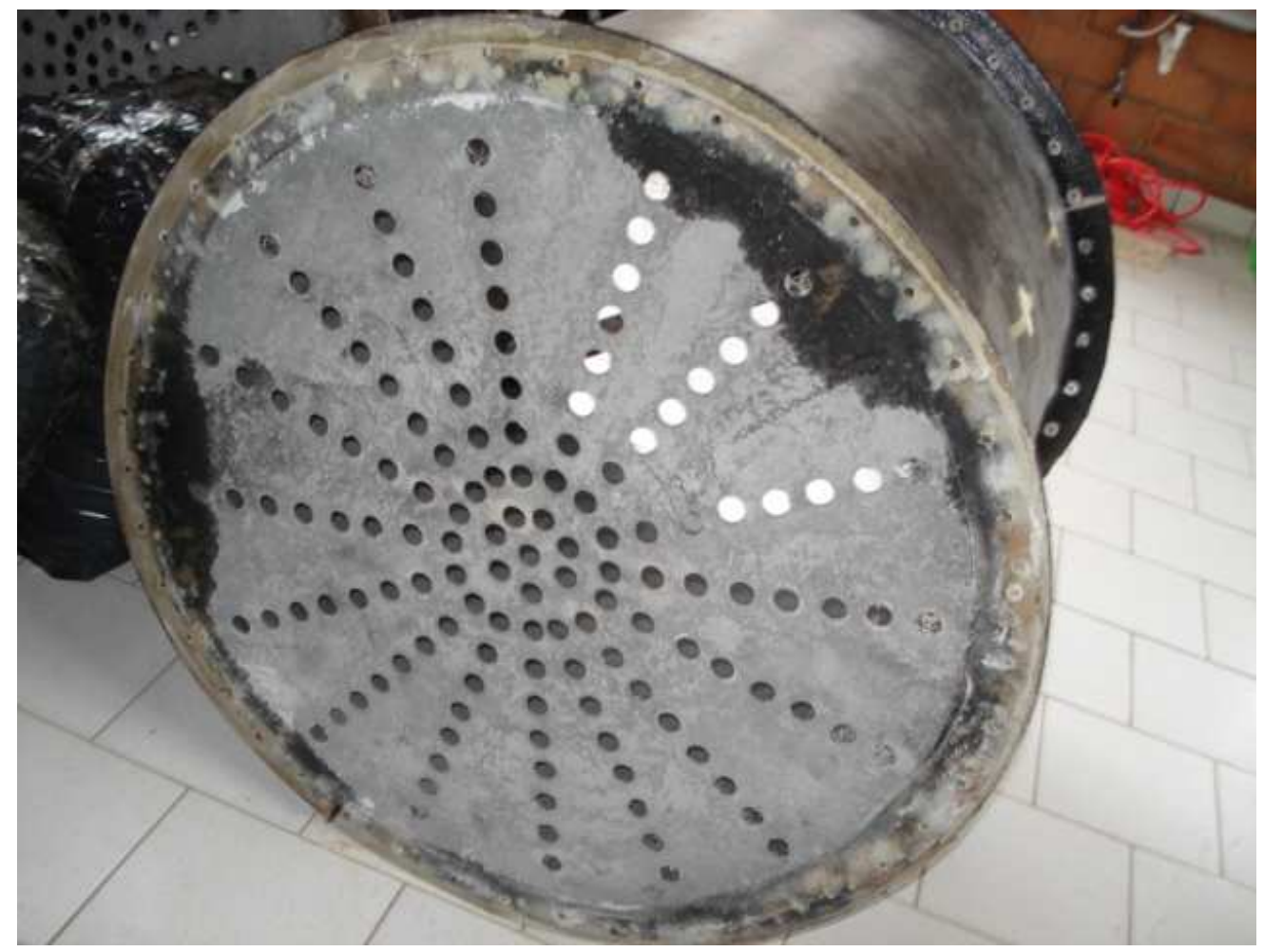

Figura 4.3 - Placa perfurada de fibra de vidro

\subsection{Materiais Suporte}

A finalidade da camada suporte é reter sólidos biológicos no interior do reator. Dessa forma, essa camada promove uniforme distribuição do escoamento no interior do reator e melhora o contato do afluente com a matéria orgânica nele contida (YOUNG, 1990).

Partículas de espuma de poliuretano, mostradas na Figura 4.4, com densidade de $23 \mathrm{~kg} / \mathrm{m}^{3}$ e porosidade de $95 \%$, aproximadamente, dispostas em matrizes cilíndricas de $5,0 \mathrm{~cm}$ de diâmetro e $6,0 \mathrm{~cm}$ de comprimento foram usadas como suporte de imobilização da biomassa em um dos compartimentos anaeróbios e no compartimento aeróbio, sendo as mesmas recobertas com polipropileno para dar maior resistência à compressão e denominadas comercialmente de BioBob ${ }^{\circledR}$. Esse dispositivo para imobilização celular para ser utilizado como suporte de biomassa em sistemas biológicos de tratamento de águas residuárias foi desenvolvido pela empresa Bio Proj 
Tecnologia Ambiental Ltda., que desenvolve projetos e presta serviços especializados na área de tratamento de águas residuárias.

A quantidade estimada de matrizes cilíndricas $\left(\mathrm{BioBob}^{\circledR}\right)$ para o preenchimento dos compartimentos foi de aproximadamente 7000 unidades. Segundo Zaiat (1996), a espuma de poliuretano é um suporte bastante adequado à imobilização de biomassa anaeróbia apresentando colonização rápida dos microrganismos, confirmada pela rápida partida do reator anaeróbio horizontal de leito fixo (RAHLF), e pelo pequeno arraste do lodo durante a operação do reator. $\mathrm{O}$ uso do suporte para imobilização de biomassa aeróbia foi avaliado com sucesso por Fazolo (2003), Araújo Jr. (2006) e Oliveira Netto (2007) para o reator combinado anaeróbio-aeróbio vertical de leito fixo.

Também foi utilizada argila expandida (cinasita), mostradas na Figura 4.4, como material suporte no primeiro compartimento da zona anaeróbia. A argila expandida é um agregado leve que se apresenta em forma irregular, com uma estrutura interna formada por uma espuma cerâmica com micro poros e com uma casca rígida e resistente. É produzida em grandes fornos rotativos, utilizando argilas especiais que se expandem a altas temperaturas $\left(1100^{\circ} \mathrm{C}\right)$, transformando-as em um produto leve, de elevada resistência mecânica ao fogo e aos principais ambientes alcalinos e ácidos. $\mathrm{O}$ uso do suporte para imobilização de biomassa anaeróbia foi avaliado com sucesso por Oliveira Netto (2007). A granulometria utilizada, nesta pesquisa, variou de $22 \mathrm{~mm}$ a 32 $\mathrm{mm}$. 


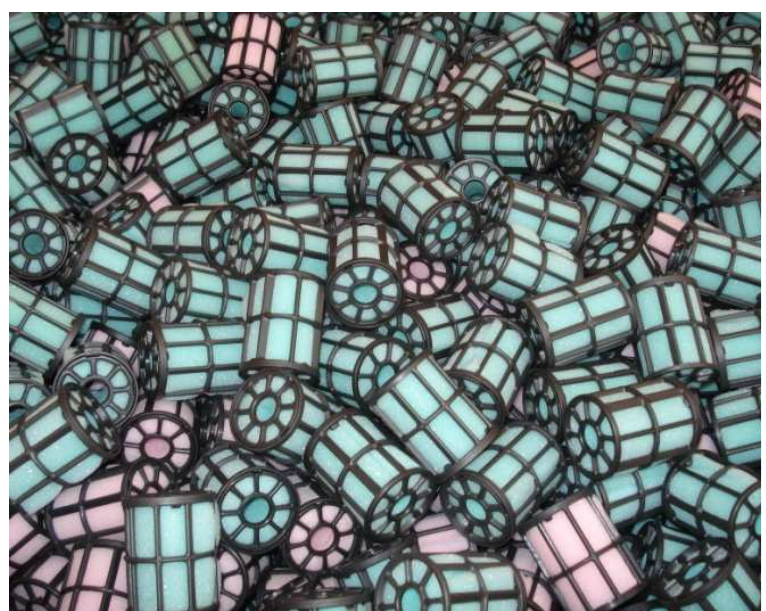

(a)

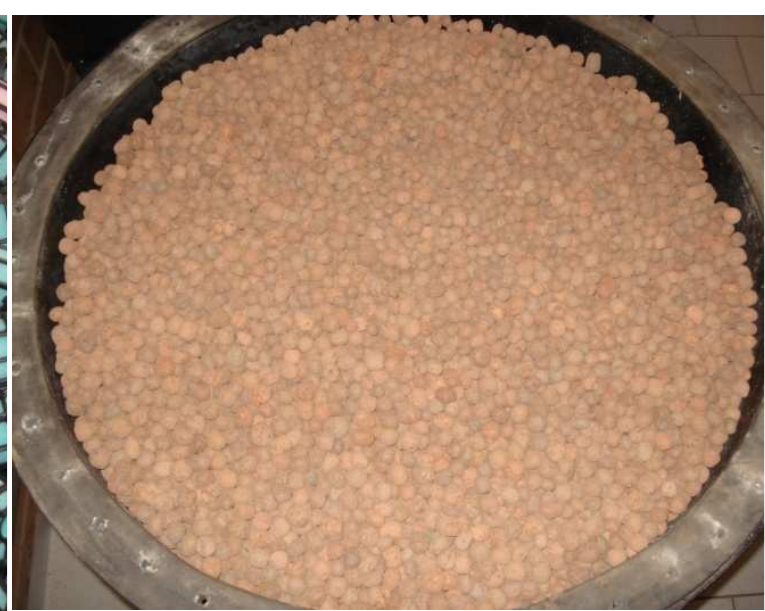

(b)

Figura 4.4 - Materiais suporte utilizados no experimento. (a) Espuma de Poliuretano

$\left(\right.$ BioBob $\left.^{\circledR}\right) ;($ b) Argila Expandida

A alocação dos suportes ao longo do reator pode ser visualizada na Figura 4.4, sendo a argila inserida no primeiro compartimento do reator e a espuma de poliuretano nos demais.

A argila expandida na zona anaeróbia e a espuma nas zonas anaeróbia e aeróbia não foram inoculadas previamente, sendo o próprio esgoto sanitário utilizado como fonte de microrganismos para aderência ao suporte. Zaiat et al. (2000) avaliaram a partida e o desempenho do reator anaeróbio horizontal de leito fixo, em escala piloto, tratando esgoto doméstico. Apesar da não inoculação do meio suporte, não ocorreu instabilidade no processo e observou-se um período curto de partida comprovado pelo monitorando de alguns parâmetros tais como DQO, composição do biogás, concentração de metano e concentração de ácidos voláteis totais (AVT).

\subsection{Esgoto Sanitário}

A água residuária deste estudo abastece a área de pesquisa em tratamento de esgoto sanitário, Figura 4.5, do Laboratório de Processos Biológicos (LPB) da Escola de Engenharia de São Carlos - EESC/USP da Universidade de São Paulo (USP) em São 
Carlos, SP. Trata-se de esgoto sanitário gerado em bairros circunvizinhos à área 2 do Campus da USP em São Carlos, compostos basicamente por unidades residenciais e poucas unidades comerciais.

A Figura 4.5 apresenta algumas fotos da seqüência de evolução das obras de adequação da área de tratamento de esgoto, a qual englobou limpeza do terreno, passando por locação de obra, escavação das valas de fundação, levantamento de alvenaria, contra piso, impermeabilização, assentamento de piso, armação metálica para apoio do forro de PVC, escada de acesso e calçada, instalações hidráulicas e elétricas, instalações de janelas, balcão com cuba acoplada e acessórios, assentamento de manilhas de concreto e construção do reservatório de armazenamento de esgoto em concreto armado entre outros.

Tanto a alimentação, quanto a recirculação impostas ao sistema foram realizadas por bombas centrífugas da marca Grundfos modelo XD-1 e potência de 0,33 cv mostradas na Figura 4.6. 


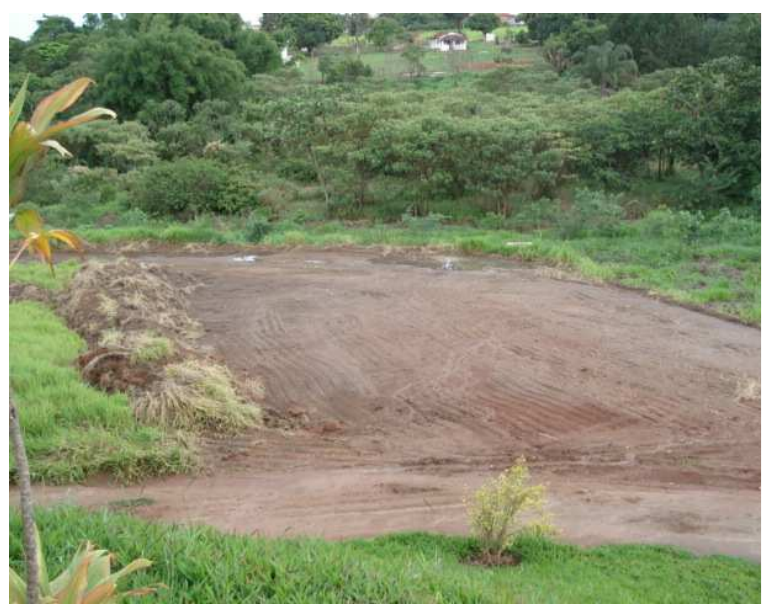

Preparação do terreno

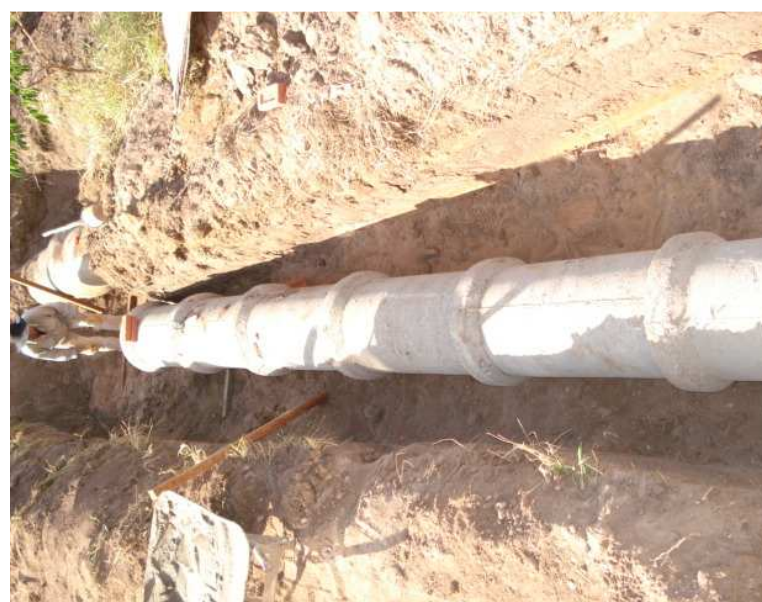

Assentamento das manilhas de concreto

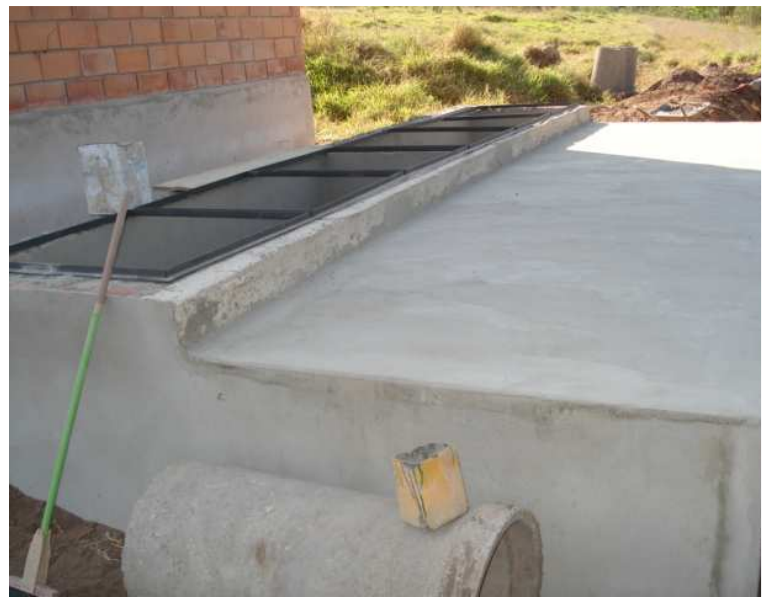

Reservatório em concreto armado

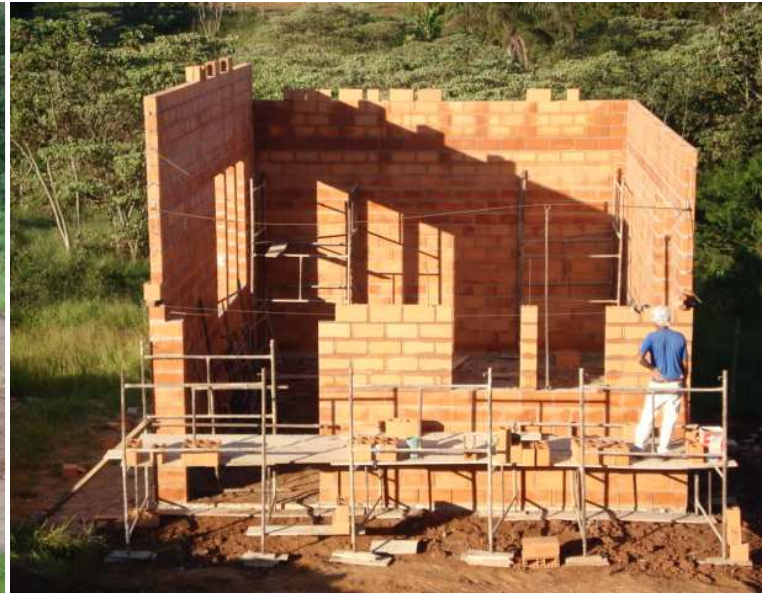

Levantamento da alvenaria

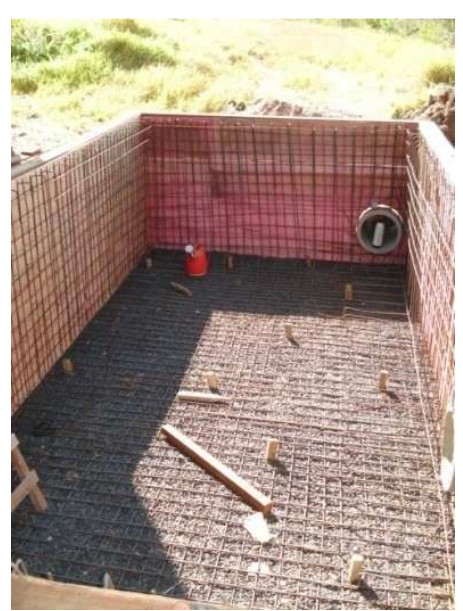

Armação da ferragem do reservatório de armazenamento

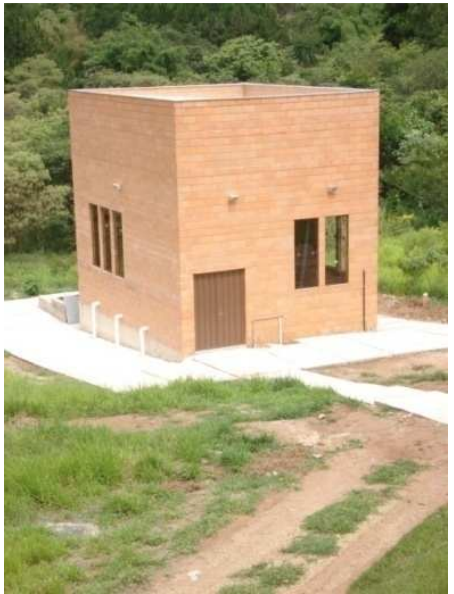

Área de tratamento de esgoto do LPB

Figura 4.5 - Área de tratamento de esgoto do Laboratório de Processos Biológicos 


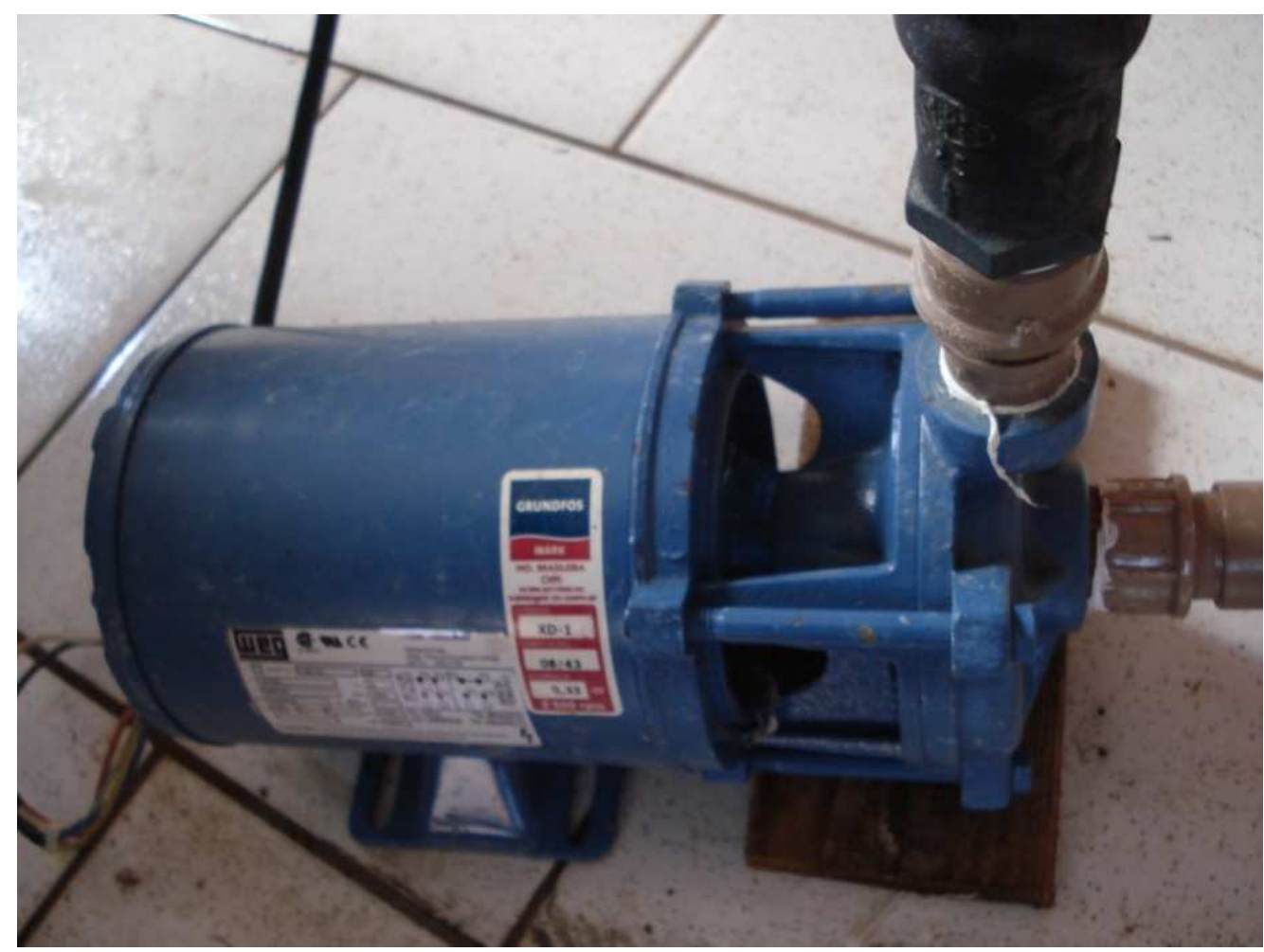

Figura 4.6 - Bombas de alimentação e recirculação utilizadas na pesquisa

\subsection{Sistema de Aeração}

Os sistemas de aeração são altamente empregados em diversos tipos de processos e configurações em estações de tratamento de efluentes (processos biológicos, químicos e físicos) e para aplicações em processos industriais. O sistema fornece oxigênio à biomassa, o que permite promover processos de oxidação de carga orgânica e remoção biológica de nutrientes, possibilita processos de mistura, equalização, flotação e digestão em todos os tipos possíveis de tanques, lagoas, valos, canais e caixas de areia aeradas.

Estudos feitos na Europa e Estados Unidos consolidaram a utilização de sistemas de aeração por ar difuso para essas aplicações devido a elevada eficiência e ao seu baixo custo de operação em relação aos que utilizam sistemas mecânicos. A economia no consumo energético pode chegar a $60 \%$ quando comparado com a utilização de 
aeradores mecânicos. Deve-se ressaltar, que para estações de tratamento de efluentes, de 50 a 90\% da energia consumida é demandada pelo sistema de aeração.

Para aeração do compartimento aeróbio do reator utilizado nesta pesquisa, foram instalados dois difusores de ar tubulares de bolha fina, mostrados na Figura 4.7, doados pela empresa B\&F Dias, com $600 \mathrm{~mm}$ de comprimento e $60 \mathrm{~mm}$ de diâmetro que possuem área de influência de 0,70 a $1,00 \mathrm{~m}^{2}$, dependendo das características do efluente a ser tratado e da vazão de ar a ser aplicada conforme informações técnicas do fabricante, vazão mínima por peça igual a $0,028 \mathrm{~m}^{3} / \mathrm{min}$ e entrada de ar rosqueada com diâmetro de 3/4". Como a área a ser aerada era igual a $0,785 \mathrm{~m}^{2}$ optou-se, por segurança, utilizar dois difusores de ar para garantir boa distribuição para a camada aeróbia do sistema. O difusor tubular de membrana de bolha fina com sistema anti-entupimento "back-flow", o qual evita o refluxo de líquido impedindo entrada de efluente na linha de ar, é montado sobre tubo termoplástico com conexões e braçadeiras em aço inoxidável evitando corrosão do material.

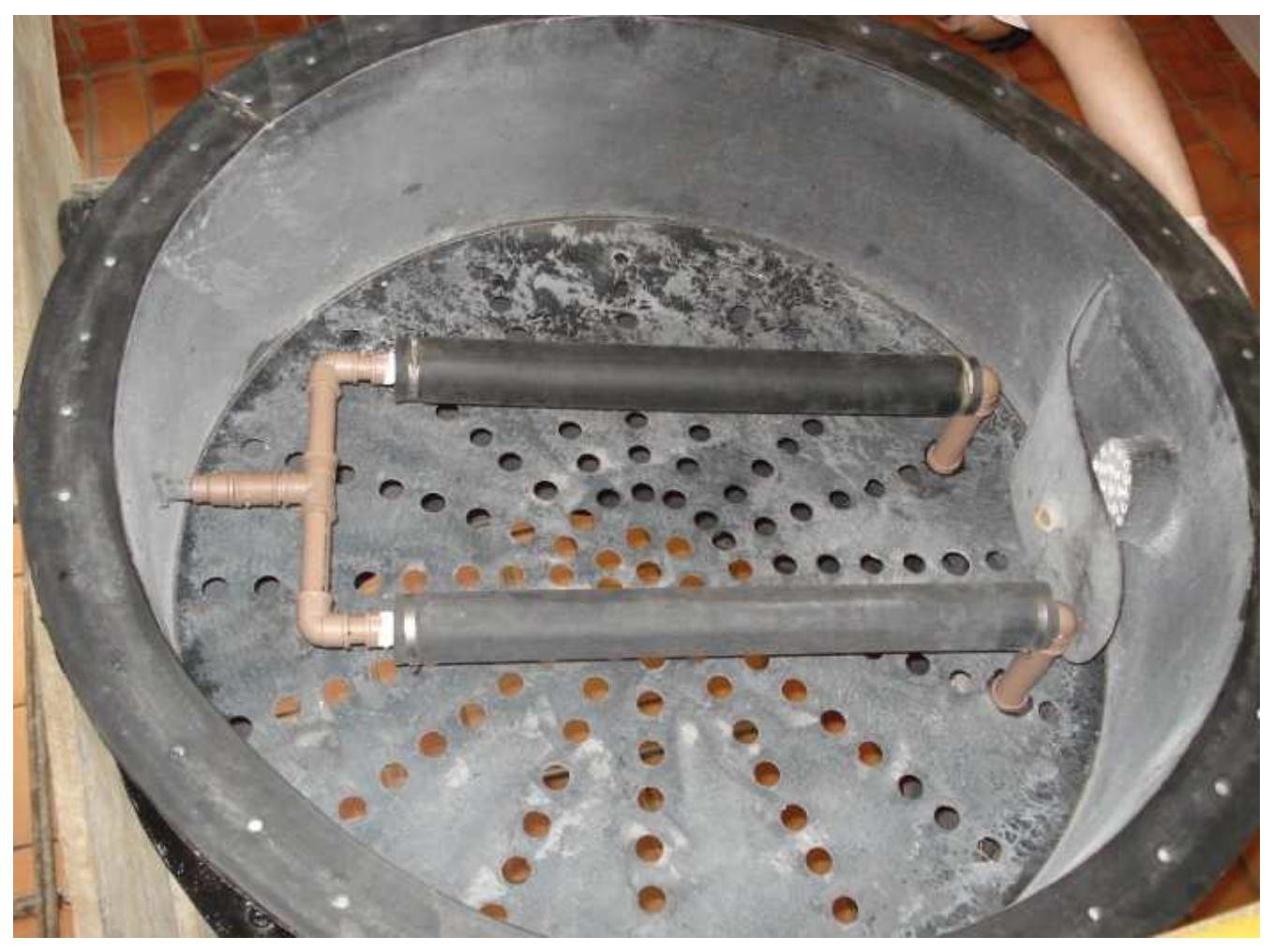

Figura 4.7 - Difusores tubulares de membrana de bolha fina 
Para geração de ar foi utilizado compressor de pistão e acionamento por correia da marca Schulz modelo CSL 6 BR/60L, mostrado na Figura 4.8, com deslocamento teórico de $170 \mathrm{~L} / \mathrm{min}$ e motor elétrico de $0,75 \mathrm{~kW}$. Foram instaladas mangueiras de pressão (ar e água) da marca HimaFlex para pressão máxima de 300 psi e diâmetro de 5/16" ( $\pm 0,8 \mathrm{~cm})$ para encaminhar o ar gerado pelo compressor até a entrada dos difusores no reator. Para medição da vazão de ar foi instalado rotâmetro da marca Dwyer (Figura 4.9) e para evitar contaminação do ar com óleo gerado pelo compressor, eliminar excesso de água, impurezas e partículas que possam prejudicar a qualidade do ar, também foi instalado na linha de ar, filtro processador da marca Arprex com dreno automático mostrado na Figura 4.9.

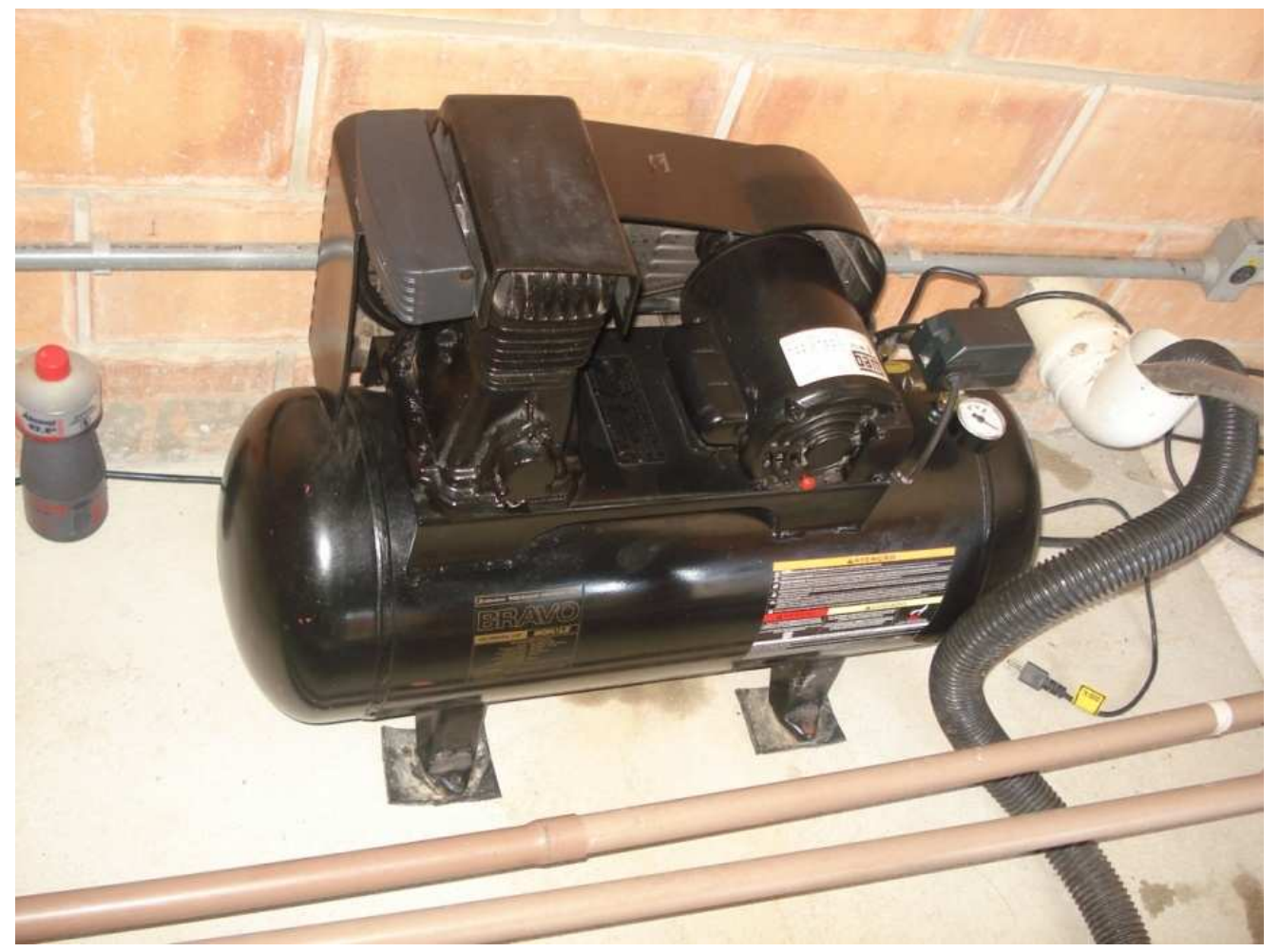

Figura 4.8 - Compressor de pistão para fornecimento de ar 


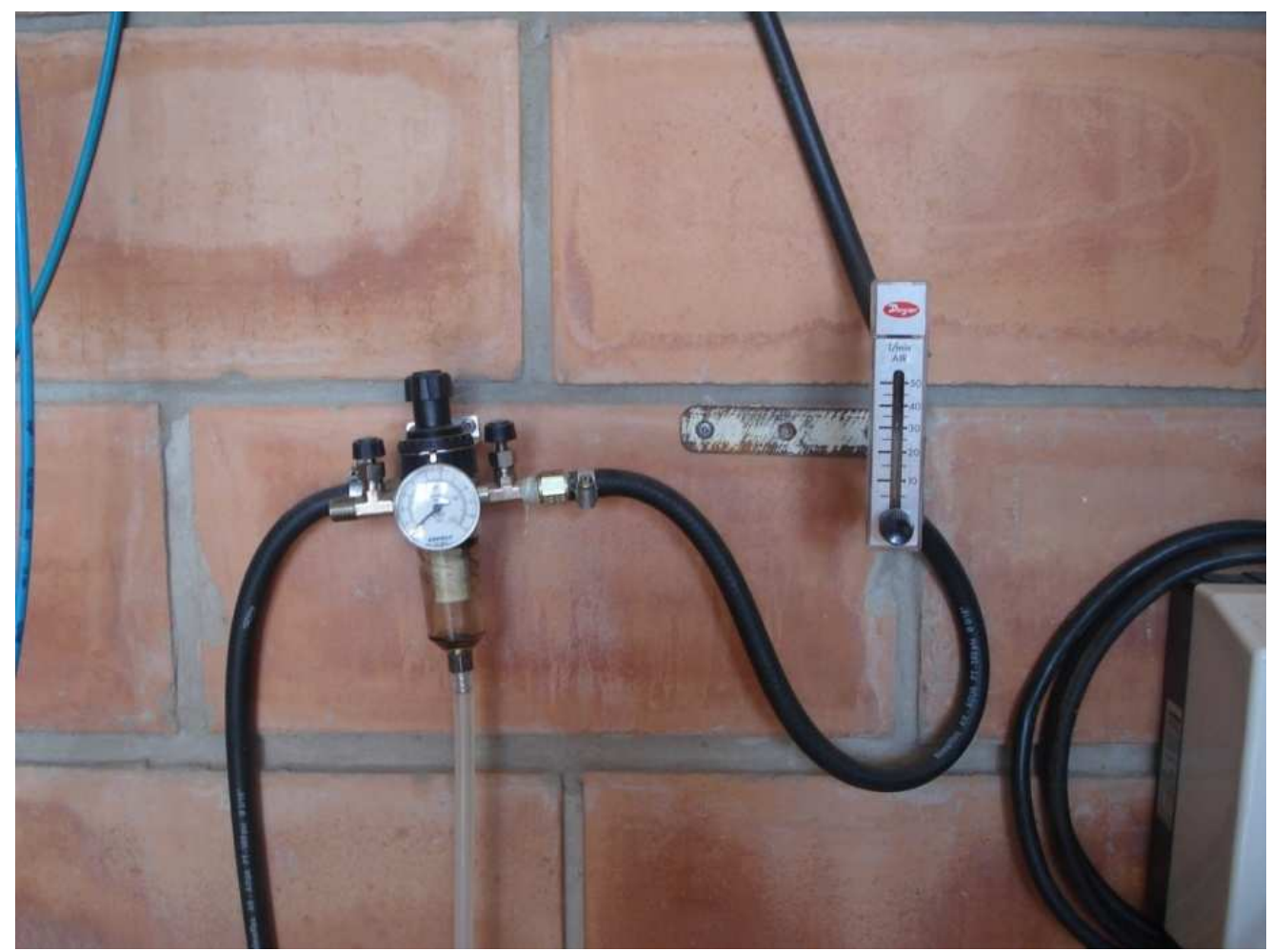

Figura 4.9 - Filtro e medidor de vazão de ar

\subsection{Sistema de sucção}

Para evitar entupimento da tubulação de sucção do esgoto que alimentava o sistema e evitar o desgaste de bombas e demais válvulas instaladas, foi instalada válvula de pé e crivo (válvula de fundo de poço) no ponto de sucção de esgoto. Para dar maior poder de "remoção" de sólidos grosseiros, a válvula de pé e crivo foi envolvida por um cesto fabricado em aço inoxidável com abertura de $3 \mathrm{~mm}$. A Figura 4.10 mostra os componentes citados. 

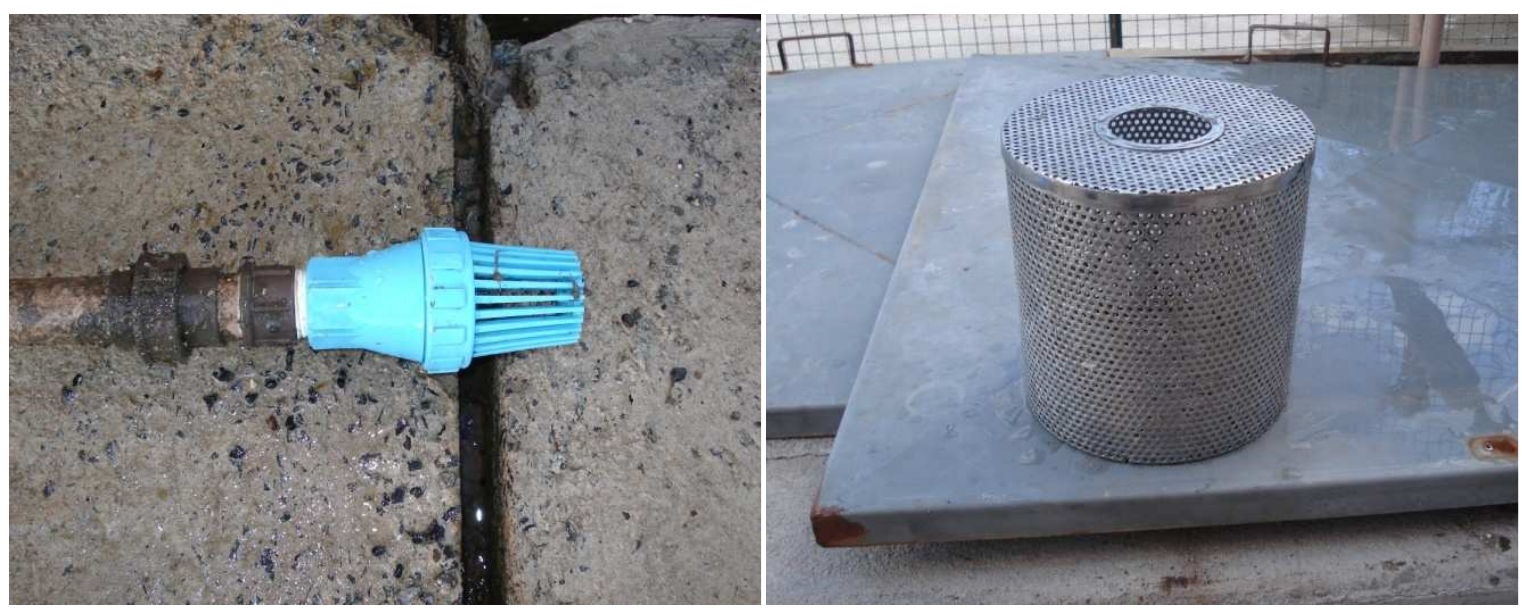

Figura 4.10 - Válvula de pé e crivo e cesto de aço inoxidável

\subsection{Métodos analíticos}

Durante a execução do experimento foram monitorados os parâmetros descritos na Tabela 4.1, segundo métodos descritos pela American Public Health Association APHA (1998). Para determinar a DQO de amostras filtradas (DQO filtrada), filtrou-se a amostra bruta em uma membrana com poros de 1,2 $\mu \mathrm{m}$. Ácidos voláteis totais (AVT), expressos como ácido acético (HAc), foram analisados de acordo com metodologia descrita por Dilallo \& Albertson (1961) e alcalinidade, expressa como $\mathrm{CaCO}_{3}$, conforme metodologia descrita por Dilallo \& Albertson (1961) e modificada por Ripley et al. (1986).

As análises foram realizadas em todas as etapas do experimento utilizando o reator combinado de leito fixo. Todos esses ensaios foram realizados no Laboratório de Processos Biológicos (LPB) da Escola de Engenharia de São Carlos - EESC/USP. 
Tabela 4.1 - Parâmetros analisados, método utilizado e freqüência de amostragem.

\section{Freqüência de}

\begin{tabular}{|c|c|c|}
\hline Parâmetro analisado & Método de análise & amostragem \\
\hline Vazão & & Diária \\
\hline Temperatura & Termômetro & Diária \\
\hline DQO bruta (mg/L) & Espectrofotométrico & $2 \mathrm{x}$ semana \\
\hline DQO filtrada (mg/L) & Espectrofotométrico & $2 \mathrm{x}$ semana \\
\hline $\mathrm{pH}$ & Potenciométrico & $2 \mathrm{x}$ semana \\
\hline Alcalinidade (mg CaCO3/L) & Titulométrico & $2 \mathrm{x}$ semana \\
\hline Ácidos voláteis (mg Hac /L) & Titulométrico & $2 \mathrm{x}$ semana \\
\hline ST, STV, SSV e SST & Gravimétrico & $2 \mathrm{x}$ semana \\
\hline N-NTK (mgN /L) & Titulométrico & $2 \mathrm{x}$ semana \\
\hline $\mathrm{N}-\mathrm{NH}_{4}{ }^{+}(\mathrm{mgN} / \mathrm{L})$ & Titulométrico & $2 \mathrm{x}$ semana \\
\hline $\mathrm{N}-\mathrm{NO}_{2}^{-}(\mathrm{mgN} / \mathrm{L})$ & Espectrofotométrico & $2 \mathrm{x}$ semana \\
\hline $\mathrm{N}-\mathrm{NO}_{3}{ }^{-}(\mathrm{mgN} / \mathrm{L})$ & Espectrofotométrico & $2 \mathrm{x}$ semana \\
\hline $\mathrm{OD}(\mathrm{mg} / \mathrm{L})$ & Polarográfico & $2 \mathrm{x}$ semana \\
\hline
\end{tabular}

Para a obtenção dos valores de oxigênio dissolvido foi utilizada a sonda multiparâmetros YSI Incorporated modelo 556 (Figura 4.11). Esta sonda era imersa pela parte superior do reator até atingir o nível do líquido na saída do efluente tratado, sendo também utilizada para realização dos perfis temporais durante as etapas de pesquisa com o reator combinado anaeróbio-aeróbio de leito fixo, possibilitando a obtenção de dados de temperatura, potencial de oxi-redução, oxigênio dissolvido, pH e condutividade durante os ensaios. 


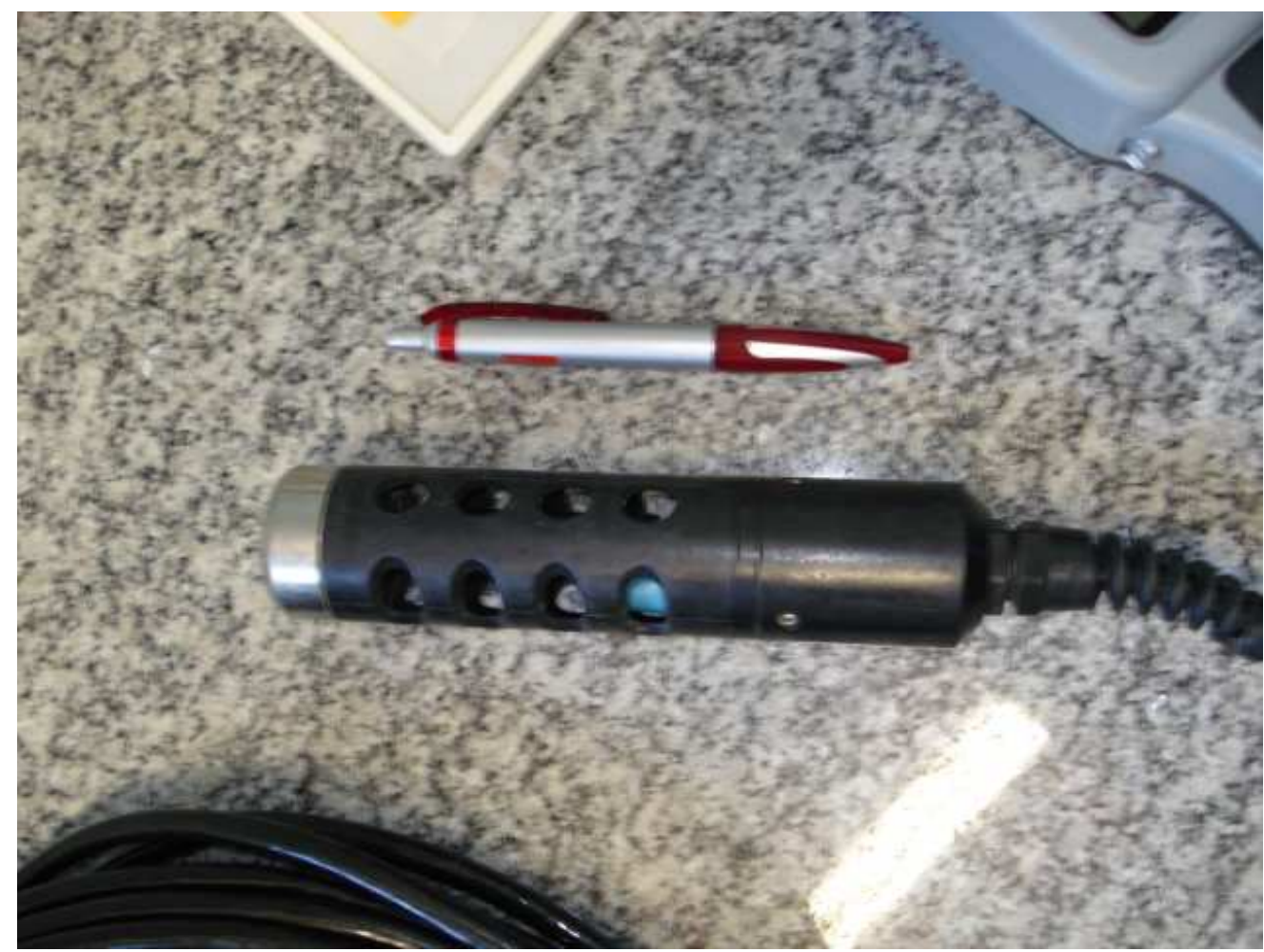

Figura 4.11 - Sonda multiparâmetros

\subsection{Procedimento Experimental}

O procedimento experimental foi dividido em três etapas. Na primeira etapa, o reator combinado anaeróbio-aeróbio foi operado com tempo de detenção hidráulica de 12 horas. Este tempo foi escolhido pelo fato de Oliveira Netto (2007) ter realizado estudo com o mesmo esquema de reator em escala de bancada, tratando esgoto sanitário, no qual obteve resultados significativos na remoção de DQO e nitrogênio total (NT) de $95 \pm 2 \%$ e $75 \pm 2 \%$, respectivamente, para $\mathrm{r}$ igual a 1,5 e TDH de $11,4 \mathrm{~h}$, com valores médios efluentes de $31 \pm 10 \mathrm{mgDQO} / \mathrm{L}$ e $10 \pm 1 \mathrm{mgNT} / \mathrm{L}$.

Após estabilização do sistema, o reator combinado anaeróbio-aeróbio foi operado com recirculação do efluente do reator para a zona anaeróbia, logo acima do leito contendo argila expandida. Nessa etapa experimental, a variável foi a razão de recirculação. Duas razões de recirculação foram adotadas: 1,5 e 3,0. Assim, a influência da razão de recirculação sobre a remoção de matéria orgânica e de nitrogênio foi 
avaliada com tempo de detenção hidráulica constante. A escolha da razão de recirculação também foi devido aos resultados satisfatórios, tanto na remoção de matéria orgânica, quanto na conversão das formas de nitrogênio, encontrados no experimento com o reator em escala de bancada operado por Oliveira Netto (2007).

$\mathrm{Na}$ segunda etapa experimental, o reator continuou a ser operado com as camadas combinadas anaeróbio-aeróbia e o tempo de detenção hidráulica do sistema foi reduzido de 12 horas para 10 horas. As mesmas razões de recirculação tiveram suas influências na remoção de matéria orgânica e nitrogenada avaliadas, assim como na primeira etapa experimental.

Na terceira etapa experimental, foi utilizado tempo de detenção hidráulica igual a 8 horas, sendo avaliada também a influência das razões de recirculação na última etapa do experimento.

Para facilitar a visualização do procedimento experimental utilizado durante pesquisa com o reator combinado de leito fixo, foi elaborada a Tabela 4.2.

Tabela 4.2 - Procedimento experimental utilizado durante a operação do sistema.

\begin{tabular}{|c|c|c|c|}
\hline Etapa & Fase & $\mathrm{TDH}(\mathrm{h})$ & Recirculação (r) \\
\hline \multirow{3}{*}{01} & Adaptação & \multirow{3}{*}{12} & 0 \\
\hline & $1^{\mathrm{a}}$ & & 1,5 \\
\hline & $2^{a}$ & & 3,0 \\
\hline \multirow{2}{*}{02} & $1^{\mathrm{a}}$ & \multirow{2}{*}{10} & 1,5 \\
\hline & $2^{a}$ & & 3,0 \\
\hline \multirow{2}{*}{03} & $1^{\mathrm{a}}$ & \multirow{2}{*}{8} & 1,5 \\
\hline & $2^{a}$ & & 3,0 \\
\hline
\end{tabular}


A partir dos dados obtidos nas três condições operacionais foi realizado balanço de massa para a matéria orgânica carbonácea e nitrogenada para estimativa das constantes cinéticas para o sistema de reator combinado anaeróbio-aeróbio de leito fixo e fluxo ascendente com recirculação da fase líquida estudado.

Durante o período operacional foram realizados perfis temporais de 24 horas para caracterização do esgoto sanitário afluente ao reator. A cada 1 hora foram coletadas amostras para análise da demanda química de oxigênio (DQO) da amostra bruta e filtrada, da concentração de nitrogênio amoniacal $\left(\mathrm{N}^{-\mathrm{NH}_{4}}{ }^{+}\right)$e sulfato com intuito, também, de averiguar a representatividade do esgoto sanitário que abastece a Área de Pesquisa em Tratamento de Esgoto Sanitário do LPB e possibilidade de utilização para fins de estudos e pesquisas.

\subsection{Considerações para realização dos balanços de massa para estimativa das constantes cinéticas}

O emprego de dados cinéticos para simulação, projeto e otimização de reatores biológicos para tratamento de águas residuárias é de fundamental importância para obtenção de unidades projetadas com fundamentação teórica. A interpretação de dados e parâmetros cinéticos obtidos através de experimentos fornece condições para uma análise cinética global dos processos biológicos através de fundamentos de engenharia das reações bioquímicas que devem ser aplicados para realização de projetos de reatores e aumento de escala.

Para realização dos balanços de massa no reator combinado anaeróbio-aeróbio de leito fixo foram tomadas algumas considerações. A idealização do escoamento de reatores é muito útil por propiciar simplificações no equacionamento matemático. Para realização de projetos e aumento de escala sempre haverá um modelo ideal como 
referência o que torna o tratamento matemático mais simples. Primeiramente segmentou-se o reator combinado em três compartimentos conforme Figura 4.12.

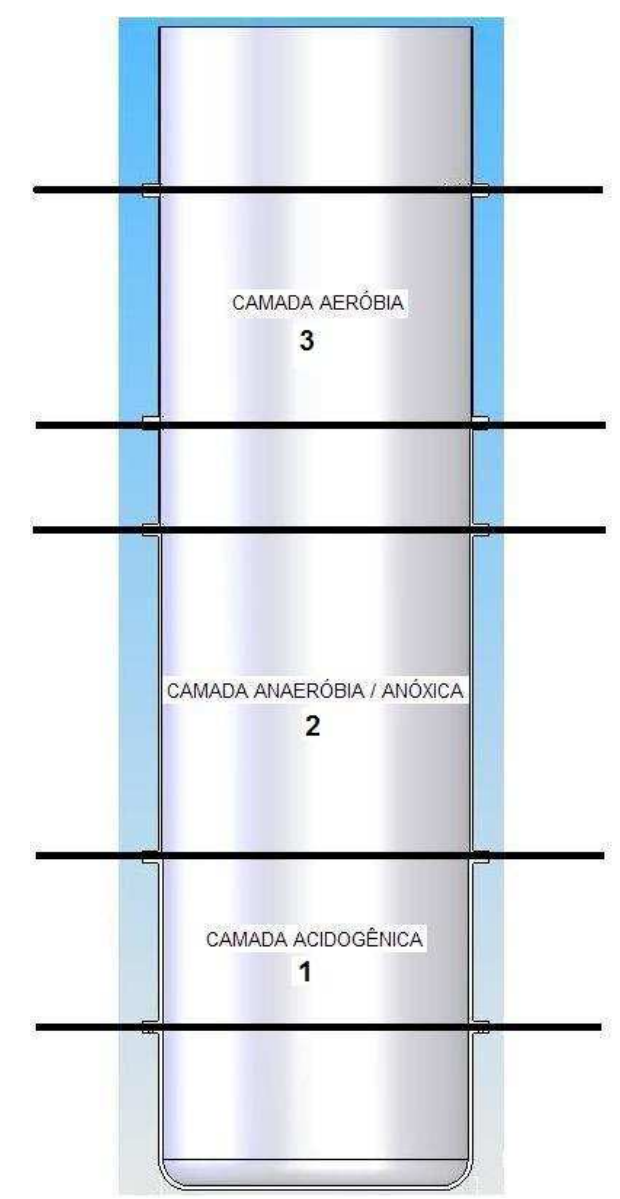

Figura 4.12 - Distribuição das camadas para realização do balanço de massa

Para a camada acidogênica, segmento $\mathrm{n}^{\mathrm{o}} 1$, considerou-se o modelo de escoamento contínuo tubular ideal, também conhecido como plug-flow ou escoamento pistonado, para tratamento matemático dos dados. Neste tipo de idealização, o fluido atravessa o reator sem mistura longitudinal. Já para as camadas anaeróbia-anóxica, segmento $\mathrm{n}^{\mathrm{o}} 2$, e aeróbia, segmento $\mathrm{n}^{\mathrm{o}} 3$, foi considerado o modelo de escoamento contínuo de mistura completa ou mistura perfeita. Neste caso, ao contrário do reator tubular ideal, a composição na corrente de saída é considerada igual à composição interna do reator que é totalmente misturado. 
Essas considerações foram baseadas nos resultados encontrados nos ensaios hidrodinâmicos realizados, tanto por Oliveira Netto (2007) como por Sonobe (2010), para o reator combinado de leito fixo em escala de bancada. Os ensaios para a avaliação do comportamento hidrodinâmico do reator de leito fixo consistiram em injetar-se um pulso de cloreto de sódio $(\mathrm{NaCl})$, utilizado como traçador, na entrada do reator em operação, e medir, ao longo do tempo, a variação que esse pulso provoca na saída do reator, de onde se chega à curva de distribuição do tempo de residência (DTR). Como resultado, os autores observaram que com a inserção da recirculação ao sistema, houve maior mistura do meio líquido, ocasionando maior dispersão da distribuição dos pontos amostrais e conseqüente aumento do valor da variância, levando essas curvas obviamente a comportamento mais próximo de mistura perfeita em relação aos ensaios sem recirculação. Como, nesta pesquisa, a recirculação interna se dava entre as camadas do leito de argila expandida e o leito de espuma de poliuretano da zona anaeróbia, esta primeira camada não sofria influência hidrodinâmica da recirculação imposta, considerando-a de fluxo pistonado.

Além da idealização dos tipos de escoamento para cada segmento do reator, são necessárias outras considerações para realização do balanço de massa. Os dados modelados foram considerados em período de estabilidade operacional, isto é, em regime permanente, que ocorre quando não há variação temporal das variáveis medidas Dessa forma, como resultado, considera-se:

$\frac{d C}{d t}=0$

Embora o reator estudado seja tipicamente heterogêneo, com reações bioquímicas ocorrendo principalmente no biofilme, com resistências para transferência 
de substratos de meio líquido para a fase sólida, considerou-se, para fins de modelagem, o sistema como pseudo-homogêneo. Para isso, os balanços foram feitos como em um reator homogêneo típico, tendo como consequência a obtenção de parâmetros cinéticos aparentes (e não intrínsecos ou verdadeiros), os quais englobam as constantes de transferência de massa além da constante cinética.

Outra consideração feita foi a de cinética de primeira ordem para a conversão da matéria orgânica e nitrogênio, o que é razoável por se tratar de água residuária com baixa concentração de matéria orgânica. Nesses casos, a concentração é sempre muito menor que a constante de saturação de substrato do modelo cinético de Monod (hipérbole), o que leva o modelo a ser aproximado a uma reta para essa faixa. 


\section{RESULTADOS E DISCUSSÕES}

Neste capítulo são discutidos os resultados do experimento com o reator de leito fixo, fluxo contínuo e com escoamento ascendente em todas as condições relatadas na metodologia. Serão apresentados os principais resultados dos parâmetros analisados e as informações básicas serão mostradas em tabelas e gráficos abrangendo todo período de coleta de dados.

A etapa experimental foi realizada de 28/02/2009 a 08/07/2010 com tempo total de operação do reator de 496 dias.

\subsection{Caracterização da água residuária afluente ao sistema}

Durante o período operacional foram realizados perfis temporais de 24 horas para caracterização do esgoto sanitário afluente ao reator. A cada 1 hora foram coletadas amostras para análise da demanda química de oxigênio (DQO) da amostra bruta e filtrada, das concentrações de nitrogênio amoniacal $\left(\mathrm{N}^{-\mathrm{NH}_{4}}{ }^{+}\right)$e de sulfato.

As Figuras 5.1, 5.2 e 5.3 mostram os resultados do perfil realizado em abril de 2009. O valor médio da DQO bruta do esgoto sanitário afluente foi de $339 \pm 211 \mathrm{mg} / \mathrm{L}$. Para DQO filtrada, o valor encontrado foi de $175 \pm 119 \mathrm{mg} / \mathrm{L}$. O valor de $\mathrm{N}^{-\mathrm{NH}_{4}}{ }^{+}$ verificado foi $27 \pm 10 \mathrm{mg} \mathrm{N}-\mathrm{NH}_{4}{ }^{+} / \mathrm{L}$. Para a concentração de sulfato foi observado o valor de $29 \pm 9 \mathrm{mg} \mathrm{SO}_{4}{ }^{2-} / \mathrm{L}$. 


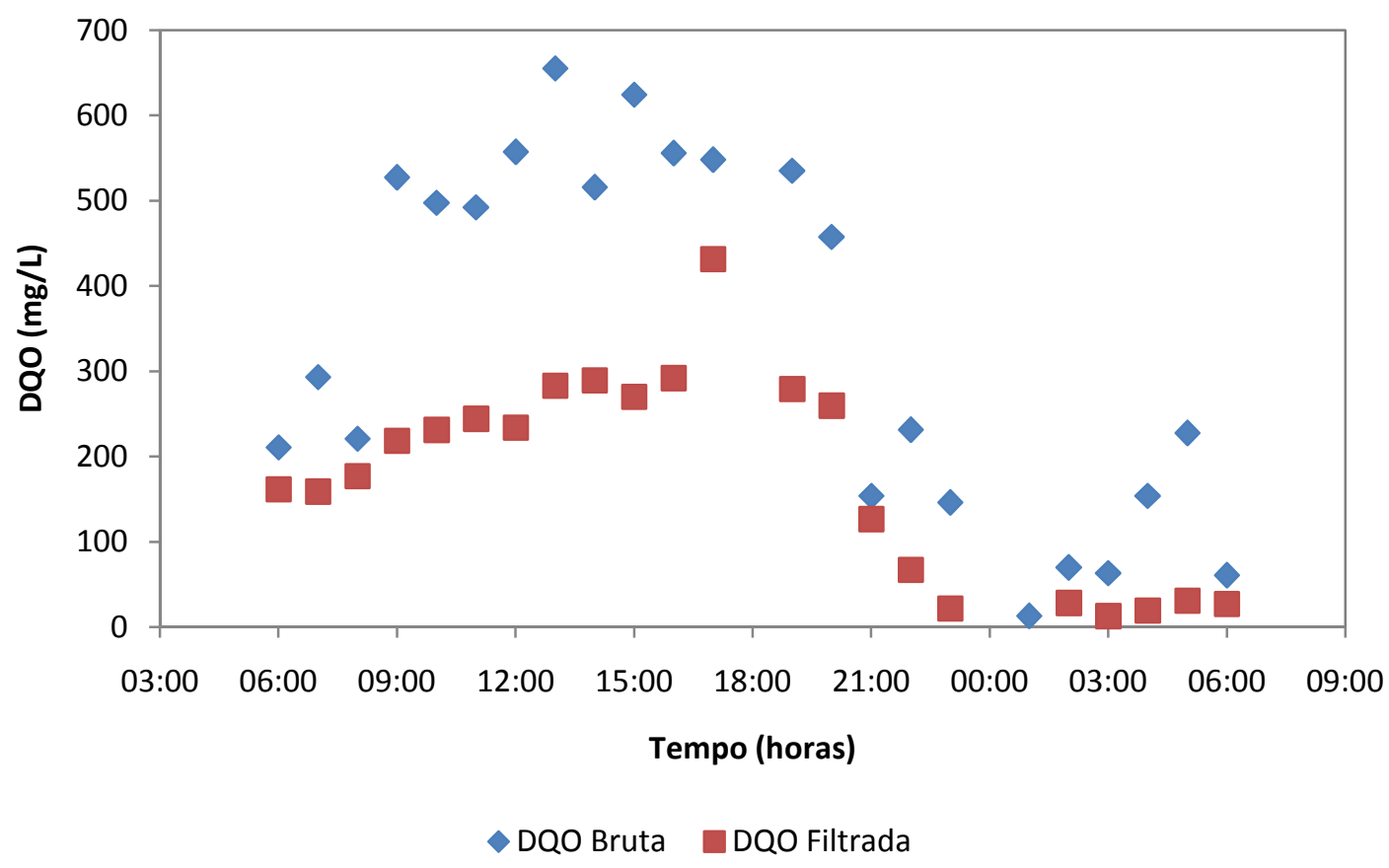

Figura 5.1. - Perfil temporal de DQO bruta e filtrada para esgoto sanitário afluente, realizado em abril de 2009

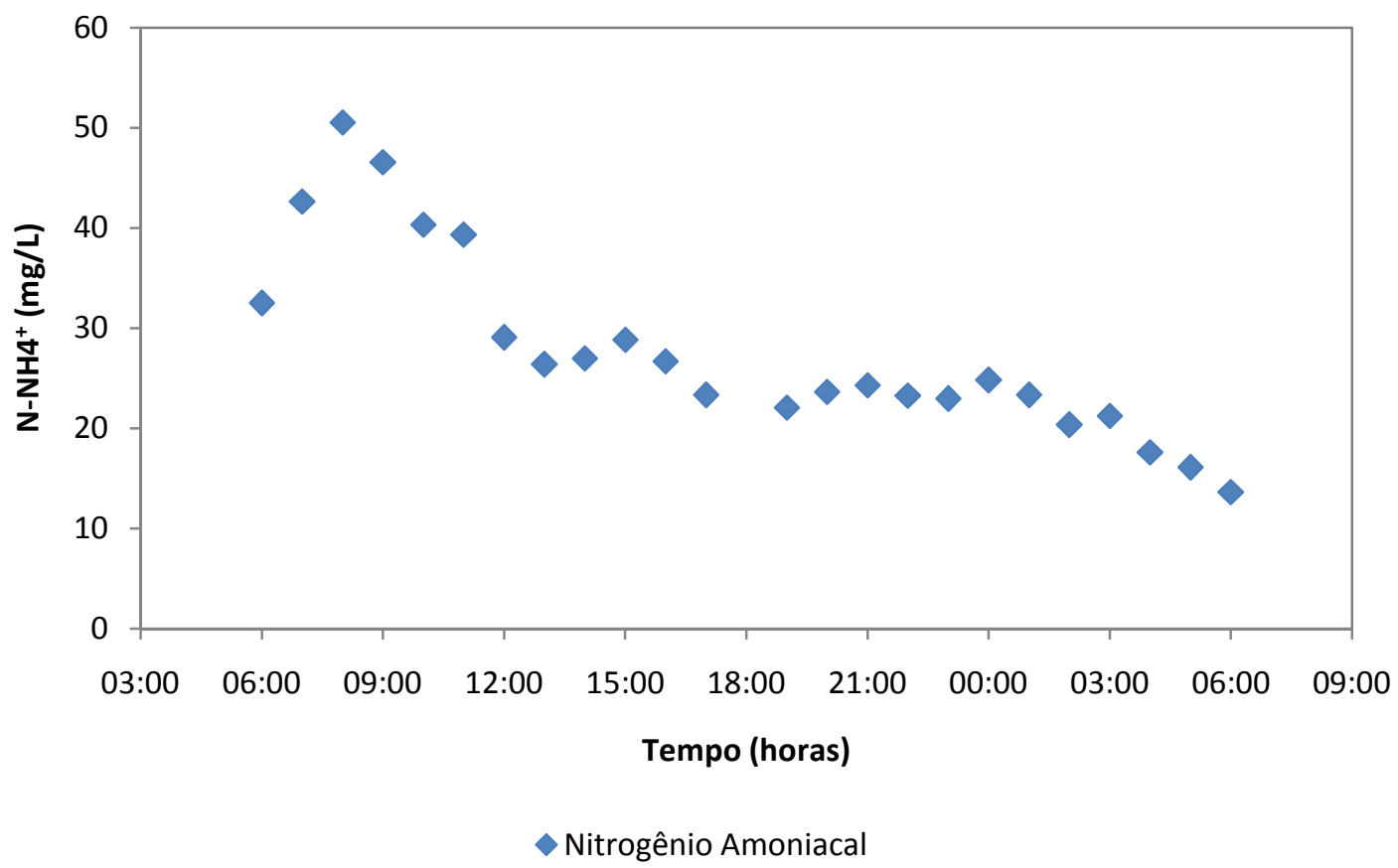

Figura 5.2 - Perfil temporal da concentração de nitrogênio amoniacal para esgoto sanitário afluente, realizado em abril de 2009 


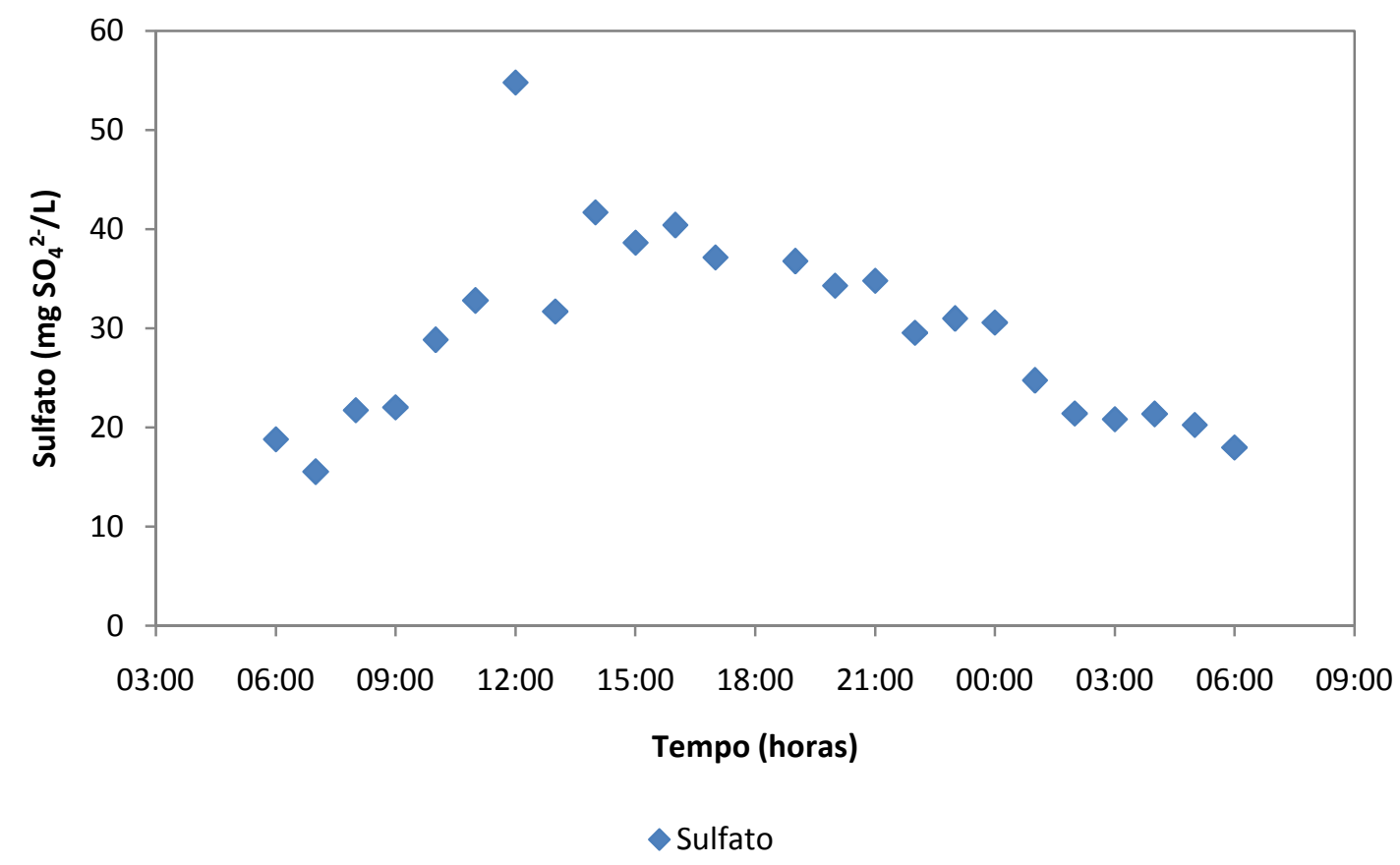

Figura 5.3 - Perfil temporal de concentração de sulfato para esgoto sanitário afluente, realizado em abril de 2009

As Figuras 5.4, 5.5 e 5.6 mostram os resultados do perfil realizado em julho de 2009. O valor médio da DQO bruta do esgoto sanitário afluente foi de $423 \pm 172 \mathrm{mg} / \mathrm{L}$, enquanto que para DQO filtrada o valor encontrado foi de $203 \pm 99 \mathrm{mg} / \mathrm{L}$. O valor de $\mathrm{N}-\mathrm{NH}_{4}{ }^{+}$verificado foi $26 \pm 8 \mathrm{mg} \mathrm{N}-\mathrm{NH}_{4}{ }^{+} / \mathrm{L}$. Para a concentração de sulfato foi observado o valor de $22 \pm 9 \mathrm{mg} \mathrm{SO}_{4}{ }^{2-} / \mathrm{L}$. 


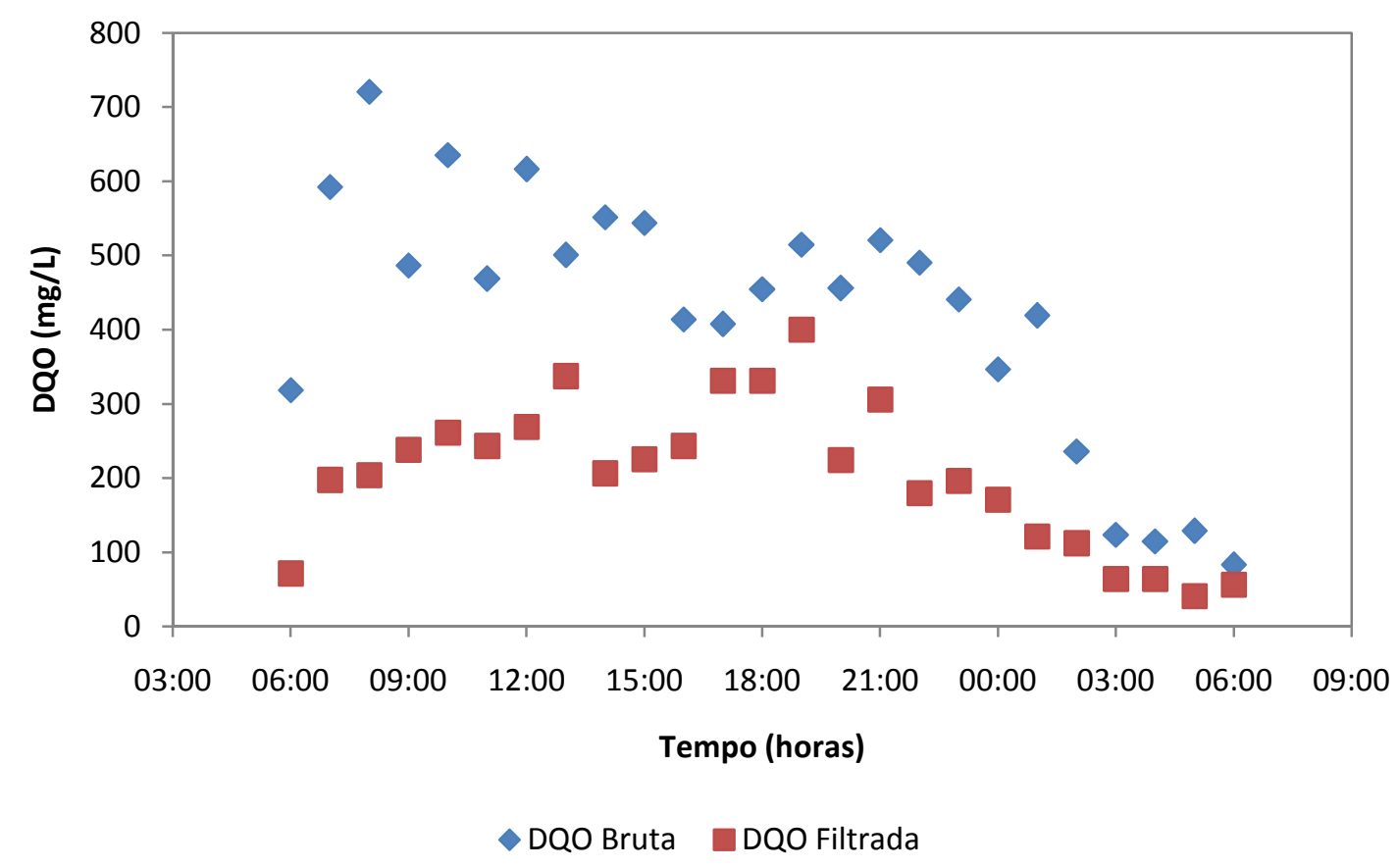

Figura 5.4. - Perfil temporal de DQO bruta e filtrada para esgoto sanitário afluente, realizado em julho de 2009

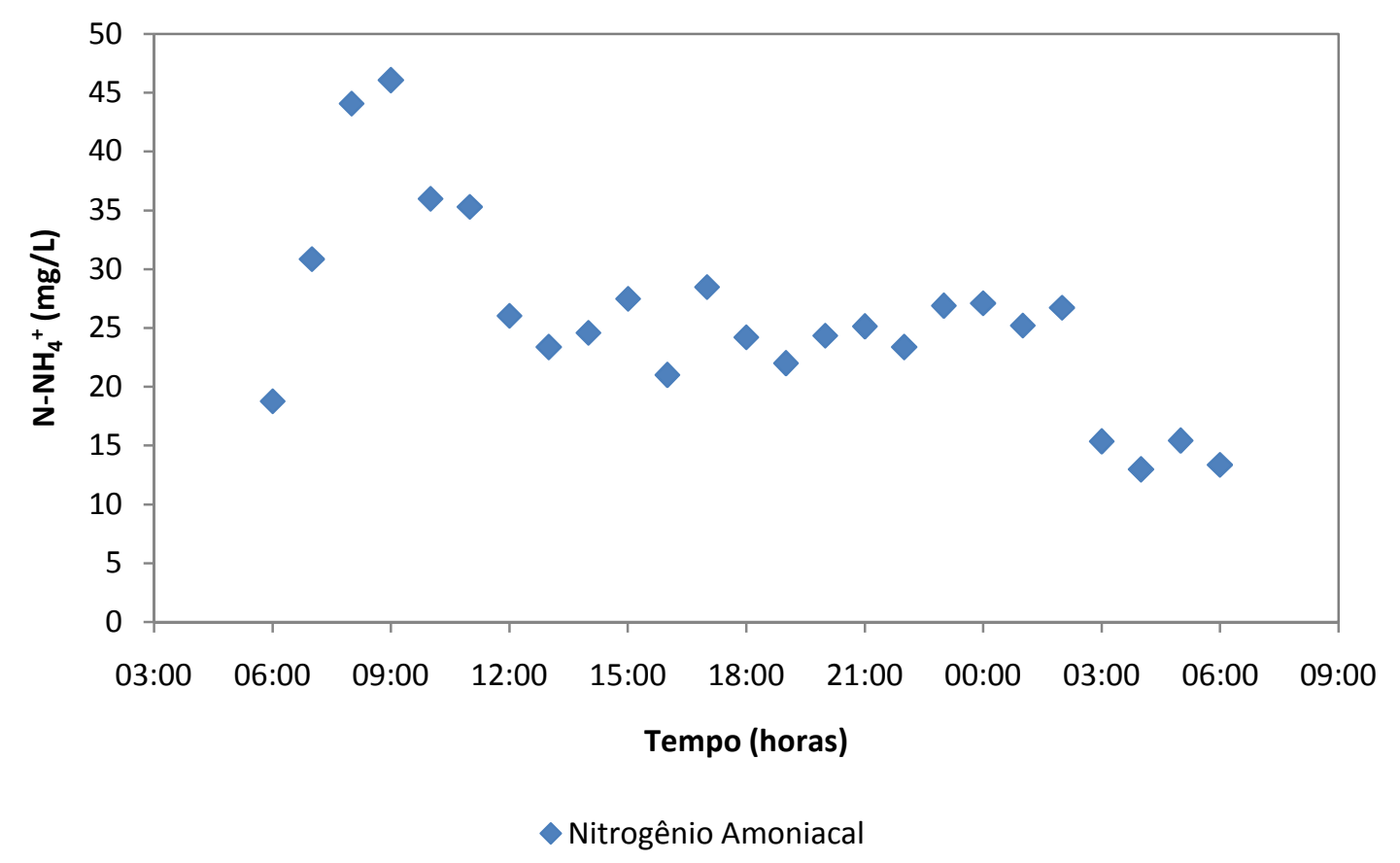

Figura 5.5. - Perfil temporal da concentração de nitrogênio amoniacal para esgoto sanitário afluente, realizado em julho de 2009 


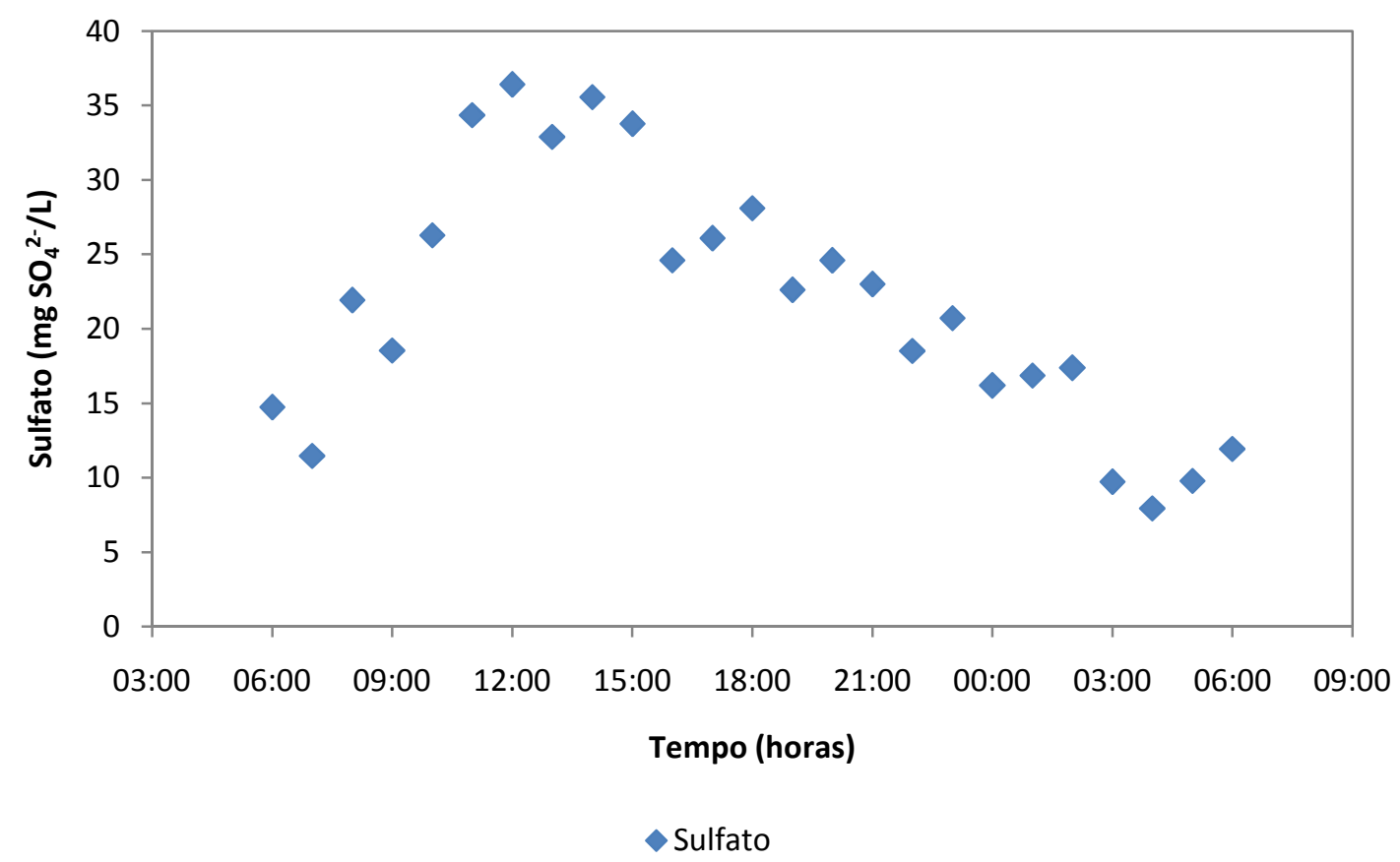

Figura 5.6. - Perfil temporal de concentração de sulfato para esgoto sanitário afluente, realizado em julho de 2009

Por problemas com a disponibilidade de pessoal para realizar mais um perfil de 24 horas, o terceiro perfil foi realizado com duração de 18 horas, abrangendo o horário das 6:00 h do dia 9/11 até a 0:00 h do dia 10/11. Essa decisão foi baseada, também, nos resultados encontrados nos dois perfis anteriores, que mostraram baixa concentração de matéria orgânica, na forma de DQO e também de nitrogênio, como já esperado para o período da madrugada. Da mesma forma que nos perfis anteriores, a cada 1 hora foram coletadas amostras para análise da demanda química de oxigênio (DQO) da amostra bruta e filtrada e das concentrações de nitrogênio amoniacal $\left(\mathrm{N}-\mathrm{NH}_{4}{ }^{+}\right)$e de sulfato.

As Figuras 5.7, 5.8 e 5.9 mostram os resultados do perfil realizado em novembro de 2009. O valor médio da DQO bruta do esgoto sanitário afluente foi de $379 \pm 111 \mathrm{mg}$ DQO/L. Para DQO filtrada, o valor encontrado foi de 
$174 \pm 63 \mathrm{mg} \mathrm{DQO} / \mathrm{L} . \mathrm{O}$ valor de $\mathrm{N}^{-\mathrm{NH}_{4}}{ }^{+}$verificado foi $21 \pm 8 \mathrm{mg} \mathrm{N}-\mathrm{NH}_{4}{ }^{+} / \mathrm{L}$. Para a concentração de sulfato foi observado o valor de $24 \pm 8 \mathrm{mg} \mathrm{SO}_{4}{ }^{2-} / \mathrm{L}$.

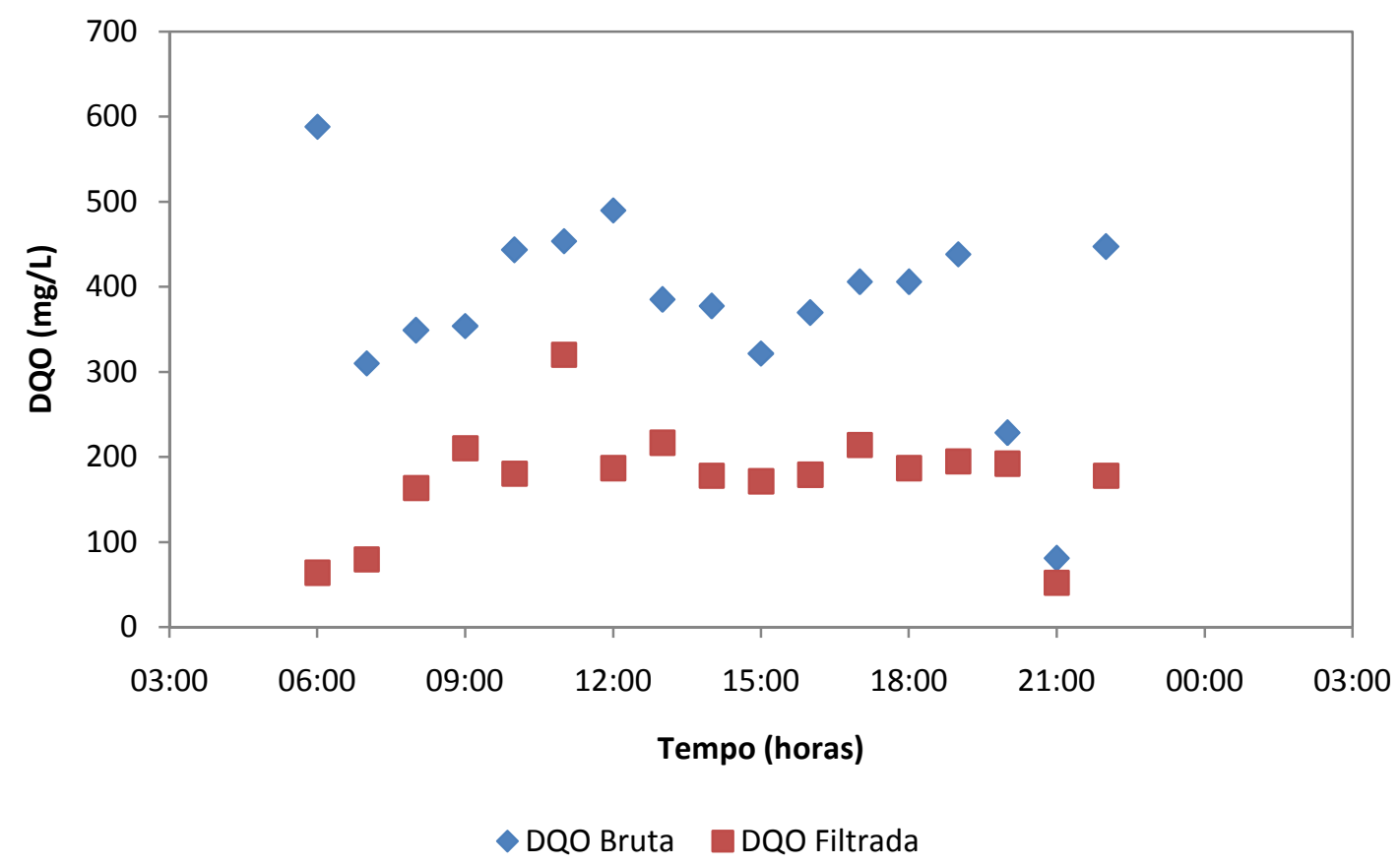

Figura 5.7 - Perfil temporal de DQO bruta e filtrada para esgoto sanitário afluente, realizado em novembro de 2009 


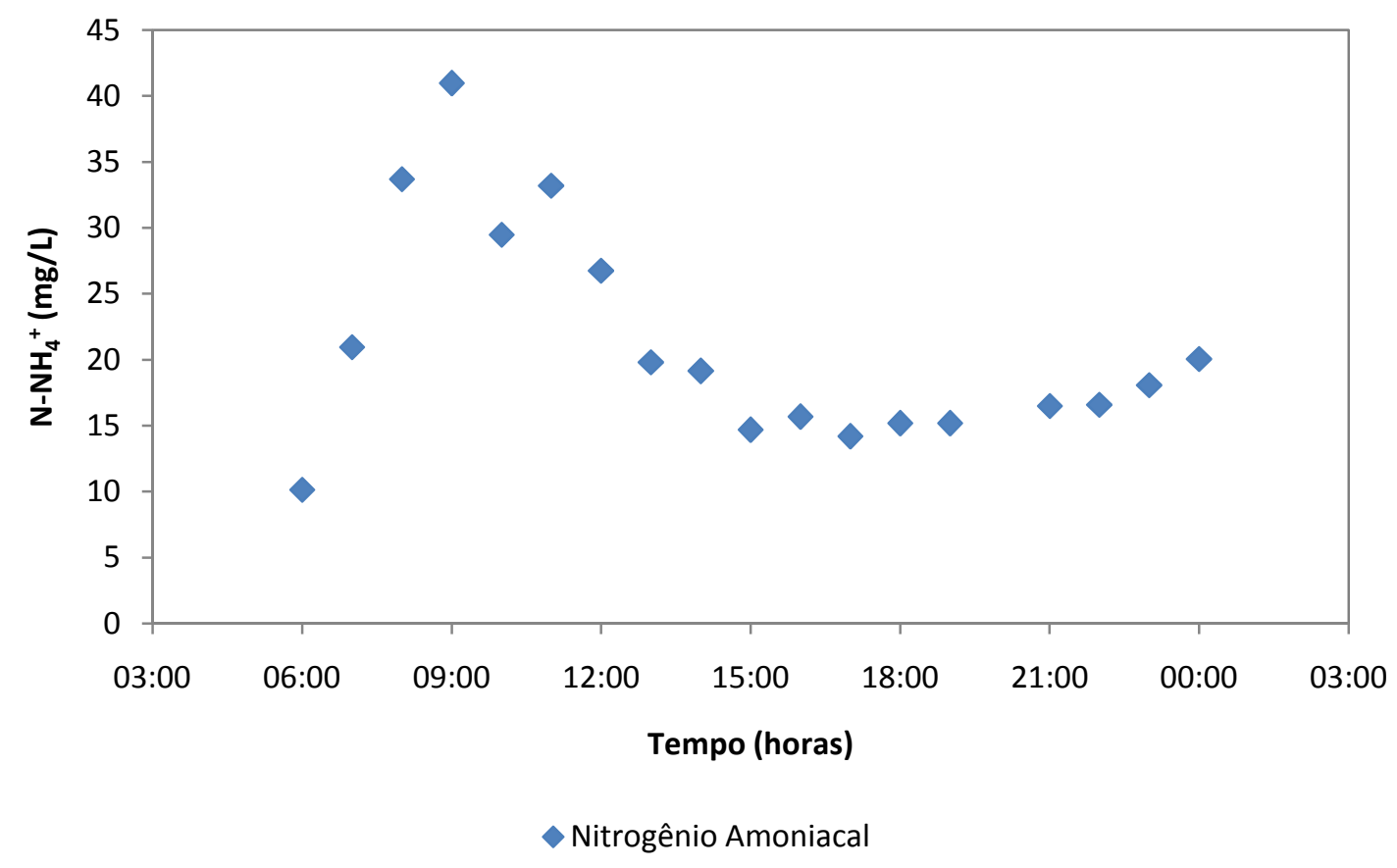

Figura 5.8 - Perfil temporal de nitrogênio amoniacal para esgoto sanitário afluente, realizado em novembro de 2009

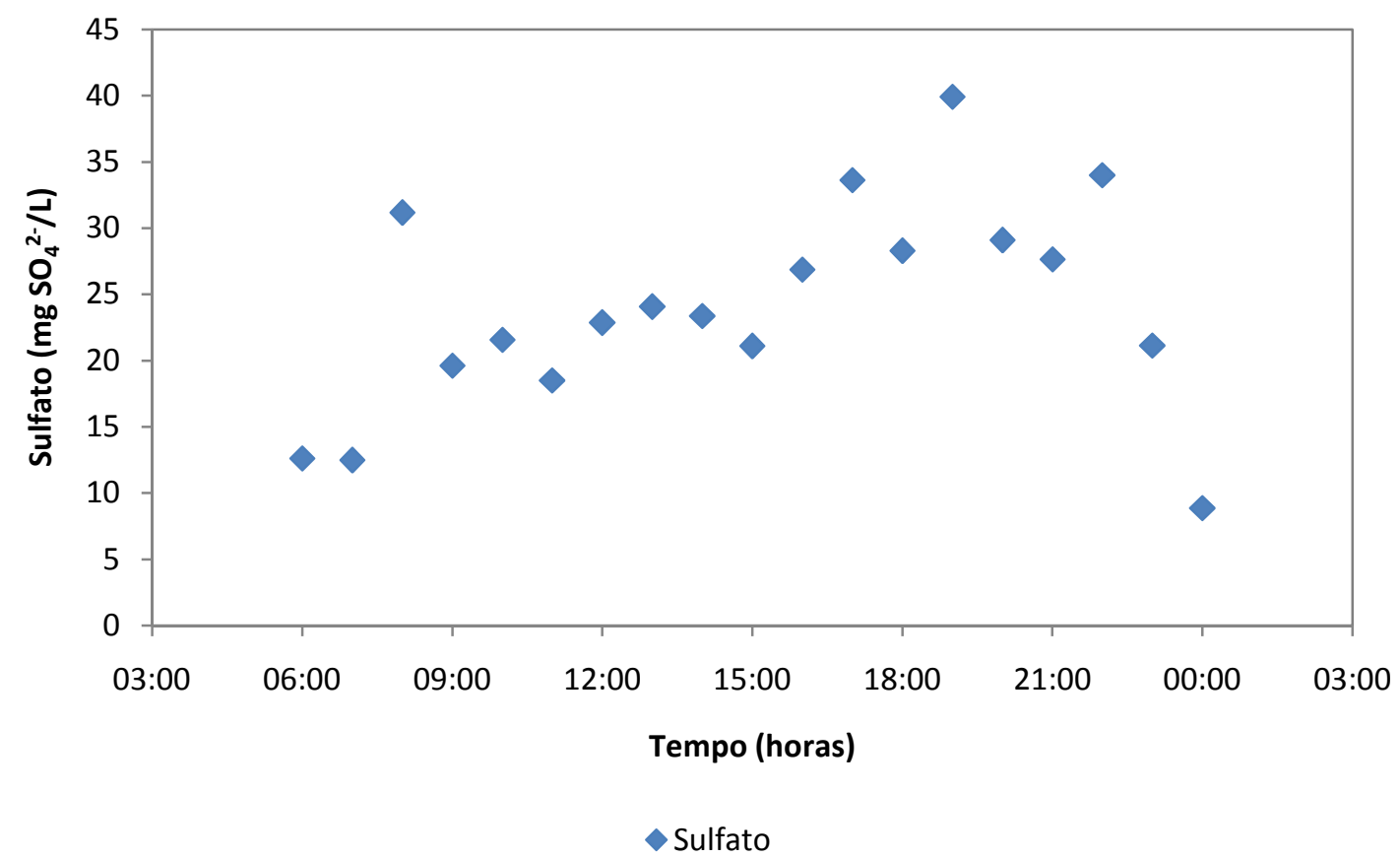

Figura 5.9 - Perfil temporal de concentração de sulfato para esgoto sanitário afluente, realizado em novembro de 2009 
Segundo von Sperling (2005), o valor da DQO bruta em esgotos domésticos abrange a faixa de $450-800 \mathrm{mg} / \mathrm{L}$, enquanto que o valor de $\mathrm{N}^{-\mathrm{NH}_{4}}{ }^{+}$varia de 20 a $35 \mathrm{mg} \mathrm{N}-\mathrm{NH}_{4}{ }^{+} / \mathrm{L}$. Dessa forma, conclui-se que o esgoto doméstico que abastece a Área de Pesquisa em Tratamento de Esgoto Sanitário do LPB é um esgoto doméstico representativo, podendo ser utilizado para fins de estudos e pesquisas.

\subsection{Avaliação do desempenho do reator}

Nesta etapa do trabalho serão apresentados e discutidos os resultados obtidos durante todo o período operacional dividido em 03 etapas. Na primeira etapa, o reator combinado anaeróbio-aeróbio foi operado com tempo de detenção hidráulica de 12 horas. Após estabilização do sistema iniciou-se a recirculação do efluente do reator para a zona anaeróbia, sendo estudadas 02 razões de recirculação: 1,5 e 3,0. Na segunda etapa experimental, o reator continuou a operar com as fases combinadas anaeróbioaeróbia e o tempo de detenção hidráulica do sistema foi reduzido de 12 horas para 10 horas e para 8 horas na etapa seguinte. As mesmas razões de recirculação tiveram suas influências na remoção de matéria orgânica e nitrogenada avaliadas, assim como na primeira etapa experimental.

\subsubsection{Avaliação do desempenho do reator combinado operado com tempo de detenção}

\section{hidráulica de 12 horas}

Na primeira etapa de operação o TDH foi fixado em 12 horas, sendo 6,5 horas na camada anaeróbia $\left(1,37 \mathrm{~m}^{3}\right)$ e 5,5 horas na camada aeróbia $\left(1,18 \mathrm{~m}^{3}\right)$. Este tempo foi escolhido pelo fato de Oliveira Netto (2007) ter realizado estudo com o mesmo esquema de reator em escala de bancada, tratando esgoto sanitário, no qual obteve resultados significativos. Nesta etapa o TDH aplicado correspondeu a uma vazão de 3,55 L/min. 
O período de operação para avaliação operacional do reator foi de 284 dias para esta etapa operacional, sendo 185 dias para a estabilização do sistema sem razão de recirculação, 43 dias para a fase com recirculação de 1,5 e 56 dias com razão de recirculação igual a 3,0.

A aeração foi mantida a uma vazão constante de $50 \mathrm{~L} / \mathrm{min}$ e verificou-se que o processo de conversão não estava limitado pela concentração de oxigênio dissolvido (O.D.), pois a mesma manteve-se sempre maior que 2,5 $\mathrm{mg} / \mathrm{L}$.

A Tabela 5.1 apresenta os valores médios dos principais parâmetros para o esgoto sanitário usado como afluente e efluente durante os dias desta etapa de operação, na qual o reator foi operado de modo contínuo com recirculação do efluente tratado em diferentes razões e TDH total de 12 horas. 
Tabela 5.1 - Comparação entre os valores afluentes e efluentes da primeira etapa

$$
\text { operacional }(\mathrm{TDH}=12 \mathrm{~h}) \text {. }
$$

\begin{tabular}{|c|c|c|c|c|}
\hline Parâmetros & Afluente & $r=0$ & $\mathrm{r}=1,5$ & $\mathrm{r}=3,0$ \\
\hline $\mathrm{pH}$ & $6,79 \pm 0,18^{(47)}$ & $6,64 \pm 0,32^{(5)}$ & $6,92 \pm 0,15^{(9)}$ & $7,15 \pm 0,29^{(9)}$ \\
\hline DQO Bruta (mg/L) & $553 \pm 170^{(47)}$ & $61 \pm 24^{(5)}$ & $57 \pm 28^{(9)}$ & $54 \pm 22^{(9)}$ \\
\hline DQO Filtrada (mg/L) & $199 \pm 45^{(47)}$ & $25 \pm 12^{(5)}$ & $16 \pm 6^{(9)}$ & $16 \pm 12^{(9)}$ \\
\hline Alc. Total (mg CaCO3/L) & $145 \pm 24^{(47)}$ & $57 \pm 34^{(5)}$ & $118 \pm 40^{(9)}$ & $92 \pm 44^{(9)}$ \\
\hline Alc. a Bicarbonato (mg CaCO3/L) & $105 \pm 23^{(47)}$ & $46 \pm 34^{(5)}$ & $90 \pm 37^{(9)}$ & $86 \pm 24^{(9)}$ \\
\hline AVT (mg HAc/L) & $56 \pm 14^{(47)}$ & $17 \pm 2^{(5)}$ & $24 \pm 7^{(9)}$ & $21 \pm 4^{(9)}$ \\
\hline NT (mg/L) & $43 \pm 11^{(45)}$ & $29 \pm 6^{(5)}$ & $25 \pm 3^{(9)}$ & $20 \pm 8^{(9)}$ \\
\hline NTK (mg/L) & $41 \pm 11^{(45)}$ & $14 \pm 5^{(5)}$ & $21 \pm 4^{(9)}$ & $14 \pm 10^{(9)}$ \\
\hline $\mathrm{NH}_{4}{ }^{+}(\mathrm{mg} / \mathrm{L})$ & $28 \pm 8^{(45)}$ & $9 \pm 6^{(5)}$ & $14 \pm 2^{(9)}$ & $9 \pm 6^{(9)}$ \\
\hline $\mathrm{NO}_{2}^{-}(\mathrm{mg} / \mathrm{L})$ & - & $3 \pm 4^{(5)}$ & $1 \pm 1^{(9)}$ & $1 \pm 1^{(9)}$ \\
\hline $\mathrm{NO}_{3}{ }^{-}(\mathrm{mg} / \mathrm{L})$ & $2 \pm 1^{(45)}$ & $11 \pm 4^{(5)}$ & $3 \pm 3^{(9)}$ & $4 \pm 4^{(9)}$ \\
\hline $\mathrm{SST}(\mathrm{mg} / \mathrm{L})$ & $242 \pm 111^{(42)}$ & $56 \pm 32^{(5)}$ & $61 \pm 16^{(8)}$ & $70 \pm 42^{(8)}$ \\
\hline SSV (mg/L) & $193 \pm 94^{(42)}$ & $38 \pm 20^{(5)}$ & $51 \pm 12^{(8)}$ & $54 \pm 34^{(8)}$ \\
\hline
\end{tabular}

Nota: Os números entre parênteses referem-se à quantidade de dados utilizados no cálculo das médias. Todos os valores foram obtidos após estabilização do sistema.

Os dados de DQO de amostras brutas do sistema em escala de bancada operado por Oliveira Netto (2007) indicaram que o reator atingiu estabilidade operacional após, aproximadamente, 20 dias de operação e após o $20^{\circ}$ dia de operação do sistema na forma combinada (anaeróbio + aeróbio), as concentrações de nitrito mantiveram-se sempre baixas, abaixo de $1 \mathrm{mg} / \mathrm{L}$, o que indica equilíbrio da nitrificação.

$\mathrm{Na}$ operação do reator em escala piloto, não houve inoculação prévia da zona anaeróbia, como ocorrido na operação do sistema de bancada, o que pode explicar o 
tempo consideravelmente superior para obtenção da estabilização da remoção de matéria orgânica, em relação ao reator de bancada, ultrapassando os 145 dias. Provavelmente houve desenvolvimento de organismos aeróbios heterótrofos na espuma de poliuretano que servia de meio suporte para a camada aeróbia do reator combinado antes da camada anaeróbia entrar em equilíbrio. Após esse período de adaptação deve ter havido substituição natural da biota heterotrófica por autotrófica.

Além disso, o reator partiu com as duas zonas, anaeróbia e a aeróbia, de forma conjunta, o que também afetou o processo de nitrificação, iniciado 12 dias depois, provavelmente ocasionada pela competição entre bactérias autotróficas e heterotróficas no início da operação do sistema e aliado ao lento crescimento das bactérias nitrificantes onde se faz necessários altos tempos de retenção celular, para permitir a permanência e o desenvolvimento da biomassa nitrificante no reator.

De acordo com estudos de Nogueira et al. (2002), a competição entre as bactérias heterótrofas e autótrofas, resulta em um biofilme estratificado, sendo que as bactérias de crescimento mais rápido localizam-se na camada externa, onde a concentração de substrato e a aderência são maiores, enquanto que as bactérias de crescimento mais lento encontram-se na camada interna. Portanto, a camada heterótrofa forma-se acima da camada nitrificante, constituindo-se em uma desvantagem para o processo de nitrificação, pela baixa disponibilidade de oxigênio, devido a seu consumo pelas bactérias heterótrofas, e pela resistência à difusão para a camada interna.

A competição entre bactérias heterótrofas e autótrofas, por substrato (oxigênio e nitrogênio amoniacal) e por espaço, é um dos aspectos importantes a ser considerado na operação de reatores com biofilme, sendo, portanto, objetivo de vários estudos.

Por outro lado, os longos tempos de residência celular e as altas concentrações de oxigênio, criam condições adequadas para o crescimento e acumulação de 
populações heterótrofas, pelo fato de que elas sempre estarão presentes, principalmente na presença de matéria orgânica (METCALF e EDDY, 2002).

Devido à competição entre as bactérias heterótrofas e autótrofas, uma nitrificação eficiente ocorrerá depois que a concentração de matéria orgânica tenha sido significativamente reduzida. Bruce et al. (1975) demonstraram que a DBO afluente deve ser menor de $30 \mathrm{mg} / \mathrm{L}$ para iniciar a nitrificação, e menor de $15 \mathrm{mg} / \mathrm{L}$ para obter a nitrificação completa.

O efluente do sistema apresentou valor médio de DQO de amostra bruta, após estabilização, de $61 \pm 24 \mathrm{mg} / \mathrm{L}$ e DQO filtrada de $25 \pm 12 \mathrm{mg} / \mathrm{L}$, evidenciando a boa remoção de matéria orgânica no reator. Os valores mantiveram-se estáveis independente das variações da DQO bruta afluente, que apresentou valor médio de $553 \pm 170 \mathrm{mg} / \mathrm{L}$. Com início da recirculação do efluente nitrificado para a zona anaeróbia/anóxica houve uma pequena redução nos valores de DQO efluente de amostra bruta que apresentaram valores médios de $57 \pm 28 \mathrm{mg} / \mathrm{L}$ e $54 \pm 22 \mathrm{mg} / \mathrm{L}$ respectivamente para $\mathrm{r}=1,5$ e $\mathrm{r}=3,0$. Provavelmente a recirculação melhorou a velocidade de transferência de massa pelo aumento da velocidade superficial do líquido no leito. Além disso, a introdução de nitrato e oxigênio dissolvido na zona anaeróbia/anóxica contendo espuma de poliuretano pode ter facilitado o processo de degradação, principalmente na hidrólise de material particulado. O gráfico da Figura 5.10 mostra o perfil temporal desta primeira etapa de operação do reator em escala piloto. A Figura 5.11 apresenta as eficiências de remoção de DQO para amostras brutas e filtradas. As eficiências foram calculadas a partir da média do afluente bruto durante este período operacional.

Houve desprendimento de biomassa no início da recirculação e também quando foi promovido o aumento da mesma, ocasionando aumento dos valores de sólidos 
suspensos e DQO efluente. Para cálculo das concentrações médias, desconsiderou-se essa fase de adaptação.

A carga orgânica volumétrica (COV) aplicada ao sistema nesta primeira etapa de operação foi de $1,17 \pm 0,55 \mathrm{~kg} \cdot \mathrm{DQO} / \mathrm{m}^{3}$.dia, sendo calculada pela divisão da carga aplicada pelo volume reacional. A carga aplicada é igual ao produto da DQO afluente pela vazão afluente aplicada ao sistema. Já a carga orgânica volumétrica removida teve pequena variação entre as fases com diferentes tipos de razão de recirculação estudadas, atingindo os valores de $1,06 \pm 0,04,1,07 \pm 0,02$ e $1,08 \pm 0,04 \mathrm{~kg} . \mathrm{DQO} / \mathrm{m}^{3}$.dia, para $\mathrm{r}=0,1,5$ e 3,0, respectivamente. A COV removida foi calculada pela divisão da carga removida pelo volume reacional. A carga removida é igual ao produto da diferença da DQO média afluente e efluente pela vazão aplicada nesta etapa operacional.

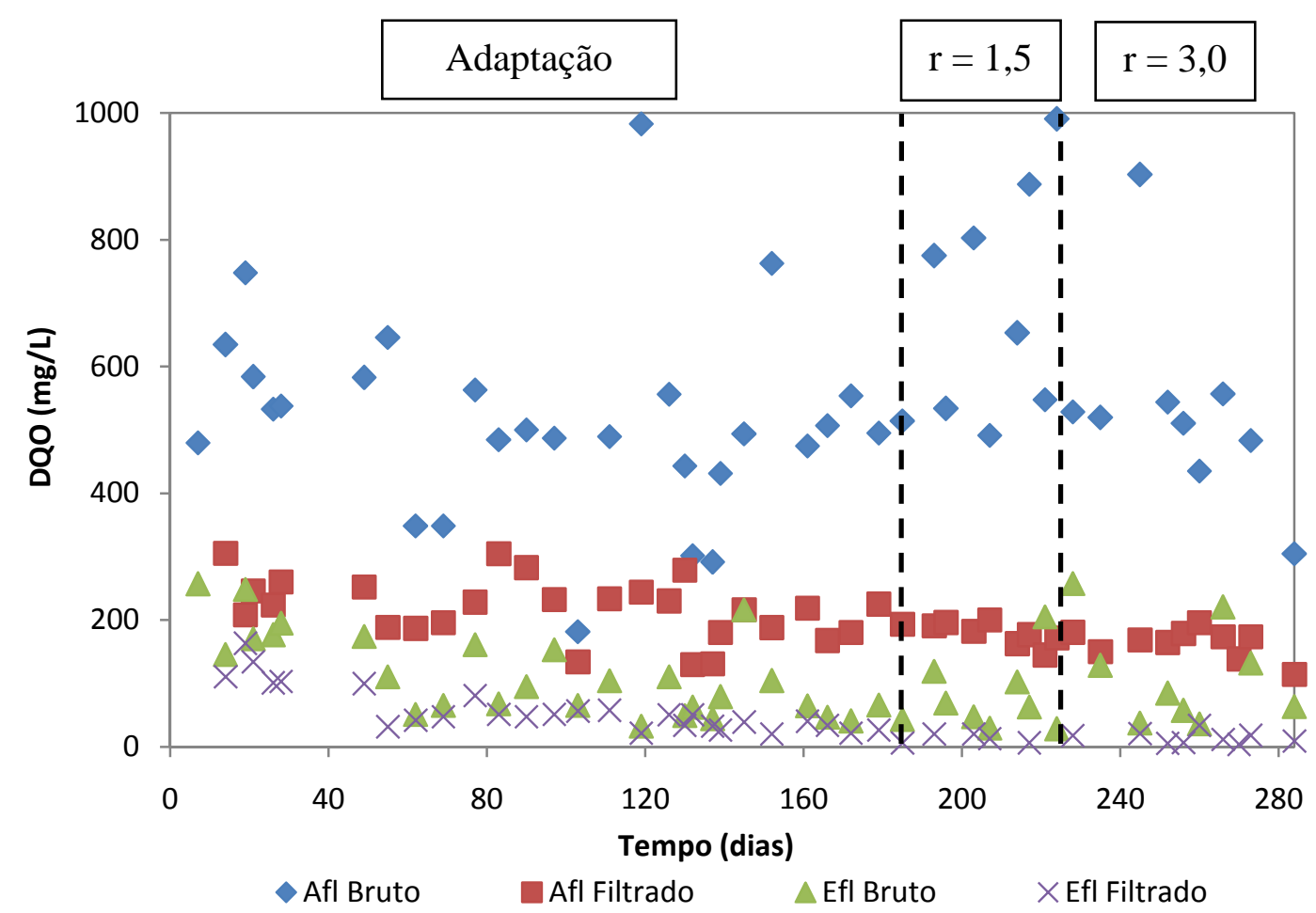

Figura 5.10 - Variação temporal da DQO para o reator de leito fixo operado de modo contínuo com TDH de 12 horas 


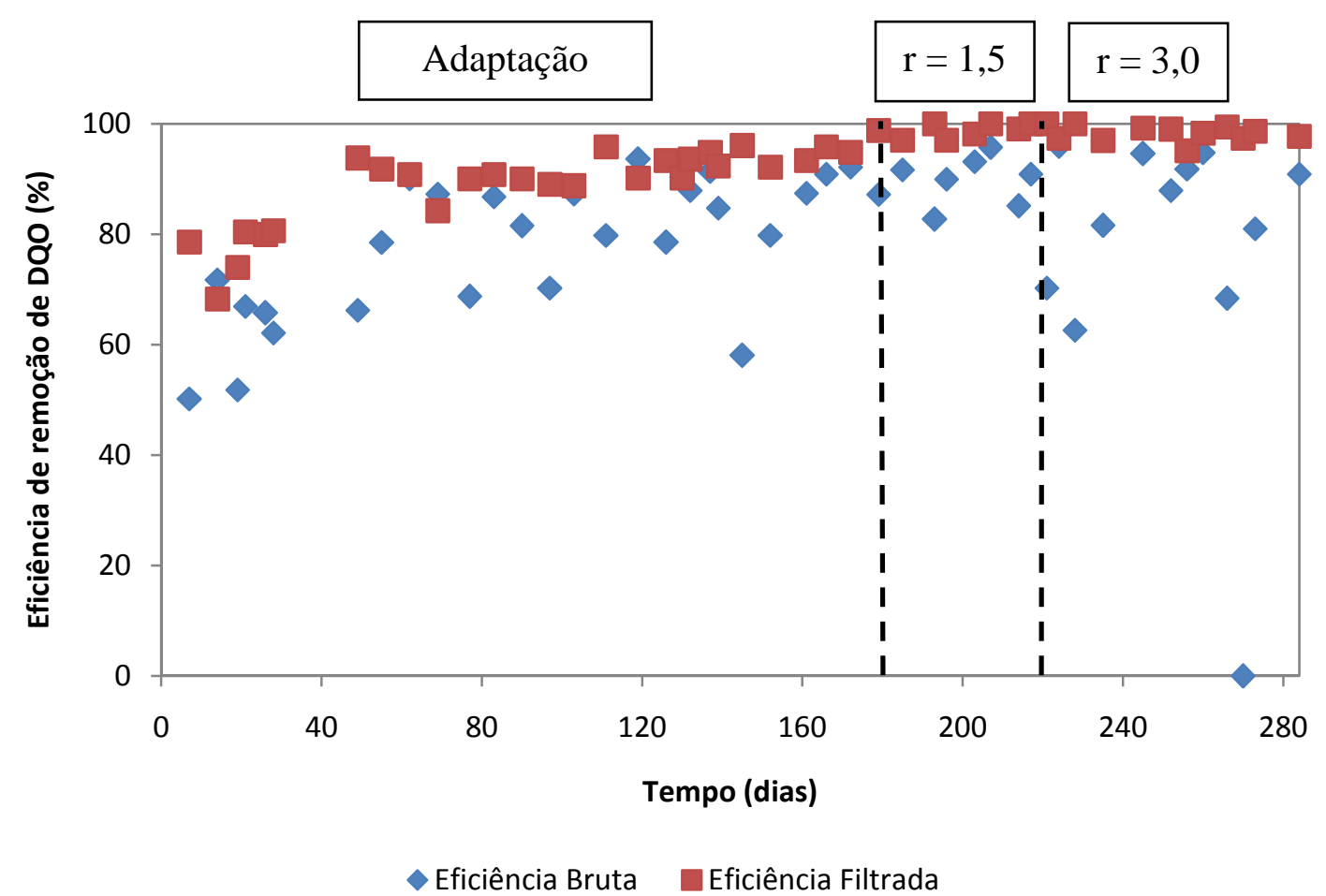

Figura 5.11 - Eficiências de remoção de DQO ao longo do tempo para o reator de leito fixo operado de modo contínuo com TDH de 12 horas

O processo de nitrificação ocorreu perto do $160^{\circ}$ dia operacional do sistema combinado e manteve-se estável até o fim dessa fase operacional (sem recirculação). A concentração de nitrato aumentou e, a partir desse dia, o $\mathrm{N}^{-\mathrm{NO}_{2}}{ }^{-}$passou a ser convertido a $\mathrm{N}_{-} \mathrm{NO}_{3}{ }^{-}$, consistindo na etapa de nitratação, que finaliza a segunda fase da nitrificação.

Com o início da nitrificação biológica, que se deu após 12 dias da estabilização do processo de remoção de matéria orgânica carbonácea (tempo similar ao encontrado no reator de bancada), a partir do $161^{\circ}$ dia de operação do sistema, o carbono inorgânico passou a ser consumido pela comunidade microbiana autotrófica com conseqüente decréscimo dos valores efluentes da alcalinidade a bicarbonato. Pode-se observar que os valores da alcalinidade a bicarbonato caíram no final da fase sem recirculação. O valor 
médio para o afluente foi $105 \pm 23 \mathrm{mgCaCO}_{3} / \mathrm{L}$ e para o efluente $132 \pm 20 \mathrm{mgCaCO}_{3} / \mathrm{L}$, antes do início da nitrificação, e $46 \pm 34 \mathrm{mgCaCO}_{3} / \mathrm{L}$ após a observação do processo de nitrificação.

Um fator que evidenciou a atividade desnitrificante foi o aumento na alcalinidade a bicarbonato no efluente tratado quando a vazão de recirculação foi aplicada ao sistema, já que esta foi reduzida com o início da nitrificação. A alcalinidade a bicarbonato no efluente tratado, para razão de recirculação igual a 1,5 foi de $90 \pm 37 \mathrm{mgCaCO}_{3} / \mathrm{L}$ e de $86 \pm 24 \mathrm{mgCaCO}_{3} / \mathrm{L}$ para $\mathrm{r}=3,0$, após adaptação do sistema à vazão de recirculação. No afluente a média ficou em $105 \pm 23 \mathrm{mgCaCO}_{3} / \mathrm{L}$. A Figura 5.12 apresenta a variação temporal da alcalinidade das amostras afluente e efluente e as Figura 5.13 e 5.14 a variação das formas de Nitrogênio no afluente e efluente.

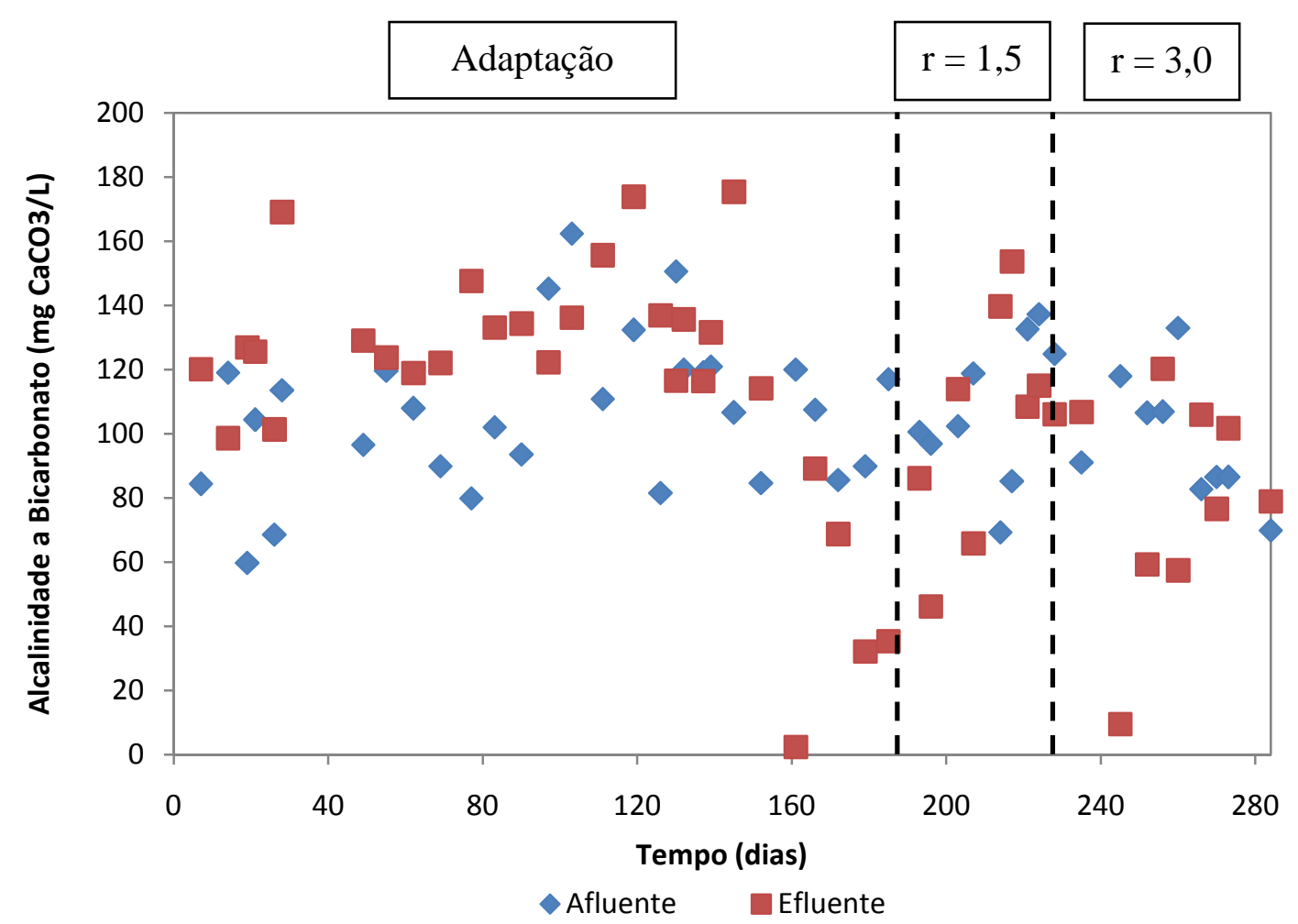

Figura 5.12 - Variação temporal da Alcalinidade a Bicarbonato afluente e efluente para o reator de leito fixo operado de modo contínuo com TDH de 12 horas 
A Figura 5.13 mostra as concentrações de N-NTK e N-Amon durante a primeira etapa operacional. Os valores médios efluentes de N-NTK e N-Amon, foram $14 \pm 5 \mathrm{mg} / \mathrm{L}, 21 \pm 4 \mathrm{mg} / \mathrm{L}, 14 \pm 10 \mathrm{mg} / \mathrm{L}$ e $9 \pm 6 \mathrm{mg} / \mathrm{L}, 14 \pm 2 \mathrm{mg} / \mathrm{L}, 9 \pm 6 \mathrm{mg} / \mathrm{L}$ respectivamente, para a fase de adaptação (início do processo de nitrificação) e razões de recirculação de 1,5 e 3,0. Vale ressaltar que estes valores estão dentro dos padrões de lançamento de efluentes exigidos pela legislação ambiental, já que segundo a resolução $n^{\circ}$ 357/05 do Conselho Nacional do Meio Ambiente (CONAMA), o valor máximo para emissões de nitrogênio amoniacal é de $20 \mathrm{mg} / \mathrm{L}$.

Pode-se observar pelos valores médios afluentes, $41 \pm 11 \mathrm{mg} / \mathrm{L}$ para N-NTK e $28 \pm 8 \mathrm{mg} / \mathrm{L}$ para $\mathrm{N}$-Amon, que a maior parte do nitrogênio afluente encontrava-se na forma amoniacal. A Figura 5.14 mostra a variação do nitrogênio orgânico (N-Org), calculado pela subtração do N-NTK pelo N-Amon, ao longo do tempo. Confirmou-se que o N-Org, na maior parte do tempo, representou parcela mínima do Nitrogênio tanto para o afluente como para o efluente.

A carga volumétrica de Nitrogênio $(\mathrm{CVN})$ aplicada ao sistema nesta primeira etapa de operação foi de $0,08 \pm 0,02 \mathrm{~kg} . \mathrm{NTK} / \mathrm{m}^{3}$.dia, sendo calculada pela divisão da carga aplicada pelo volume reacional. A carga aplicada é igual ao produto da concentração de Nitrogênio Total Kjeldahl afluente pela vazão afluente aplicada ao sistema. Já a carga de Nitrogênio removida ficou em torno de $0,05 \pm 0,01 \mathrm{~kg} . \mathrm{NTK} / \mathrm{m}^{3}$.dia, para fase sem recirculação, $0,04 \pm 0,01 \mathrm{~kg} . \mathrm{NTK} / \mathrm{m}^{3}$.dia e $0,06 \pm 0,02 \mathrm{~kg} \cdot \mathrm{NTK} / \mathrm{m}^{3}$.dia, para $\mathrm{r}=1,5$ e $\mathrm{r}=3,0$ respectivamente. A carga de Nitrogênio removida foi calculada pela divisão da carga removida pelo volume reacional. A carga removida é igual ao produto da diferença da concentração média de Nitrogênio Total Kjeldahl afluente e efluente pela vazão aplicada nesta etapa operacional. 


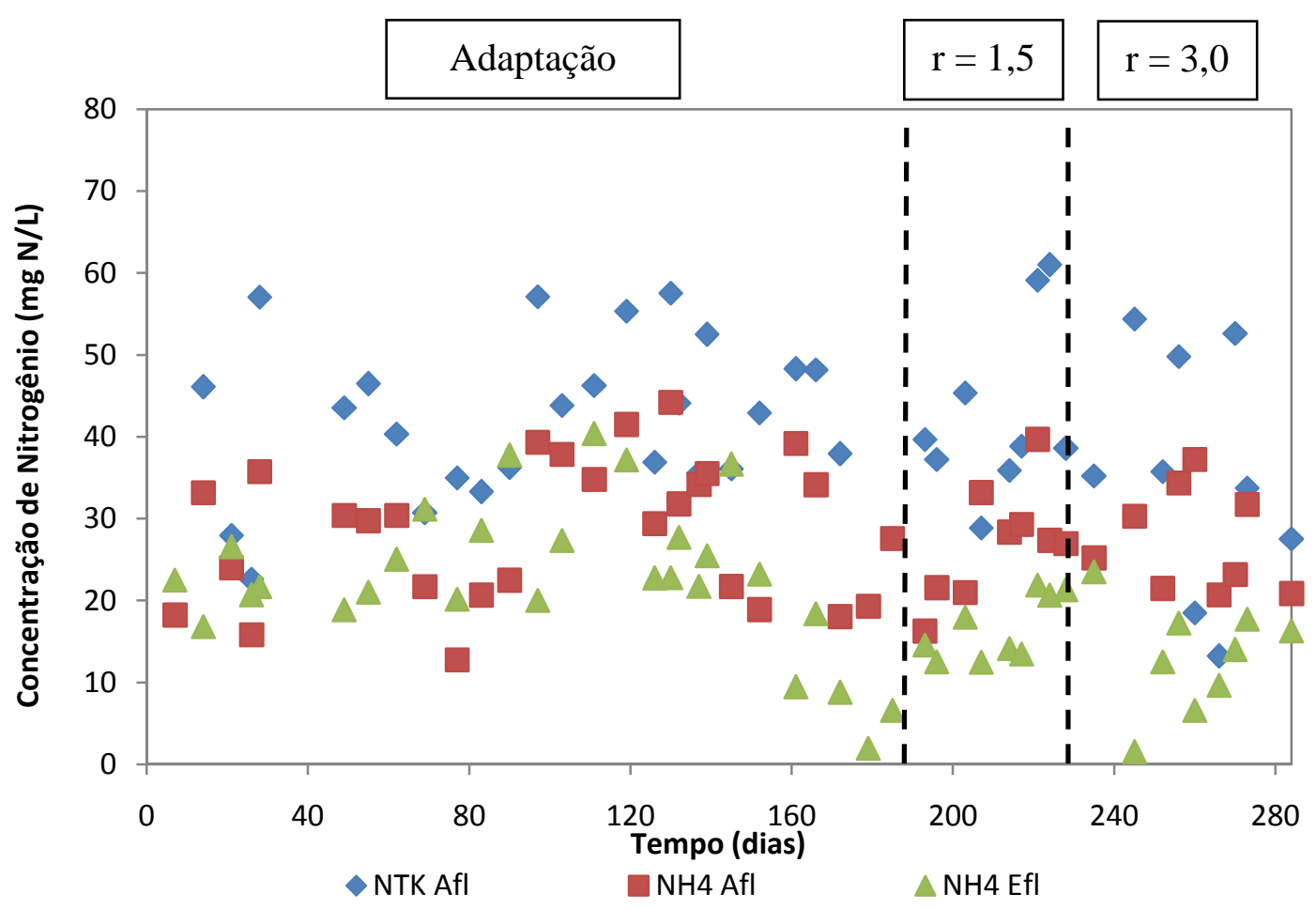

Figura 5.13 - Variação temporal da concentração das formas de Nitrogênio para o reator de leito fixo operado de modo contínuo com TDH de 12 horas

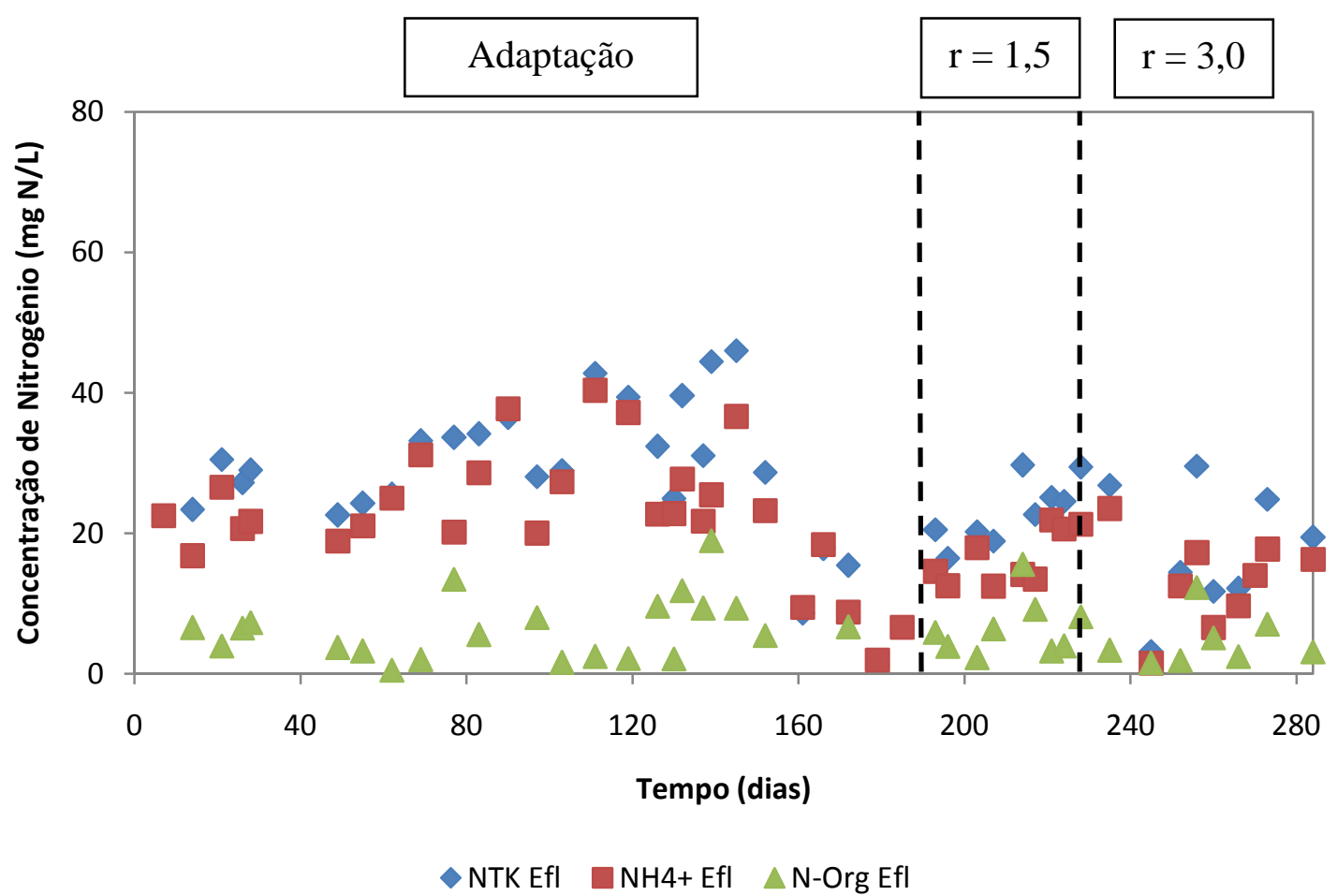

Figura 5.14 - Variação temporal das concentrações efluentes das formas de Nitrogênio para o reator de leito fixo operado de modo contínuo com TDH de 12 horas 
$\mathrm{Na}$ Figura 5.15 são observados os resultados de $\mathrm{N}_{-} \mathrm{NO}_{2}^{-}$e $\mathrm{N}_{-} \mathrm{NO}_{3}{ }^{-}$. É possível observar que a nitrificação ocorreu perto do $160^{\circ}$ dia operacional e manteve-se estável até o fim da fase sem recirculação. $\mathrm{O} \mathrm{N}^{-N_{2}}{ }_{2}^{-}$passou a ser convertido a $\mathrm{N}^{-\mathrm{NO}_{3}}{ }^{-}$, consistindo na etapa de nitratação, que finaliza a segunda fase da nitrificação. Devido à desnitrificação promovida na zona anaeróbia do reator, as concentrações efluentes de nitrito e nitrato variaram devido à inclusão da vazão de recirculação ao sistema.

Com o aumento da recirculação interna de efluente tratado, aumentou-se a quantidade de nitrato reduzido a nitrogênio gasoso por meio da desnitrificação na zona anaeróbia do reator, com consequente queda na concentração efluente de NT. A concentração média de NT no efluente tratado para razão de recirculação igual a 1,5 foi de $25 \pm 3 \mathrm{mg} \mathrm{N} / \mathrm{L}$ e de $20 \pm 8 \mathrm{mg} \mathrm{N} / \mathrm{L}$ para razão igual a 3,0 . 


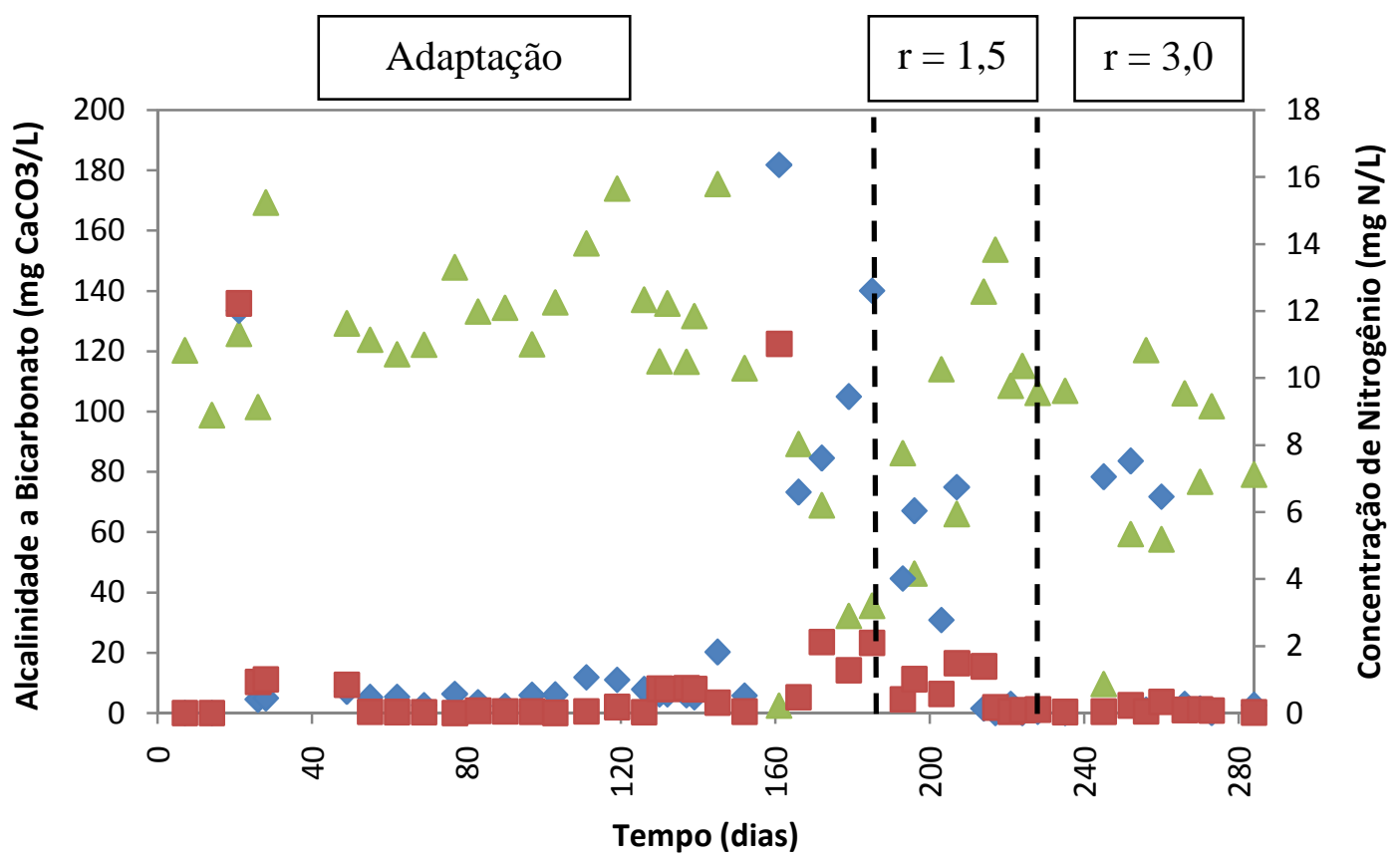

$\triangle$ Alc Efluente $\diamond$ NO3- Efl $\square$ NO2- Efl

Figura 5.15 - Variação temporal das concentrações efluentes de Nitrito, Nitrato e alcalinidade para o reator de leito fixo operado de modo contínuo com TDH de 12 horas

Nesta etapa de operação o pH efluente manteve-se superior ao afluente em praticamente todo o tempo, o que confirma estabilidade operacional. Somente após o início do processo de nitrificação, o pH efluente que se manteve em uma faixa próxima a 7,14 $\pm 0,21$, antes da nitrificação, caiu para $6,64 \pm 0,32$. Isso confirma a afirmação anterior sobre crescimento das bactérias nitrificantes. Nessa etapa operacional o valor médio do $\mathrm{pH}$ afluente ficou em 6,79 $\pm 0,18$ e do efluente em 6,92 $\pm 0,15$ para $\mathrm{r}=1,5 \mathrm{e}$ $7,15 \pm 0,29$ para $\mathrm{r}=3,0$. A Figura 5.16 mostra a variação temporal do $\mathrm{pH}$ afluente e efluente para o reator de leito fixo operado de modo contínuo com TDH total de 12 horas. 
Analogamente ao que ocorreu com a alcalinidade, os valores de $\mathrm{pH}$ no efluente tratado também apresentaram tendência de crescimento com a inserção e aumento da vazão de recirculação.

Para avaliação da estabilidade do reator, também observou-se a variação temporal da concentração de Ácidos Voláteis Totais (AVT). Pela Figura 5.17 é possível verificar que desde o primeiro dia operacional o valor da concentração de AVT do efluente foi menor que do afluente, caracterizando equilíbrio do processo. $\mathrm{O}$ valor médio para o afluente foi $56 \pm 14 \mathrm{mgHAc} / \mathrm{L}$ e para o efluente foi $17 \pm 2 \mathrm{mgHAc} / \mathrm{L}$ ( $\mathrm{r}=0$ e após estabilização); $25 \pm 7 \mathrm{mgHAc} / \mathrm{L}$ para $\mathrm{r}=1,5$ e $21 \pm 4 \mathrm{mgHAc} / \mathrm{L}$ para $\mathrm{r}=3,0$.

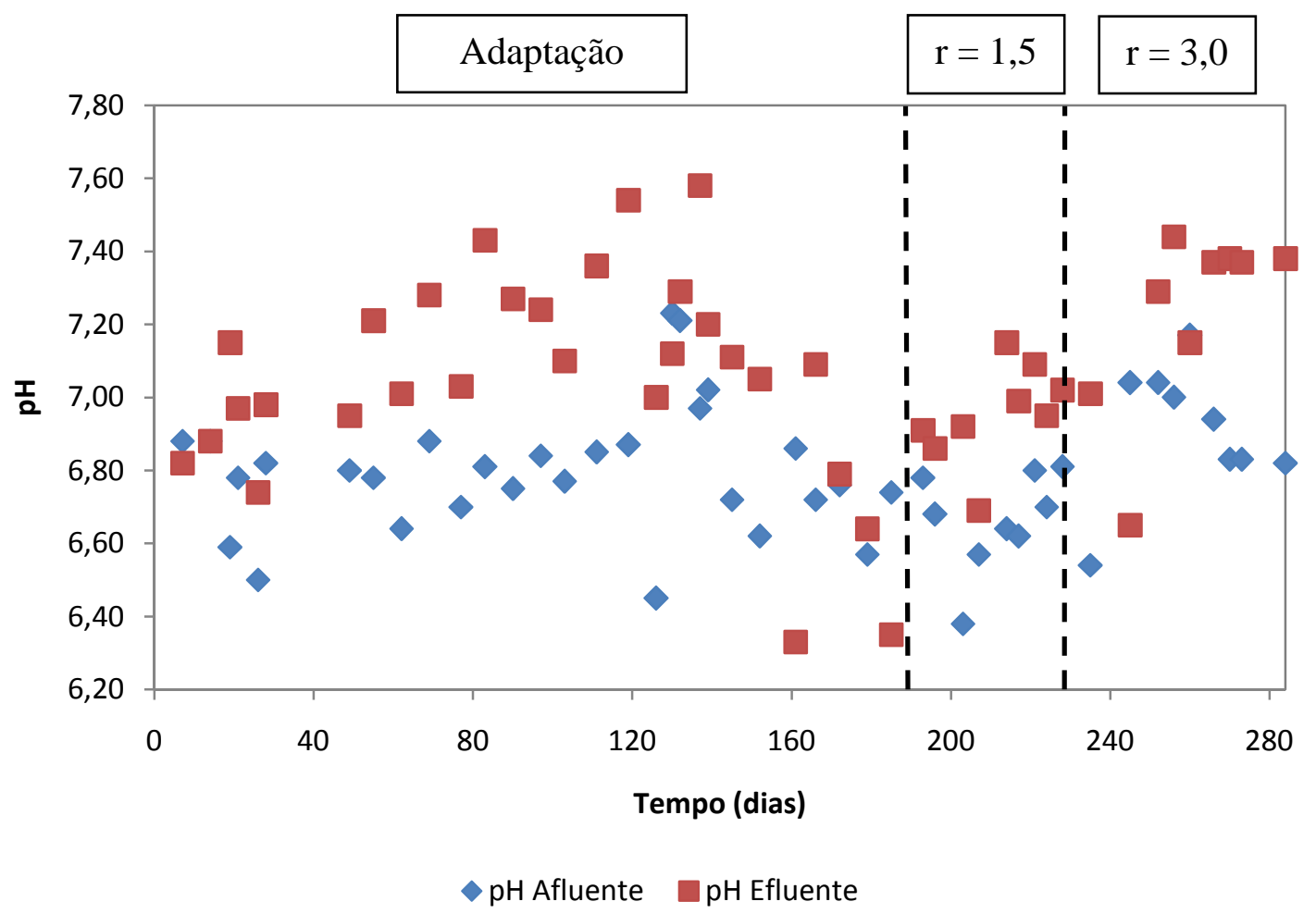

Figura 5.16 - Variação temporal do pH afluente e efluente para o reator de leito fixo operado de modo contínuo com TDH de 12 horas 


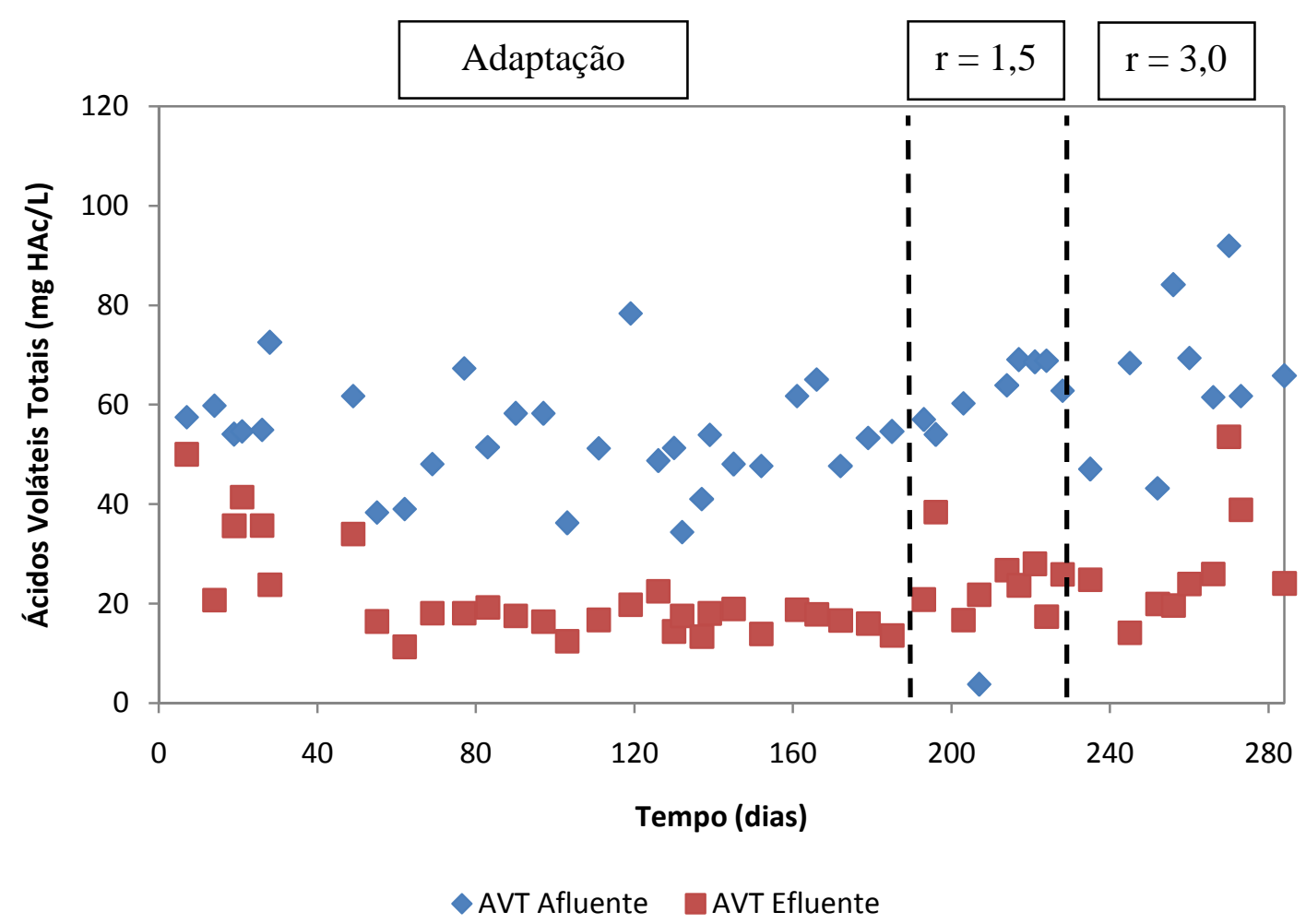

Figura 5.17 - Variação temporal da concentração de AVT afluente e efluente para o reator de leito fixo operado de modo contínuo com TDH de 12 horas

Nas Figuras 5.18 e 5.19 estão apresentados os valores de Sólidos Suspensos Totais (SST) e Sólidos Suspensos Voláteis (SSV) para esta etapa operacional com TDH total de 12 horas.

Pode-se observar a similaridade entre o comportamento dos SST e dos SSV. A média de SST afluente foi de $242 \pm 111 \mathrm{mg} / \mathrm{L}$ e $56 \pm 32 \mathrm{mg} / \mathrm{L}, 61 \pm 16 \mathrm{mg} / \mathrm{L} \mathrm{e}$ $70 \pm 42 \mathrm{mg} / \mathrm{L}$ para o efluente após estabilização, $\mathrm{r}=1,5$ e $\mathrm{r}=3,0$, respectivamente. Ressalta-se que os altos valores encontrados na fase com $r=3,0$ podem ter sido gerados por falha durante a coleta da amostra sendo os mesmos descartados para o cálculo das médias e desvios. No ponto de saída do efluente do reator foi instalado um tubo de PVC corrugado flexível que descartava o efluente na rede de esgoto da área de tratamento de 
esgoto do Laboratório de Processos Biológicos (LPB). No momento da coleta da amostra era necessário a retirada do tubo do ponto de descarte, movimento este, muitas vezes brusco, o que proporcionava desprendimento de biofilme formado na lateral do tubo corrugado afetando alguns resultados. Nas demais coletas foram tomados os devidos cuidados para evitar tais movimentações.

Para os SSV, a média afluente foi de $193 \pm 94 \mathrm{mg} / \mathrm{L}$ e $38 \pm 20 \mathrm{mg} / \mathrm{L}$, $51 \pm 12 \mathrm{mg} / \mathrm{L}$ e $54 \pm 34 \mathrm{mg} / \mathrm{L}$ para o efluente após estabilização, $\mathrm{r}=1,5$ e $\mathrm{r}=3,0$. Da mesma forma que ocorreu com os dados de SST, foram desconsiderados os resultados com valores elevados devido a provável falha na coleta.

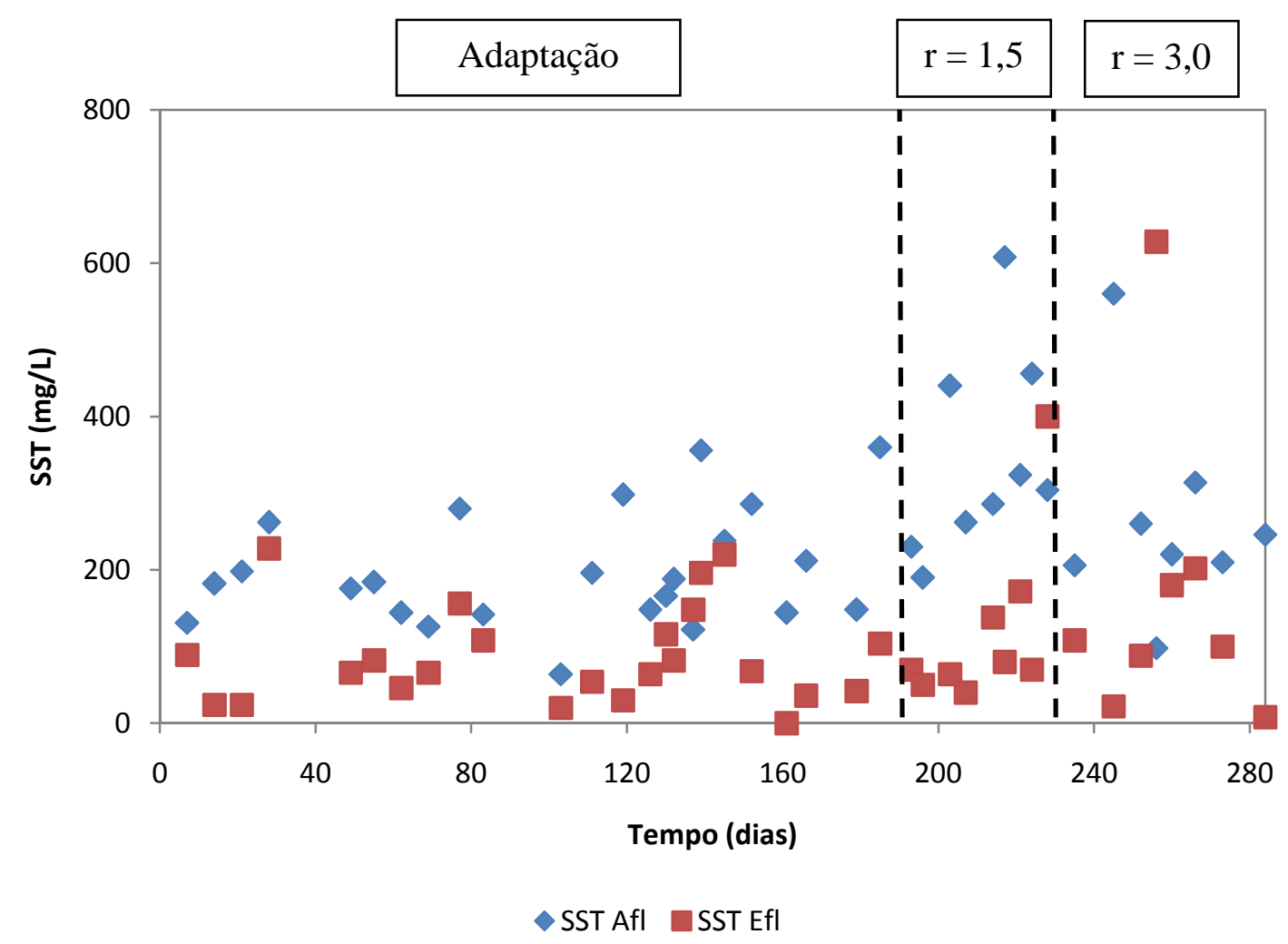

Figura 5.18 - Variação temporal da concentração de SST afluente e efluente para o reator de leito fixo operado de modo contínuo com TDH de 12 horas 


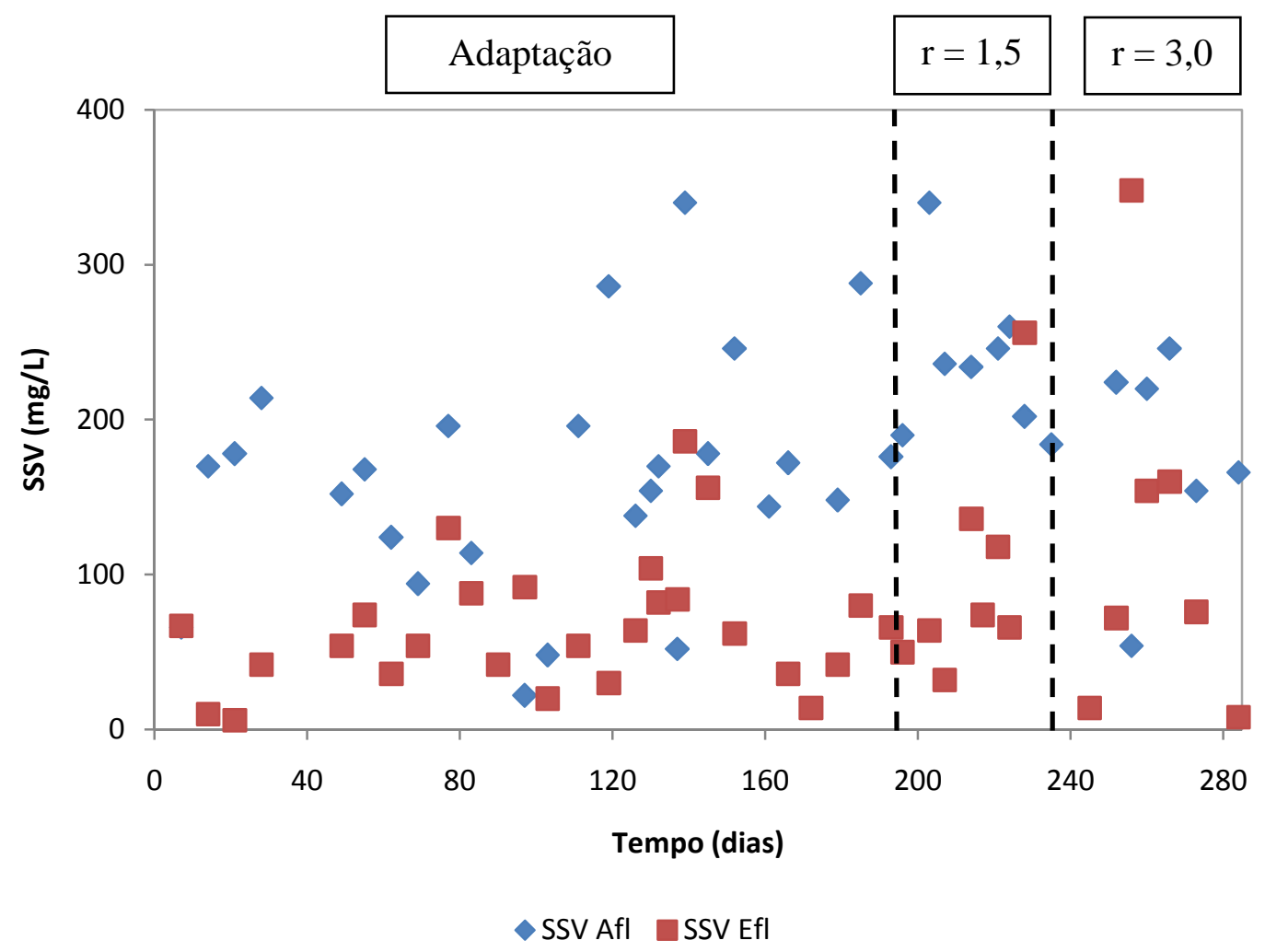

Figura 5.19 - Variação temporal da concentração de SSV afluente e efluente para o reator de leito fixo operado de modo contínuo com TDH de 12 horas

Ao final da primeira etapa de operação foram realizados perfis temporais e espaciais (ao longo do comprimento do reator) de DQO e N-Amon afluente e efluente. O valor médio da DQO do esgoto sanitário afluente foi de $795 \pm 166 \mathrm{mg} / \mathrm{L}$ para amostra bruta e o efluente de $90 \pm 28 \mathrm{mg} / \mathrm{L}$ e de $27 \pm 19 \mathrm{mg} / \mathrm{L}$ para amostra bruta e filtrada, respectivamente. Já o $\mathrm{N}$-Amon afluente foi de $21 \pm 4 \mathrm{mg} / \mathrm{L}$ e de $10 \pm 3 \mathrm{mg} / \mathrm{L}$ para o efluente. Os resultados dos dois perfis realizados são apresentados nas Figuras 5.20, $5.21,5.22$ e 5.23 .

Os valores médios de DQO afluente e efluente foram maiores que as médias encontradas e apresentadas na Tabela 5.1 quando o reator combinado anaeróbio-aeróbio de leito fixo operou com TDH igual a 12 horas. Vale ressaltar que o ensaio ocorreu após 
dia bastante chuvoso, o que acarretou aumento visível de sólidos e material inerte no afluente com consequente aumento na DQO, somado à inexistência de tratamento preliminar para remoção de sólidos grosseiros e areia na Área de Pesquisa em Tratamento de Esgoto Sanitário do LPB.

Os resultados obtidos por meio desses perfis mostram que, para amostras brutas e filtradas, os valores da DQO efluente não variaram muito ao longo do dia. Por esse motivo, não houve necessidade de retirada de amostras compostas, pois coletas de amostras pontuais, feitas em horário equivalente à média de DQO do dia, foram suficientes para obtenção de resultados condizentes com a realidade.

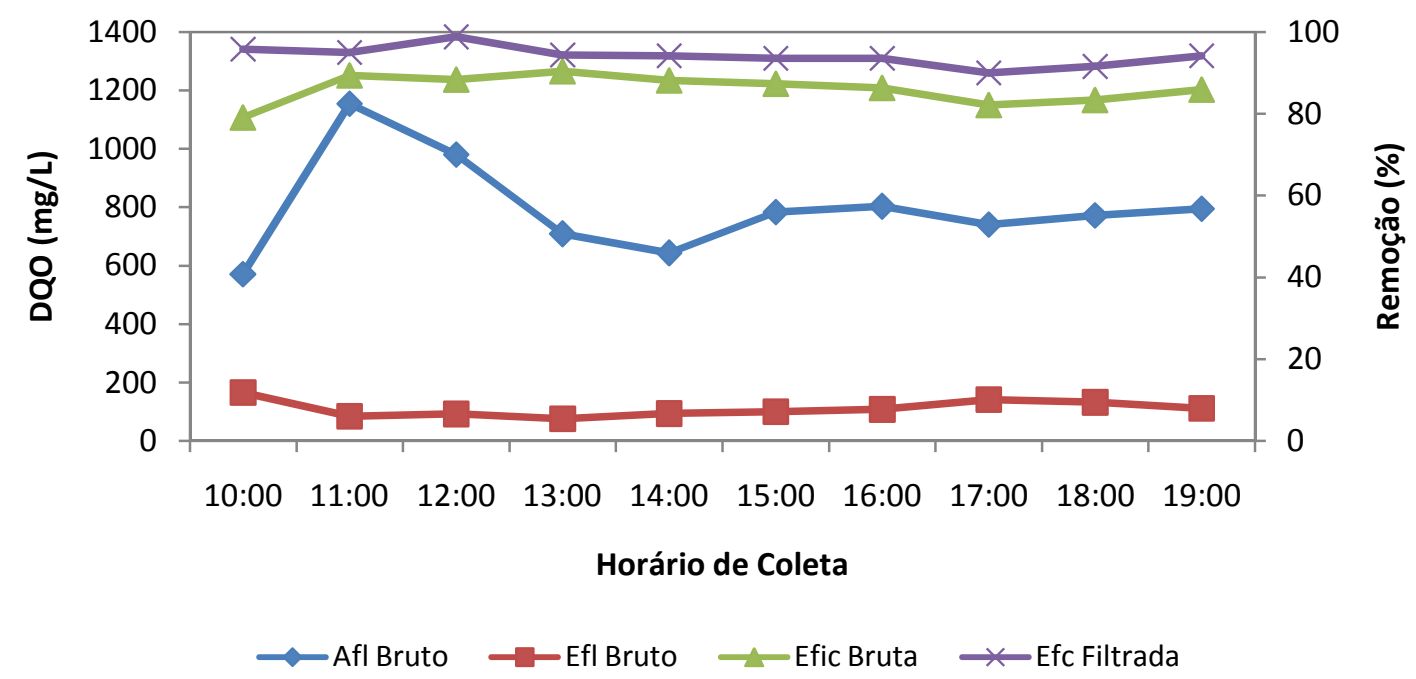

Figura 5.20 - Perfil temporal de DQO, para esgoto doméstico afluente e efluente para o reator de leito fixo operado de modo contínuo com TDH de 12 horas e $r=3,0$ 


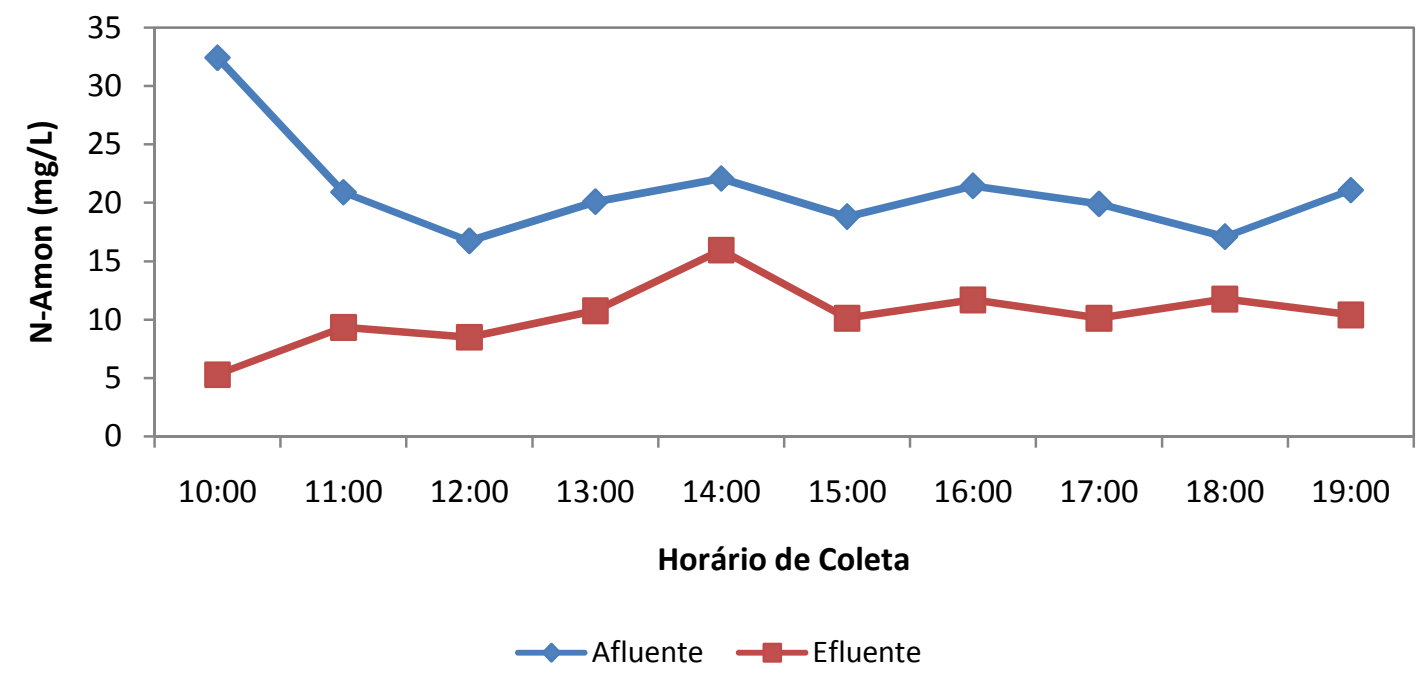

Figura 5.21 - Perfil temporal de Nitrogênio Amoniacal, para esgoto doméstico afluente e efluente para o reator de leito fixo operado de modo contínuo com TDH de 12 horas e

$$
r=3,0
$$

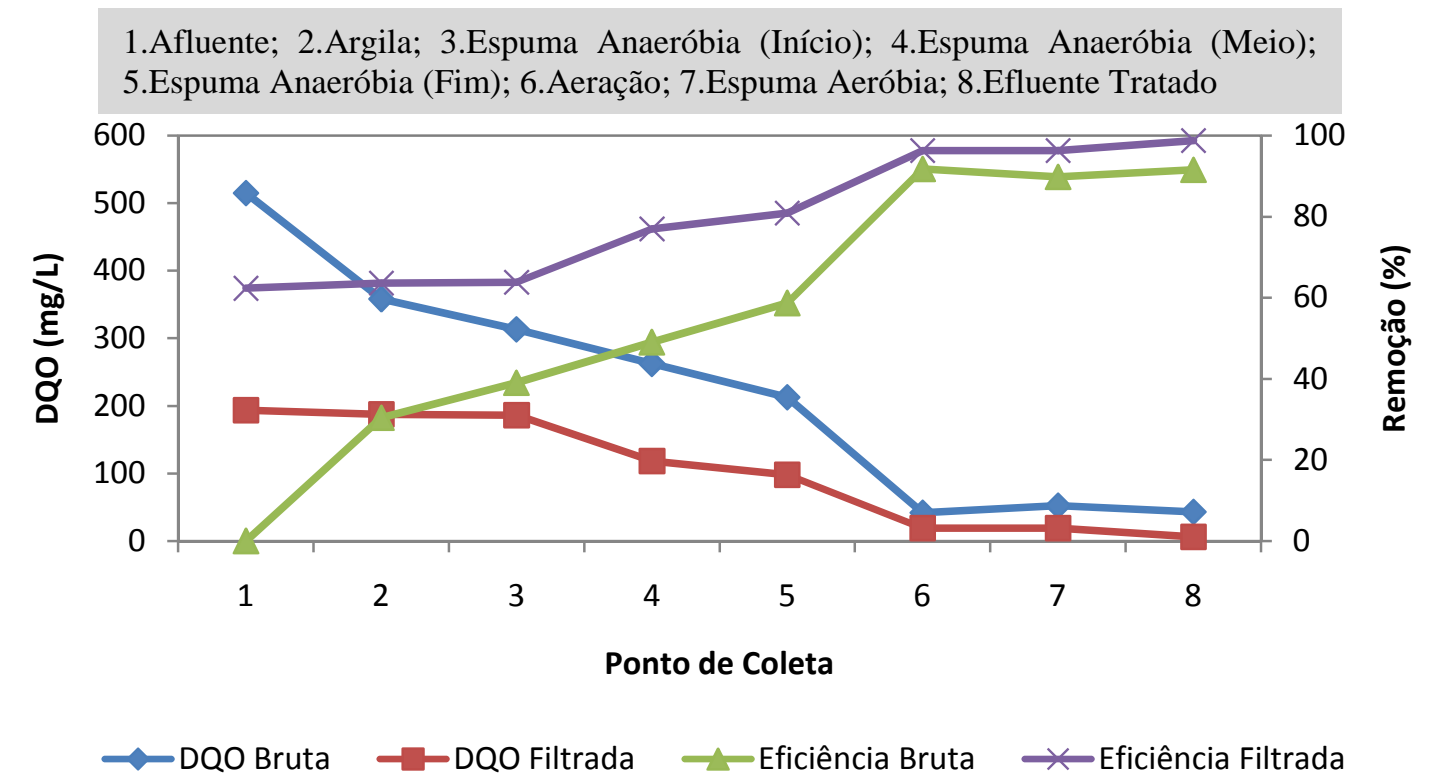

Figura 5.22 - Perfil espacial de DQO para o reator de leito fixo operado de modo contínuo com TDH de 12 horas e $\mathrm{r}=3,0$ 


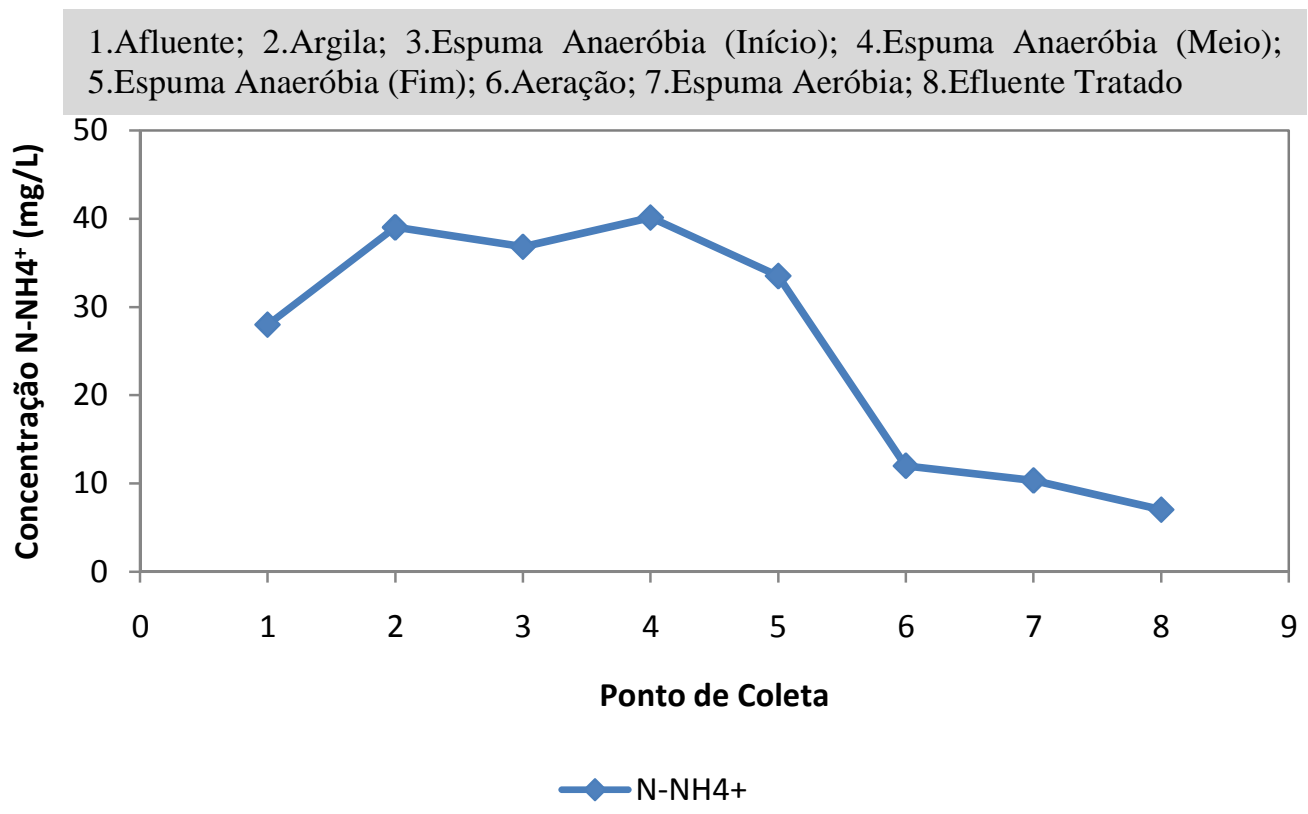

Figura 5.23 - Perfil espacial de Nitrogênio Amoniacal para o reator de leito fixo operado de modo contínuo com TDH de 12 horas e $\mathrm{r}=3,0$

Os perfis espaciais, tanto para remoção de DQO quanto para conversão de Nitrogênio, comprovam a remoção sequencial ao longo do reator. Além disso, os perfis ao longo da altura do sistema permitem que se tenha idéia do que ocorre com o esgoto sanitário durante sua passagem pelo interior do reator. Destaca-se que o efluente da zona anaeróbia/anóxica do reator apresentou, para este perfil, valor de DQO igual a $213 \mathrm{mg} / \mathrm{L}$ e concentração de $\mathrm{NH}_{4}{ }^{+}$de $33 \mathrm{mg} / \mathrm{L}$, passando a ter valores iguais a $43 \mathrm{mg} / \mathrm{L}$ e $7 \mathrm{mg} / \mathrm{L}$ respectivamente para DQO e $\mathrm{NH}_{4}{ }^{+}$, após passagem pela camada aerada do reator combinado.

Nas próximas duas etapas de operação combinada, os tempos foram reduzidos de 12 horas, para 10 horas e 8 horas respectivamente, elevando-se a vazão de alimentação do sistema. Ainda que o aumento da vazão reduza o tempo de detenção hidráulica, pode ocorrer a elevação da velocidade de transferência de massa líquidosólido pela elevação da velocidade superficial no leito. Assim, enquanto a redução do 
TDH possa ser desfavorável para o processo, a elevação das velocidades de transferência de massa pode resultar em efeito contrário, contribuindo para a melhoria do desempenho.

\subsubsection{Avaliação do desempenho do reator combinado operado com tempo de detenção}

\section{hidráulica de 10 horas}

Na segunda etapa de operação o TDH total do sistema foi reduzido para 10 horas, sendo 5,4 horas na camada anaeróbia $\left(1,37 \mathrm{~m}^{3}\right)$ e 4,6 horas na camada aeróbia $\left(1,18 \mathrm{~m}^{3}\right)$. Essa atitude teve a intenção de aumentar as cargas carbonácea e nitrogenada aplicadas ao sistema para verificar sua robustez. Nesta etapa o TDH aplicado correspondeu a uma vazão de $4,25 \mathrm{~L} / \mathrm{min}$.

A carga orgânica volumétrica (COV) aplicada ao sistema na segunda etapa de operação foi de $1,48 \pm 0,63 \mathrm{~kg}$.DQO $/ \mathrm{m}^{3}$.dia, sendo calculada com base no volume reacional. Já a carga orgânica volumétrica removida ficou em torno de $1,04 \pm 0,35 \mathrm{~kg} \cdot \mathrm{DQO} / \mathrm{m}^{3}$.dia, para $\mathrm{r}=1,5$. A obtenção deste parâmetro para a fase com recirculação igual a 3,0 ficou prejudicada devido ao excesso de material sólido carreado, e consequente elevação da DQO bruta efluente, discussão que será aprofundada posteriormente.

Já a carga volumétrica de Nitrogênio (CVN) aplicada ao sistema nesta etapa operacional foi de $0,09 \pm 0,03 \mathrm{~kg} \cdot \mathrm{NTK} / \mathrm{m}^{3}$.dia, próxima a da etapa anterior, sendo calculada com base no volume reacional, enquanto a carga de Nitrogênio removida ficou em torno de $0,04 \pm 0,02 \mathrm{~kg} . \mathrm{NTK} / \mathrm{m}^{3}$. dia para a fase com $\mathrm{r}=1,5$. Da mesma forma que ocorreu para a COV removida, a CVN removida para a fase com $r=3,0$ não foi obtida em virtude dos resultados insatisfatórios encontrados nesta fase operacional. 
O período de operação para avaliação operacional do reator foi de 113 dias para esta etapa operacional, sendo 63 para a fase com recirculação de 1,5 e 50 dias com razão de recirculação igual a 3,0.

A aeração foi mantida a uma vazão constante de $50 \mathrm{~L} / \mathrm{min}$, assim como na etapa anterior.

A Tabela 5.2 apresenta os valores médios dos principais parâmetros para o esgoto sanitário afluente e efluente obtidos para o reator operando na segunda etapa.

Tabela 5.2 - Comparação entre os valores afluentes e efluentes da segunda etapa operacional $(\mathrm{TDH}=10 \mathrm{~h})$.

\begin{tabular}{|c|c|c|c|}
\hline Parâmetros & Afluente & $\mathrm{r}=1,5$ & $\mathrm{r}=3,0$ \\
\hline $\mathrm{pH}$ & $6,94 \pm 0,11^{(11)}$ & $7,29 \pm 0,10^{(5)}$ & $7,16 \pm 0,16^{(6)}$ \\
\hline DQO Bruta (mg/L) & $550 \pm 164^{(10)}$ & $183 \pm 147^{(4)}$ & $1126 \pm 495^{(6)}$ \\
\hline DQO Filtrada (mg/L) & $135 \pm 46^{(10)}$ & $28 \pm 14^{(4)}$ & $29 \pm 14^{(6)}$ \\
\hline Alc. Total (mg CaCO3/L) & $128 \pm 30^{(11)}$ & $113 \pm 21^{(5)}$ & $122 \pm 27^{(6)}$ \\
\hline Alc. a Bicarbonato (mg CaCO3/L) & $84 \pm 27^{(11)}$ & $86 \pm 20^{(5)}$ & $72 \pm 24^{(6)}$ \\
\hline AVT (mg HAc/L) & $61 \pm 14^{(11)}$ & $38 \pm 7^{(5)}$ & $71 \pm 21^{(6)}$ \\
\hline $\mathrm{NT}(\mathrm{mg} / \mathrm{L})$ & $37 \pm 14^{(11)}$ & $29 \pm 13^{(5)}$ & $93 \pm 62^{(6)}$ \\
\hline NTK (mg/L) & $36 \pm 14^{(11)}$ & $28 \pm 13^{(5)}$ & $90 \pm 59^{(6)}$ \\
\hline $\mathrm{NH}_{4}{ }^{+}(\mathrm{mg} / \mathrm{L})$ & $20 \pm 8^{(11)}$ & $15 \pm 4^{(5)}$ & $17 \pm 2^{(6)}$ \\
\hline $\mathrm{NO}_{2}^{-}(\mathrm{mg} / \mathrm{L})$ & - & - & - \\
\hline $\mathrm{NO}_{3}^{-}(\mathrm{mg} / \mathrm{L})$ & $1 \pm 1^{(11)}$ & $1 \pm 2^{(5)}$ & $2 \pm 5^{(6)}$ \\
\hline SST (mg/L) & $245 \pm 105^{(10)}$ & $130 \pm 92^{(4)}$ & $1076 \pm 707^{(6)}$ \\
\hline $\mathrm{SSV}(\mathrm{mg} / \mathrm{L})$ & $188 \pm 90^{(10)}$ & $115 \pm 87^{(4)}$ & $782 \pm 574^{(6)}$ \\
\hline
\end{tabular}


A Figura 5.24 mostra os valores de DQO de amostras bruta e filtrada, variando ao longo do período operacional com TDH total de 10 horas, para afluente e para o efluente.

Pode-se observar que a matéria orgânica não foi removida eficientemente no reator de leito fixo, operando em condição anaeróbia seguida de aeróbia e com recirculação. Pode-se observar que os valores obtidos para o efluente, principalmente para amostra bruta, foram inconstantes durante todo o período operacional. O sistema se manteve instável durante todo o tempo de operação e os valores médios efluentes para DQO de amostra bruta e filtrada foram maiores comparando-se com a etapa anterior, quando o reator operou de forma combinada com TDH total de 12 horas.

O efluente apresentou valor médio de DQO de amostra bruta de $183 \pm 147 \mathrm{mg} / \mathrm{L}$ para a fase com $r=1,5$ e de $1126 \pm 495 \mathrm{mg} / \mathrm{L}$ para $\mathrm{r}=3,0$.

As Demandas Químicas de Oxigênio nas amostras filtradas do efluente não apresentaram a variabilidade das amostras brutas e mantiveram-se estáveis em relação à mudança de razão de recirculação. O valor médio da DQO filtrada efluente para a fase com $r=1,5$ foi $28 \pm 14 \mathrm{mg} / \mathrm{L}$ enquanto para $\mathrm{r}=3,0$ foi $29 \pm 14 \mathrm{mg} / \mathrm{L}$. Pode-se observar que não houve melhora na eficiência de remoção de matéria orgânica do sistema após aumento da vazão de alimentação.

Pode-se observar na Figura 5.25 e com auxílio da Tabela 5.2 que as eficiências alcançadas para o reator anaeróbio-aeróbio com TDH de 10 horas não foram melhores que a etapa anterior com TDH de 12 horas. Não houve melhora na transferência de massa pelo aumento da velocidade superficial do líquido no leito. As eficiências foram calculadas a partir da média do afluente bruto durante este período operacional. 


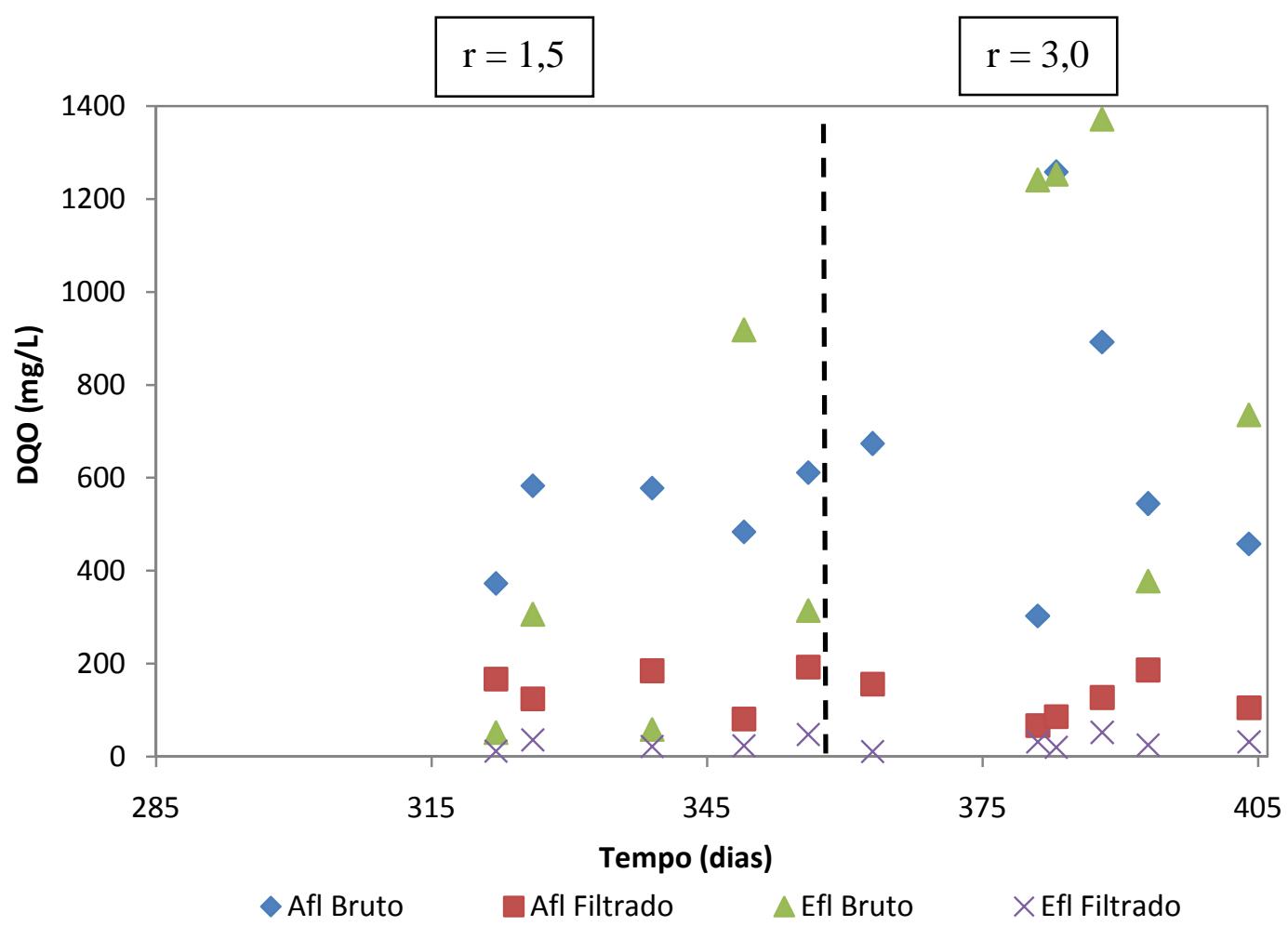

Figura 5.24 - Variação temporal da DQO para o reator de leito fixo operado de modo contínuo com TDH de 10 horas

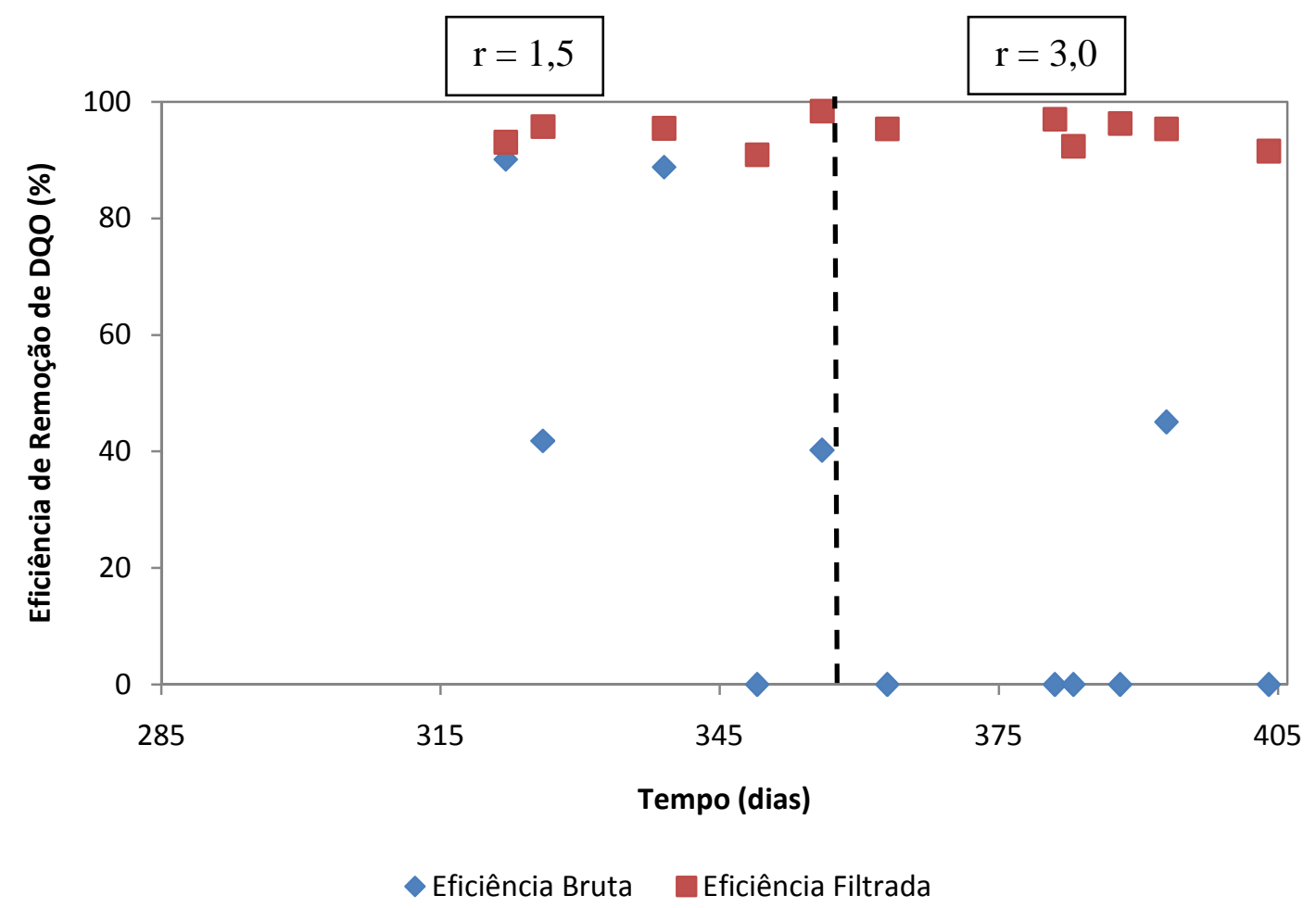

Figura 5.25 - Eficiências de remoção de DQO ao longo do tempo para o reator de leito fixo operado de modo contínuo com TDH de 10 horas 
Em toda etapa operacional, como mostra a Figura 5.26, a Alcalinidade a Bicarbonato manteve comportamento similar no afluente e efluente. O valor médio para o afluente, nesta etapa, foi $84 \pm 27 \mathrm{mgCaCO}_{3} / \mathrm{L}$ e para o efluente foi $86 \pm 20 \mathrm{mgCaCO}_{3} / \mathrm{L}$ com $\mathrm{r}=1,5$ e $72 \pm 24 \mathrm{mgCaCO}_{3} / \mathrm{L}$ para $\mathrm{r}=3,0$.

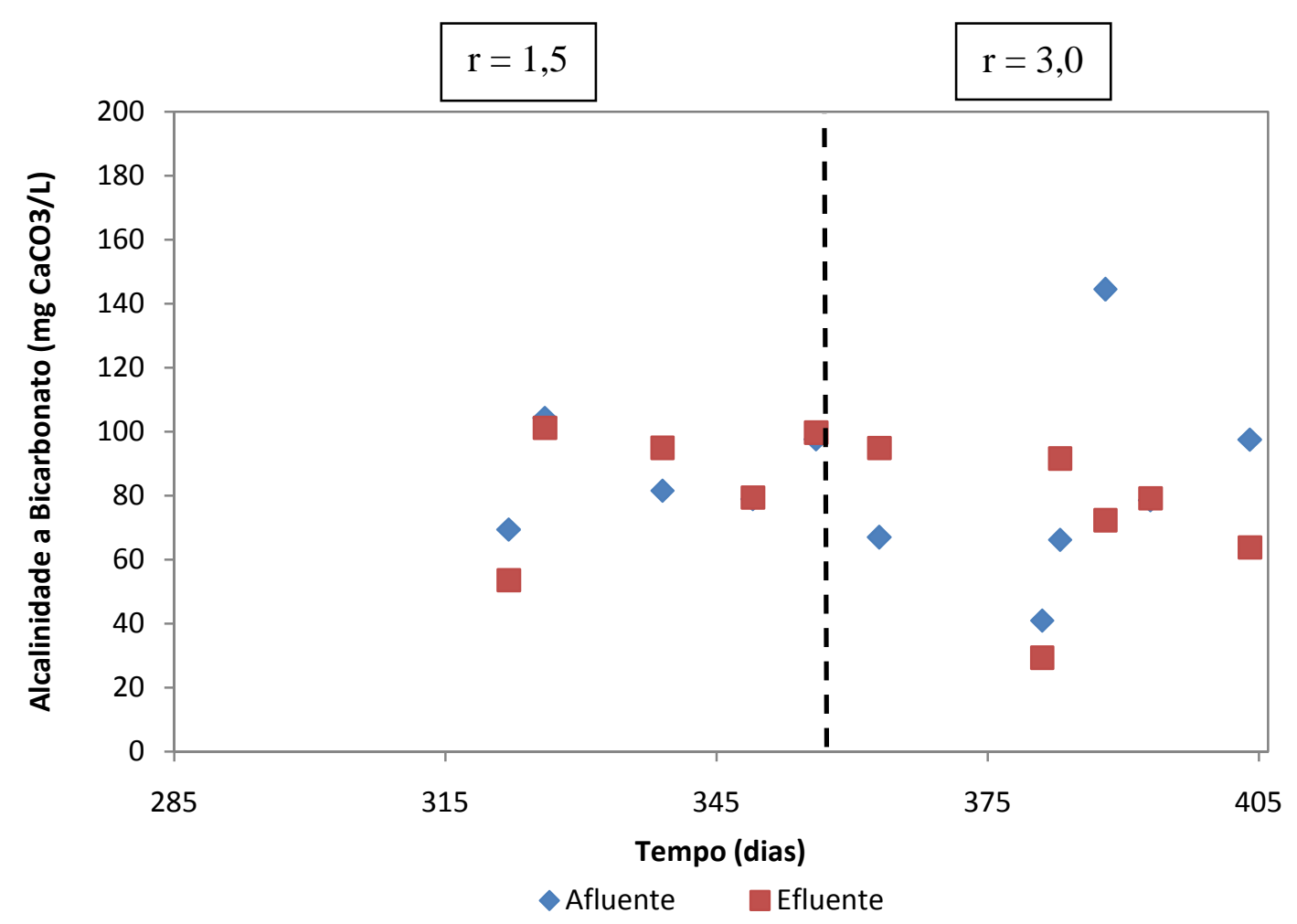

Figura 5.26 - Variação temporal da Alcalinidade a Bicarbonato afluente e efluente para o reator de leito fixo operado de modo contínuo com TDH de 10 horas

As Figuras 5.27 e 5.28 mostram as concentrações afluentes e efluentes de N-NTK e N-Amon. Os valores médios efluentes de N-NTK e N-Amon, foram $28 \pm 13 \mathrm{mg} / \mathrm{L}, 90 \pm 59 \mathrm{mg} / \mathrm{L} ;$ e $15 \pm 4 \mathrm{mg} / \mathrm{L}, 17 \pm 2 \mathrm{mg} / \mathrm{L}$ para razão de recirculação de 1,5 e 3,0 respectivamente. As elevadas concentrações para NTK devem-se, provavelmente, pela não filtragem das amostras brutas coletadas nesta fase, já que as mesmas apresentaram elevada concentração de sólidos interferindo no método analítico. 
Pode-se observar pelos valores médios afluentes, $36 \pm 14 \mathrm{mg} / \mathrm{L}$ para N-NTK e $20 \pm 8 \mathrm{mg} / \mathrm{L}$ para $\mathrm{N}$-Amon, que a maior parte do nitrogênio afluente encontrava-se na forma amoniacal. A Figura 5.28 mostra a variação do nitrogênio orgânico (N-Org), calculado pela subtração do N-NTK pelo N-Amon, ao longo do tempo, juntamente com o N-NTK e N-Amon efluentes. Confirmou-se que o N-Org, na maior parte do tempo, representou parcela mínima do Nitrogênio tanto para o afluente como para o efluente, assim como ocorreu na etapa anterior. Excetuam-se da afirmação acima, os pontos onde foram observados elevada concentração de N-NTK, no efluente, devido ao excessivo arraste de sólidos, provavelmente ocasionado pelo aumento da velocidade ascensional promovida pela elevação da razão de recirculação.

$\mathrm{Na}$ Figura 5.29 são observados os resultados de $\mathrm{N}_{-} \mathrm{NO}_{2}{ }^{-}$e $\mathrm{N}^{-\mathrm{NO}_{3}}{ }^{-}$, respectivamente. As concentrações efluentes de nitrito e nitrato variaram com o aumento da vazão de recirculação aplicada ao sistema. $O$ processo de nitrificação/desnitrificação foi bastante afetado pelo arraste de sólidos observado no efluente durante esta etapa operacional. 


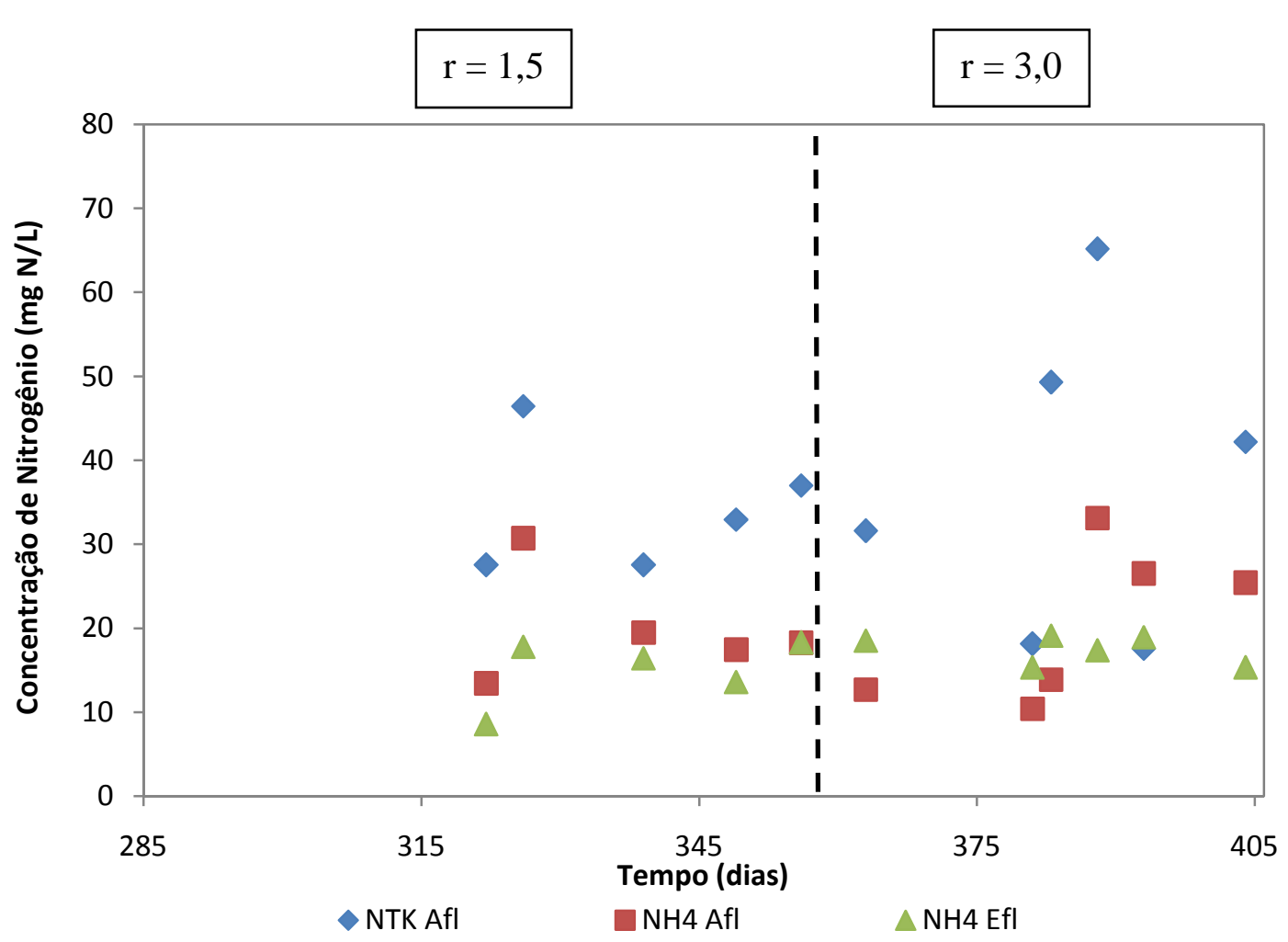

Figura 5.27 - Variação temporal da concentração das formas de Nitrogênio para o reator de leito fixo operado de modo contínuo com TDH de 10 horas

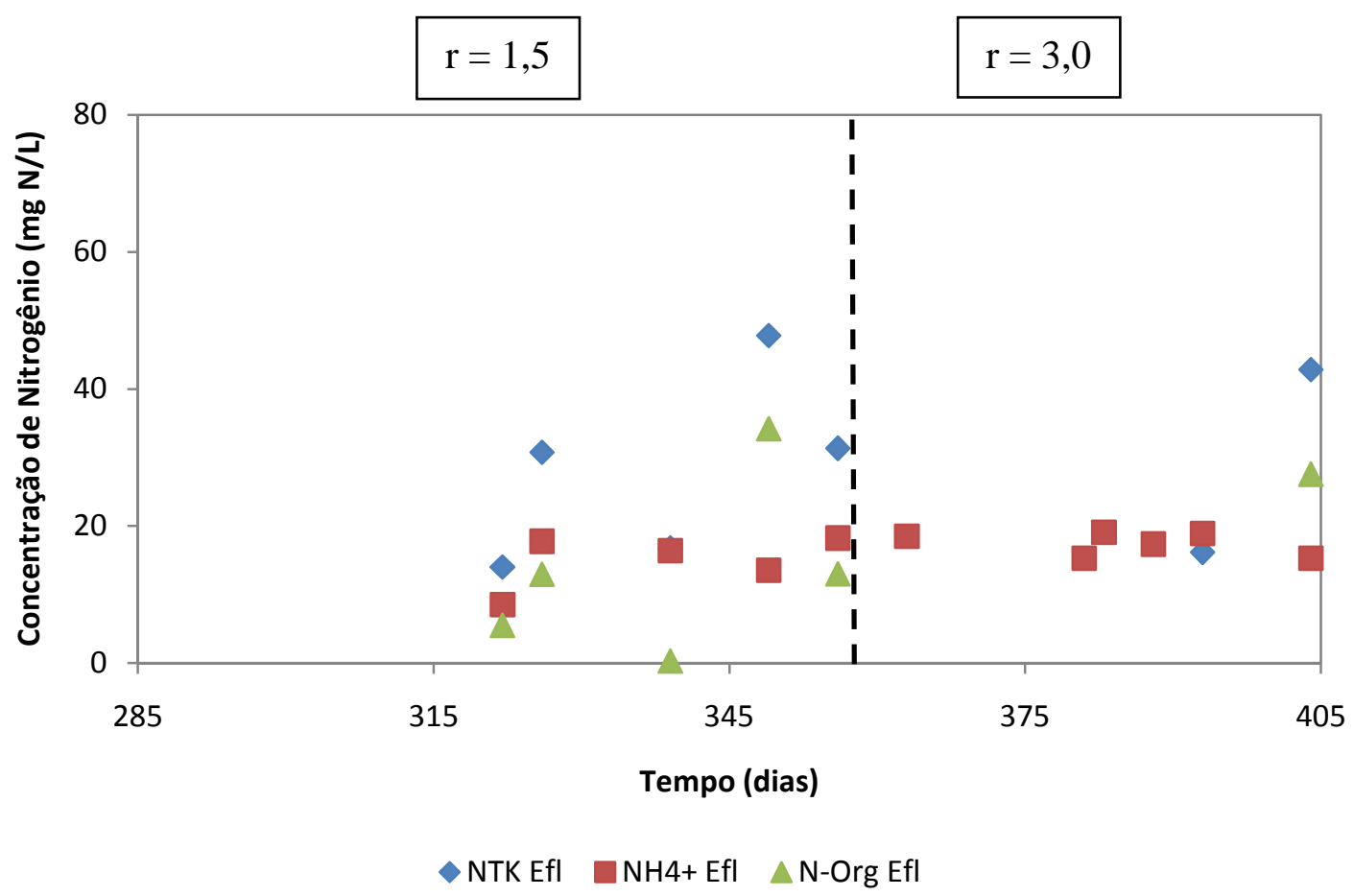

Figura 5.28 - Variação temporal das concentrações efluentes das formas de Nitrogênio para o reator de leito fixo operado de modo contínuo com TDH de 10 horas 


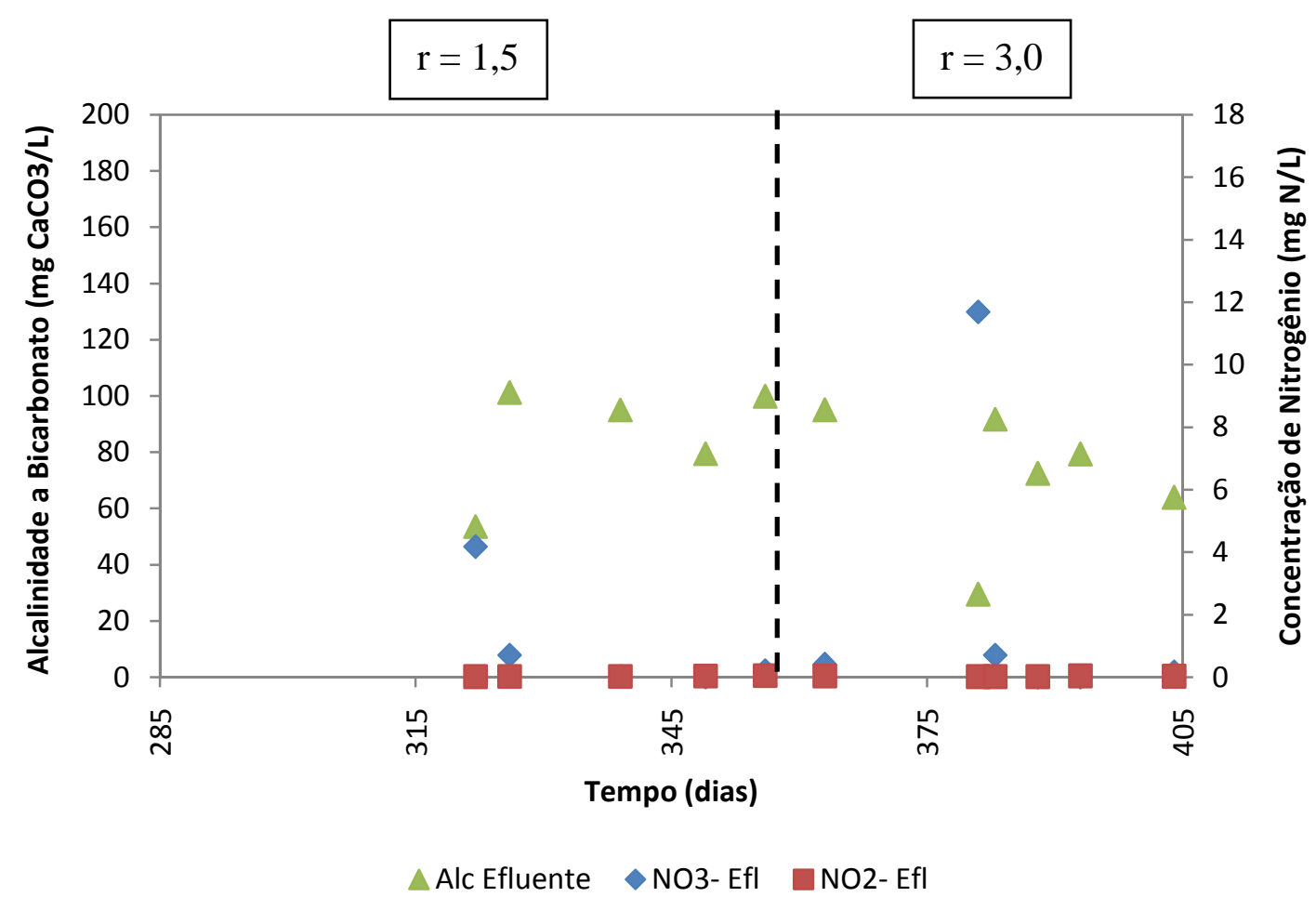

Figura 5.29 - Variação temporal das concentrações efluentes de Nitrito, Nitrato e alcalinidade para o reator de leito fixo operado de modo contínuo com TDH de 10 horas

Nesta etapa de operação com TDH total de 10 horas o pH efluente foi maior que o afluente durante todo o período. $\mathrm{O}$ valor médio do $\mathrm{pH}$ afluente ficou em 6,94 $\pm 0,11$. Já o efluente ficou em 7,29 $\pm 0,10$ para $r=1,5$ e 7,16 $\pm 0,16$ para $r=3,0$. A Figura 5.30 mostra a variação temporal do $\mathrm{pH}$ afluente e efluente para o reator de leito fixo operado de modo contínuo.

Para avaliação da estabilidade do reator, também observou-se a variação temporal da concentração de Ácidos Voláteis Totais (AVT) assim como feito com a Alcalinidade a Bicarbonato.

Pela Figura 5.31 é possível verificar que desde o primeiro dia operacional com TDH total de 10 horas o valor da concentração de AVT do efluente foi menor que do afluente. Quando houve aumento na razão de recirculação para $r=3,0$ e aumento do 
arraste de sólidos no efluente, os valores efluentes de AVT tornaram-se maiores que os afluentes, demonstrando produção de ácidos e conseqüente desequilíbrio do processo. $\mathrm{O}$ valor médio para o afluente foi $61 \pm 14 \mathrm{mgHAc} / \mathrm{L}$ e para o efluente foi $38 \pm 7 \mathrm{mgHAc} / \mathrm{L}$ para $\mathrm{r}=1,5$ e $71 \pm 21 \mathrm{mgHAc} / \mathrm{L}$ para $\mathrm{r}=3,0$.

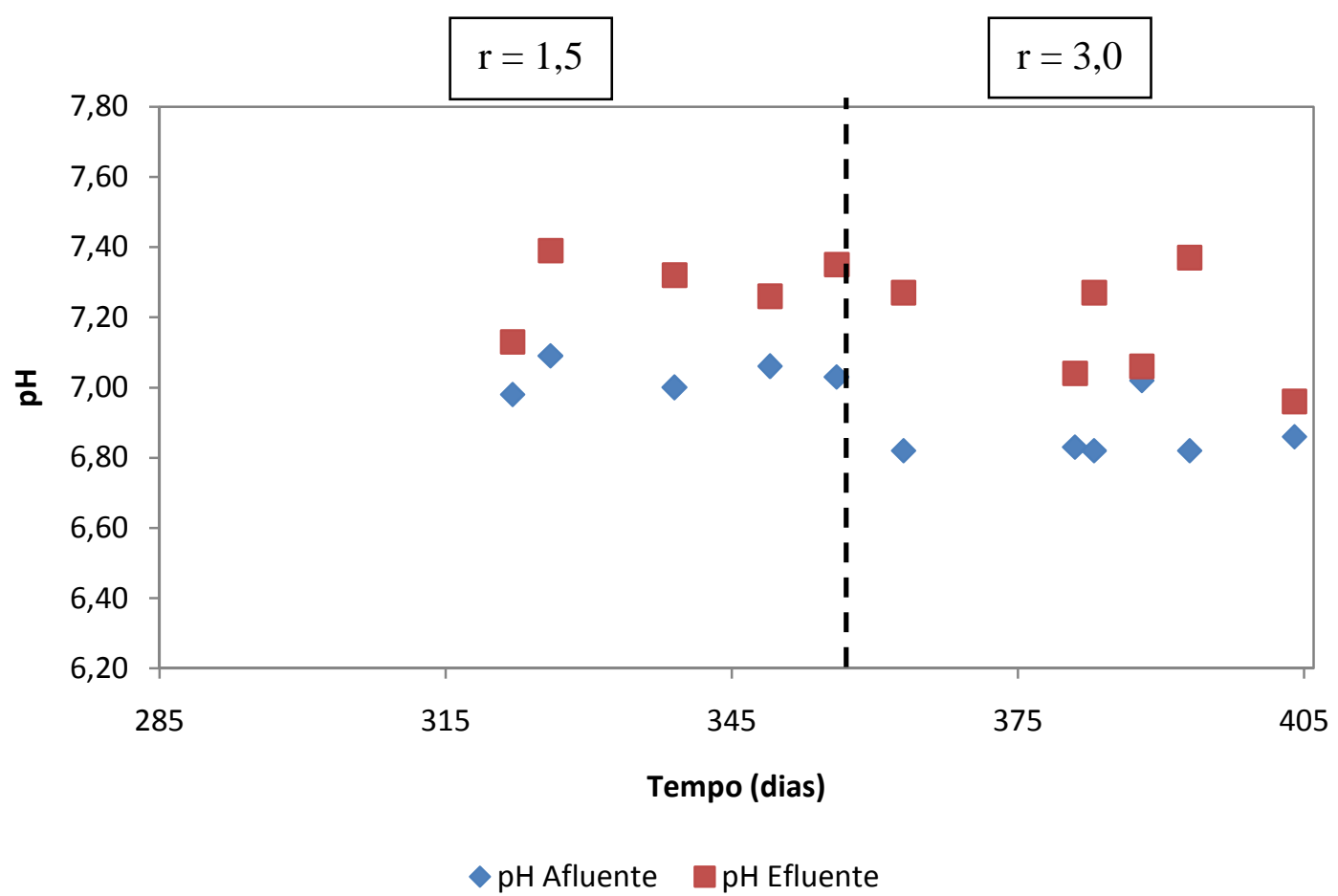

Figura 5.30 - Variação temporal do pH afluente e efluente para o reator de leito fixo operado de modo contínuo com TDH de 10 horas 


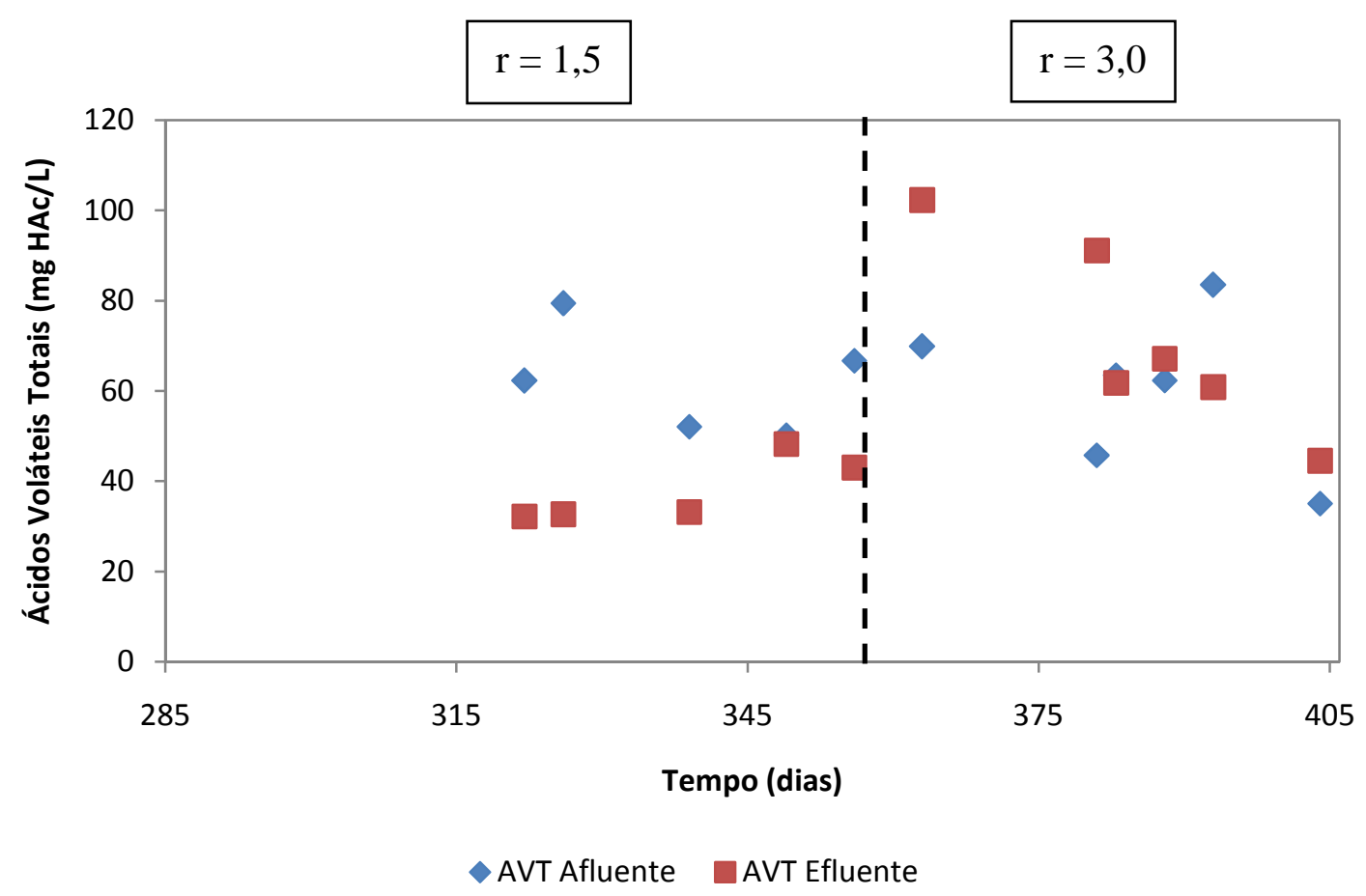

Figura 5.31 - Variação temporal da concentração de AVT afluente e efluente para o reator de leito fixo operado de modo contínuo com TDH de 10 horas

Nas Figuras 5.32 e 5.33 estão apresentados os valores de Sólidos Suspensos Totais (SST) e Sólidos Suspensos Voláteis (SSV) para a segunda etapa operacional. Pode-se observar certa similaridade entre o comportamento dos SST e dos SSV, excluindo o período de desequilíbrio do sistema, onde ocorreu arraste excessivo de sólidos no efluente. A média de SST afluente foi de $245 \pm 105 \mathrm{mg} / \mathrm{L}$ e efluente de $130 \pm 92 \mathrm{mg} / \mathrm{L}$ para razão igual a 1,5 e de $1076 \pm 707 \mathrm{mg} / \mathrm{L}$ para razão de 3,0, respectivamente. Para SSV, a média foi de $188 \pm 90 \mathrm{mg} / \mathrm{L}$ para o afluente e de $115 \pm 87 \mathrm{mg} / \mathrm{L}$ para razão igual a 1,5 e de $782 \pm 574 \mathrm{mg} / \mathrm{L}$ para razão de 3,0 respectivamente, para o efluente. 


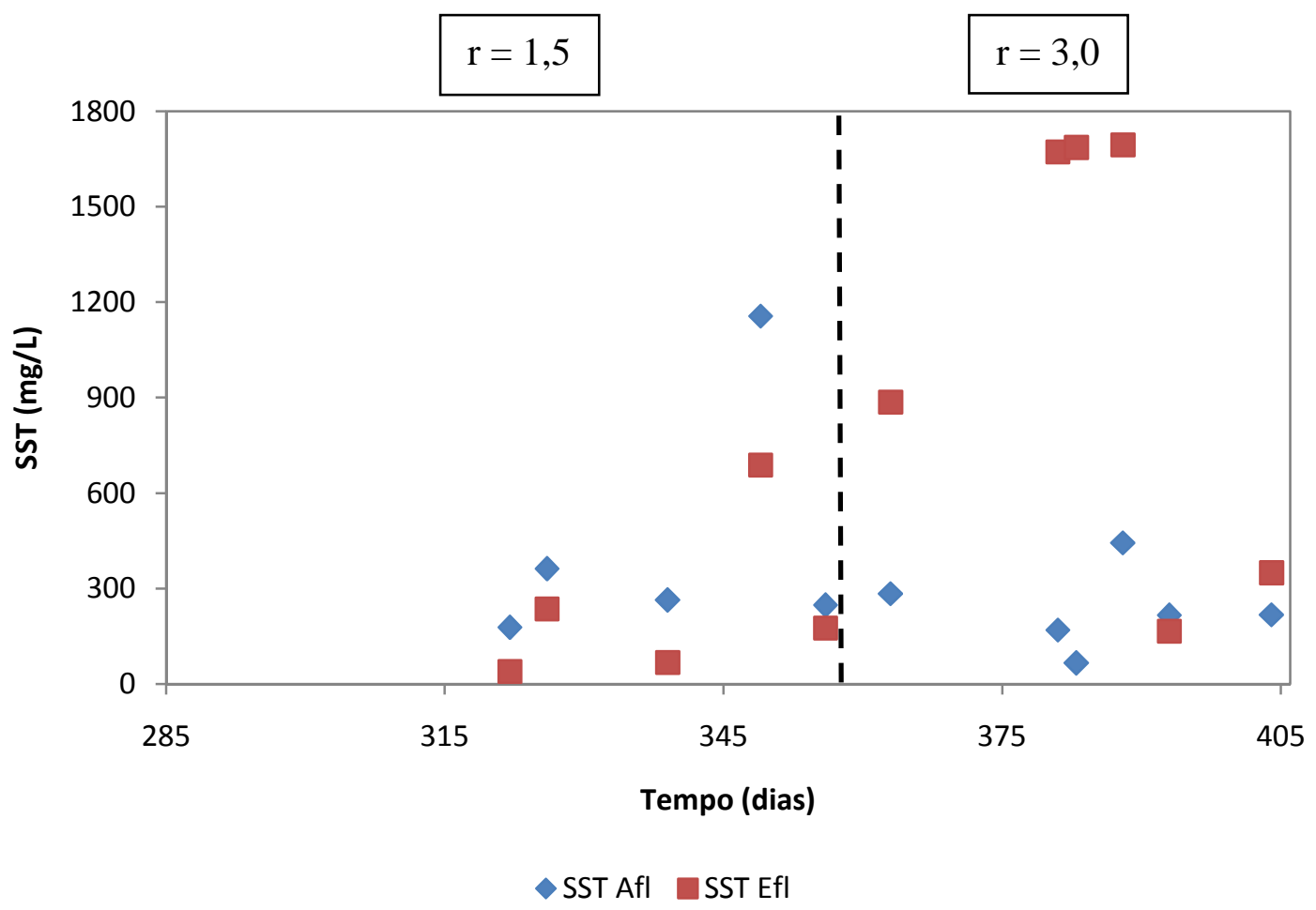

Figura 5.32 - Variação temporal da concentração de SST afluente e efluente para o reator de leito fixo operado de modo contínuo com TDH de 10 horas

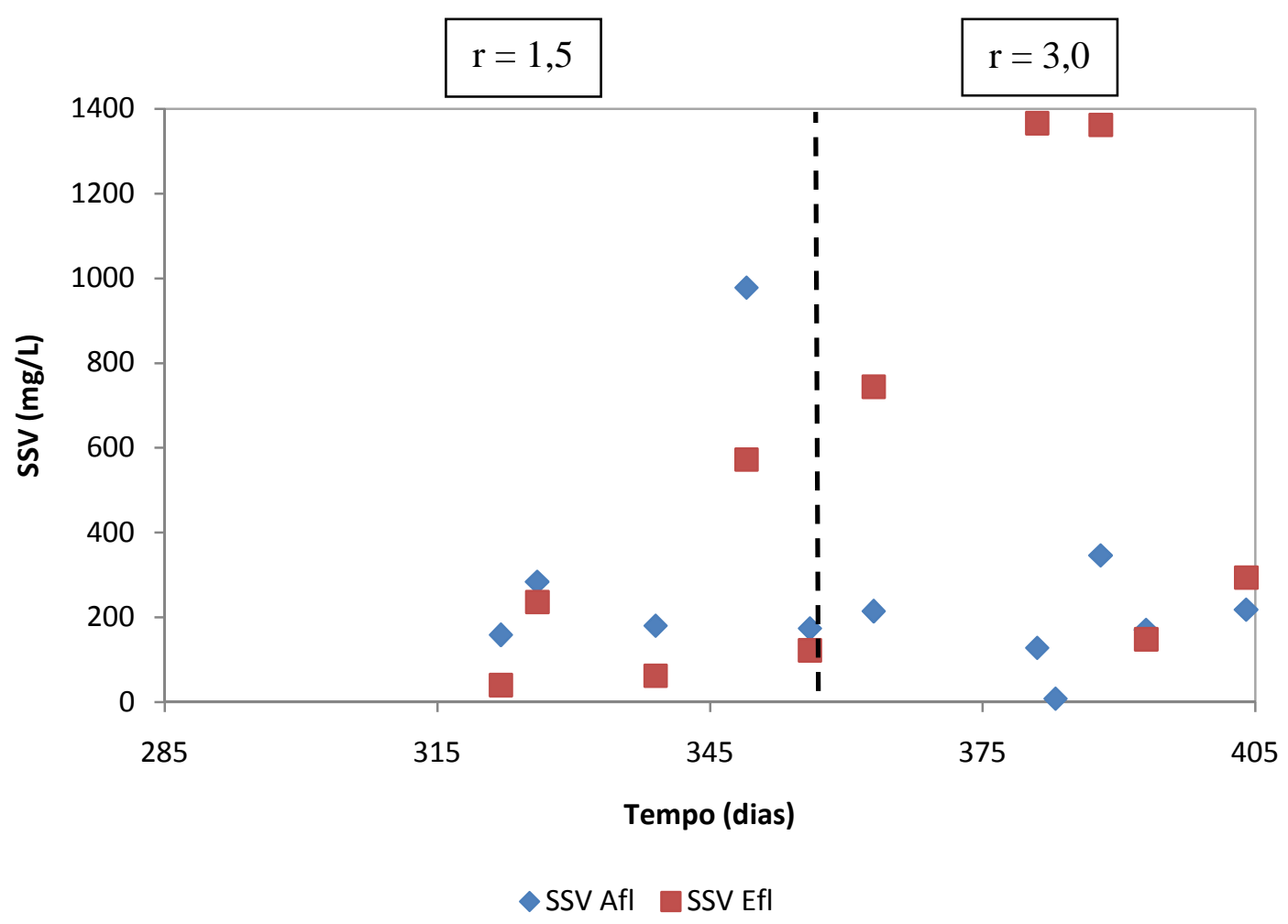

Figura 5.33 - Variação temporal da concentração de SSV afluente e efluente para o reator de leito fixo operado de modo contínuo com TDH de 10 horas 
Ao final da segunda etapa de operação não foram realizados perfis temporais e espaciais de DQO e N-Amon afluente e efluente como ocorrido ao final da primeira etapa operacional, já que o sistema não respondeu satisfatoriamente aos aumentos das cargas orgânica e nitrogenada aplicadas.

Com intuito de recuperar a performance do sistema, ao final desta etapa operacional foi realizado um descarte de fundo para posterior retomada do sistema, visto que o alto arraste de material particulado não cessou, ocasionando problemas no desempenho do reator combinado de leito fixo.

A redução do TDH de 12 horas para 10 horas, com conseqüente aumento da velocidade superficial de líquido no leito, não resultou em melhoria na eficiência do processo. Pelo contrário, houve instabilidade do processo de remoção de Nitrogênio e arraste de sólidos no efluente. Como conseqüência, os valores de DQO bruta efluente foram superiores aos encontrados na etapa com TDH total de 12 horas e o processo de desnitrificação foi afetado. A redução do TDH resultou em aumento na carga orgânica aplicada ao sistema e da velocidade superficial, fatores estes que podem ter interferido de forma significativa no rendimento do sistema. Pode-se dizer que os resultados obtidos nesta etapa não foram satisfatórios, tendo a etapa com TDH de 12 horas melhores resultados no que diz respeito à remoção de matéria orgânica e nitrogenada. $O$ próximo passo foi investigar a influência de outra redução no TDH para 8 horas.

No entanto, pela observação dos resultados de DQO efluente da amostra filtrada, pode-se dizer que o processo respondeu satisfatoriamente. O descarte de fundo e/ou a substituição de parte do material suporte, realizados de forma regular, podem resultar numa diminuição da perda de biomassa no efluente, a qual também afetou a remoção de nitrogênio. 
Caso o descarte de fundo tivesse sido realizado ao final da primeira etapa, assim como ocorreu ao término da etapa atual, talvez, os efeitos do crescimento excessivo de biomassa não tivessem ocorrido, ou ao menos teriam sido minimizados, melhorando a performance do sistema nesta etapa. Portanto, a investigação da influência de nova redução no TDH foi mantida conforme previsto no cronograma inicial, após descarte de fundo, na tentativa de recuperar o bom rendimento do sistema.

\subsubsection{Avaliação do desempenho do reator combinado operado com tempo de detenção}

\section{hidráulica de 8 horas}

Na terceira e última etapa de operação o TDH foi fixado em 8 horas, sendo 4,3 horas na camada anaeróbia $\left(1,37 \mathrm{~m}^{3}\right)$ e 3,7 horas na camada aeróbia $\left(1,18 \mathrm{~m}^{3}\right)$. Nesta etapa o TDH aplicado correspondeu a uma vazão de 5,32 L/min.

O período de operação para avaliação operacional do reator foi de 88 dias para esta etapa operacional, sendo 48 dias para a fase com recirculação de 1,5 e 40 dias com razão de recirculação igual a 3,0.

A aeração foi mantida a uma vazão constante de $50 \mathrm{~L} / \mathrm{min}$ assim como aconteceu para as etapas antecedentes.

A carga orgânica volumétrica (COV) aplicada ao sistema na terceira e última etapa da operação do reator combinado anaeróbio-aeróbio de leito fixo foi de 1,64 $\pm 0,53 \mathrm{~kg} . \mathrm{DQO} / \mathrm{m}^{3}$.dia, sendo calculada com base no volume reacional. Já a carga orgânica volumétrica removida ficou em torno de $1,10 \pm 0,21 \mathrm{~kg} . \mathrm{DQO} / \mathrm{m}^{3}$.dia, para $\mathrm{r}=1,5$ e $1,21 \pm 0,16 \mathrm{~kg} \cdot \mathrm{DQO} / \mathrm{m}^{3} \cdot$ dia, para $\mathrm{r}=3,0$.

Já a carga volumétrica de Nitrogênio Total (CVN) aplicada ao sistema nesta etapa operacional foi de $0,13 \pm 0,05 \mathrm{~kg} \cdot \mathrm{NTK} / \mathrm{m}^{3}$.dia, sendo calculada com base no volume reacional, enquanto a carga de Nitrogênio removida ficou em torno de 
$0,05 \pm 0,03 \mathrm{~kg} \cdot \mathrm{NTK} / \mathrm{m}^{3}$.dia para a fase com $\mathrm{r}=1,5$ e $0,04 \pm 0,02 \mathrm{~kg} \cdot \mathrm{NTK} / \mathrm{m}^{3}$.dia para $\mathrm{r}=3,0$.

A Tabela 5.3 apresenta os valores médios dos principais parâmetros para o esgoto sanitário usado como afluente e efluente durante a última etapa de operação, onde o reator foi operado de modo contínuo com recirculação do efluente tratado em diferentes razões e TDH total de 8 horas.

Tabela 5.3 - Comparação entre os valores afluentes e efluentes da terceira etapa operacional $(\mathrm{TDH}=8 \mathrm{~h})$.

\begin{tabular}{|c|c|c|c|}
\hline Parâmetros & Afluente & $\mathrm{r}=1,5$ & $\mathrm{r}=3,0$ \\
\hline $\mathrm{pH}$ & $6,93 \pm 0,21^{(15)}$ & $7,17 \pm 0,17^{(8)}$ & $7,26 \pm 0,13^{(7)}$ \\
\hline DQO Bruta (mg/L) & $577 \pm 203^{(15)}$ & $198 \pm 83^{(8)}$ & $143 \pm 53^{(7)}$ \\
\hline DQO Filtrada (mg/L) & $188 \pm 44^{(15)}$ & $80 \pm 21^{(8)}$ & $65 \pm 7^{(7)}$ \\
\hline Alc. Total (mg CaCO3/L) & $158 \pm 19^{(15)}$ & $150 \pm 14^{(8)}$ & $145 \pm 40^{(7)}$ \\
\hline Alc. a Bicarbonato (mg CaCO3/L) & $104 \pm 16^{(15)}$ & $126 \pm 9^{(8)}$ & $125 \pm 22^{(7)}$ \\
\hline AVT (mg HAc/L) & $76 \pm 14^{(15)}$ & $34 \pm 12^{(8)}$ & $46 \pm 22^{(7)}$ \\
\hline $\mathrm{NT}(\mathrm{mg} / \mathrm{L})$ & $44 \pm 17^{(15)}$ & $28 \pm 10^{(8)}$ & $32 \pm 6^{(6)}$ \\
\hline NTK (mg/L) & $42 \pm 17^{(15)}$ & $27 \pm 10^{(8)}$ & $31 \pm 7^{(6)}$ \\
\hline $\mathrm{NH}_{4}{ }^{+}(\mathrm{mg} / \mathrm{L})$ & $29 \pm 8^{(15)}$ & $27 \pm 4^{(8)}$ & $21 \pm 9^{(6)}$ \\
\hline $\mathrm{NO}_{2}^{-}(\mathrm{mg} / \mathrm{L})$ & - & - & - \\
\hline $\mathrm{NO}_{3}^{-}(\mathrm{mg} / \mathrm{L})$ & $1 \pm 0^{(15)}$ & $1 \pm 0^{(8)}$ & $1 \pm 1^{(6)}$ \\
\hline SST (mg/L) & $293 \pm 135^{(14)}$ & $114 \pm 53^{(7)}$ & $100 \pm 67^{(5)}$ \\
\hline $\mathrm{SSV}(\mathrm{mg} / \mathrm{L})$ & $218 \pm 87^{(14)}$ & $81 \pm 24^{(7)}$ & $84 \pm 61^{(5)}$ \\
\hline
\end{tabular}

Nota: Os números entre parênteses referem-se à quantidade de dados utilizados no cálculo das médias. 
A Figura 5.34 mostra os valores de DQO de amostras bruta e filtrada, variando ao longo do período operacional com TDH total de 8 horas, para afluente e para o efluente.

Pode-se observar que a remoção de matéria orgânica foi superior à encontrada na etapa anterior, porém não removida eficientemente no reator de leito fixo - como esperado para sistemas aeróbios tratando esgoto sanitário onde se atingem remoções superiores a $80 \%$ - operando em condição anaeróbia seguida de aeróbia e com razão de recirculação como ocorrido na primeira etapa operacional. Pode-se observar que os valores obtidos para o efluente, para amostras brutas e filtradas, foram relativamente constantes durante todo o período operacional, excetuando-se dois pontos onde apresentaram picos relacionados à alta concentração de sólidos no efluente, comprovados pelos gráficos da variação temporal de SST e SSV apresentados nas Figuras 5.42 e 5.43, respectivamente. Apesar da aparente estabilidade, os valores médios efluentes para DQO de amostra bruta e filtrada foram maiores comparando-se com a etapa inicial, quando o reator operou de forma combinada com TDH total de 12 horas, demonstrando que o aumento da carga orgânica aplicada ao sistema não foi benéfica para o processo.

Em relação à segunda etapa operacional, percebe-se claramente melhor desempenho quando da redução do TDH, porém, ressalta-se a realização de descarte de fundo antes do início operacional da última etapa de estudo, o que provavelmente reduziu os efeitos do crescimento excessivo de biomassa, redução dos espaços vazios e arraste de sólidos.

O efluente apresentou valor médio de DQO de amostra bruta de $198 \pm 93 \mathrm{mg} / \mathrm{L}$ para a fase com $r=1,5$ e de $143 \pm 53 \mathrm{mg} / \mathrm{L}$ para $\mathrm{r}=3,0$. 
As Demandas Químicas de Oxigênio nas amostras filtradas do efluente mantiveram-se estáveis em relação à mudança de razão de recirculação e durante todo período operacional. O valor médio da DQO filtrada efluente para a fase com $r=1,5$ foi $80 \pm 21 \mathrm{mg} / \mathrm{L}$ enquanto para $\mathrm{r}=3,0$ foi $65 \pm 7 \mathrm{mg} / \mathrm{L}$. Pode-se observar que houve melhora na eficiência de remoção de matéria orgânica do sistema após aumento da vazão de recirculação.

Constata-se pela Figura 5.35 e Tabela 5.3 que as eficiências alcançadas para o reator anaeróbio-aeróbio com TDH de 8 horas, calculadas a partir da média do afluente bruto durante este período operacional, não foram melhores que a etapa anterior com TDH de 12 horas. Não houve melhora na transferência de massa pelo aumento da velocidade superficial do líquido no leito, se comparado os TDH aplicados, já se a comparação for feita nesta etapa, conclui-se que houve melhora na remoção de matéria orgânica quando se elevou a razão de recirculação.

Essa melhora constatada também na primeira etapa operacional do sistema foi evidenciada por Rojas et al. (2008) que estudaram comportamento da produção de metano $\left(\mathrm{CH}_{4}\right)$ em lodo anaeróbio-anóxico de reator combinado anaeróbio-aeróbio de leito fixo, operado de modo contínuo, aplicado ao tratamento de esgoto sanitário com diferentes razões de recirculação da fase líquida para remover carbono e nitrogênio. Foram realizados ensaios de atividade metanogênica específica (AME) adaptados de vários autores sendo a medição da concentração do metano realizada mediante cromatografia gasosa. Ao final dos experimentos observou-se que a presença de oxigênio dissolvido, promovida pela recirculação da fase líquida, não inibiu o comportamento dos organismos metanogênicos e a velocidade de produção de $\mathrm{CH}_{4}$ foi maior em comparação aos resultados obtidos na fase em que o reator operou de forma anaeróbia. Foi observado, também, aumento da velocidade inicial de produção de 
metano, comparando-se as fases com razão de recirculação de 0,5 e 1,5 e posterior estabilização, o que também enfatiza maior velocidade de crescimento específico das bactérias facultativas em relação às arqueas metanogênicas.

Pontes et al. (2009) estudaram o efeito do retorno de lodo aeróbio sobre as características da biomassa presente em reatores UASB tratando esgoto sanitário e também não verificaram influência negativa na atividade metanogênica específica.

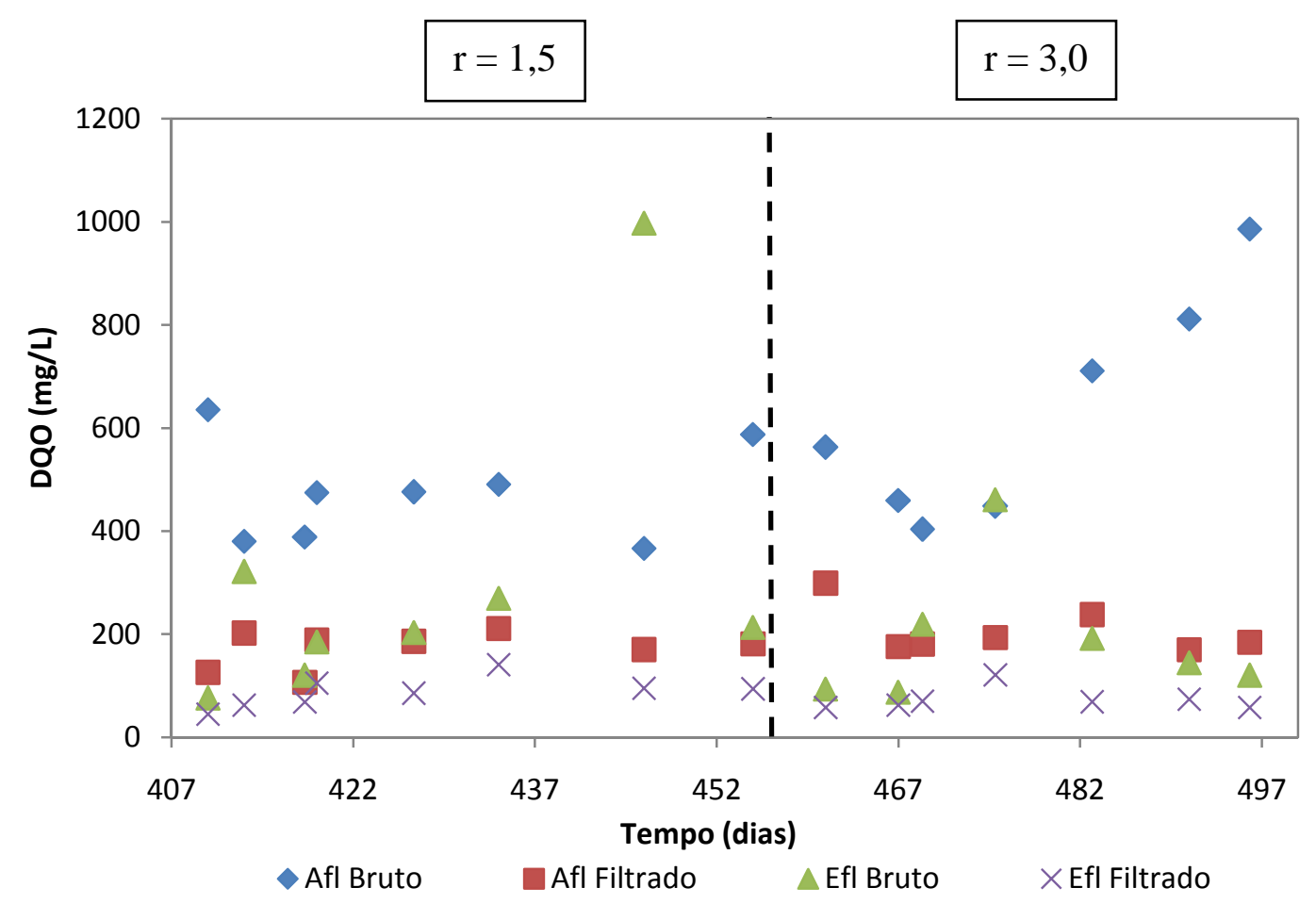

Figura 5.34 - Variação temporal da DQO para o reator de leito fixo operado de modo contínuo com TDH de 8 horas 


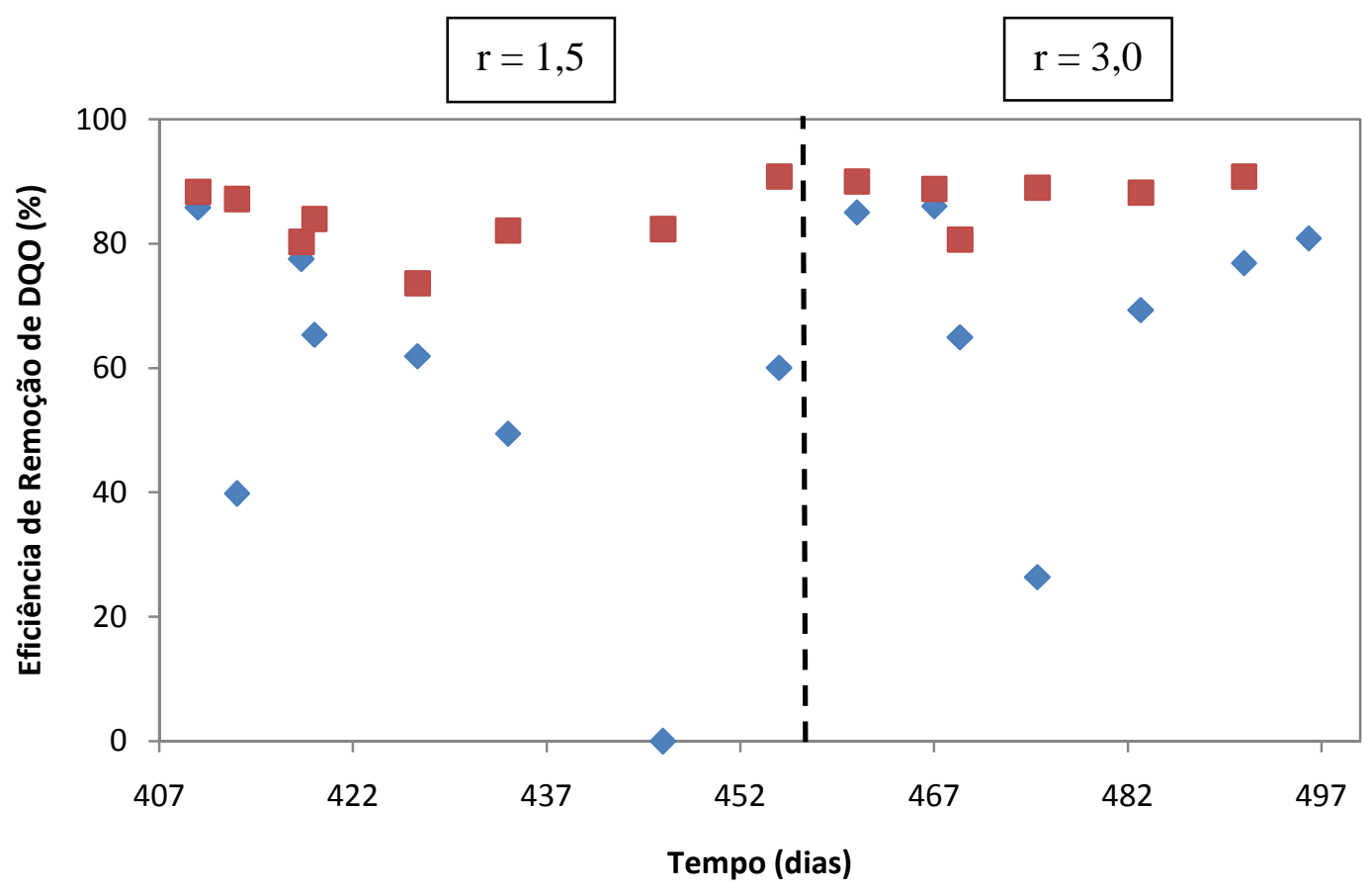

$\diamond$ Eficiência Bruta Eficiência Filtrada

Figura 5.35 - Eficiências de remoção de DQO ao longo do tempo para o reator de leito fixo operado de modo contínuo com TDH de 8 horas

Para observar a estabilidade do reator, foi monitorada a variação temporal da concentração da Alcalinidade a Bicarbonato (Figura 5.36) e dos Ácidos Voláteis Totais (Figura 5.41).

Em praticamente todo o processo, como mostra a Figura 5.36, a Alcalinidade a Bicarbonato foi maior no efluente que no afluente. O valor médio para o afluente foi $104 \pm 16 \mathrm{mgCaCO}_{3} / \mathrm{L}$ e para o efluente foi $126 \pm 9 \mathrm{mgCaCO}_{3} / \mathrm{L}$ para razão de recirculação igual a 1,5 e de $125 \pm 22 \mathrm{mgCaCO} / \mathrm{L}$ para razão igual a 3,0. 


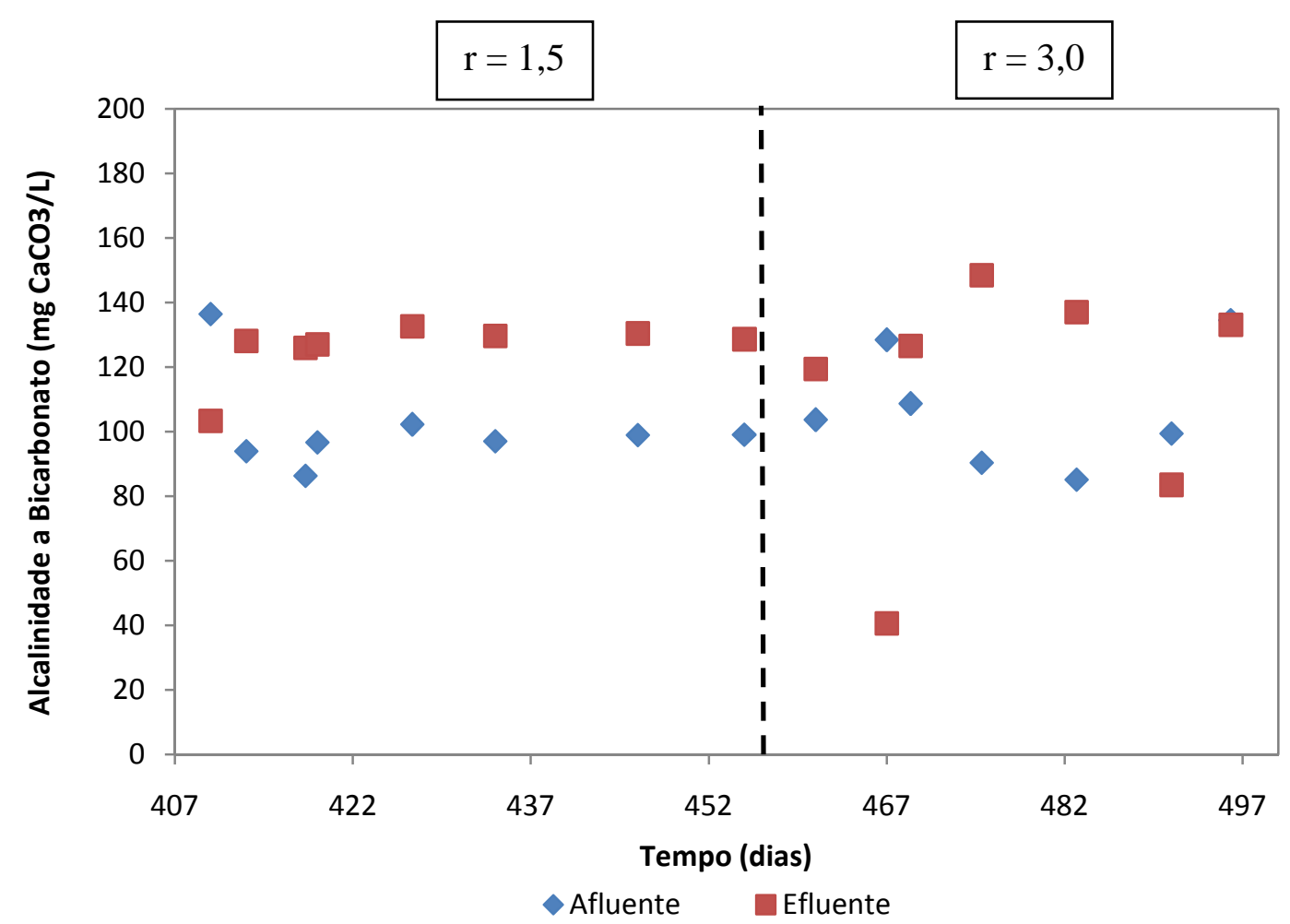

Figura 5.36 - Variação temporal da Alcalinidade a Bicarbonato afluente e efluente para o reator de leito fixo operado de modo contínuo com TDH de 8 horas

As Figuras 5.37 e 5.38 mostram as concentrações afluentes e efluentes de $\mathrm{N}$-NTK e N-Amon. Os valores médios efluentes de N-NTK e N-Amon, foram $27 \pm 10 \mathrm{mg} / \mathrm{L}, 31 \pm 7 \mathrm{mg} / \mathrm{L}$; e $27 \pm 4 \mathrm{mg} / \mathrm{L}, 21 \pm 9 \mathrm{mg} / \mathrm{L}$ para razão de recirculação de 1,5 e 3,0 respectivamente. Apesar de ter havido melhora na remoção de matéria orgânica quando foi elevada a razão de recirculação, observa-se que o mesmo não ocorreu para a remoção de Nitrogênio. Vale ressaltar que estes valores estão fora dos padrões de lançamento de efluentes exigidos pela legislação ambiental vigente, já que segundo a resolução $n^{\circ}$ 357/05 do Conselho Nacional do Meio Ambiente (CONAMA), o valor máximo para emissões de nitrogênio amoniacal é de $20 \mathrm{mg} / \mathrm{L}$.

Pode-se observar pelos valores médios afluentes, $42 \pm 17 \mathrm{mg} / \mathrm{L}$ para N-NTK e $29 \pm 8 \mathrm{mg} / \mathrm{L}$ para $\mathrm{N}$-Amon, que a maior parte do nitrogênio afluente encontrava-se na 
forma amoniacal. A Figura 5.38 mostra a variação do nitrogênio orgânico (N-Org), calculado pela subtração do N-NTK pelo N-Amon, ao longo do tempo, juntamente com o N-NTK e N-Amon efluentes. Confirmou-se que o N-Org, na maior parte do tempo, representou parcela mínima do Nitrogênio tanto para o afluente como para o efluente, assim como ocorreu na etapa anterior.

$\mathrm{Na}$ Figura 5.39 são observados os resultados de $\mathrm{N}-\mathrm{NO}_{2}{ }^{-}$e $\mathrm{N}_{-\mathrm{NO}_{3}}{ }^{-}$, respectivamente. As concentrações efluentes de nitrito e nitrato variaram com o aumento da vazão de recirculação aplicada ao sistema. $O$ processo de nitrificação/desnitrificação foi bastante afetado pelo arraste de sólidos observado no efluente durante esta etapa operacional.

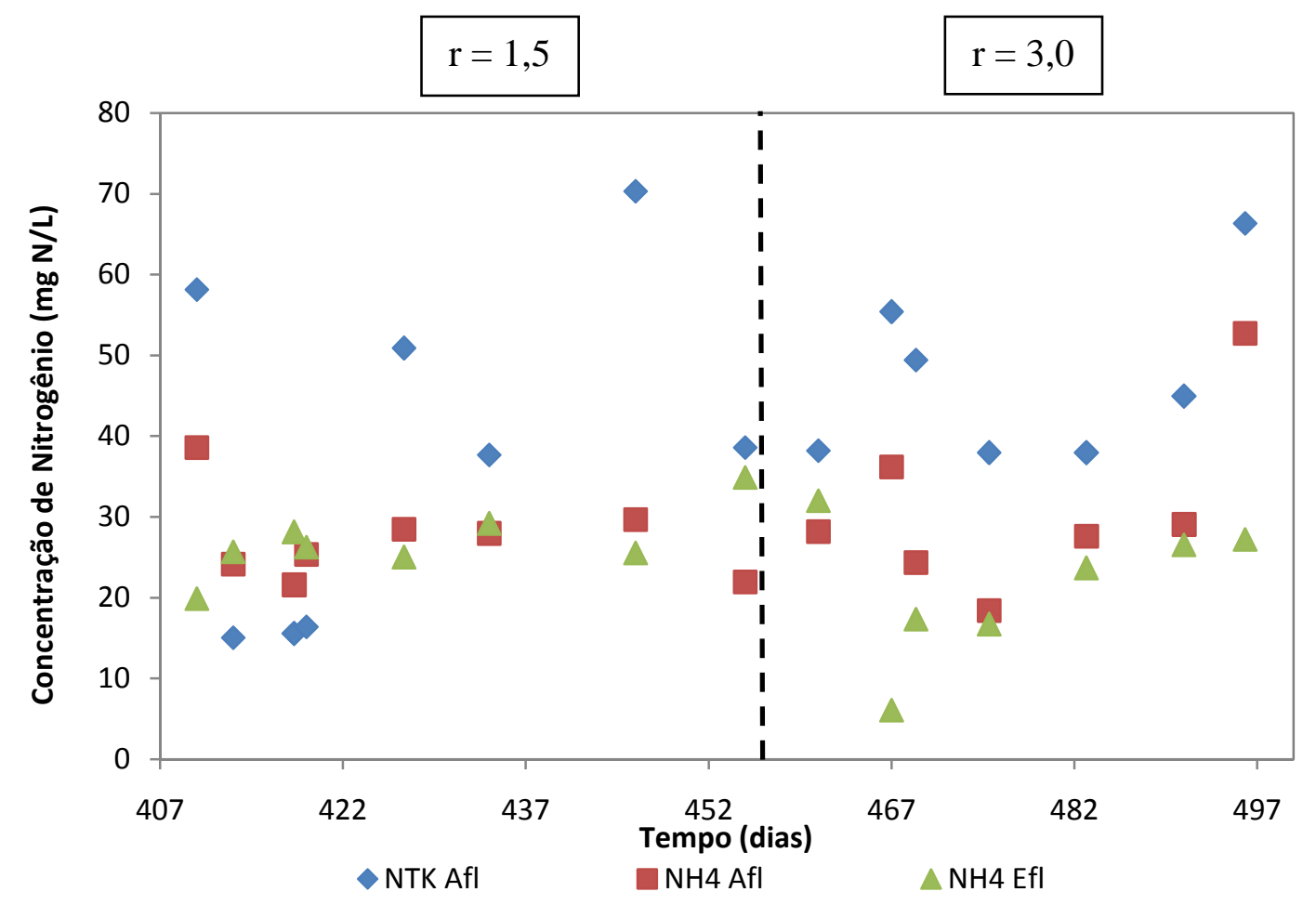

Figura 5.37 - Variação temporal da concentração das formas de Nitrogênio para o reator de leito fixo operado de modo contínuo com TDH de 8 horas 


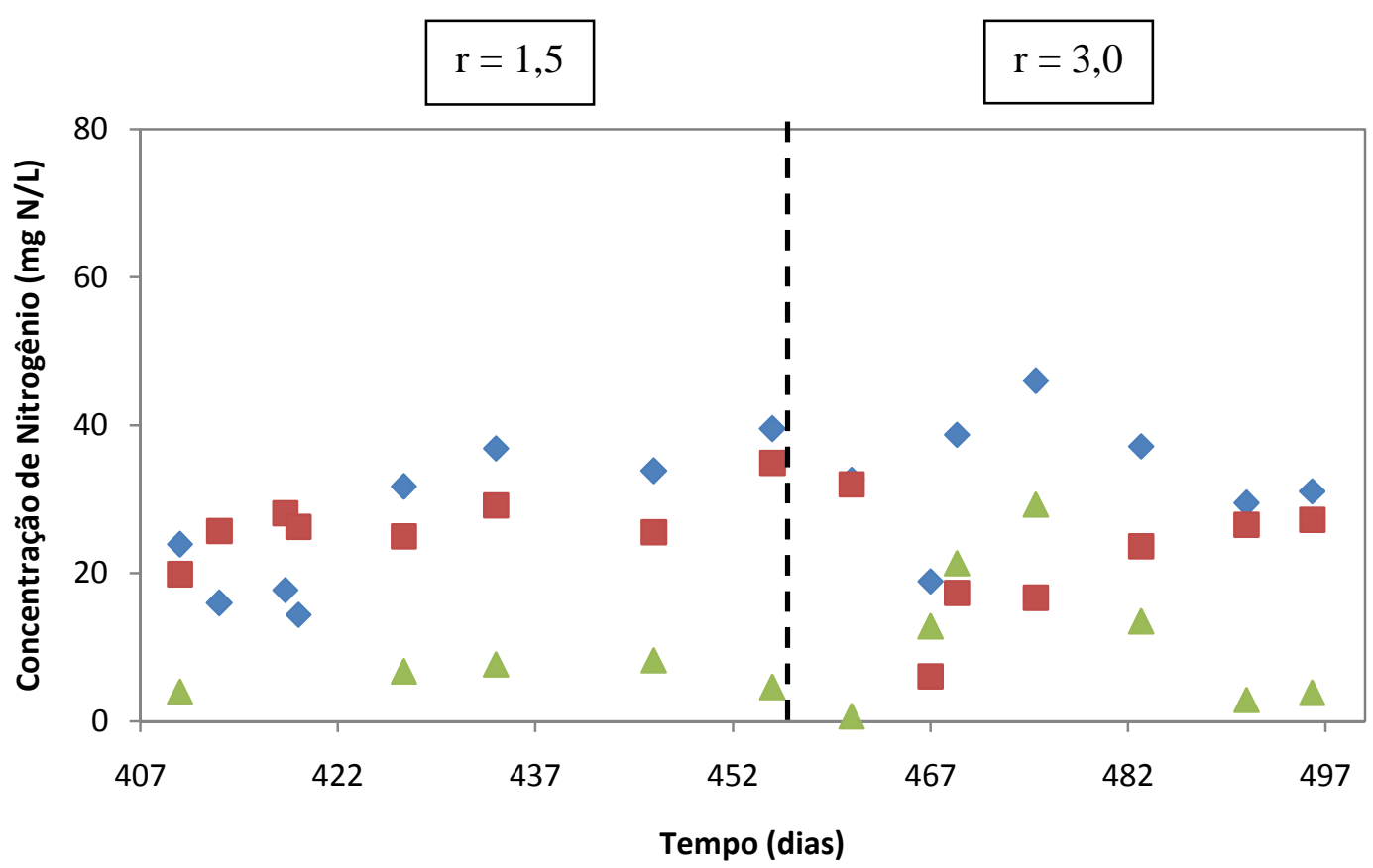

$\diamond \mathrm{NTK}$ Efl $\square \mathrm{NH} 4+\mathrm{Efl} \quad \triangle \mathrm{N}-\mathrm{Org} \mathrm{Efl}$

Figura 5.38 - Variação temporal das concentrações efluentes das formas de Nitrogênio para o reator de leito fixo operado de modo contínuo com TDH de 8 horas

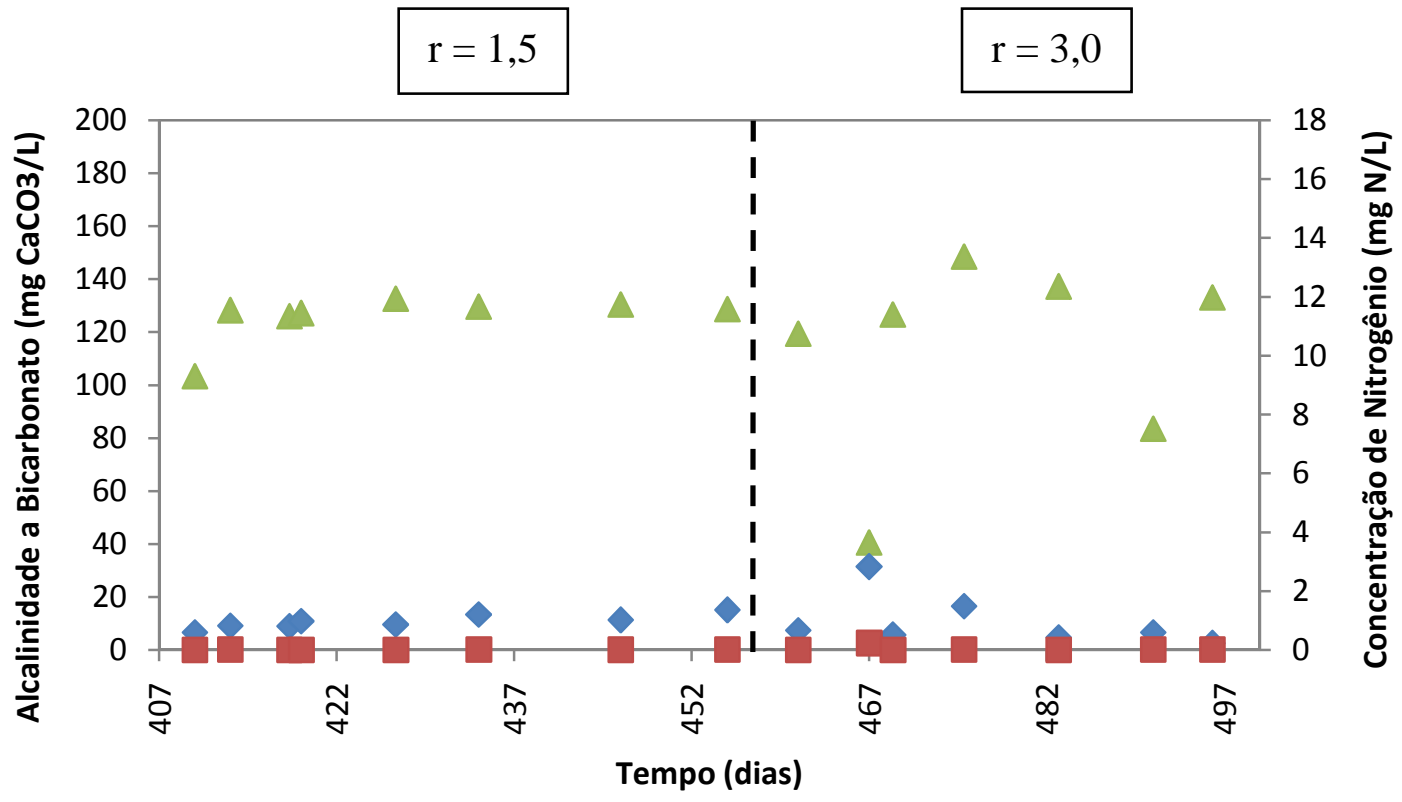

$\triangle$ Alc Efluente $\diamond \mathrm{NO} 3-\mathrm{Efl} \square \mathrm{NO} 2-\mathrm{Efl}$

Figura 5.39 - Variação temporal das concentrações efluentes de Nitrito, Nitrato e alcalinidade para o reator de leito fixo operado de modo contínuo com TDH de 8 horas 
Nesta última etapa de operação com TDH total de 8 horas o pH efluente foi maior que o afluente durante praticamente todo o período. $\mathrm{O}$ valor médio do $\mathrm{pH}$ afluente ficou em $6,93 \pm 0,21$. Já o efluente ficou em $7,17 \pm 0,17$ para razão igual a 1,5 e 7,26 $\pm 0,13$ para razão igual a 3,0. A Figura 5.40 mostra a variação temporal do pH afluente e efluente para o reator de leito fixo operado de modo contínuo.

Para avaliação da estabilidade do reator, também observou-se a variação temporal da concentração de Ácidos Voláteis Totais (AVT) assim como feito com a alcalinidade a bicarbonato.

Pela Figura 5.41 é possível verificar que desde o primeiro dia operacional com TDH total de 8 horas o valor da concentração de AVT do efluente foi menor que do afluente, excetuando-se apenas um ponto deste espaço amostral. O valor médio para o afluente foi $76 \pm 14 \mathrm{mgHAc} / \mathrm{L}$ e para o efluente foi $34 \pm 12 \mathrm{mgHAc} / \mathrm{L}$ para razão de recirculação igual a 1,5 e $46 \pm 22$ mgHAc/L para razão de recirculação igual a 3,0.

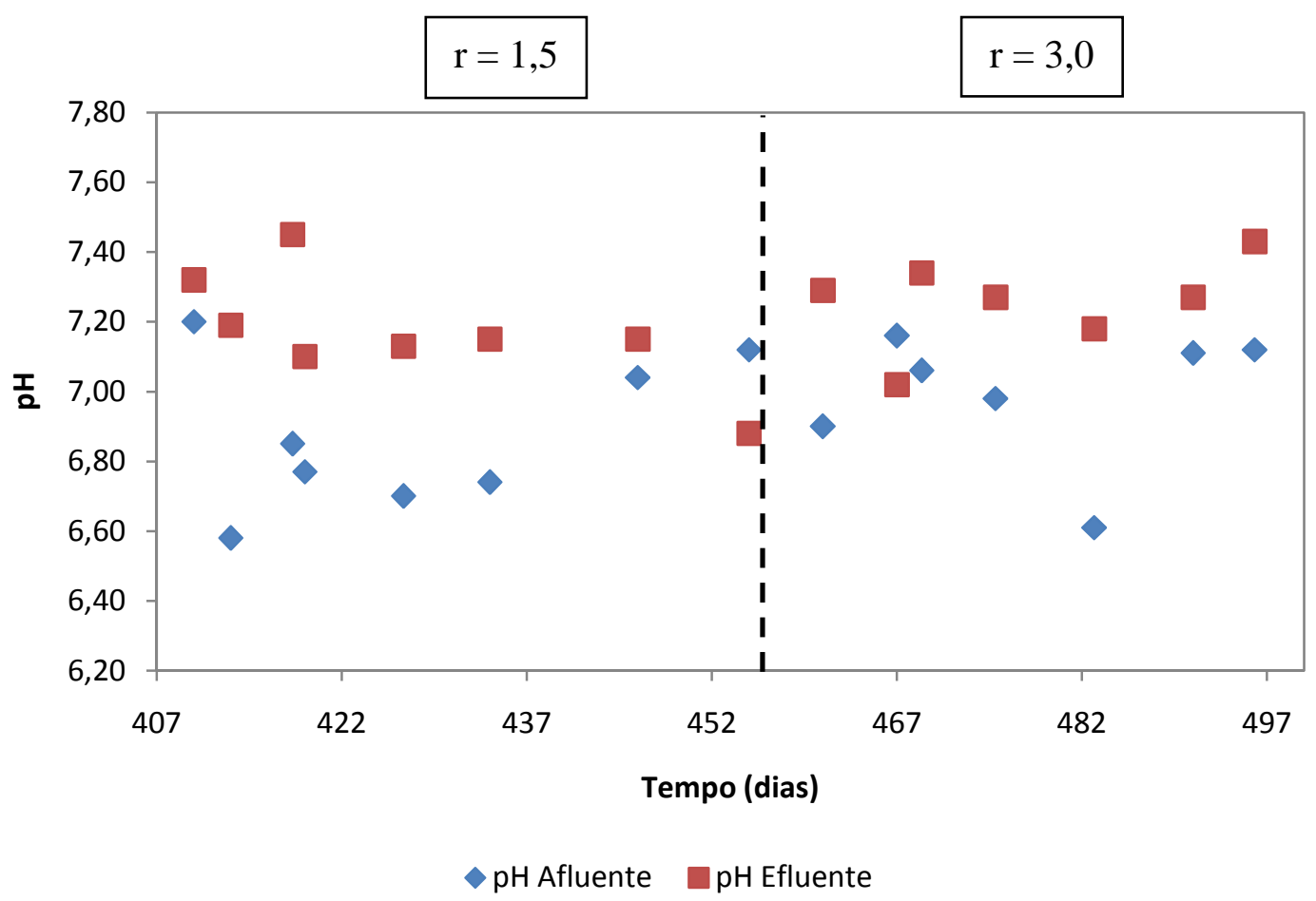

Figura 5.40 - Variação temporal do pH afluente e efluente para o reator de leito fixo operado de modo contínuo com TDH de 8 horas 


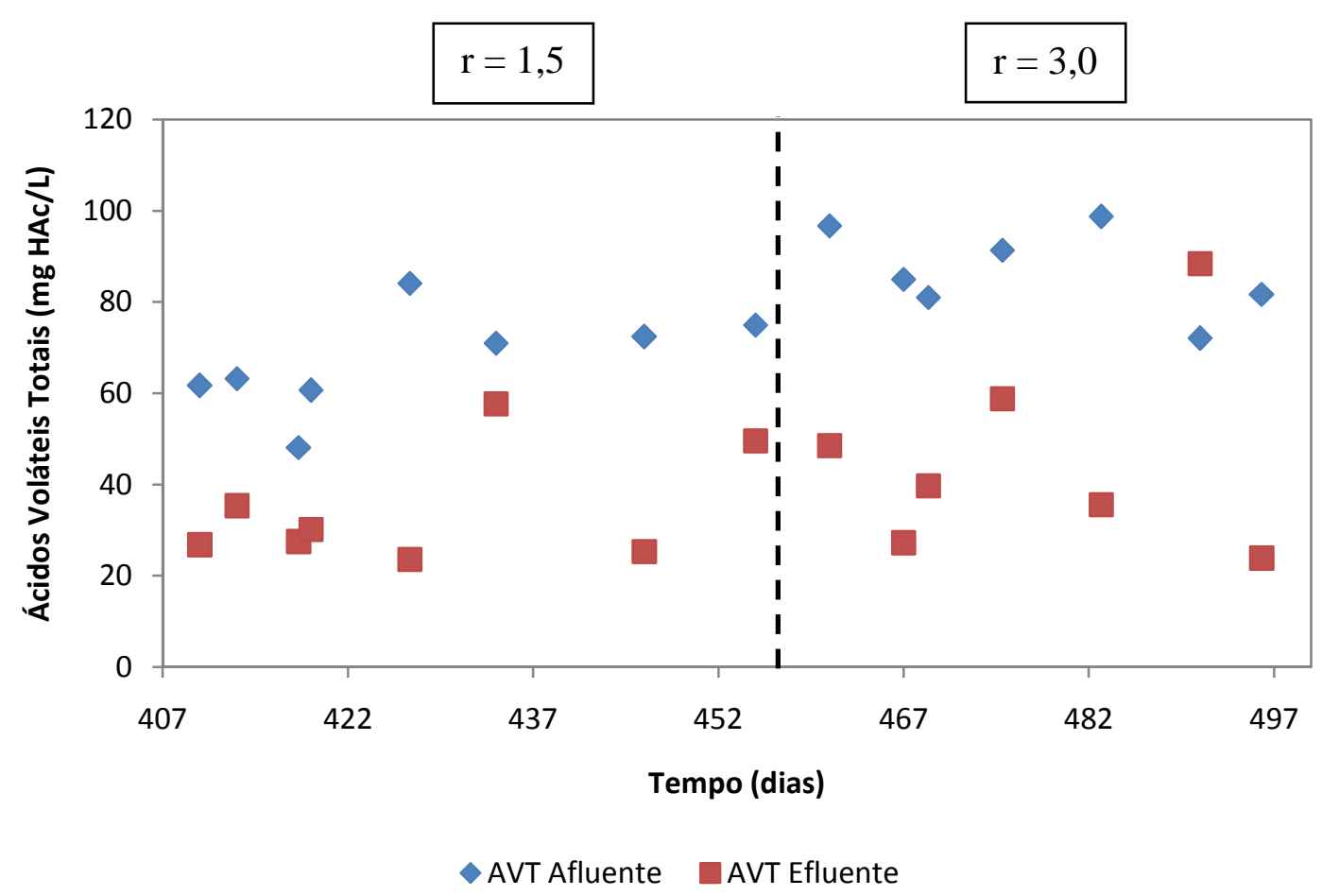

Figura 5.41 - Variação temporal da concentração de AVT afluente e efluente para o reator de leito fixo operado de modo contínuo com TDH de 8 horas

Nas Figuras 5.42 e 5.43 estão apresentados os valores de Sólidos Suspensos Totais (SST) e Sólidos Suspensos Voláteis (SSV) para a última etapa operacional. Podese observar certa similaridade entre o comportamento dos SST e dos SSV, excluindo-se os casos pontuais de arraste excessivo de sólidos no efluente. A média de SST afluente foi de $293 \pm 135 \mathrm{mg} / \mathrm{L}$ e efluente de $114 \pm 53 \mathrm{mg} / \mathrm{L}$ para razão igual a 1,5 e de $100 \pm 67$ mg/L para razão de 3,0, respectivamente. Para SSV, a média foi de $218 \pm 87 \mathrm{mg} / \mathrm{L}$ para o afluente e de $81 \pm 24 \mathrm{mg} / \mathrm{L}$ para razão igual a 1,5 e de $84 \pm 61 \mathrm{mg} / \mathrm{L}$ para razão de 3,0, respectivamente, para o efluente. 


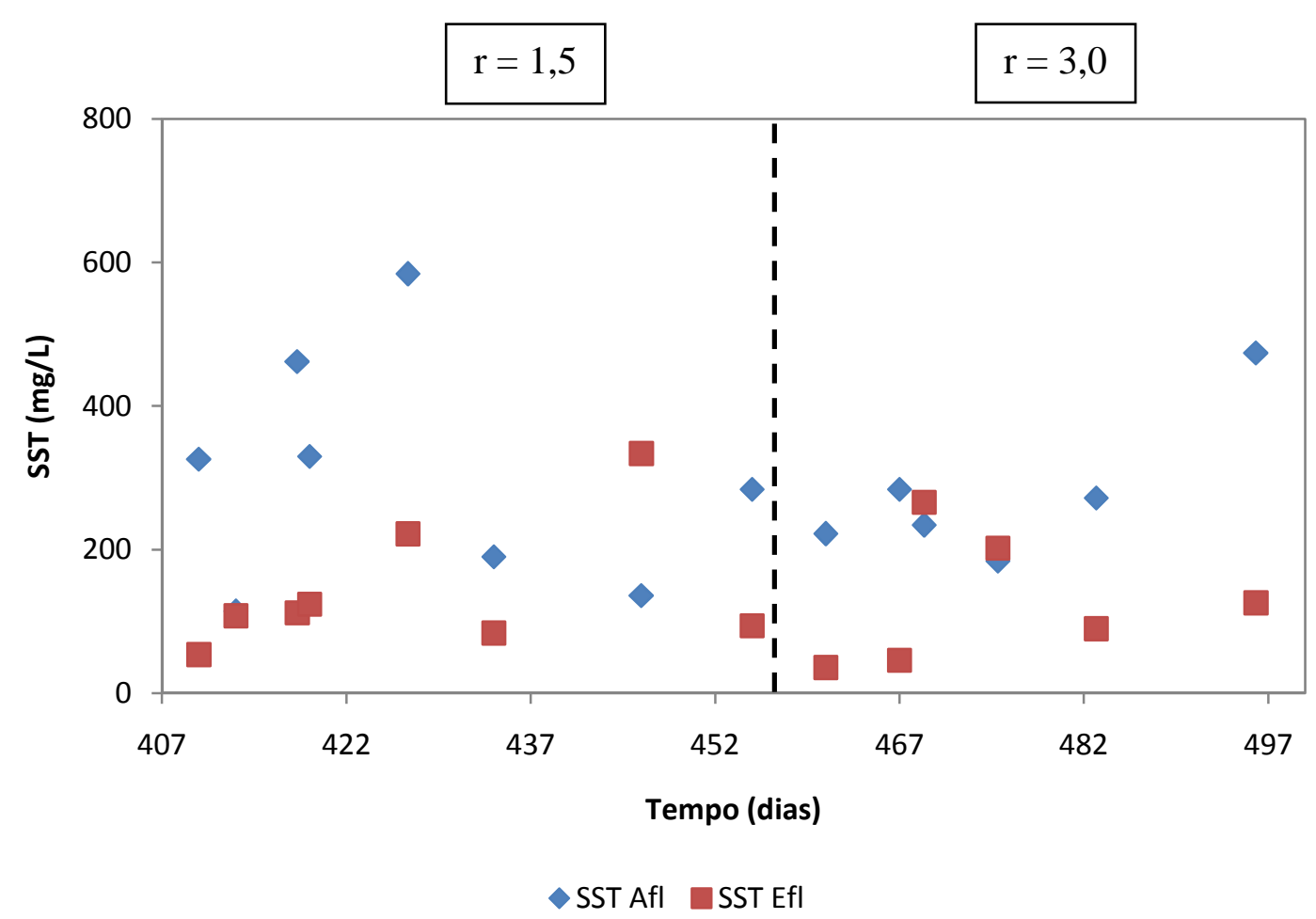

Figura 5.42 - Variação temporal da concentração de SST afluente e efluente para o reator de leito fixo operado de modo contínuo com TDH de 8 horas

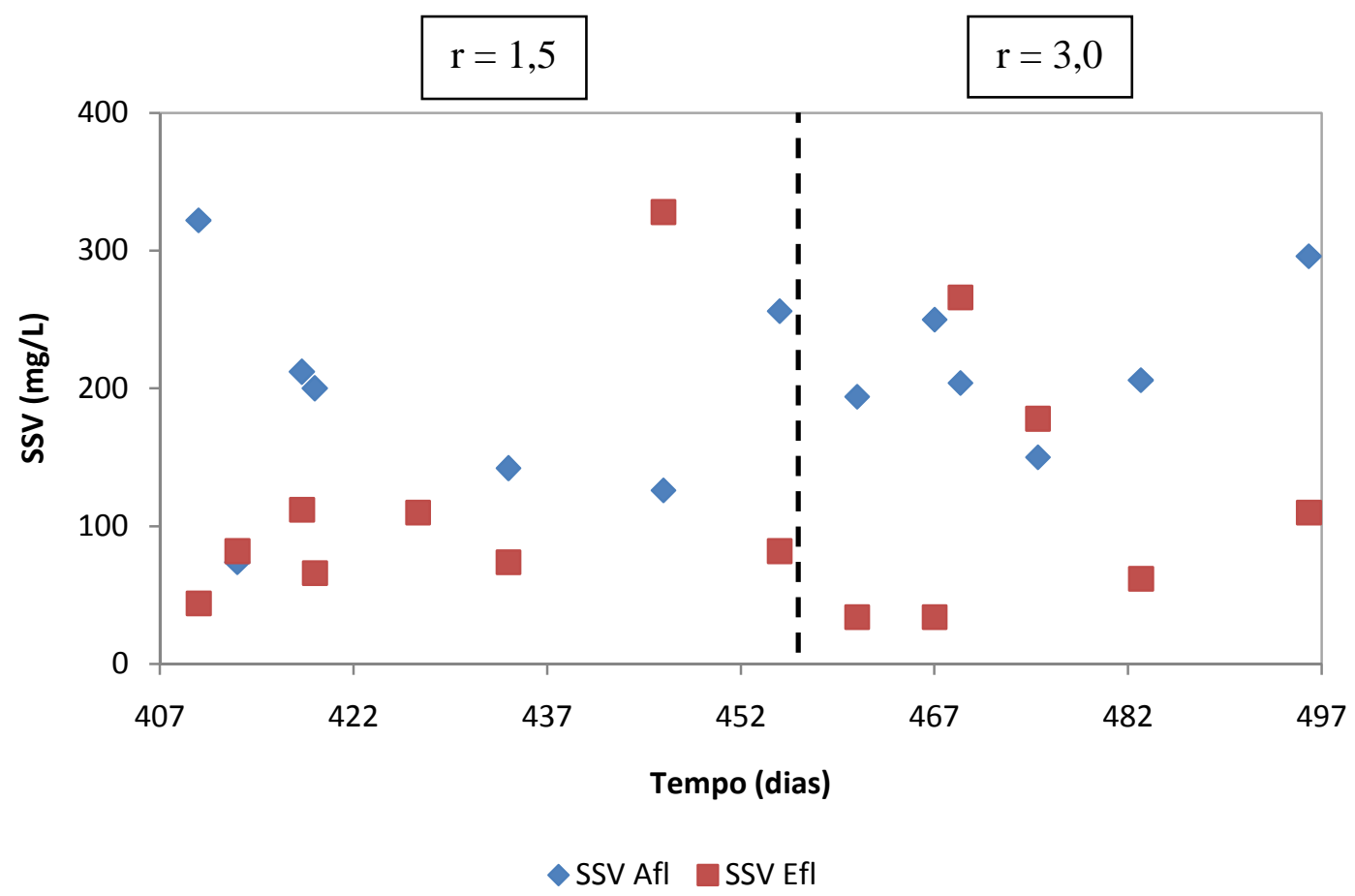

Figura 5.43 - Variação temporal da concentração de SSV afluente e efluente para o reator de leito fixo operado de modo contínuo com TDH de 8 horas 
Ao final da terceira e última etapa de operação foram realizados perfis temporais e espaciais de DQO e N-Amon afluente e efluente. O valor médio da DQO do esgoto sanitário afluente foi de $786 \pm 140 \mathrm{mg} / \mathrm{L}$ para amostra bruta e o efluente de $181 \pm 62 \mathrm{mg} / \mathrm{L}$ e de $73 \pm 23 \mathrm{mg} / \mathrm{L}$ para amostra bruta e filtrada, respectivamente. Já o $\mathrm{N}$-Amon afluente foi de $27 \pm 3 \mathrm{mg} / \mathrm{L}$ e de $26 \pm 2 \mathrm{mg} / \mathrm{L}$ para o efluente. Os resultados dos dois perfis realizados são apresentados nas Figuras 5.44, 5.45, 5.46 e 5.47.

Os resultados obtidos por meio desses perfis mostram que, para amostras brutas e filtradas, os valores da DQO efluente tiveram maior variação, ao longo do dia, se comparados aos resultados encontrados na primeira etapa operacional. Comprova-se, também, a perda de eficiência na remoção de matéria orgânica, em relação à etapa inicial do sistema e a não efetivação do processo de conversão de Nitrogênio.

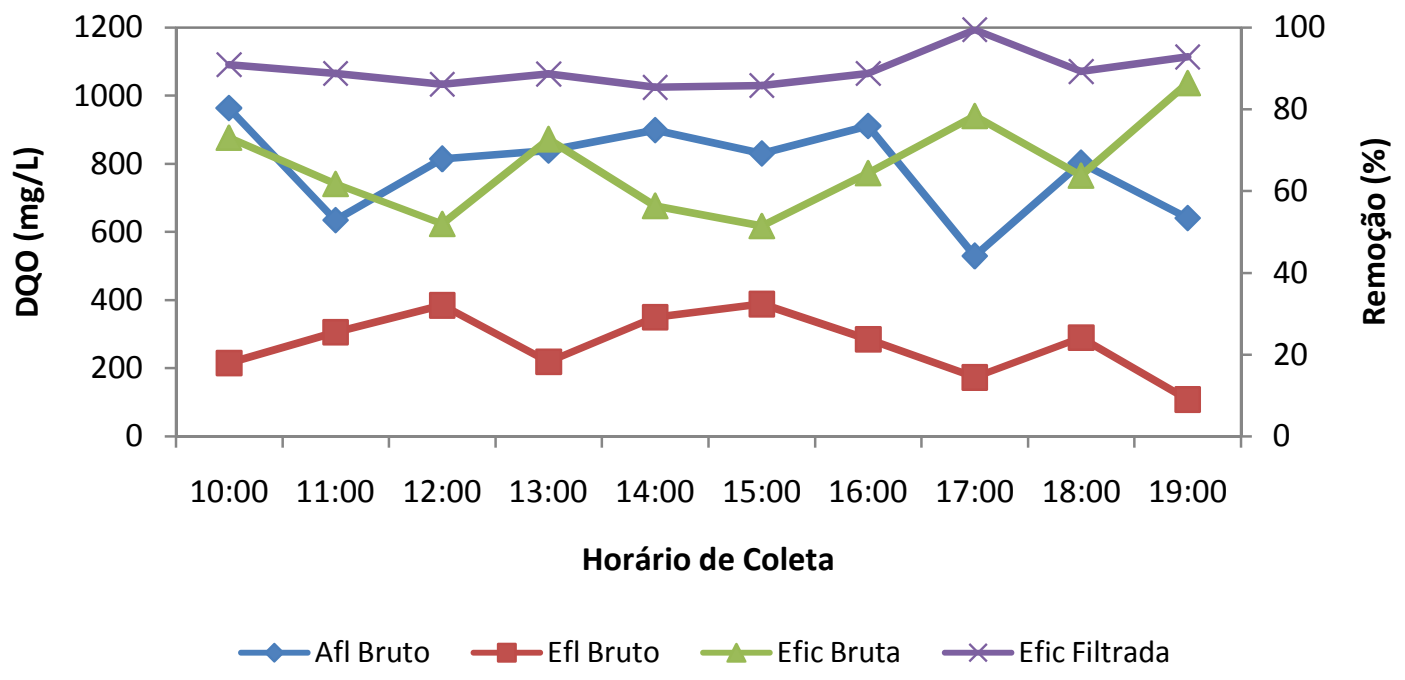

Figura 5.44 - Perfil temporal de DQO, para esgoto doméstico afluente e efluente para o reator de leito fixo operado de modo contínuo com TDH de 8 horas e $r=3,0$ 


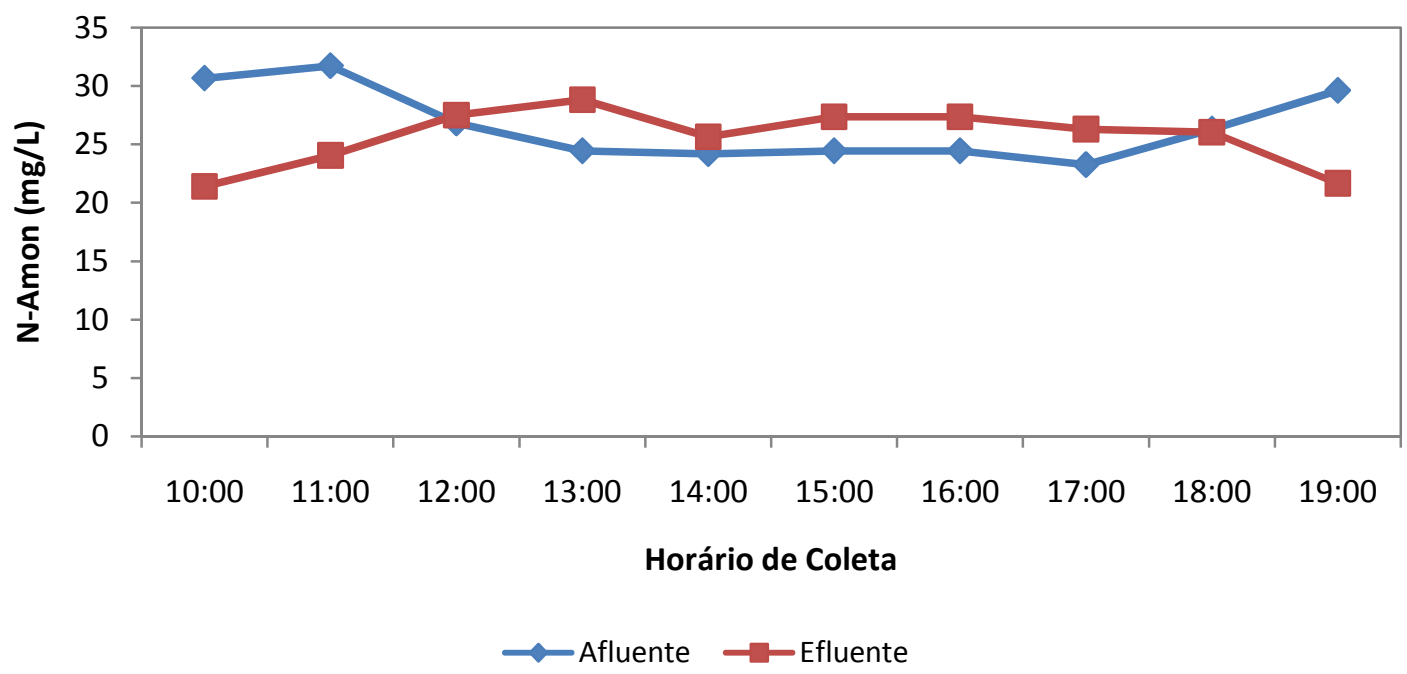

Figura 5.45 - Perfil temporal de Nitrogênio Amoniacal, para esgoto doméstico afluente e efluente para o reator de leito fixo operado de modo contínuo com TDH de 8 horas e

$$
r=3,0
$$

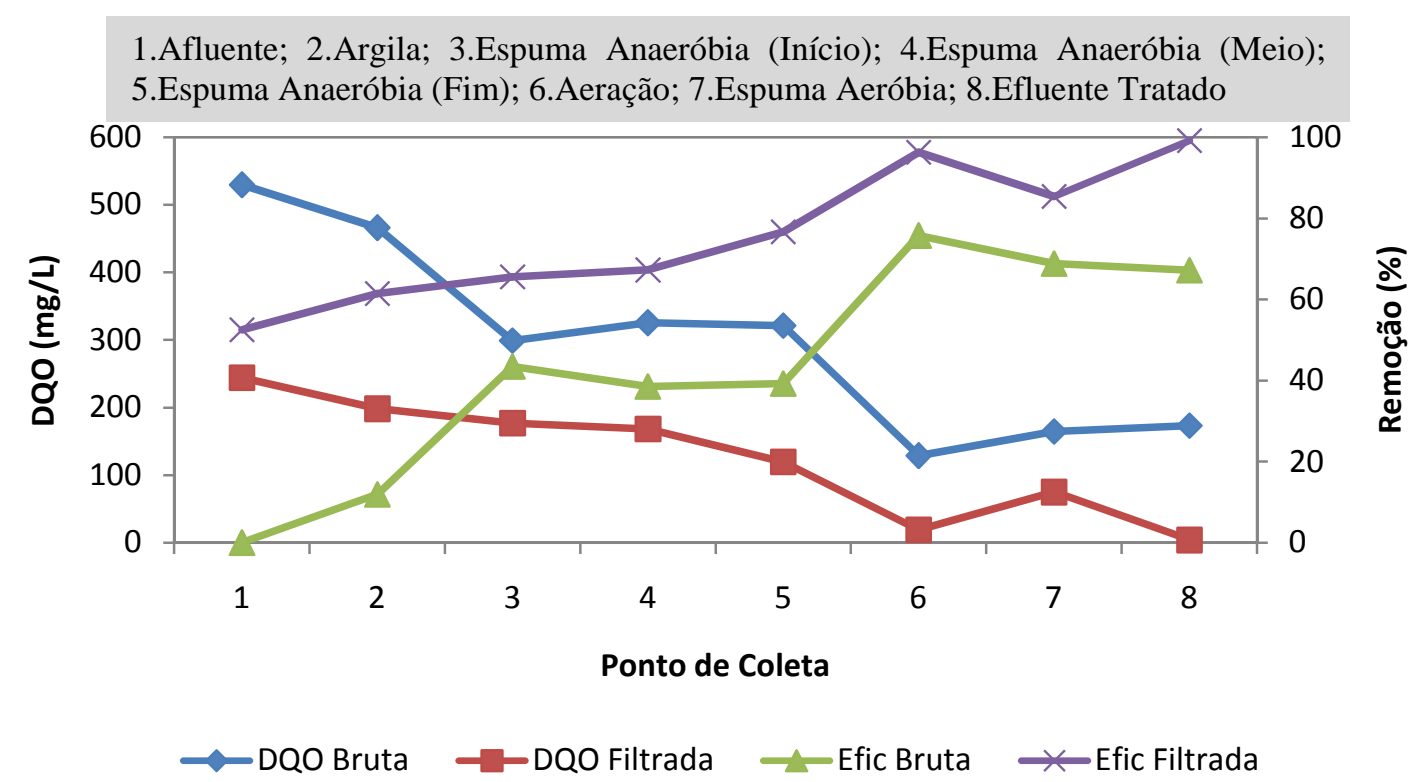

Figura 5.46 - Perfil espacial de DQO para o reator de leito fixo operado de modo contínuo com TDH de 8 horas e $\mathrm{r}=3,0$ 


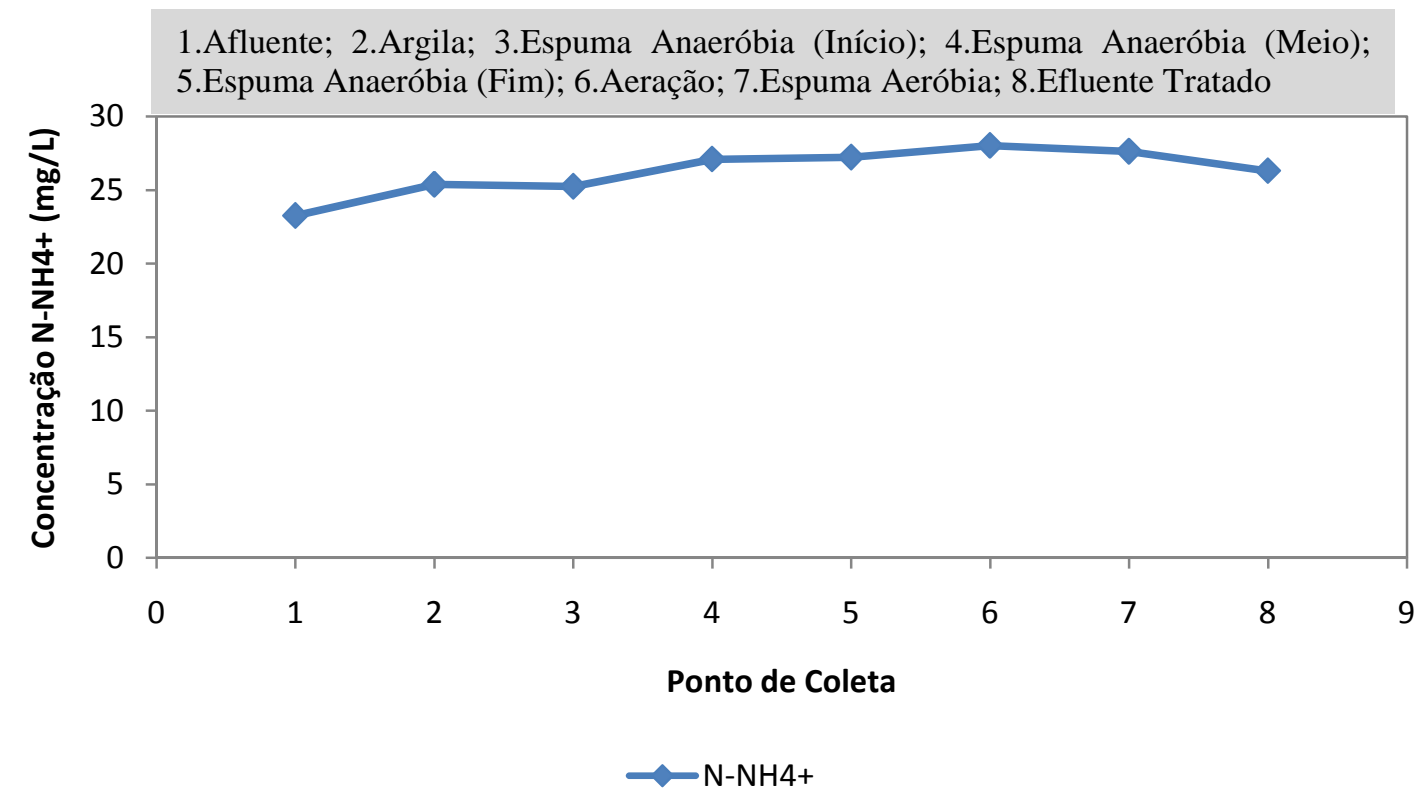

Figura 5.47 - Perfil espacial de Nitrogênio Amoniacal para o reator de leito fixo operado de modo contínuo com TDH de 8 horas e $\mathrm{r}=3,0$

Na Figura 5.48, são apresentados os resultados obtidos com auxílio da sonda multiparâmetros YSI modelo 556 e do software EcoWatch versão 3.18. O ensaio foi realizado ao final da operação do sistema e durou 24 horas. $\mathrm{O}$ pH efluente apresentou média de 7,17 $\pm 0,03$ com valor máximo de 7,25 e mínimo de 7,11. Já o oxigênio dissolvido teve média de 1,37 \0,84 mg/L com valor máximo de 3,12 mg/L e mínimo de $0,33 \mathrm{mg} / \mathrm{L}$. Durante o ensaio a temperatura mínima atingida pelo efluente tratado foi de $22,2^{\circ} \mathrm{C}$ e a máxima de $24,2^{\circ} \mathrm{C}$.

Pelo perfil de OD conclui-se que a aeração empregada foi insatisfatória no período em que a concentração ficou abaixo dos $1,5 \mathrm{mg} / \mathrm{L}$. Este fato pode ser explicado pela visível piora na distribuição de ar provocada pelo aumento da colmatação do leito devido à formação exagerada de camada de biopolímeros evidenciada ao redor da parte interna do reator. Uma sobrecarga de matéria orgânica durante este período também pode ter contribuído para maior consumo de oxigênio. 

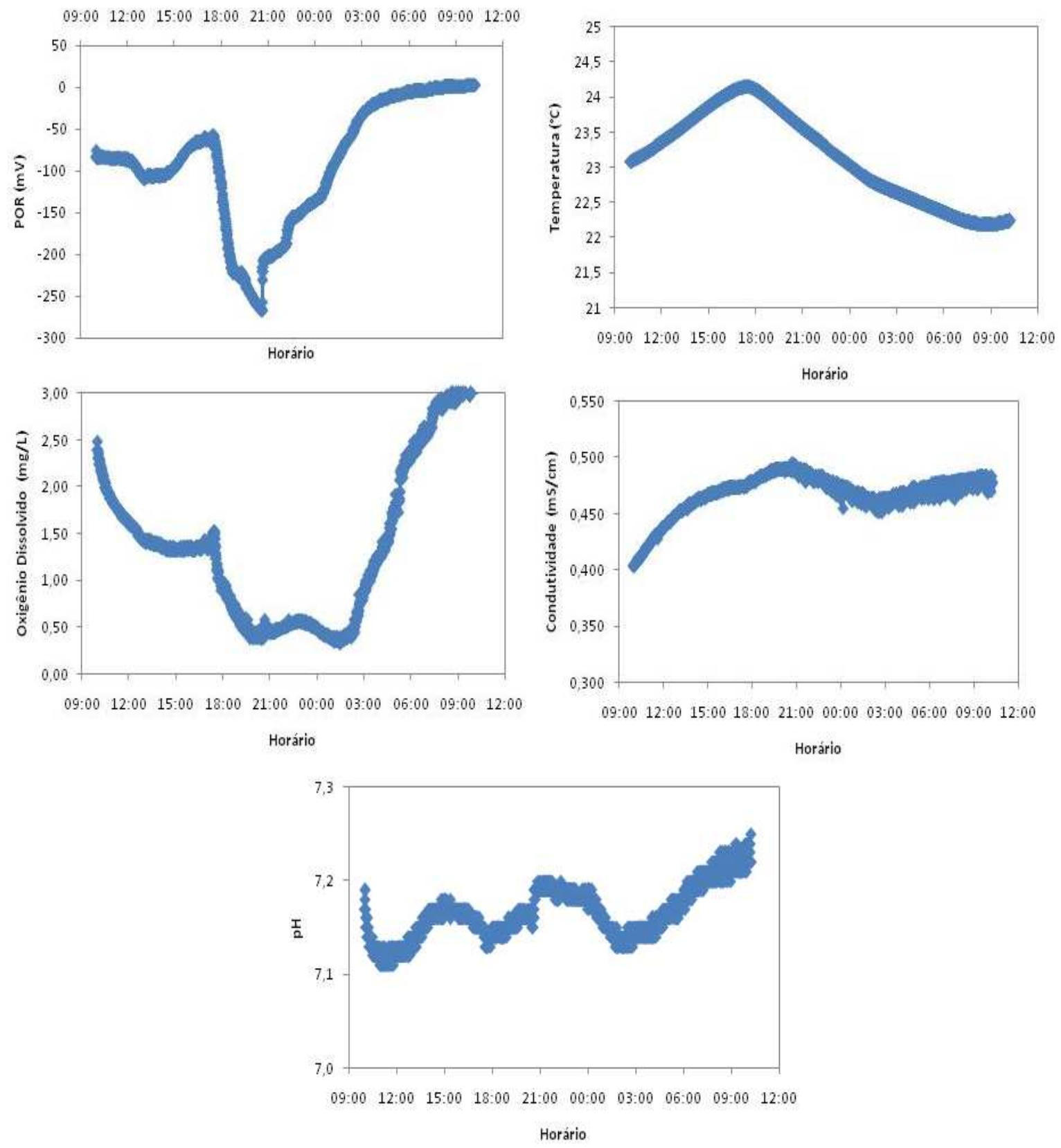

Figura 5.48 - Perfil temporal de 24 horas para esgoto doméstico efluente para o reator de leito fixo operado de modo contínuo ao final da operação com TDH de 8 horas e

$$
r=3,0
$$

Após descarte de fundo realizado ao final da segunda etapa operacional, observou-se significativa melhora nos parâmetros analisados. No entanto, o sistema não foi eficiente em relação à remoção de carbono, se comparado à primeira etapa 
operacional, e principalmente na remoção de nitrogênio, visto que durante toda esta etapa de operação, as concentrações de nitrogênio amoniacal, por exemplo, mantiveram-se com médias acima dos padrões exigidos para descarte segundo Legislação em vigor e praticamente não sofreram decaimento ao longo do tempo.

\subsubsection{Comparação entre as etapas estudadas}

Para facilitar a observação e conseqüente análise dos resultados obtidos durante toda etapa combinada, os resultados dos principais parâmetros foram agrupados na Tabela 5.4. São mostrados apenas valores efluentes para as três etapas estudadas, evidenciando ganhos quando feita recirculação do efluente tratado, durante a primeira e última etapa, principalmente em relação à remoção de matéria orgânica e conversão de Nitrogênio e perdas quando da redução do tempo de detenção hidráulica do sistema.

Na Tabela 5.5 são apresentados os valores das cargas orgânicas e de Nitrogênio aplicadas e removidas e demais correlações, além das eficiências de remoção para as etapas estudadas. 
Tabela 5.4 - Comparação entre os valores efluentes das três etapas estudadas.

\begin{tabular}{|c|c|c|c|c|c|c|}
\hline \multirow[b]{2}{*}{ Parâmetros } & \multicolumn{3}{|c|}{ Razão de Recirculação = 1,5 } & \multicolumn{3}{|c|}{ Razão de Recirculação = 3,0 } \\
\hline & $\mathrm{TDH}=12 \mathrm{~h}$ & $\mathrm{TDH}=10 \mathrm{~h}$ & $\mathrm{TDH}=8 \mathrm{~h}$ & $\mathrm{TDH}=12 \mathrm{~h}$ & $\mathrm{TDH}=10 \mathrm{~h}$ & $\mathrm{TDH}=8 \mathrm{~h}$ \\
\hline $\mathrm{pH}$ & $6,92 \pm 0,15^{(9)}$ & $7,29 \pm 0,10^{(5)}$ & $7,17 \pm 0,17^{(8)}$ & $7,15 \pm 0,29^{(9)}$ & $7,16 \pm 0,16^{(6)}$ & $7,26 \pm 0,13^{(7)}$ \\
\hline DQO Bruta (mg/L) & $57 \pm 28^{(9)}$ & $183 \pm 147^{(4)}$ & $198 \pm 83^{(8)}$ & $54 \pm 22^{(9)}$ & $1126 \pm 495^{(6)}$ & $143 \pm 53^{(7)}$ \\
\hline DQO Filtrada (mg/L) & $16 \pm 6^{(9)}$ & $28 \pm 14^{(4)}$ & $80 \pm 21^{(8)}$ & $16 \pm 12^{(9)}$ & $29 \pm 14^{(6)}$ & $65 \pm 7^{(7)}$ \\
\hline Alc. Total (mg CaCO3/L) & $118 \pm 40^{(9)}$ & $113 \pm 21^{(5)}$ & $150 \pm 14^{(8)}$ & $92 \pm 44^{(9)}$ & $122 \pm 27^{(6)}$ & $145 \pm 40^{(7)}$ \\
\hline Alc. a Bicarbonato (mg CaCO3/L) & $90 \pm 37^{(9)}$ & $86 \pm 20^{(5)}$ & $126 \pm 9^{(8)}$ & $86 \pm 24^{(9)}$ & $72 \pm 24^{(6)}$ & $125 \pm 22^{(7)}$ \\
\hline $\operatorname{AVT}(m g ~ H A c / L)$ & $24 \pm 7^{(9)}$ & $38 \pm 7^{(5)}$ & $34 \pm 12^{(8)}$ & $21 \pm 4^{(9)}$ & $71 \pm 21^{(6)}$ & $46 \pm 22^{(7)}$ \\
\hline NT (mg/L) & $25 \pm 3^{(9)}$ & $29 \pm 13^{(5)}$ & $28 \pm 10^{(8)}$ & $20 \pm 8^{(9)}$ & $93 \pm 62^{(6)}$ & $32 \pm 6^{(6)}$ \\
\hline NTK (mg/L) & $21 \pm 4^{(9)}$ & $28 \pm 13^{(5)}$ & $27 \pm 10^{(8)}$ & $14 \pm 10^{(9)}$ & $90 \pm 59^{(6)}$ & $31 \pm 7^{(6)}$ \\
\hline $\mathrm{NH}_{4}^{+}(\mathrm{mg} / \mathrm{L})$ & $14 \pm 2^{(9)}$ & $15 \pm 4^{(5)}$ & $27 \pm 4^{(8)}$ & $9 \pm 6^{(9)}$ & $17 \pm 2^{(6)}$ & $21 \pm 9^{(6)}$ \\
\hline $\mathrm{NO}_{2}^{-}(\mathrm{mg} / \mathrm{L})$ & $1 \pm 1^{(9)}$ & - & - & $1 \pm 1^{(9)}$ & - & - \\
\hline $\mathrm{NO}_{3}{ }^{-}(\mathrm{mg} / \mathrm{L})$ & $3 \pm 3^{(9)}$ & $1 \pm 2^{(5)}$ & $1 \pm 0^{(8)}$ & $4 \pm 4^{(9)}$ & $2 \pm 5^{(6)}$ & $1 \pm 1^{(6)}$ \\
\hline $\mathrm{SST}(\mathrm{mg} / \mathrm{L})$ & $61 \pm 16^{(8)}$ & $130 \pm 92^{(4)}$ & $114 \pm 53^{(7)}$ & $70 \pm 42^{(8)}$ & $1076 \pm 707^{(6)}$ & $100 \pm 67^{(5)}$ \\
\hline $\mathrm{SSV}(\mathrm{mg} / \mathrm{L})$ & $51 \pm 12^{(8)}$ & $115 \pm 87^{(4)}$ & $81 \pm 24^{(7)}$ & $54 \pm 34^{(8)}$ & $782 \pm 574^{(6)}$ & $84 \pm 61^{(5)}$ \\
\hline
\end{tabular}


Tabela 5.5 - Comparação entre os parâmetros operacionais das três etapas estudadas.

\begin{tabular}{|c|c|c|c|c|c|c|c|}
\hline \multirow{2}{*}{ Parâmetro } & \multicolumn{3}{|c|}{$\mathrm{TDH}=12 \mathrm{~h}$} & \multicolumn{2}{|c|}{$\mathrm{TDH}=10 \mathrm{~h}$} & \multicolumn{2}{|c|}{$\mathrm{TDH}=8 \mathrm{~h}$} \\
\hline & $\mathrm{r}=0$ & $r=1,5$ & $\mathrm{r}=3,0$ & $r=1,5$ & $\mathrm{r}=3,0$ & $\mathrm{r}=1,5$ & $\mathrm{r}=3,0$ \\
\hline $\mathrm{COV}_{\text {aplicada }}\left(\mathrm{kg} . \mathrm{DQO} / \mathrm{m}^{3} . \mathrm{d}\right)$ & \multicolumn{3}{|c|}{$1,17 \pm 0,55$} & \multicolumn{2}{|c|}{$1,48 \pm 0,63$} & \multicolumn{2}{|c|}{$1,64 \pm 0,53$} \\
\hline $\mathrm{COV}_{\text {removida }}\left(\mathrm{kg} . \mathrm{DQO} / \mathrm{m}^{3} . \mathrm{d}\right)$ & $1,06 \pm 0,04$ & $1,07 \pm 0,02$ & $1,08 \pm 0,04$ & $1,04 \pm 0,35$ & - & $1,10 \pm 0,21$ & $1,21 \pm 0,16$ \\
\hline $\mathrm{CVN}_{\text {aplicada }}\left(\mathrm{kg} . \mathrm{NTK} / \mathrm{m}^{3} . \mathrm{d}\right)$ & \multicolumn{3}{|c|}{$0,08 \pm 0,02$} & \multicolumn{2}{|c|}{$0,09 \pm 0,03$} & \multicolumn{2}{|c|}{$0,13 \pm 0,05$} \\
\hline $\mathrm{CVN}_{\text {removida }}\left(\mathrm{kg} . \mathrm{NTK} / \mathrm{m}^{3} . \mathrm{d}\right)$ & $0,05 \pm 0,01$ & $0,04 \pm 0,01$ & $0,06 \pm 0,02$ & $0,04 \pm 0,02$ & - & $0,05 \pm 0,03$ & $0,04 \pm 0,02$ \\
\hline Remoção de DQO (\%) & $88 \pm 5$ & $90 \pm 5$ & $92 \pm 3$ & $65 \pm 27$ & - & $67 \pm 13$ & $77 \pm 8$ \\
\hline Remoção de N (\%) & $65 \pm 9$ & $54 \pm 7$ & $68 \pm 11$ & $41 \pm 8$ & - & $40 \pm 21$ & $38 \pm 20$ \\
\hline COV/CVN (aplicada) & \multicolumn{3}{|c|}{14,6} & \multicolumn{2}{|c|}{16,4} & \multicolumn{2}{|c|}{12,6} \\
\hline COV/CVN (removida) & 21,2 & 26,7 & 18 & 26 & - & 22 & 30,2 \\
\hline $\mathrm{COV}_{\text {removida }} / \mathrm{COV}_{\text {aplicada }}$ & 0,90 & 0,91 & 0,92 & 0,70 & - & 0,67 & 0,74 \\
\hline $\mathrm{CVN}_{\text {removida }} / \mathrm{CVN}_{\text {aplicada }}$ & 0,62 & 0,50 & 0,69 & 0,43 & - & 0,41 & 0,34 \\
\hline
\end{tabular}


Pode-se observar que na etapa de operação com $\mathrm{TDH}=12 \mathrm{~h}$ e razão de recirculação igual a 3,0, a carga orgânica removida e a nitrogenada são mais próximas das cargas orgânica e de nitrogênio aplicadas ao sistema. Observa-se, também, pela relação COV/CVN (removida), que a etapa com $\mathrm{TDH}=12 \mathrm{~h}$ e $\mathrm{r}=0$ mais se aproximou da COV/CVN (aplicada) explicado pelo fato da remoção de Nitrogênio ter sofrido pequena variação entre as fases com $\mathrm{r}=0$ e $\mathrm{r}=3,0$ e pela maior carga orgânica removida nesta última citada, o que elevou a relação COV/CVN.

Um dos fatores que provavelmente prejudicaram o bom funcionamento do sistema ao longo do tempo foi a inexistência de tratamento preliminar para remoção de sólidos grosseiros e areia na Área de Pesquisa em Tratamento de Esgoto Sanitário do LPB acarretando aumento significativo dos SST no efluente com conseqüente aumento das concentrações de DQO. A formação de camada de biopolímeros na lateral da zona de aeração foi evidenciada formando caminhos preferenciais que afetaram o processo pela redução do tempo de permanência do meio líquido no sistema.

Em relação à segunda etapa operacional, percebe-se claramente aumento considerável da DQO efluente e piora no desempenho do reator combinado anaeróbioaeróbio de leito fixo na fase com razão de recirculação igual a 3,0. Caso houvesse a realização de descarte de fundo antes do início operacional da etapa em questão, talvez, os efeitos do crescimento excessivo de biomassa não tivessem ocorrido, ou ao menos teriam sido minimizados, melhorando a performance do sistema e, provavelmente, reduzindo os efeitos do crescimento excessivo de biomassa, redução dos espaços vazios e arraste de sólidos, como constatado nos valores da concentração efluente de sólidos suspensos totais apresentados na Tabela 5.4 que compara os resultados obtidos nas três etapas de operação estudadas. 
No entanto, pela observação dos resultados de DQO efluente da amostra filtrada, pode-se dizer que o processo respondeu satisfatoriamente durante a segunda etapa de operação. O descarte de fundo e/ou a substituição de parte do material suporte, realizados de forma regular, podem resultar numa diminuição da perda de biomassa no efluente, a qual também afetou a remoção de nitrogênio, já que a falta de mecanismos efetivos para o controle da espessura do biofilme pode contribuir para limitações à transferência de massa.

O baixo tempo de detençao hidráulica do sistema justificaria a não ocorrência de nitrificação, pois o efluente proveniente da zona anaeróbia, possivelmente rico em matéria orgânica a ser consumida, favoreceu o crescimento de bactérias heterotróficas na zona aeróbia do sistema em detrimento das bactérias nitrificicantes autotróficas.

\subsection{Aspectos construtivos e comparação com outras tecnologias}

O avanço tecnológico das últimas décadas viabilizou a operação de sistemas de tratamento biológico com a utilização reduzida de mão-de-obra e de energia. Nesta mesma época, a busca por soluções mais compactas e eficientes para o tratamento de esgoto doméstico e a conscientização da sociedade sobre os efeitos da poluição hídrica na qualidade de vida alavancaram as pesquisas em saneamento.

Dessa forma, tecnologias apropriadas devem ser aplicadas no tratamento de águas residuárias com maior eficiência e com os mais baixos custos possíveis. Qualquer sistema a ser implementado tende a alcançar os objetivos principais de sustentabilidade, isto é, pouco uso de energia e de substâncias químicas com recuperação ou reuso de recursos. 
A realização de um experimento em escala piloto ou real a partir de experiências de laboratório, apresenta sempre diversas incógnitas relacionadas com a mudança da escala, com o regime de escoamento e também com as características do efluente.

Neste item do presente trabalho, apresenta-se comparativamente o comportamento e os resultados obtidos com sistemas similares combinando os processos anaeróbio e aeróbio utilizados para o tratamento de esgoto sanitário.

A comparação do comportamento e estabilidade do reator combinado anaeróbioaeróbio de leito fixo em escala real e laboratório permite realçar que as condições operacionais do sistema em escala real são mais desfavoráveis em relação aquelas que são proporcionadas em escala de bancada, fato este comprovado pelas eficiências de remoção de matéria orgânica e conversão de Nitrogênio. Contudo o sistema de escala real consegue atingir uma situação de estabilidade e eficiência bem elevada, devido à progressiva adaptação das populações bacterianas às condições reais de alimentação. A Tabela 5.6 compara os resultados obtidos por diversos autores que trabalharam sistemas combinados anaeróbio-aeróbio tratando esgoto sanitário. 
Tabela 5.6 - Comparação entre diversos estudos com sistemas combinados tratando esgoto sanitário.

\begin{tabular}{|c|c|c|c|c|c|c|c|c|c|c|}
\hline $\begin{array}{l}\text { Parâmetros } \\
\end{array}$ & Atual $^{1}$ & O. Netto $(2007)^{2}$ & Kato et al. (2001) & Santos (2004) & Mendonça (2004) & Rodríguez (2006) & $\begin{array}{c}\text { Hoffmann et al. } \\
(2007)\end{array}$ & Chan et al. (2007) & $\begin{array}{l}\text { La Motta et al. } \\
\text { (2007) }\end{array}$ & $\begin{array}{l}\text { Fontana } \text { et al. } \\
\quad(2007)\end{array}$ \\
\hline Tecnologia & $\mathrm{RCLF}^{3}$ & RCLF & $\mathrm{EGSB}^{4}$ & $\begin{array}{l}\text { UASB / LMFFAe / } \\
\text { LMFFAn / CDC }\end{array}$ & RAALEx $^{6}$ & $\mathrm{UASB} / \mathrm{FBAA}^{7}$ & $\mathrm{LA}^{8}$ & $\mathrm{BFCW}^{9}$ & UASB/ASC ${ }^{10}$ & $\mathrm{UASB} / \mathrm{BF}^{11}$ \\
\hline Volume (L) & 2.500 & 6,72 & 802 & 71,48 & 159.000 & 470 & 840.000 & 40.800 & 907 & 106 \\
\hline TDH (h) & 12 & 11,4 & 12 & 20 & 10 & 8,6 & 12 & 24 & 6,2 & 14 \\
\hline Material & Fibra de vidro & Acrílico & - & PVC & Concreto armado & Polipropileno/PVC & Concreto armado & Concreto armado & Polietileno & $\mathrm{PVC}$ \\
\hline $\mathrm{pH}_{\mathrm{a}}$ & $6,79 \pm 0,18$ & $7,0 \pm 0,2$ & $6,84 \pm 0,23$ & - & $7,15-7,30$ & $6,5-7,0$ & - & $7,21 \pm 0,27$ & - & $6,7 \pm 0,2$ \\
\hline $\mathrm{pH}_{\mathrm{e}}$ & $7,15 \pm 0,29$ & $7,4 \pm 0,2$ & & $6,75-8,01$ & $6,60-6,94$ & $6,5-7,3$ & - & & - & $5,9 \pm 0,6$ \\
\hline $\mathrm{DQO}_{\mathrm{a}}(\mathrm{mg} / \mathrm{L})$ & $553 \pm 170$ & $627 \pm 319$ & $228 \pm 73$ & & 875 & $237 \pm 60$ & 348 & $80,82 \pm 31,52$ & $341 \pm 85$ & $406 \pm 171$ \\
\hline $\mathrm{DQO}_{\mathrm{e}}(\mathrm{mg} / \mathrm{L})$ & $54 \pm 22$ & $31 \pm 10$ & $84 \pm 33$ & $35-169$ & 188 & $54 \pm 23$ & 62 & & 46 & $45 \pm 31$ \\
\hline $\mathrm{DQO}_{\mathrm{rem}}(\%)$ & 92 & 95 & 63 & 87,6 & 79 & 77 & 82 & 65 & 86,5 & 87,5 \\
\hline $\mathrm{CO}_{\text {apl }}\left(\mathrm{kg} \cdot \mathrm{DQO} / \mathrm{m}^{3} \cdot \mathrm{d}\right)$ & 1,13 & 1,32 & 0,64 & 0,78 & 2,1 & 0,26 & 0,7 & 0,08 & 1,32 & 0,57 \\
\hline $\mathrm{AB}_{\mathrm{a}}\left(\mathrm{mgCaCO}_{3} / \mathrm{L}\right)$ & $105 \pm 23$ & $119 \pm 20$ & 2 & - & - & 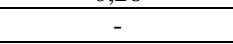 & 250 & 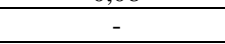 & - & - \\
\hline $\mathrm{AB}_{\mathrm{c}}(\mathrm{mgCaCO} / \mathrm{L})$ & $86 \pm 24$ & $75 \pm 36$ & - & - & - & - & 85 & - & - & - \\
\hline $\mathrm{NTK}_{\mathrm{a}}(\mathrm{mg} / \mathrm{L})$ & $41 \pm 11$ & $40 \pm 3$ & $26,5 \pm 16,1$ & - & 43 & 31 & 57 & $35,56 \pm 9,69$ & - & $35,2 \pm 5,7$ \\
\hline $\mathrm{NTK}_{\mathrm{e}}(\mathrm{mg} / \mathrm{L})$ & $14 \pm 10$ & $6 \pm 2$ & $21,6 \pm 11,3$ & 4,0 & 30 & 11 & 6,1 & - & - & $7,6 \pm 13,4$ \\
\hline $\mathrm{NTK}_{\mathrm{rem}}(\%)$ & 68 & 85 & 18 & 92,8 & 30 & 64 & 89 & - & - & 80,2 \\
\hline $\mathrm{CN}_{\mathrm{apl}}\left(\mathrm{kg} . \mathrm{NTK} / \mathrm{m}^{3} \mathrm{~d}\right.$ ) & 0,08 & 0,08 & 0,05 & 0,07 & 0,10 & 0,09 & 0,11 & 0,03 & - & 0,06 \\
\hline $\begin{array}{l}\text { Fonte de Carbono para } \\
\text { desnitrificacão }\end{array}$ & Esgoto & Esgoto & - & Esgoto & - & Biogás & Esgoto & - & - & - \\
\hline $\mathrm{SST}_{\mathrm{a}}(\mathrm{mg} / \mathrm{L})$ & $242 \pm 111$ & $129 \pm 72$ & $118 \pm 136$ & $594-1806$ & 217 & $121 \pm 75$ & - & $23,26 \pm 8,73$ & $189 \pm 69$ & - \\
\hline $\mathrm{SST}_{\mathrm{e}}(\mathrm{mg} / \mathrm{L})$ & $70 \pm 42$ & $15 \pm 6$ & $27 \pm 37$ & $74-508$ & 52 & & - & & 12 & $39 \pm 34$ \\
\hline $\mathrm{SST}_{\mathrm{rem}}(\%)$ & 75 & 88 & 77 & 44,4 & 76 & - & - & 80 & 93,6 & - \\
\hline
\end{tabular}

${ }^{1}$ Recirculação de 3,0

${ }^{2}$ Escala de Bancada e Recirculação de 1,5

${ }^{3}$ RCLF - Reator Combinado de Leito Fixo

${ }^{4}$ EGSB - Expanded Granular Sludge Bed

${ }^{5}$ LMFFAe - Leito Móvel e Filme Fixo Aeróbio, LMFFAn - Leito Móvel e Filme Fixo Anóxico, CDC - Compartimento de Decantação e Coleta do efluente tratado

${ }^{6}$ RAALEx - Reator Anaeróbio-Aeróbio de Leito Expandido

${ }^{7} \mathrm{FBAA}$ - Filtro Biológico Anaeróbio/Aeróbio

${ }^{8} \mathrm{LA}$ - Lodos Ativados

${ }^{9} \mathrm{BFCW}$ - Batch- fed Constructed Wetland

${ }^{10}$ ASC - Aerated Solids Contact, SC - Secondary Clarifier

${ }^{11} \mathrm{BF}$ - Biofiltro 
Verifica-se que em termos de remoção de matéria orgânica, os sistemas apresentaram semelhança no comportamento e removeram DQO de forma satisfatória, atingindo carga orgânica aplicada ao sistema de até $2,1 \mathrm{~kg} . \mathrm{DQO} / \mathrm{m}^{3}$.dia verificado no trabalho de Mendonça (2004) trabalhando com RAALEx (reator anaeróbio-aeróbio de leito expandido) com volume total de $159 \mathrm{~m}^{3}$. Foram observadas remoções de $95 \%$ e 92\% nas pesquisas realizadas por Oliveira Netto (2007) com sistema em escala de bancada e na pesquisa atual, respectivamente, atingindo valores de DQO efluente iguais a $31 \pm 10 \mathrm{mg} / \mathrm{L}$ e $54 \pm 22 \mathrm{mg} / \mathrm{L}$.

Em termos de conversão de material nitrogenado, houve variação a depender da utilização ou não do processo de desnitrificação. Os resultados mais satisfatórios foram encontrados por Santos (2004) utilizando pós-tratamento do efluente do reator UASB em LMFFAe (reator de leito móvel e filme fixo aeróbio) e LMFFAn (reator de leito móvel e filme fixo anóxico) atingindo 92,8\% de conversão de N-NTK obtendo valores efluentes de 4,0 mgN-NTK/L. No presente trabalho atingiu-se valores de $14 \pm 10 \mathrm{mgN}-\mathrm{NTK} / \mathrm{L}$ com conversão de $68 \%$ e TDH igual a $12 \mathrm{~h}$. As cargas nitrogenadas aplicadas aos sistemas estudados variaram de 0,03 a $0,11 \mathrm{~kg} \cdot \mathrm{N}-\mathrm{NTK} / \mathrm{m}^{3} \cdot$ dia.

Para o caso de remoção de sólidos suspensos totais, a semelhança dos resultados também é verificada. Atingiu-se valores de remoção de 93,6\% com valor efluente médio de apenas $12 \mathrm{mg} / \mathrm{L}$ na pesquisa realizada por La Motta et. al. (2007) que trabalharam com UASB seguido de ASC (Aerated Solids Contact) e SC (Secondary Clarifier), sistema este, com volume total de $907 \mathrm{~L}$ e TDH de 6,2 h. Nesta pesquisa obteve-se remoção média $71 \%$ e valor efluente ao sistema igual a $61 \pm 16 \mathrm{mg} / \mathrm{L}$ para TDH de $12 \mathrm{~h}$ com volume total de $2500 \mathrm{~L}$. 
O reator combinado anaeróbio-aeróbio com recirculação da fase líquida, além de manter altas eficiências de remoção de matéria orgânica, também apresentou boa eficiência de remoção de nitrogênio (total), principalmente após a inserção da vazão de recirculação, quando foram atingidas eficiências de 75\% para um TDH de 11,4 h, razão de recirculação de 1,5 e escala de bancada (OLIVEIRA NETTO, 2007) e 54\% para um TDH de 12 h, razão de recirculação de 3,0 e escala piloto, na pesquisa atual. A análise dos resultados revela ganhos obtidos quando houve aumento na vazão de recirculação do efluente tratado, principalmente em relação à remoção de matéria orgânica e nitrogênio, comprovando ser esta uma variável de grande importância para a melhora do comportamento do reator, não havendo necessidade de adição de alcalinidade nem de fonte exógena de fonte de carbono para promover a desnitrificação em níveis substanciais tanto para a escala de laboratório quanto para a escala piloto.

Em relação a utilização de fonte externa de carbono para promover o processo de desnitrificação, cada pesquisa apresentou sua peculiaridade.

No trabalho realizado por Kato et al. (2001) que pesquisaram o tratamento de esgotos sanitários em reatores tipo EGSB anaeróbio e aeróbio, a remoção completa de nitrogênio por desnitrificação, no reator anaeróbio sequencial, ficou prejudicada devido a problemas operacionais no reator aeróbio relacionados com a aeração e a perda de biomassa nitrificante, não sendo possível concretizar a recirculação do efluente para o reator anaeróbio, em regime seqüencial, para promover o processo de desnitrificação. Na pesquisa de Mendonça (2004), face ao pequeno período experimental sob condição anaeróbia-aeróbia e ao incidente operacional ocorrido, em virtude de descarga grave de oxigênio na região anaeróbia, logo no início de estudo com as duas regiões anaeróbiaaeróbia, o reator (RAALex) não teve tempo suficiente para alcançar o regime de equilíbrio dinâmico aparente. 
Já Santos (2004) utilizou bomba própria responsável pela introdução de fonte de carbono externa (próprio esgoto) no reator anóxico para promoção da desnitrificação. Rodríguez (2006) utilizou como fonte de doadores de elétrons para a desnitrificação, o biogás gerado no reator UASB, o qual possui composição média apresentada na Tabela 5.7. Hoffmann et al. (2007) apresentaram estudo do tratamento biológico de efluente sanitário em reator de lodo ativado em batelada seqüencial (RBS) em escala real, a fim de alcançar a nitrificação e desnitrificação na mesma fase em paralelo, realizada por limitação de oxigênio. Fontana et al. (2007), durante o período de funcionamento do sistema, introduziram fonte externa de alcalinizante (cal hidratada). Uma vez por semana, adicionava-se cuidadosamente $180 \mathrm{~g}$ de cal em 200 L (reservatório intermediário). A partir de então, aguardava-se o bombeamento da totalidade do volume do reservatório intermediário, que alimentava os biofiltros aeróbios, para novo enchimento do mesmo com o efluente do reator UASB.

Tabela 5.7 - Composição média do biogás utilizado como fonte de doadores de elétrons na pesquisa de Rodríguez (2006). (Fonte: GARBOSSA, $2005^{1}$ apud RODRÍGUEZ, 2006)

\begin{tabular}{c|c}
\hline Componente & Concentração (mg/L) \\
\hline $\mathrm{CH}_{4}$ & 376 \\
$\mathrm{CO}_{2}$ & 112 \\
$\mathrm{H}_{2} \mathrm{~S}$ & 0,493 \\
\hline
\end{tabular}

Comparando com sistemas convencionais de tratamento, como por exemplo, filtro biológico (FB), filtro aeróbio submerso (FAS), lodo ativado (LA) e reator UASB, que já são utilizados em grande escala, o reator combinado anaeróbio-aeróbio de leito 
fixo apresentou desempenho satisfatório no tratamento de esgoto sanitário, com desempenho médio de $92 \pm 3 \%$ na remoção de DQO e $68 \pm 11 \%$ na remoção de NTK para TDH de 12 h e razão de recirculação igual a 3,0.

Na Tabela 5.8 são apresentados parâmetros operacionais típicos dos sistemas de tratamento convencionais em questão, citados por Jordão e Pessoa (2005), em comparação com os parâmetros obtidos para o reator combinado vertical de leito fixo.

Tabela 5.8 - Comparação entre os parâmetros operacionais de sistemas de tratamento convencionais e reator combinado anaeróbio-aeróbio vertical de leito fixo.

\begin{tabular}{|c|c|c|c|}
\hline Sistema de Tratamento & COV (kg.DQO $/ \mathrm{m}^{3}$.dia) & Nitrificação & TDH (h) \\
\hline FB - Baixa Capacidade & $0,2-0,6$ & $\operatorname{Sim}^{*}$ & \\
\hline FB - Capacidade Intermediária & $0,4-1,0$ & Possível & \\
\hline UASB & $2,5-3,5$ & Não & $6-9$ \\
\hline FAS - Enchimento Estruturado & $1,6-2,0$ & Possível & $1-1,5$ \\
\hline LA - Convencional & $0,6-1,2$ & Possível & $4-8$ \\
\hline LA - Aeração Prolongada & $0,1-0,8$ & Sim & $16-36$ \\
\hline Reator Combinado de Leito Fixo & 1,2 & Sim & 12 \\
\hline
\end{tabular}

Em relação ao sistema de aeração por ar difuso, devido a tecnologia e inovação construtiva, foi instalado no compartimento intermediário do reator combinado de leito fixo, assegurando maior transferência de oxigênio em razão do maior tempo de contato e 
melhor forma de distribuição, garantida pela distribuição homogênea dos difusores, entre o oxigênio e a biomassa aderida ao material suporte. Para aeração do compartimento aeróbio do reator utilizado nesta pesquisa, foram instalados dois difusores de ar tubulares de bolha fina.

Além disso, a tecnologia de aeração por ar difuso proporciona mistura suave evitando quebra ou desprendimento de flocos e material aderido à espuma. O ruído gerado pelos sopradores ou compressores é facilmente controlado se instalados em abrigos apropriados.

O sistema de aeração por ar difuso apresenta como uma de suas principais vantagens, o consumo de energia elétrica de até $60 \%$ a menos que os aeradores mecânicos. Apesar do maior investimento para aquisição de um sistema com ar difuso em relação a um sistema com aeradores mecânicos, a diferença de investimento pode ser recuperada em menos de um ano de operação, segundo informações técnicas do fabricante. O resultado do menor consumo de energia e o baixo custo com produtos operacionais tornam o sistema de aeração por ar difuso mais econômico.

Na pesquisa com o reator combinado anaeróbio-aeróbio de leito fixo em escala de bancada a aeração foi feita por meio de uma bomba da marca Big Air modelo A360, que injetava o ar na câmara de aeração através de uma pedra porosa responsável pela difusão do mesmo na parte aeróbia do reator. Na pesquisa de Kato et al. (2001), o suprimento de ar no reator aeróbio era assegurado por um compressor SCHULZ MS 3,6/2C de 0,5 CV e de 1 estágio. $\mathrm{O}$ ar era injetado na base do corpo do EGSB através de um difusor de aço sinterizado, o qual atravessava o leito em fluxo ascendente, em sentido co-corrente com o esgoto. No FBAA da pesquisa de Rodríguez (2006), o fornecimento de ar atmosférico, utilizado como fonte de oxigênio, foi otimizado pela construção de janelas verticais e perimetrais. No trabalho de Hoffmann et al. (2007), a aeração e a mistura de lodo no 
reator foram realizadas com dois aeradores do tipo Weatherford (MO-15), localizados no fundo de cada tanque. Já Fontana et al. (2007), com o objetivo de melhorar a distribuição do ar no biofiltro, utilizaram uma pedra porosa acoplada no final da mangueira de ar para produção de bolhas de pequeno diâmetro.

$\mathrm{Na}$ entrada do reator LMFFAe, da pesquisa realizada por Santos (2004), havia aplicação de oxigênio puro através de um anel de PVC com furos de 1,0 mm de diâmetro espaçados de 10,0 em 10,0 mm. Foram feitos furos em várias direções no anel para se obter maior eficiência na distribuição do oxigênio. No RAALEx, da pesquisa de Mendonça (2004), o fornecimento de oxigênio ao reator foi realizado por meio de tanque criogênico (TM-1500-White Martins) de cerca de $14,16 \mathrm{~m}^{3}$, no qual o oxigênio líquido era encaminhado para o vaporizador, passando pelo painel de controle de oxigênio (manômetro, válvula de alívio de pressão, válvula de retenção, rotâmetro) e desse seguindo por tubulação de diâmetro igual a 12,5 mm para dispositivo poroso de aço inox, do qual o oxigênio era distribuído ao reator por meio de tubulação perfurada com orifícios nas alturas de 6,7 ou $9 \mathrm{~m}$ acima do fundo do reator.

Em termos construtivos os reatores apresentaram estruturas variadas. Foram encontradas estruturas em PVC, fibra de vidro, acrílico, polietileno, polipropileno e até concreto armado. Existem vantagens de cada material para cada tipo de especificidade.

Atualmente os reservatórios confeccionados à base de fibra de vidro são resultados da utilização de alta tecnologia, sendo fabricados à base de PRFV (plástico reforçado com fibra de vidro) substituindo com inegáveis vantagens as antigas caixas d'água e reservatórios de amianto ou chapa de ferro. O reator combinado anaeróbioaeróbio de leito fixo foi fabricado pelo processo "spray-up", que consiste na aplicação de resina de poliéster (70\%) e como reforço estrutural foi aplicado fibra de vidro picotada (30\%), esta combinação forma um composto de alta resistência e durabilidade, unidades 
leves que não enferrujam e de fácil manejo na instalação, sendo possível confeccionar unidades com grandes volumes, a depender do formato e tipo de utilização.

Os reservatórios de fibra de vidro (PRFV) podem ser utilizados na construção civil como reservatórios de água potável, na agricultura também como reservatórios de água potável, para consumo humano, armazenamento de água para pulverização de pomares, armazenamento de grãos, forragens ou cereais, entre outros. O reator combinado de leito fixo possuiu tampa perfurada, para evitar acúmulo de gases, de fácil encaixe e fixada com parafusos zincados, garantindo a vedação e impedindo a entrada de insetos e corpos indesejados. Esse processo de fabricação também garante a redução de quebra e formação de trincas, no corpo do reservatório, durante o processo de manuseio e instalação e redução na necessidade de manutenção, pois não há problemas com oxidação, como ocorre nos reservatórios metálicos.

Como o coeficiente de dilatação térmico é baixo e aliado a sua pouca absorção de calor e água, a fibra de vidro não sofre deformações apreciáveis com variações de temperatura e umidade. Materiais produzidos com fibra de vidro geralmente apresentam excelentes propriedades mecânicas e baixa densidade.

Os reservatórios fabricados com o emprego desse tipo de material construtivo permitem uma ampla flexibilidade de projetos, possibilitando a moldagem de peças complexas, grandes ou pequenas, sem emendas e com grande valor funcional e estético, sem juntas, parafusos ou rebites.

Em geral, os produtos feitos com a fibra de vidro são mais leves e apresentam melhor resistência aos meios ácidos, possuindo também rapidez de execução, baixo custo de moldes, facilidade de correção de erros no projeto, baixos custos de fabricação e simplicidade para produção. Destaca-se também como vantagem referente ao material fibra de vidro a sua facilidade de adaptação a qualquer tipo de forma mantendo a mesma 
facilidade de execução, a qual permite total liberdade à concepção arquitetônica, estrutural e de método construtivos, que poucos materiais fornecem, principalmente se associados à economia.

Uma desvantagem do uso dos reservatórios em fibra de vidro está na relação à resistência ao calor, pois esse material possui baixa resistência ao fogo, principalmente quando comparado ao concreto armado, seu tempo de resistência é significativamente inferior.

Biazin (2010), após estudar os materiais utilizados e seus custos tanto para os reservatórios de fibra de vidro como para os de polietileno e concreto armado, chegou à conclusão que o custo e o tempo de execução dos reservatórios de concreto armado são muito superiores se comparados aos de fibra de vidro e polietileno. Segundo os resultados obtidos, a utilização dos reservatórios em fibra de vidro é viável devido a diversos aspectos construtivos e financeiros aliado às excelentes propriedades mecânicas deste material.

Ressalta-se, então, a importância da correta escolha do material a ser empregado na confecção da unidade de tratamento levando-se em consideração aspectos técnicos e econômicos. A escolha do material mais adequado a ser empregado na construção de um reservatório/sistema de tratamento deve levar em consideração o seu custo de fabricação, por modificar, entre outros aspectos, a quantidade de material a ser utilizado, a qualificação da mão de obra durante execução e o tipo de manutenção do reservatório durante sua vida útil; além das características físico-químicas e volume do material/efluente a ser tratado e/ou armazenado.

A comparação entre os parâmetros operacionais de sistemas de tratamento que utilizam tecnologias avançadas, com reatores alternativos, e dos mais convencionalmente utilizados, visando a remoção de matéria orgânica e conversão das formas de Nitrogênio, 
confirmam o reator combinado anaeróbio-aeróbio de leito fixo como solução tecnológica para tratamento de esgoto sanitário tendo em vista o bom desempenho em absorver altas cargas orgânicas e nitrogenadas necessitando de tempo de detenção hidráulica compatível com as demais tecnologias apresentadas, possibilitando a construção de unidades compactas de tratamento, com remoção de DQO superior a sistemas unicamente anaeróbios, sem geração de odores e produção de lodo e consumo energético inferiores aos encontrados em unidades de tratamento aeróbias.

\subsection{Balanço de massa para estimativa das constantes cinéticas}

Para realização dos balanços de massa foram tomadas algumas considerações relacionadas no Capítulo 4. Neste item, da presente pesquisa, serão apresentados os balanços para o carbono e material nitrogenado no reator combinado anaeróbio-aeróbio de leito fixo. 


\subsubsection{Balanço para o carbono: $C \stackrel{k_{C}}{\longrightarrow}$ Produtos}

\subsubsection{Camada Acidogênica}

Representação Esquemática:

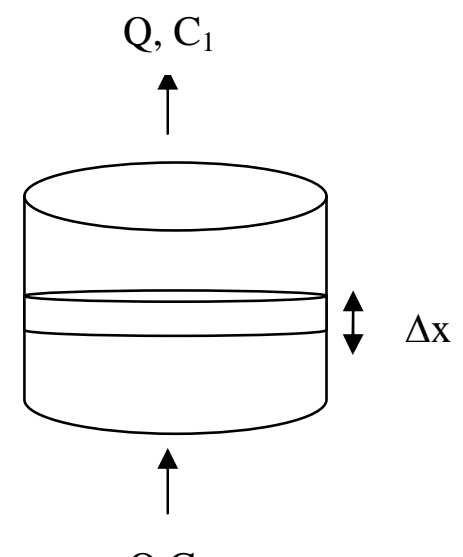

Camada 1: Leito de Argila Expandida

$\mathrm{Q}, \mathrm{C}_{0}$

em que:

Q: Vazão afluente;

$\mathrm{C}_{0}$ : Concentração de Carbono na vazão afluente;

$\mathrm{C}_{1}$ : Concentração de Carbono na vazão efluente.

Para a camada acidogênica, segmento $\mathrm{n}^{\circ}$, considerou-se o modelo de escoamento contínuo tubular ideal, também conhecido como plug-flow ou escoamento pistonado, para tratamento matemático dos dados. Neste tipo de idealização, o escoamento ocorre sem mistura e o fluido atravessa o reator sem mistura longitudinal. Estabelecendo-se como volume de controle uma seção transversal do reator tubular com espessura $\Delta \mathrm{x}$, tem-se:

$$
\begin{aligned}
& (\text { Entrada })-(\text { Saída }) \pm(\operatorname{Re} a c ̧ a ̃ o)=(\text { Acúmulo }) \\
& \left.Q \cdot C_{0}\right|_{x}-\left.Q \cdot C_{1}\right|_{x+\Delta x}-\left(-r_{c 1}\right) \cdot A \cdot \Delta x=V_{1} \cdot \frac{d C}{d t}+C \cdot \frac{d V_{1}}{d t}
\end{aligned}
$$


Considerando o regime do sistema permanente, como já anteriormente discutido no Capítulo 4, e o volume de controle adotado constante, tem-se:

$Q \cdot\left(\left.C_{0}\right|_{x}-\left.C_{1}\right|_{x+\Delta x}\right)=\left(-r_{c 1}\right) \cdot \Delta x \cdot A$

Dividindo a equação por $Q \cdot \Delta x$ :

$\frac{\left(\left.C_{0}\right|_{x}-\left.C_{1}\right|_{x+\Delta x}\right)}{\Delta x}=\frac{\left(-r_{c 1}\right) \cdot A}{Q}$

Levando-se em consideração o conceito de derivada, pode-se expressar a variação da concentração de carbono em relação à variação de um elemento diferencial x da seguinte forma:

$-\frac{d C}{d x}=\frac{\left(-r_{c 1}\right) \cdot A}{Q}$

Assumindo o septo transversal do reator constante, pode-se escrever:

$d V_{1}=A \cdot d x$

Então:

$-\frac{d C}{d x \cdot A}=\frac{\left(-r_{c 1}\right)}{Q} \Leftrightarrow-\frac{d C}{d V}=\frac{\left(-r_{c 1}\right)}{Q} \Leftrightarrow d C=-\frac{\left(-r_{c 1}\right)}{Q} \cdot d V_{1}$

Integrando a equação em intervalos definidos:

$\int_{C_{0}}^{C_{1}} \frac{d C}{\left(-r_{c 1}\right)}=-\frac{1}{Q} \cdot \int_{0}^{V 1} d V_{1}$

O termo $\left(-r_{c 1}\right)$ é escrito como:

$\left(-r_{c 1}\right)=k_{1} \cdot C_{1}$

Considerou-se reação de $1^{\mathrm{a}}$ ordem para elaboração do balanço de massa, pois, sabe-se que para esgoto doméstico, em termos práticos, a velocidade específica de remoção de substrato é função da concentração de substrato no sistema, e diminui à medida que o mesmo decresce, obedecendo a cinética de primeira ordem. 
Dessa forma:

$$
\begin{aligned}
& \int_{C_{0}}^{C_{1}} \frac{d C}{\left(-r_{c 1}\right)}=-\frac{1}{Q} \cdot \int_{0}^{V 1} d V_{1} \\
& \frac{1}{k_{1}} \cdot \int_{C_{0}}^{C_{1}} \frac{d C}{C}=-\frac{1}{Q} \cdot \int_{0}^{V 1} d V_{1} \\
& \left.\frac{1}{k_{1}} \cdot \ln C\right|_{C_{0}} ^{C_{1}}=-\frac{V_{1}}{Q} \\
& -\theta h_{1}=\frac{1}{k_{1}} \cdot \ln \left(C_{1}-C_{0}\right) \\
& -k_{1} \cdot \theta h_{1}=\ln \left(\frac{C_{1}}{C_{0}}\right) \\
& k_{1}=-\frac{\ln \left(\frac{C_{1}}{C_{0}}\right)}{\theta h_{1}}
\end{aligned}
$$




\title{
5.4.1.2 Camada Anaeróbia/Anóxica/Aeróbia
}

Representação Esquemática:

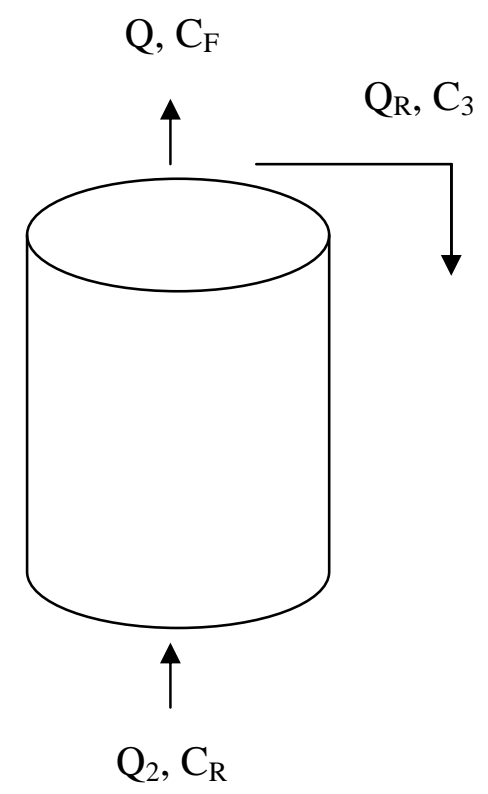

Camada 2: Leito de Espuma Anaeróbio/Anóxico

\author{
$+$ \\ Camada 3: Leito de Espuma Aeróbio
}

em que:

$\mathrm{Q}_{2}$ : Vazão afluente;

Q: Vazão efluente;

$\mathrm{Q}_{\mathrm{R}}$ : Vazão de recirculação;

$\mathrm{C}_{\mathrm{R}}$ : Concentração de Carbono na vazão afluente;

$\mathrm{C}_{\mathrm{F}}$ : Concentração de Carbono na vazão efluente;

$\mathrm{C}_{3}$ : Concentração de Carbono na vazão de recirculação.

Tem-se:

$Q_{R}=Q \cdot r$

$Q_{2}=Q+Q_{R}=Q+Q \cdot r=Q \cdot(1+r)$

Neste caso, considera-se a camada anaeróbia/anóxica (segmento $n^{\circ} 2$ ) mais a camada aeróbia (segmento $\mathrm{n}^{\circ} 3$ ) como reator de mistura perfeita, conforme já discutido 
no item 4.7, que são reatores contínuos (isso é, com correntes de entrada e saída), completamente misturados, de forma que a concentração de dado elemento é a mesma em qualquer ponto do reator e na corrente de saída. O volume de controle para esta camada é mostrado na Figura 5.49.

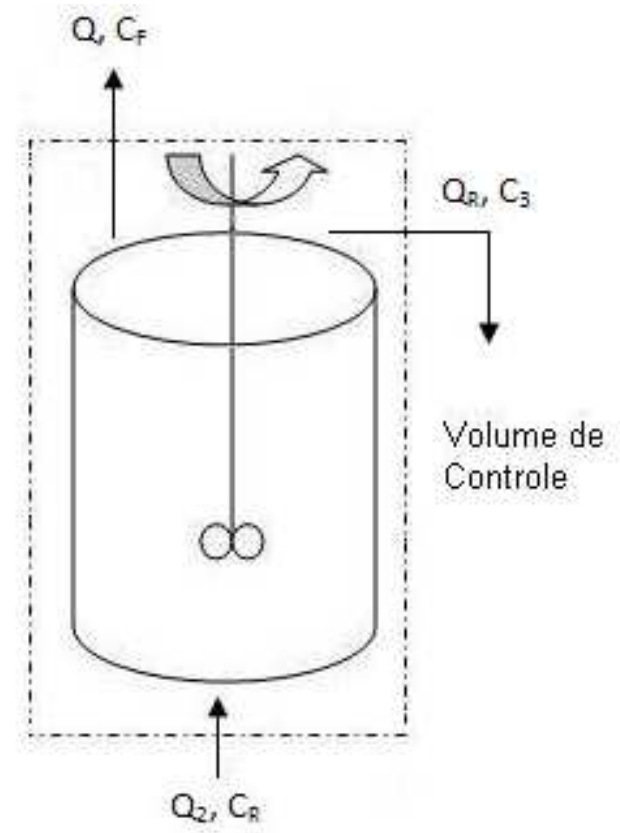

Figura 5.49 - Volume de controle da camada anaeróbia-anóxica-aeróbia do reator combinado para o balanço de carbono

Para este caso específico, houve junção dos segmentos (camadas) 2 e 3, devido ao fato da corrente proveniente da recirculação gerar indeterminação no balanço de massa, acarretando na obtenção de constante cinética com valor incoerente (negativo), ou seja, significando que houve produção de matéria orgânica na camada anaeróbia/anóxica. Essa indeterminação é explicada pelo fato da corrente de recirculação ser entendida como corrente externa pelo volume de controle estabelecido, o que não é verdade, visto que esta é função da corrente de saída, sendo então necessário a conjugação dos segmentos 
para realização do balanço de massa e obtenção da constante cinética de degradação da matéria orgânica para estas camadas.

Para realização do balanço, considera-se regime permanente. Primeiramente explica-se que $C_{R}$ é a concentração de DQO resultante da combinação da corrente efluente do segmento de argila expandida (segmento 1) e corrente proveniente da recirculação imposta ao sistema resultando em:

$$
\begin{aligned}
& C_{R}=\frac{Q \cdot C_{1}+Q_{R} \cdot C_{3}}{Q+Q_{R}} \\
& (\text { Entrada })-(\text { Saída }) \pm(\operatorname{Re} a c ̧ \tilde{a} o)=(\text { Acúmulo }) \\
& Q_{2} \cdot C_{R}-Q \cdot C_{F}-Q_{R} \cdot C_{3}-\left(-r_{c 2 / 3}\right) \cdot V_{2 / 3}=0 \\
& \left(Q+Q_{R}\right) \cdot C_{R}-Q \cdot C_{F}-Q_{R} \cdot C_{3}=\left(-r_{c 2 / 3}\right) \cdot V_{2 / 3} \\
& \text { O termo }\left(-r_{c 2 / 3}\right) \text { é escrito como: } \\
& \left(-r_{c 2 / 3}\right)=k_{2 / 3} \cdot C_{3}
\end{aligned}
$$

Dessa forma:

$$
\begin{aligned}
& \left(Q+Q_{R}\right) \cdot C_{R}-Q \cdot C_{F}-Q_{R} \cdot C_{3}=k_{2 / 3} \cdot C_{3} \cdot V_{2 / 3} \\
& (Q+Q \cdot r) \cdot C_{R}-Q \cdot C_{F}-Q \cdot r \cdot C_{3}=k_{2 / 3} \cdot C_{3} \cdot V_{2 / 3} \\
& Q \cdot(1+r) \cdot C_{R}-Q \cdot C_{F}-Q \cdot r \cdot C_{3}=k_{2 / 3} \cdot C_{3} \cdot V_{2 / 3} \\
& (1+r) \cdot C_{R}-C_{F}-r \cdot C_{3}=k_{2 / 3} \cdot C_{3} \cdot \theta h_{2 / 3} \\
& k_{2 / 3}=\frac{(1+r) \cdot C_{R}-C_{F}-r \cdot C_{3}}{C_{3} \cdot \theta h_{2 / 3}}
\end{aligned}
$$


Para $\mathrm{r}=0$ é válida a seguinte relação para a camada anaeróbia/anóxica (segmento 2):

Representação Esquemática:

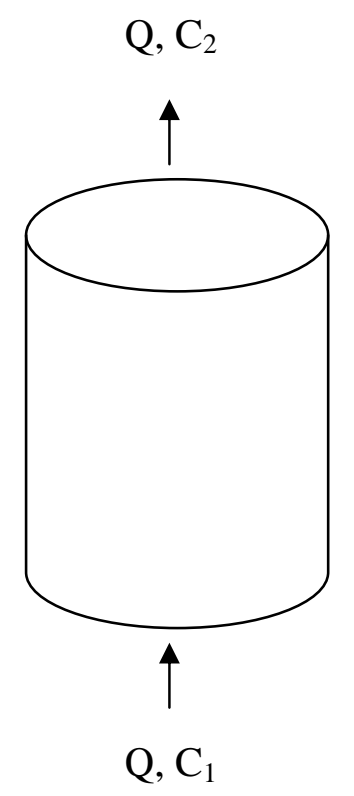

Camada 2: Leito de Espuma de Poliuretano

em que:

Q: Vazão afluente;

$\mathrm{C}_{1}$ : Concentração de Carbono na vazão afluente;

$\mathrm{C}_{2}$ : Concentração de Carbono na vazão efluente.

$($ Entrada $)-($ Saída $) \pm(\operatorname{Re} a c ̧ \tilde{a} o)=($ Acúmulo $)$

$Q \cdot C_{1}-Q \cdot C_{2}-\left(-r_{c 2}^{*}\right) \cdot V_{2}=0$

O termo $\left(-r_{c 2}{ }^{*}\right)$ é escrito como:

$\left(-r_{c 2}^{*}\right)=k_{2}^{*} \cdot C_{2}$

Dessa forma:

$Q \cdot C_{1}-Q \cdot C_{2}-\left(k_{2}{ }^{*} \cdot C_{2}\right) \cdot V_{2}=0$

$Q \cdot\left(C_{1}-C_{2}\right)=k_{2}^{*} \cdot C_{2} \cdot V_{2}$ 
$\left(C_{1}-C_{2}\right)=k_{2}^{*} \cdot C_{2} \cdot \theta h_{2} \rightarrow k_{2}^{*}=\frac{\left(C_{1}-C_{2}\right)}{C_{2} \cdot \theta h_{2}}$

Para $\mathrm{r}=0$ é válida a seguinte relação para a camada aeróbia (segmento 3):

Representação Esquemática:

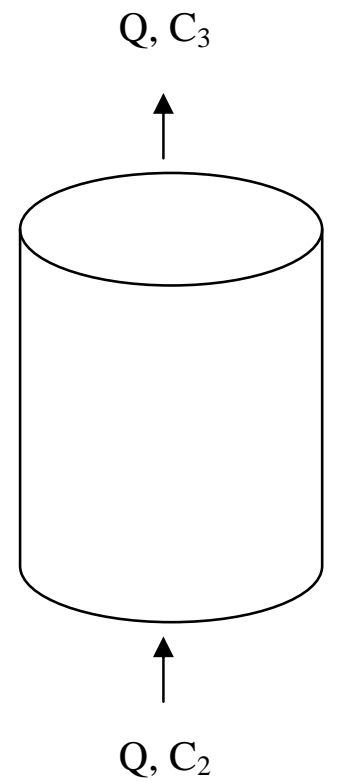

Camada 3: Leito de Espuma de Poliuretano

em que:

Q: Vazão afluente;

$\mathrm{C}_{2}$ : Concentração de Carbono na vazão afluente;

$\mathrm{C}_{3}$ : Concentração de Carbono na vazão efluente.

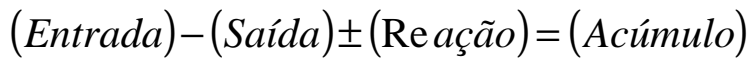

$Q \cdot C_{2}-Q \cdot C_{F}-\left(-r_{c 3}{ }^{*}\right) \cdot V_{3}=0$

O termo $\left(-r_{c 3}{ }^{*}\right)$ é escrito como:

$\left(-r_{c 3}{ }^{*}\right)=k_{3}^{*} \cdot C_{F}$

Dessa forma: 


$$
\begin{aligned}
& Q \cdot C_{2}-Q \cdot C_{F}-\left(k_{3}{ }^{*} \cdot C_{F}\right) \cdot V_{3}=0 \\
& Q \cdot\left(C_{2}-C_{F}\right)=k_{3}{ }^{*} \cdot C_{F} \cdot V_{3} \\
& \left(C_{2}-C_{F}\right)=k_{3}{ }^{*} \cdot C_{F} \cdot \theta h_{3} \rightarrow k_{3}^{*}=\frac{\left(C_{2}-C_{F}\right)}{C_{F} \cdot \theta h_{3}}
\end{aligned}
$$

5.4.2 Balanço para o Nitrogênio: $N_{\text {org }} \rightarrow \mathrm{NH}_{4}^{+} \rightarrow \mathrm{NO}_{2}^{-} \rightarrow \mathrm{NO}_{3}^{-} \rightarrow \mathrm{N}_{2}$

\subsubsection{Camada Acidogênica}

Representação Esquemática:

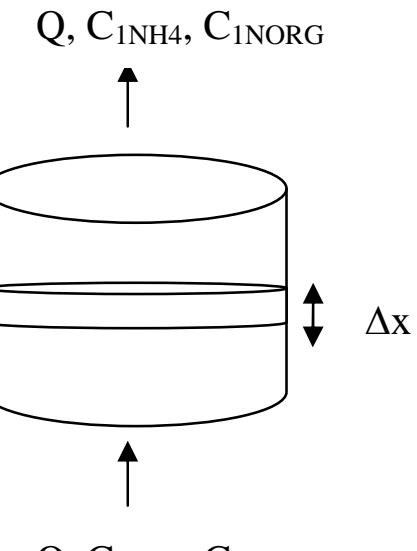

Camada 1: Leito de Argila Expandida

$\mathrm{Q}, \mathrm{C}_{0 \mathrm{NH} 4}, \mathrm{C}_{0 \mathrm{NORG}}$

em que:

Q: Vazão afluente;

$\mathrm{C}_{0 \mathrm{NH} 4}$ : Concentração de Nitrogênio Amoniacal na vazão afluente;

$\mathrm{C}_{\text {ONORG }}$ : Concentração de Nitrogênio Orgânico na vazão afluente;

$\mathrm{C}_{1 \mathrm{NH} 4}$ : Concentração de Nitrogênio Amoniacal na vazão efluente;

$\mathrm{C}_{1 \mathrm{NORG}}$ : Concentração de Nitrogênio Orgânico na vazão efluente. 
Para a camada acidogênica, segmento $\mathrm{n}^{\mathrm{o}} 1$, considerou-se $\mathrm{o}$ modelo de escoamento contínuo tubular ideal, como realizado para o balanço de massa para o carbono. Estabelecendo-se como volume de controle uma seção transversal do reator tubular com espessura $\Delta \mathrm{x}$, regime do sistema permanente e o volume de controle adotado constante, tem-se a seguinte formulação para o balanço do Nitrogênio Amoniacal:

$$
\begin{aligned}
& (\text { Entrada })-(\text { Saída }) \pm(\operatorname{Re} a c ̧ \tilde{o} o)=(\text { Acúmulo }) \\
& Q \cdot C_{0 N H 4}-Q \cdot C_{1 N H 4}+\left(r_{1 N H 4}\right) \cdot d V_{1}=0 \\
& Q \cdot\left(C_{0 N H 4}-C_{1 N H 4}\right)=-\left(r_{1 N H 4}\right) \cdot d V_{1} \\
& Q \cdot d C_{N H 4}=-\left(r_{1 N H 4}\right) \cdot d V_{1}
\end{aligned}
$$

Integrando a equação em intervalos definidos:

$$
\begin{aligned}
Q \cdot \int_{C_{0 N H} 4}^{C_{1 N H 4}} \frac{d C_{N H 4}}{\left(r_{1 N H 4}\right)} & =\int_{0}^{V 1} d V_{1} \\
\text { O termo } & \left(r_{1 N H 4}\right) \text { é escrito como: }
\end{aligned}
$$

$$
\left(r_{1 N H 4}\right)=k_{1 N H 4} \cdot C_{1 N H 4}
$$

Dessa forma:

$$
\begin{aligned}
& Q \cdot \int_{C_{0 N H 4}}^{C_{1 N H 4}} \frac{d C_{N H 4}}{\left(k_{1 N H 4} \cdot C_{1 N H 4}\right)}=\left(V_{1}-0\right) \\
& \theta h_{1}=\frac{1}{k_{1 N H 4}} \cdot \int_{C_{0 N H 4}}^{C_{1 N H 4}} \frac{d C_{N H 4}}{C_{1 N H 4}}=\frac{1}{k_{1 N H 4}} \cdot\left[\ln \left(C_{1 N H 4}\right)-\ln \left(C_{0 N H 4}\right)\right]=\frac{1}{k_{1 N H 4}} \cdot \ln \left(\frac{C_{1 N H 4}}{C_{0 N H 4}}\right) \\
& \ln \left(\frac{C_{1 N H 4}}{C_{0 N H 4}}\right)=k_{1 N H 4} \cdot \theta h_{1} \rightarrow \frac{C_{1 N H 4}}{C_{0 N H 4}}=e^{k_{1 N H 4} \cdot \theta h_{1}} \\
& k_{1 N H 4}=\frac{\ln \left(\frac{C_{1 N H 4}}{C_{0 N H 4}}\right)}{\theta h_{1}}
\end{aligned}
$$


Estabelecendo-se como volume de controle uma seção transversal do reator tubular com espessura $\Delta \mathrm{x}$, regime permanente, tem-se a seguinte formulação para $\mathrm{o}$ balanço do Nitrogênio Orgânico:

$$
\begin{aligned}
& (\text { Entrada })-(\text { Saída }) \pm(\operatorname{Re} a c ̧ \tilde{o} o)=(\text { Acúmulo }) \\
& Q \cdot C_{0 N O R G}-Q \cdot C_{1 N O R G}-\left(-r_{1 N O R G}\right) \cdot d V_{1}=0
\end{aligned}
$$

Para efeito de simplificação do balanço, considerou-se a conversão total do Nitrogênio Orgânico afluente ao sistema à Nitrogênio Amoniacal ao final da primeira zona do reator combinado anaeróbio-aeróbio de leito fixo tratando esgoto sanitário. Essa simplificação pode ser aceita verificando-se o perfil espacial realizado na primeira etapa de operação e reapresentado na Figura 5.50, na qual constata-se o processo de amonificação após passagem do afluente pelo leito acidogênico preenchido com argila expandida.

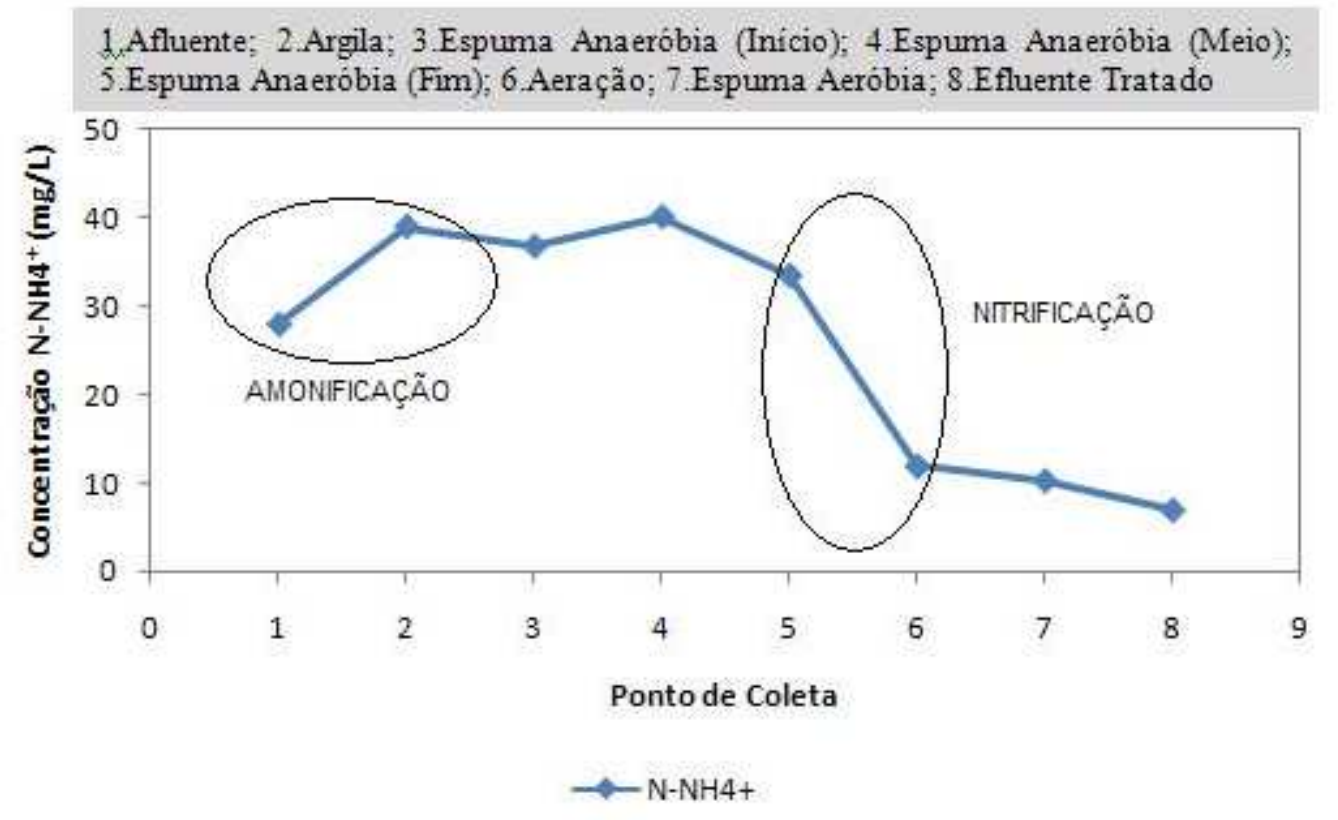

Figura 5.50 - Perfil espacial de Nitrogênio Amoniacal, para esgoto doméstico no reator de leito fixo operado de modo contínuo com TDH de 12 horas 
Pode-se observar pelos valores médios afluentes, $41 \pm 11 \mathrm{mg} / \mathrm{L}$ para N-NTK e $28 \pm 8 \mathrm{mg} / \mathrm{L}$ para $\mathrm{N}$-Amon, encontrados para esta etapa operacional e apresentados na Tabela 5.1, que a maior parte do nitrogênio afluente encontrava-se na forma amoniacal. A variação do nitrogênio orgânico (N-Org) foi calculada pela subtração do N-NTK pelo $\mathrm{N}$-Amon, ao longo do tempo. Confirma-se que o N-Org representou parcela mínima do Nitrogênio após passagem pela camada acidogênica do reator, visto que os valores do $\mathrm{N}$-Amon estiveram próximos a $40 \mathrm{mg} / \mathrm{L}$ durante a passagem do meio líquido na camada posterior anaeróbia/anóxica e este praticamente não apresentou variação ao longo desta camada.

\subsubsection{Camada Anaeróbio/Anóxica}

Representação Esquemática:

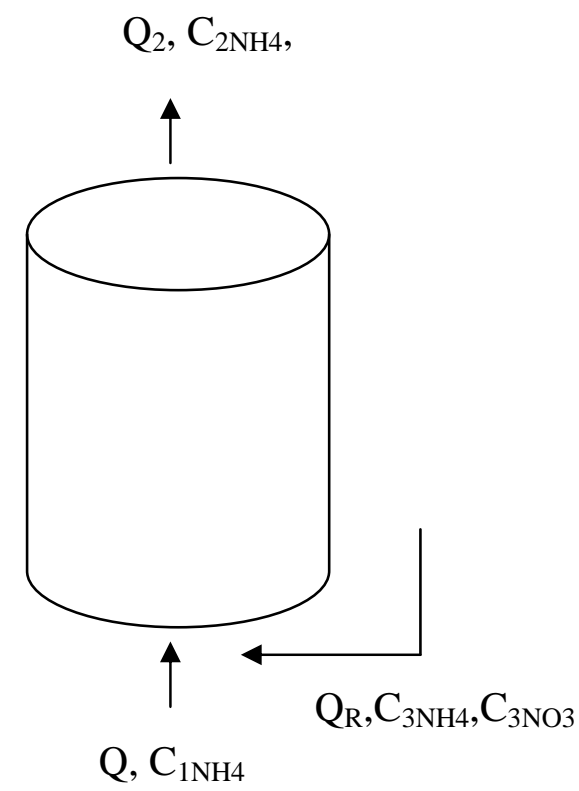

Camada 2: Leito de Espuma de Poliuretano

em que:

Q: Vazão afluente; 
$\mathrm{Q}_{2}$ : Vazão efluente;

$\mathrm{Q}_{\mathrm{R}}$ : Vazão de recirculação;

$\mathrm{C}_{1 \mathrm{NH} 4}$ : Concentração de Nitrogênio Amoniacal na vazão afluente;

$\mathrm{C}_{3 \mathrm{NH} 4}$ : Concentração de Nitrogênio Amoniacal na vazão de recirculação;

$\mathrm{C}_{2 \mathrm{NH} 4}$ : Concentração de Nitrogênio Amoniacal na vazão efluente;

$\mathrm{C}_{3 \mathrm{NO} O}$ : Concentração de Nitrato na vazão de recirculação;

$\mathrm{C}_{2 \mathrm{NO} 3}$ : Concentração de Nitrato na vazão efluente.

Tem-se:

$Q_{R}=Q \cdot r$

$Q_{2}=Q+Q_{R}=Q+Q \cdot r=Q \cdot(1+r)$

Neste caso, considera-se a camada anaeróbia/anóxica como reator de mistura perfeita, como realizado para o balanço de massa para o carbono. Para realização do balanço, considera-se regime permanente com volume de controle apresentado na Figura 5.51 . 


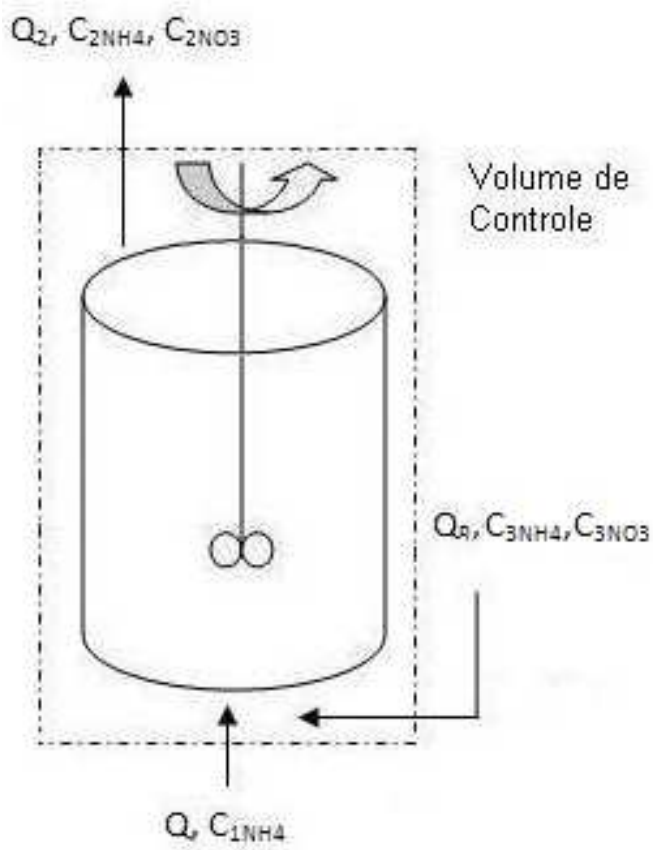

Figura 5.51 - Volume de controle para camada anaeróbia-anóxica do reator combinado para o balanço de nitrogênio

Considerando que praticamente não há variação do Nitrogênio na forma de $\mathrm{N}$-Amon durante a passagem do meio líquido pela camada anaeróbia/anóxica (segmento $\mathrm{n}^{\mathrm{o}}$ 2) do reator combinado de leito fixo, tem-se, então, a seguinte formulação para o balanço do Nitrogênio Amoniacal:

$$
\begin{aligned}
& (\text { Entrada })-(\text { Saída }) \pm(\operatorname{Re} \text { ação })=(\text { Acúmulo }) \\
& Q \cdot C_{1 N H 4}+Q_{R} \cdot C_{3 N H 4}-Q_{2} \cdot C_{2 N H 4}+\left(r_{2 N H 4}\right) \cdot V_{2}=0 \\
& \text { O termo }\left(r_{2 N H 4}\right) \text { é escrito como: } \\
& \left(r_{2 N H 4}\right)=0
\end{aligned}
$$

Dessa forma:

$$
C_{2 N H 4} \cong C_{1 N H 4}
$$


Para o balanço do Nitrogênio na forma de Nitrato, tem-se a formulação apresentada a seguir. Assim como no balanço para o carbono, considera-se este segmento como reator de mistura perfeita. Para realização do balanço, considera-se regime permanente. Diferentemente do que aconteceu no balanço de massa para o carbono, não houve necessidade de conjugar as duas camadas anaeróbia/anóxica e aeróbia, já que neste caso há reação de conversão das formas de Nitrogênio, não há corrente afluente de nitrato e nem indeterminação no balanço.

$$
\begin{aligned}
& (\text { Entrada })-(\text { Saída }) \pm(\operatorname{Re} \text { ação })=(\text { Acúmulo }) \\
& Q_{R} \cdot C_{3 \mathrm{NO} 3}-Q_{2} \cdot C_{2 \mathrm{NO} 3}-\left(-r_{2 \mathrm{NO} 3}\right) \cdot V_{2}=0 \\
& Q \cdot r \cdot C_{3 \mathrm{NO} 3}-Q \cdot(1+r) \cdot C_{2 \mathrm{NO} 3}=\left(-r_{2 \mathrm{NO} 3}\right) \cdot V_{2} \\
& \mathrm{O} \text { termo }\left(-r_{2 \mathrm{NO} 3}\right) \text { é escrito como: } \\
& \left(-r_{2 \mathrm{NO} 3}\right)=k_{2 \mathrm{NO} 3} \cdot C_{2 \mathrm{NO} 3}
\end{aligned}
$$

Dessa forma:

$$
\begin{aligned}
& Q \cdot r \cdot C_{3 \mathrm{NO} 3}-Q \cdot(1+r) \cdot C_{2 \mathrm{NO} 3}=k_{2 \mathrm{NO} 3} \cdot C_{2 \mathrm{NO} 3} \cdot V_{2} \\
& r \cdot C_{3 \mathrm{NO} 3}-(1+r) \cdot C_{2 \mathrm{NO} 3}=k_{2 \mathrm{NO} 3} \cdot C_{2 \mathrm{NO} 3} \cdot \theta h_{2} \\
& {\left[k_{2 \mathrm{NO} 3} \cdot \theta h_{2}+(1+r)\right] \cdot C_{2 N O 3}=r \cdot C_{3 \mathrm{NO} 3}} \\
& \frac{r \cdot C_{3 \mathrm{NO} 3}}{C_{2 \mathrm{NO} 3}}-(1+r) \\
& k_{2 \mathrm{NO} 3}
\end{aligned}
$$

$\mathrm{Na}$ fase sem recirculação, não haverá concentração de Nitrato na vazão de recirculação, o valor de $\mathrm{C}_{2 \mathrm{NO} 3}$ será nulo e conseqüentemente a constante cinética $\mathrm{k}_{2 \mathrm{NO} 3}$ não existirá. Para este caso específico, no módulo anaeróbio/anóxico apenas ocorrerá redução de matéria orgânica, já que a concentração de $\mathrm{N}$-Amon praticamente não 
apresentou variação ao longo desta camada como já discutido e apresentado em gráfico do perfil espacial realizado para o sistema.

\subsubsection{Camada Aeróbia}

Representação Esquemática:

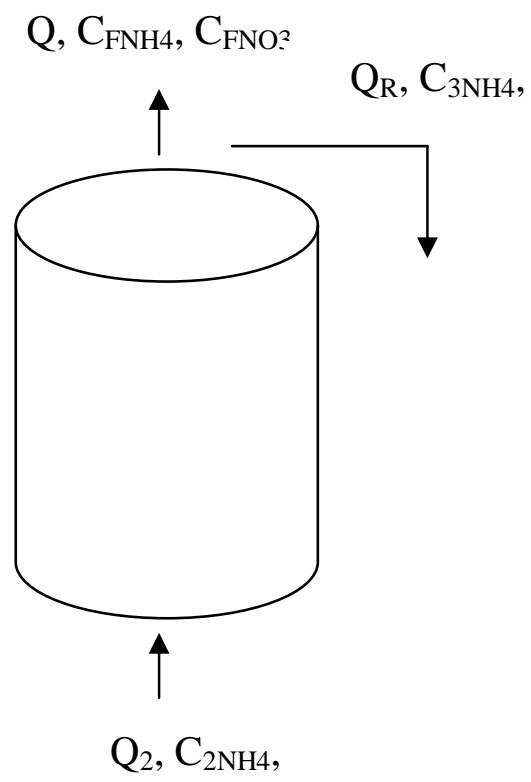

Camada 3: Leito de Espuma de Poliuretano

em que:

Q: Vazão efluente;

$\mathrm{Q}_{2}$ : Vazão afluente;

$\mathrm{Q}_{\mathrm{R}}$ : Vazão de recirculação;

$\mathrm{C}_{2 \mathrm{NH} 4}$ : Concentração de Nitrogênio Amoniacal na vazão afluente;

$\mathrm{C}_{3 \mathrm{NH} 4}$ : Concentração de Nitrogênio Amoniacal na vazão de recirculação;

$\mathrm{C}_{\mathrm{FNH} 4}$ : Concentração de Nitrogênio Amoniacal na vazão efluente;

$\mathrm{C}_{2 \mathrm{NO} 3}$ : Concentração de Nitrato na vazão afluente;

$\mathrm{C}_{3 \mathrm{NO} O 3}$ : Concentração de Nitrato na vazão de recirculação;

$\mathrm{C}_{\mathrm{FNO} 3}$ : Concentração de Nitrato na vazão efluente. 
Temos:

$Q_{R}=Q \cdot r$

$Q_{2}=Q+Q_{R}=Q+Q \cdot r=Q \cdot(1+r)$

Neste caso, considera-se a camada aeróbia (segmento $\mathrm{n}^{\circ} 3$ ) como reator de mistura perfeita. Para realização do balanço, considera-se regime permanente e volume de controle apresentado na Figura 5.52.

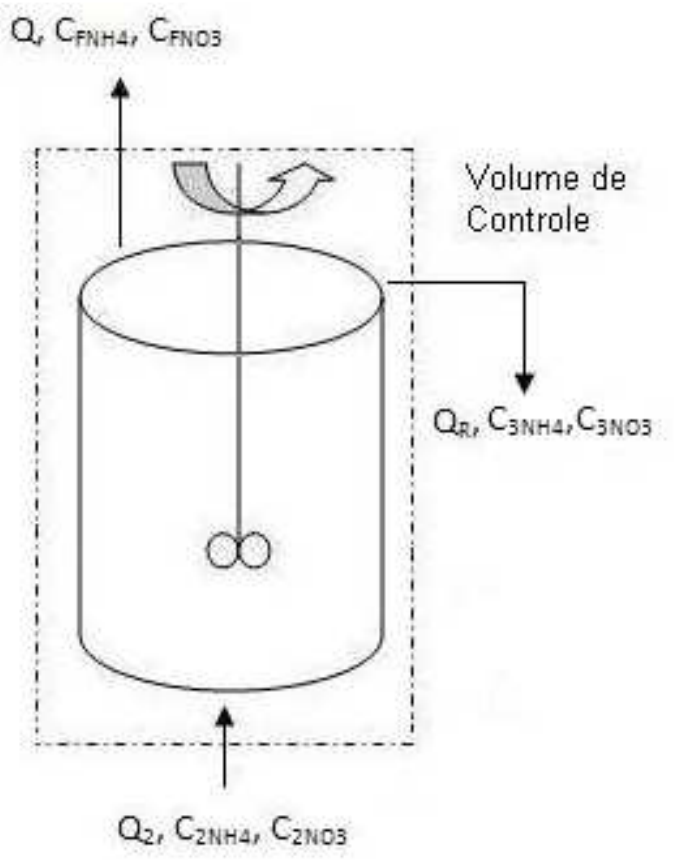

Figura 5.52 - Volume de controle para camada aeróbia do reator combinado para o balanço de nitrogênio

Tem-se, então, a seguinte formulação para o balanço do Nitrogênio Amoniacal:

$($ Entrada $)-($ Saída $) \pm(\operatorname{Re} a c ̧ \tilde{a} o)=($ Acúmulo $)$

$Q_{2} \cdot C_{2 N H 4}-Q_{R} \cdot C_{3 N H 4}-Q \cdot C_{F N H 4}-\left(-r_{3 N H 4}\right) \cdot V_{3}=0$ 
$Q \cdot(1+r) \cdot C_{2 N H 4}-Q \cdot r \cdot C_{3 N H 4}-Q \cdot C_{F N H 4}=\left(-r_{3 N H 4}\right) \cdot V_{3}$

O termo $\left(-r_{3 N H 4}\right)$ é escrito como:

$\left(-r_{3 N H 4}\right)=k_{3 N H 4} \cdot C_{3 N H 4}$

Dessa forma:

$Q \cdot(1+r) \cdot C_{2 N H 4}-Q \cdot r \cdot C_{3 N H 4}-Q \cdot C_{F N H 4}=k_{3 N H 4} \cdot C_{3 N H 4} \cdot V_{3}$

$(1+r) \cdot C_{2 N H 4}-r \cdot C_{3 N H 4}-C_{F N H 4}=k_{3 N H 4} \cdot C_{3 N H 4} \cdot \theta h_{3}$

$k_{3 N H 4}=\frac{(1+r) \cdot C_{2 N H 4}-r \cdot C_{3 N H 4}-C_{F N H 4}}{C_{3 N H 4} \cdot \theta h_{3}}$

Para $\mathrm{r}=0$ é válida a seguinte relação:

$($ Entrada $)-($ Saída $) \pm(\operatorname{Re} a c ̧ a \tilde{o})=($ Acúmulo $)$

$Q \cdot C_{2 N H 4}-Q \cdot C_{F N H 4}-\left(-r_{3 N H 4}{ }^{*}\right) \cdot V_{3}=0$

O termo $\left(-r_{3 N H 4}{ }^{*}\right)$ é escrito como:

$\left(-r_{3 N H 4}{ }^{*}\right)=k_{3 N H 4}{ }^{*} \cdot C_{F N H 4}$

Dessa forma:

$Q \cdot C_{2 N H 4}-Q \cdot C_{F N H 4}-\left(k_{3 N H 4}{ }^{*} \cdot C_{F N H 4}\right) \cdot V_{3}=0$

$Q \cdot\left(C_{2 N H 4}-C_{F N H 4}\right)=k_{3 N H 4}{ }^{*} \cdot C_{F N H 4} \cdot V_{3}$

$C_{2 N H 4}-C_{F N H 4}=k_{3 N H 4}{ }^{*} \cdot C_{F N H 4} \cdot \theta h_{3} \rightarrow k_{3 N H 4}{ }^{*}=\frac{\left(C_{2 N H 4}-C_{F N H 4}\right)}{C_{F N H 4} \cdot \theta h_{3}}$

Para o balanço do Nitrogênio na forma de Nitrato, tem-se a formulação apresentada a seguir. Assim como no balanço para o carbono, considera-se este segmento 
como reator de mistura perfeita. Para realização do balanço, considera-se regime permanente.

$$
\begin{aligned}
& (\text { Entrada })-(\text { Saída }) \pm(\operatorname{Re} \text { ação })=(\text { Acúmulo }) \\
& Q_{2} \cdot C_{2 \mathrm{NO} 3}-Q_{R} \cdot C_{3 \mathrm{NO} 3}-Q \cdot C_{\mathrm{FNO}}+\left(r_{3 \mathrm{NO} 3}\right) \cdot V_{3}=0 \\
& Q \cdot(1+R) \cdot C_{2 \mathrm{NO} 3}-Q \cdot R \cdot C_{3 \mathrm{NO} 3}-Q \cdot C_{\mathrm{FNO}_{3}}=-\left(r_{3 \mathrm{NO} 3}\right) \cdot V_{3}
\end{aligned}
$$

Nesta camada aeróbia o Nitrogênio Amoniacal é convertido à Nitrogênio na forma de Nitrato. Ressalta-se que para esta formulação, despreza-se o Nitrogênio na forma de nitrito como intermediário da reação, então, o termo $\left(r_{3 N O 3}\right)$ pode ser escrito como:

$$
\left(-r_{3 N \mathrm{H} 4}\right)=\left(r_{3 \mathrm{NO} 3}\right)=k_{3 \mathrm{NO} 3} \cdot C_{3 \mathrm{NO} 3}
$$

Dessa forma:

$$
\begin{aligned}
& Q \cdot(1+r) \cdot C_{2 \mathrm{NO} 3}-Q \cdot r \cdot C_{3 \mathrm{NO} 3}-Q \cdot C_{\mathrm{FNO}_{3}}=-k_{3 \mathrm{NO} 3} \cdot C_{3 \mathrm{NO} 3} \cdot V_{3} \\
& (1+r) \cdot C_{2 \mathrm{NO} 3}-r \cdot C_{3 \mathrm{NO} 3}-C_{\mathrm{FNO}_{3}}=-k_{3 \mathrm{NO} 3} \cdot C_{3 \mathrm{NO} 3} \cdot \theta h_{3} \\
& -(1+r) \cdot C_{2 \mathrm{NO} 3}+r \cdot C_{3 \mathrm{NO} 3}+C_{F N O 3}=k_{3 \mathrm{NO} 3} \cdot C_{3 \mathrm{NO} 3} \cdot \theta h_{3} \\
& k_{3 \mathrm{NO} 3}=\frac{r \cdot C_{3 \mathrm{NO} 3}+C_{F N O 3}-(1+r) \cdot C_{2 \mathrm{NO} 3}}{C_{3 \mathrm{NO} 3} \cdot \theta h_{3}}
\end{aligned}
$$

Para $\mathrm{r}=0$ é válida a seguinte relação:

$$
\begin{aligned}
& \left(-r_{3 N H 4}{ }^{*}\right)=\left(r_{3 N O 3}{ }^{*}\right) \rightarrow k_{3 N H 4}{ }^{*} \cdot C_{F_{N H} 4}=k_{3 N O 3}{ }^{*} \cdot C_{F N O 3} \rightarrow k_{3 N O 3}{ }^{*}=k_{3 N H 4}{ }^{*} \cdot \frac{C_{F N H 4}}{C_{F N O 3}} \\
& \text { Considerando que a relação } \frac{k_{3 N O 3}{ }^{*}}{k_{3 N H 4}{ }^{*}} \text { é mantida para as demais fases com }
\end{aligned}
$$
recirculação do efluente nitrificado para a camada anaeróbia/anóxica, com intuito de se promover o processo de desnitrificação, pode-se escrever que: 


$$
\begin{aligned}
& \frac{k_{3 N O 3}{ }^{*}}{k_{3 N H 4}{ }^{*}}=\frac{k_{3 N O 3}}{k_{3 N H 4}}=k_{R} \\
& k_{R}=\frac{r \cdot C_{3 N O 3}+C_{F N O 3}-(1+r) \cdot C_{2 N O 3}}{C_{3 N O 3} \cdot \theta h_{3}} \\
& \quad \frac{C_{3 N H 4} \cdot \theta h_{3}}{C_{3 N O 3}+C_{F N O 3}-(1+r) \cdot C_{2 N O 3}}=k_{R} \cdot \frac{(1+r) \cdot C_{2 N H 4}-r \cdot C_{3 N H 4}-C_{F N H 4}}{C_{3 N H 4} \cdot \theta h_{3}} \\
& r \cdot C_{3 N O 3}+C_{F N O 3}-(1+r) \cdot C_{2 N O 3}=k_{R} \cdot C_{3 N O 3} \cdot \theta h_{3} \cdot \frac{\left[(1+r) \cdot C_{2 N H 4}-r \cdot C_{3 N H 4}-C_{F N H 4}\right]}{C_{3 N H 4} \cdot \theta h_{3}} \\
& -r \cdot C_{3 N O 3}-C_{F N O 3}+(1+r) \cdot C_{2 N O 3}=-k_{R} \cdot C_{3 N O 3} \cdot \frac{\left[(1+r) \cdot C_{2 N H 4}-r \cdot C_{3 N H 4}-C_{F N H 4}\right]}{C_{3 N H 4}} \\
& C_{2 N O 3}=\frac{(1+r)}{r \cdot C_{3 N O 3}+C_{F N O 3}-\frac{k_{R} \cdot C_{3 N O 3} \cdot\left[(1+r) \cdot C_{2 N H 4}-r \cdot C_{3 N H 4}-C_{F N H 4}\right]}{C_{3 N H 4}}} \\
& (1+r) \cdot C_{2 N O 3}=r \cdot C_{3 N O 3}+C_{F N O 3}-\frac{k_{R} \cdot C_{3 N O 3} \cdot\left[(1+r) \cdot C_{2 N H 4}-r \cdot C_{3 N H 4}-C_{F N H 4}\right]}{C_{3 N H 4}}
\end{aligned}
$$

\subsubsection{Estimativa das constantes cinéticas}

Utilizando as equações encontradas nos balanços de massa realizados para o reator combinado anaeróbio-aeróbio de leito fixo em escala piloto, encontram-se os valores das constantes cinéticas aparentes apresentados na Tabela 5.9. A mesma Tabela ainda mostra os valores dos parâmetros utilizados para os respectivos cálculos. 
Tabela 5.9 - Constantes cinéticas aparentes para o reator combinado anaeróbioaeróbio de leito fixo.

\begin{tabular}{ccc|cc|cc}
\hline Constante & Valor $\left(\mathrm{h}^{-1}\right)$ & Reação & Parâmetro & Valor & Parâmetro & Valor \\
Cinética $^{* *}$ & & & & & \\
\hline $\mathrm{k}_{1}$ & 0,27 & Consumo & $\mathrm{C}_{0}$ & $514,6 \mathrm{mg} / \mathrm{L}$ & $\mathrm{C}_{3 \mathrm{NH} 4}$ & $10,4 \mathrm{mg} / \mathrm{L}$ \\
$\mathrm{k}_{2 / 3}$ & 0,99 & Consumo & $\mathrm{C}_{1}$ & $313,5 \mathrm{mg} / \mathrm{L}$ & $\mathrm{C}_{\mathrm{FNH} 4}$ & $7,0 \mathrm{mg} / \mathrm{L}$ \\
$\mathrm{k}_{1 \mathrm{NH} 4}$ & 0,18 & Produção & $\mathrm{C}_{2}$ & $212,9 \mathrm{mg} / \mathrm{L}$ & $\mathrm{C}_{2 \mathrm{NO} 3}{ }^{* *}$ & $<0 \mathrm{mg} / \mathrm{L}$ \\
$\mathrm{k}_{2 \mathrm{NO} 3}$ & $>\mathrm{k}_{3 \mathrm{NO} 3}$ & Consumo & $\mathrm{C}_{3}$ & $63,4 \mathrm{mg} / \mathrm{L}$ & $\mathrm{C}_{3 \mathrm{NO} 3}$ & $7,4 \mathrm{mg} / \mathrm{L}$ \\
$\mathrm{k}_{3 \mathrm{NH} 4}$ & 4,39 & Consumo & $\mathrm{C}_{\mathrm{F}}$ & $43,5 \mathrm{mg} / \mathrm{L}$ & $\mathrm{C}_{\mathrm{FNO} 3}$ & $4,0 \mathrm{mg} / \mathrm{L}$ \\
$\mathrm{k}_{3 \mathrm{NH} 4}{ }^{*}$ & 1,29 & Consumo & $\mathrm{C}_{\mathrm{R}}{ }^{* *}$ & $125,9 \mathrm{mg} / \mathrm{L}$ & $\mathrm{TDH}_{1}$ & $1,84 \mathrm{~h}$ \\
$\mathrm{k}_{3 \mathrm{NO} 3}$ & 1,37 & Produção & $\mathrm{C}_{0 \mathrm{NH} 4}$ & $28,0 \mathrm{mg} / \mathrm{L}$ & $\mathrm{TDH}_{2}$ & $3,69 \mathrm{~h}$ \\
$\mathrm{k}_{3 \mathrm{NO} 3}{ }^{*}$ & 1,06 & Produção & $\mathrm{C}_{1 \mathrm{NH} 4}$ & $39,0 \mathrm{mg} / \mathrm{L}$ & $\mathrm{TDH}_{3}$ & $2,58 \mathrm{~h}$ \\
& & & $\mathrm{C}_{2 \mathrm{NH} 4}$ & $39,0 \mathrm{mg} / \mathrm{L}$ & $\mathrm{TDH}_{2 / 3}$ & $6,27 \mathrm{~h}$ \\
\hline
\end{tabular}

\footnotetext{
Valores calculados através das equações geradas pelos balanços de massa.
}

Os valores dos parâmetros utilizados para cálculo das constantes cinéticas aparentes foram retirados do ensaio do comportamento espacial do reator combinado de leito fixo para a etapa de operação com TDH de 12 h e razão de recirculação igual a 3,0, a qual apresentou os resultados mais satisfatórios, tanto para a remoção de carbono quanto para conversão das forma de Nitrogênio. Valores médios encontrados para a fase sem recirculação foram utilizados para cálculo da relação $\frac{k_{3 N O 3}{ }^{*}}{k_{3 N H 4}{ }^{*}}$.

Uma breve análise dos dados obtidos revela que o tempo de residência na camada anaeróbia-anóxica foi suficiente para promover a redução do nitrato proveniente da zona aeróbia do reator, tendo em vista o valor encontrado para tal parâmetro $\left(\mathrm{C}_{2 \mathrm{NO} 3}\right)$. Com 
isso, o valor da constante de desnitrificação $\left(\mathrm{k}_{2 \mathrm{NO} 3}\right)$ foi considerado superior ao da constante de nitrificação $\left(\mathrm{k}_{3 \mathrm{NO} 3}\right)$.

Observa-se que a recirculação imposta promoveu aumento dos valores das constantes de consumo de nitrogênio amoniacal e formação de nitrato, assim como foi evidenciado durante a etapa experimental constatando melhora devido a elevação da velocidade de transferência de massa líquido-sólido pela elevação da velocidade superficial no leito.

A Tabela 5.10 apresenta valores de constantes cinéticas de degradação de matéria orgânica encontrados por Castillo et al. (1999) em um estudo cinético para sistema combinado anaeróbio-aeróbio tratando esgoto sanitário composto por reator tipo UASB seguido por dois reatores aeróbios tipo RBC (rotating biological contactor), em série, com difusores de ar instalados no fundo dos tanques e por Fazolo (2003) em estudo para estimativa dos parâmetros cinéticos e de transferência de massa em um reator aeróbio de leito fixo utilizado no pós-tratamento de efluente anaeróbio, em comparação com as constantes encontradas para o reator combinado de leito fixo. 
Tabela 5.10 - Comparação entre as constantes cinéticas de alguns estudos com sistemas combinados tratando esgoto sanitário.

\begin{tabular}{cccc}
\hline Tecnologia & Constante Cinética $\left(\mathrm{h}^{-1}\right)$ & Conversão & Fonte \\
\hline UASB & $0,3096 \pm 0,004$ & Carbono & Castillo et al. (1999) \\
RBC-1 & $1,960 \pm 0.781$ & Carbono & Castillo et al. (1999) \\
RBC-2 & $1,077 \pm 1.362$ & Carbono & Castillo et al. (1999) \\
RAHLF + RRLF & $0,2514^{\mathrm{c}}$ & Nitrogênio & Fazolo (2003) \\
RAHLF + RRLF & $6,624^{\mathrm{d}}$ & Nitrogênio & Fazolo (2003) \\
RCLF ${ }^{\mathrm{b}}$ (Leito Anaeróbio) & 0,27 & Carbono & Estudo atual \\
RCLF (Leito Combinado) & 0,99 & Carbono & Estudo atual \\
RCLF & $4,39^{\mathrm{e}}$ & Nitrogênio & Estudo atual \\
RCLF & $1,37^{\mathrm{f}}$ & Nitrogênio & Estudo atual
\end{tabular}

\footnotetext{
${ }^{\text {a }}$ Reator Anaeróbio Horizontal de Leito Fixo + Reator Radial de Leito Fixo.

${ }^{\mathrm{b}}$ Reator combinado de leito fixo.

${ }^{c}$ conversão do nitrogênio amoniacal a nitrito

${ }^{\mathrm{d}}$ conversão do nitrito a nitrato

${ }^{\text {e }}$ consumo de nitrogênio amoniacal

${ }^{\mathrm{f}}$ produção de nitrato
}

Observa-se, também, que o nitrogênio amoniacal consumido na zona aeróbia do reator não foi totalmente convertido a nitrato, ocasionando diferentes velocidades de consumo e produção, respectivamente. Isso significa que, parte do nitrogênio foi removido do sistema via assimilação celular ou nitrificação e desnitrificação simultâneas (NDS) na zona aeróbia do reator. 


\subsection{Considerações Finais}

Os resultados encontrados durante a pesquisa mostraram que o reator combinado anaeróbio-aeróbio vertical de leito fixo com recirculação de efluente tratado tem potencial para fornecer expressivos resultados de remoção de matéria orgânica e nitrogênio através de método biológico, se respeitados alguns dos parâmetros operacionais do processo.

Comparado com outros sistemas de tratamento de esgoto sanitário para a remoção de matéria orgânica e nitrogênio, o reator combinado de leito fixo com recirculação de efluente tratado, para promover o processo de desnitrificação, apresentou ótimo desempenho, obtendo eficiências médias na remoção de DQO e NTK de $92 \pm 3 \%$ e $68 \pm 11 \%$, respectivamente, para razão de recirculação igual a 3,0 e TDH de 12 h, com carga orgânica volumétrica removida de $1,08 \pm 0,04 \mathrm{kgDQO} / \mathrm{m}^{3}$.dia obtendo-se relação $\mathrm{COV}_{\text {removida }} / \mathrm{COV}_{\text {aplicada }}$ igual a 0,92 .

Deve ser ressaltado principalmente que este tipo de reator permite a ciclagem interna das fontes de carbono para a desnitrificação e a recuperação da alcalinidade, visto que não foi necessário a adição de bicarbonato de cálcio no afluente ao reator combinado anaeróbio-aeróbio de leito fixo, para suprir a demanda de alcalinidade consumida no processo de nitrificação, já que com as razões de recirculação impostas ao sistema, durante a primeira etapa operacional com $\mathrm{TDH}$ de $12 \mathrm{~h}$, houve grande mistura e consequente homogeneização do meio líquido no reator acarretando recuperação da alcalinidade. Outro benefício da recirculação de efluente tratado foi a ciclagem interna das fontes de carbono e doadores de elétrons para promover a desnitrificação, não sendo necessário também adição de uma fonte exógena de fonte de carbono, necessária quando são operados reatores combinados anaeróbio-aeróbio-anóxico com a finalidade de remoção de matéria orgânica e de nitrogênio. 
O reator combinado anaeróbio-aeróbio de leito fixo revelou ser uma unidade interessante para ser utilizada como unidade de tratamento para pequenas comunidades ou pequenas vazões, pois alcança bons resultados e valores reduzidos de concentração dos compostos de nitrogênio, mesmo sem fornecimento de matéria orgânica. Os resultados positivos foram obtidos provavelmente pelo fato de a configuração proporcionar grande mistura e apresentar zonas anaeróbias e aeróbias conjugadas.

Já as equações encontradas com auxílio dos balanços de massa realizados para o reator combinado anaeróbio-aeróbio de leito fixo em escala piloto, possibilitaram a estimativa e comparação dos valores das constantes cinéticas aparentes, tanto para remoção da matéria orgânica ao longo dos módulos do sistema, quanto para conversão das formas de Nitrogênio. 


\section{CONCLUSÕES}

Os resultados obtidos nesse trabalho mostram a importância da utilização de novas alternativas para o tratamento de águas residuárias. $\mathrm{O}$ reator combinado de leito fixo e escoamento ascendente, em escala piloto, apresentou ótimo desempenho com relação à remoção de matéria orgânica e nitrogênio de esgoto sanitário, durante a primeira etapa de operação, evidenciado pela comparação com as demais tecnologias utilizadas em larga escala.

A etapa operacional com tempo de detenção hidráulica de 12 horas foi mais efetiva que as outras duas etapas estudadas $(10$ e $8 \mathrm{~h})$, tanto para a eficiência global do processo quanto para a estabilidade do processo de digestão anaeróbia. Com isso, foi possível verificar a importância de um adequado TDH no sistema, que pode ser considerado a variável mais significativa para o desempenho global do reator, influenciando de forma direta nas cargas orgânica e nitrogenada aplicadas. Houve boa remoção de sólidos no sistema, com média acima dos $80 \%$ para sólidos suspensos totais, sendo encontrados baixos valores efluentes de SST e SSV durante esta etapa experimental.

Após análise dos resultados para o reator combinado anaeróbio-aeróbio, pôde-se constatar que a união dos aspectos positivos de cada processo traz grandes vantagens para o tratamento de esgoto sanitário. A combinação do processo anaeróbio com o aeróbio foi vantajosa para polimento final, com remoção da matéria orgânica remanescente e, também, para nitrificação biológica do efluente, visto que esta teve início após 12 dias da estabilização do processo de remoção de matéria orgânica carbonácea, atingindo uma $\mathrm{CVN}_{\text {removida }}$ de $0,06 \mathrm{kgNTK} / \mathrm{m}^{3}$.dia, após recirculação do efluente nitrificado e obtenção do processo de desnitrificação. A camada aeróbia reduziu efetivamente a concentração 
total de matéria orgânica no efluente chegando a valores de DQO bem próximos a 50 mg/L e remoção acima de 90\%, com o sistema operando com TDH de 12 h.

O reator combinado anaeróbio-aeróbio com recirculação da fase líquida, além de manter altas eficiências de remoção de matéria orgânica, também apresentou boa eficiência de remoção de nitrogênio, principalmente após a inserção da vazão de recirculação, quando foram atingidas eficiências de $68 \%$ para NTK, na fase com razão de recirculação de 3,0 e TDH igual a 12 h. A análise dos resultados revela ganhos obtidos quando houve aumento na vazão de recirculação do efluente tratado, principalmente em relação à remoção de matéria orgânica e nitrogênio, inclusive pela observação dos valores encontrados para as constantes cinéticas aparentes, comprovando ser esta uma variável de grande importância para a melhora do comportamento do reator, não havendo necessidade de adição de alcalinidade nem de fonte exógena de fonte de carbono para promover a desnitrificação em níveis substanciais.

A comparação do comportamento e estabilidade do reator combinado anaeróbioaeróbio de leito fixo em escala piloto e laboratório permite realçar que as condições operacionais do sistema em maior escala são mais desfavoráveis em relação aquelas que são proporcionadas em escala de bancada, fato este comprovado pelas eficiências de remoção de matéria orgânica, 92\% e 95\%, de remoção de Nitrogênio (NTK), 68\% e 85\%, respectivamente, e pelo tempo necessário para adaptação do sistema. Contudo o sistema em escala piloto consegue atingir uma situação de estabilidade e eficiência elevada, devido à progressiva adaptação das populações bacterianas às condições reais de alimentação, mantendo resultados próximos aos encontrados em escala de laboratório.

A comparação entre os parâmetros operacionais de sistemas de tratamento que utilizam tecnologias avançadas, com reatores alternativos, e dos mais convencionalmente utilizados, visando a remoção de matéria orgânica e conversão das formas de Nitrogênio, 
confirmam o reator combinado anaeróbio-aeróbio de leito fixo como solução tecnológica para tratamento de esgoto sanitário tendo em vista o bom desempenho em absorver altas cargas orgânicas e nitrogenadas necessitando de tempo de detenção hidráulica compatível com as demais tecnologias apresentadas, possibilitando a construção de unidades compactas de tratamento, com remoção de DQO superior a sistemas unicamente anaeróbios, sem geração de odores e produção de lodo e consumo energético inferiores aos encontrados em unidades de tratamento aeróbias.

O estudo de novas tecnologias de tratamento biológico de esgoto sanitário, e demais tipos de efluentes, continuará extremamente desafiante, pelo fato principal da necessidade de se utilizar a água de forma responsável e, quando descartada, a água residuária deverá apresentar a melhor qualidade possível. Além disso, deve-se ressaltar a importância da correta escolha do material a ser empregado para construção da unidade de tratamento levando-se em consideração aspectos técnicos e econômicos. 


\section{SUGESTÕES}

Diante dos resultados obtidos nesse trabalho, as seguintes ações são sugeridas para o aprimoramento dos reatores combinados de leito fixo e escoamento ascendente:

- Efetuar ensaios específicos no biofilme anaeróbio e aeróbio do reator combinado de leito fixo e fluxo contínuo para avaliar a cinética de consumo da matéria orgânica e de consumo e produção do material nitrogenado a fim de comparar com os resultados encontrados através dos balanços de massa realizados;

- Estudar a composição e o tratamento dos gases gerados no reator combinado de leito fixo quando operado sob condições anaeróbia e anaeróbia-aeróbia;

- Realizar ensaios hidrodinâmicos após o término do período operacional para verificar aspectos relacionados a hidrodinâmica existente na zona de reação do reator anaeróbio-aeróbio de leito fixo;

- Inserir flanges ao longo da altura do reator para servirem como amostradores de partículas e possibilitar manutenção dos difusores de ar sem a necessidade de esvaziamento por completo do sistema, facilitando a limpeza ou troca dos aeradores, evitando problemas com entupimento devido a formação de biopolímeros;

- Investigar estratégias de limpeza do leito reacional do reator visando a remoção do excesso de biomassa formado durante operação do sistema;

- Reavaliar a capacidade de remoção de matéria orgânica e de consumo e produção do material nitrogenado utilizando afluente provido de sistema de tratamento preliminar; 
- Avaliar os custos operacional e de instalação deste processo, visando sua aplicação em escala real. 


\section{REFERÊNCIAS BIBLIOGRÁFICAS}

APHA. (1998). Standard methods for the examination of waste and wastewater. American Public Health association, Washington, D.C. 19th Ed.

ARAÚJO JR., M.M. (2006). Reator combinado anaeróbio-aeróbio de leito fixo para remoção de matéria orgânica e nitrogênio de água residuária de indústria produtora de lisina. Tese (Doutorado) - Escola de Engenharia de São Carlos, Universidade de São Paulo. 136p.

BARNES, D.; BLISS, P.J. (1983). Biological control of nitrogen in wastewater treatment. London, E. \& F. N. Spon, p.4-47.

BIAZIN, J. F. (2010). Estudo comparativo entre reservatórios de concreto armado, fibra de vidro e polietileno. Monografia - Universidade Católica de Salvador (UCSal).

BODIK, I.; KRATOTCHVÍL, K.; HERDOVA, B., TAPIA, G.; GASPARIKOVÁ, E. (2002). Municipal wastewater treatment in the anaerobic-aerobic baffled filter reactor at ambient temperature. Water Science and Technology, 46 (8): 127-135.

BODIK, I.; KRATOTCHVÍL, K.; GASPARIKOVÁ, E.; HUTNAN, M. (2003). Nitrogen removal in an anaerobic baffled filter reactor with aerobic posttreatment. Bioresource Technology, v. 86, p. 79-84.

BONIFÁCIO, S. N. (2001). Estação de Tratamento de Esgotos - ETE em Ferrocimento Composta de Reator Anaeróbio de Fluxo Ascendente, Filtro Anaeróbio e Leito de Secagem. In: $21^{\circ}$ Congresso Brasileiro de Engenharia Sanitária e Ambiental. João Pessoa, 2001. Anais do $21^{\circ}$ Congresso Brasileiro de Engenharia Sanitária e Ambiental. Rio de Janeiro: ABES, 2001. CD-ROM.

BOTHE, H.; JOST G.; SCHLOTER M.; WARD B. B.; WITZEL K. (2000). Molecular analysis of ammonia oxidation and denitrification in natural environments. FEMS 
Microbiology Reviews. v.24, p.673-690.

BRUCE, A. M.; MERKENS, J. C.; HAYNES, B. A. O. (1975). Pilot-scale studies on the treatment of domestic sewage by two-stage biological nitrification with special reference nitrification. Water pollution control, v. 74, pp.80-100.

CALLADO, N. H.; FORESTI E. (2000). Tratamento de esgoto doméstico com remoção de nitrogênio e fósforo em reatores sequenciais em batelada. In: Congresso Interamericano de Ingenieria Sanitaria Y Ambiental, 27, Porto Alegre. Porto Alegre, 2000. Anais, Porto Alegre.

CALLADO, N. H. (2001). Reatores seqüenciais em batelada em sistemas anaeróbioaeróbio tratando esgoto sanitário sintético e com remoção de nutrientes. Tese (Doutorado) - Escola de Engenharia de São Carlos, Universidade de São Paulo.

CASTILLO A.; LLABRES P.; MATA-ALVAREZ J. (1999). A kinetic study of a combined anaerobic-aerobic system for treatment of domestic sewage. Wat. Res., Vol. 33, No. 7, pp. 1742-1747.

CHAN, S. Y.; TSANG Y. F.; CUI L. H.; CHUA H. (2008). Domestic wastewater treatment using batch-fed constructed wetland and predictive model development for NH3-N removal. Process Biochemistry 43: 297-305.

CHERNICHARO C. A. L. (2006). Post-treatment options for the anaerobic treatment of domestic wastewater. Reviews in Environmental Science and Bio/Technology, 5:7392.

COSTA C.; DIJKEMA C.; FRIEDRICH M.; ENCINA P. G.; FERNÁNDEZ P.; STAMS A. J. M. (2000). Denitrification with methane as electron donor in oxygen-limited bioreactors. Applied microbiology and biotechnology. v.53, p.754-762.

Del POZO, R.; DIEZ V. (2005). Integrated anaerobic-aerobic fixed-film reactor for slaughterhouse wastewater treatment. Water Research, 39: 1114-1122. 
DILALlO, R.; ALBERTSON, O.E. (1961). Volatile acids by direct tritation. Journal WPCF, 33: 356-365.

DOS SANTOS P. P.; DI-BERARDINO S. (1997). Performance of an Anaerobic Hybrid Filter Treating Milk Processing Wastewater. Proc 8 Int. Congress Anaer. Dig. (poster session) May 25-29, Sendai, Japan.

EISENTRAEGER, A. (2001). Denitrification of groundwater with methane as sole hydrogen donor. Water research. v.35, n.9, p.2261-2267.

FAZOLO, A. (2003). Determinação de parâmetros cinéticos e de transferência de massa em reator radial aeróbio-anóxico alimentado com esgoto sanitário tratado em reator anaeróbio. Tese (Doutorado) - Escola de Engenharia de São Carlos, Universidade de São Paulo.

FONTANA, H.; OLIVEIRA NETTO A. P.; DANIEL, L. A.; CARVALHO Jr. O. (2007). Desempenho técnico de biofiltro aerado submerso preenchido com carvão granular utilizado no pós-tratamento de esgoto sanitário. $24^{\circ}$ Congresso Brasileiro de Engenharia Sanitária e Ambiental, ABES.

FORESTI, E; ZAIAT, M; VALLERO, M. (2006). Anaerobic processes as the core technology for sustainable domestic wastewater treatment: Consolidated applications, new trends, perspectives and challenges. Reviews in Environmental Science an Bio/Technology, 5:3-19.

GARBOSSA, L. H. P. (2003). Desenvolvimento e avaliação de sistema de leito fixo reator misto radial seguido de reator anóxico horizontal - para remoção de matéria orgânica e nitrogênio de esgoto sanitário. Dissertação (Mestrado) - Escola de Engenharia de São Carlos, Universidade de São Paulo.

GARBOSSA, L. H. P. (2006). Avaliação de sistemas anaeróbio - aeróbio com biomassa imobilizada para remoção de matéria carbonácea e nitrogênio de esgoto sanitário e 
uso do biogás na desnitrificação. Tese (Doutorado) - Escola de Engenharia de São Carlos, Universidade de São Paulo.

GASPAR, P. M. F. (2003). Pós-tratamento de efluente de reator UASB em sistema de lodos ativados visando a remoção biológica do nitrogênio associada à remoção físico-química do fósforo. Dissertação (Mestrado) - Escola de Engenharia de São Carlos, Universidade de São Paulo.

HOFFMANN, H.; THANS, F. C.; RAE, M. J.; PLATZER, C.; COSTA, R. H. R. (2007). Controle da nitrificação e desnitrificação em paralelo via concentração de oxigênio em reator operado em bateladas seqüenciais ( $r b s$ em escala real para tratamento de esgotos sanitários. $24^{\circ}$ Congresso Brasileiro de Engenharia Sanitária e Ambiental, ABES.

IBGE - Instituto Brasileiro de Geografia e Estatística. Pesquisa Nacional por Amostra de Domicícios - PNAD (2003). Disponível em: <http://www.ibge.gov.br>.

JORDÃO, E. P.; PESSOA, C. A. (2005). Tratamento de esgotos domésticos. 4. ed. Rio de Janeiro: Associação Brasileira de Engenharia Sanitária e Ambiental. 932 p.

KATO, M. T.; ANDRADE NETO, C. O.; CHERNICHARO C. A. L.; FORESTI E.; CYBIS, L. F. (1999). Configurações de reatores anaeróbios. In: Campos, J. R. (coord.). Tratamento de esgotos sanitários por processo anaeróbio e disposição controlada no solo. Projeto PROSAB, Rio de Janeiro, pp.53-99.

KATO, M. T.; FLORÊNCIO L.; ARANTES F. R. M. (2001). Tratamento de esgotos sanitários em reatores EGSB anaeróbio e aeróbio. Pós-tratamento de efluentes de reatores anaeróbios. Coletânea de Trabalhos Técnicos, volume 2, pp. 165-174.

La MOTTA, E. J.; SILVA, E.; BUSTILlOS, A.; PADRÓN, H.; LUQUE, J. (2007). Combined Anaerobic/Aerobic Secondary Municipal Wastewater Treatment: Pilot- 
Plant Demonstration of the UASB/Aerobic Solids Contact System. Journal of Environmental Engineering, Vol. 133, No. 4, pp. 397-403.

LEME, E. J. A. (2008). Manual Prático de Tratamento de Águas Residuárias. São Carlos: EdUFSCar. 595 p.

MAHMOUD, M.; TAWFIK, A; SAMHAN, F; EL-GOHARY, E. (2009). Sewage treatment using an integrated system consisting of anaerobic hybrid reactor (AHR) and downflow hanging sponge (DHS). Desalination and Water Treatment - Science and Engineering, 4 (1-3): 168-176.

MENDONÇA, N. M. (2004). Tratamento de esgoto sanitário empregando reator de leito expandido em escala plena com zonas anaeróbia e aeróbia sobrepostas: concepção, construção e operação. Tese (Doutorado) - Escola de Engenharia de São Carlos, Universidade de São Paulo.

METCALF \& EDDY. INC. (1991). Wastewater Engineering - treatment disposal reuse. 3ed. New York, McGraw-Hill Book.

METCALF \& EDDY (2003). Wastewater Engineering, McGrawHill, New York.

NOGUEIRA, R.; MELO L. F.; PURKHOLD, U.; WUERTZ, S.; WAGNER, M. (2002). Nitrifying and heterotrophic population dynamics in biofilm reactor: effects and hydraulic retention time and the presence of organic carbon. Water Research, v.36, p. 469-481.

NOUR, E. A. A; CAMARGO, S. A. R.; ROSTON D. M.; PATERNIANI J. E. S.; BARRETTO, A. S. (2007). Avaliação da redução de nitrogênio, fósforo e coliformes termotolerantes em sistema de tratamento de esgoto sanitário visando reuso. $24^{\circ}$ Congresso Brasileiro de Engenharia Sanitária e Ambiental, ABES. 
ORTEGA, F S; ROCHA, K M; ZAIAT, M.; PANDOLFELLI, V. C. (2001). Aplicação de Espumas Cerâmicas Produzidas via Gelcasting em Biorreator para Tratamento de Águas Residuárias. Cerâmica, v. 47, n.304 p. 199-203.

OLIVEIRA NETTO, A. P. (2007). Reator anaeróbio-aeróbio de leito fixo, com recirculação da fase líquida, aplicado ao tratamento de esgoto sanitário. Dissertação (Mestrado) - Escola de Engenharia de São Carlos, Universidade de São Paulo.

PONTES, P. P.; CHERNICHARO, C. A. L. (2009). Efeito do retorno de lodo aeróbio sobre as características da biomassa presente em reatores UASB tratando esgoto sanitário. Engenharia Sanitária e Ambiental, 14 (2): 223-234.

RIBEIRO, R; VARESCHE, M B A; FORESTI, E; ZAIAT, M. (2005). Influence of the Carbon Source on the Anaerobic Biomass Adhesion on Polyurethane Foam Matrices. Journal of Environmental Management, v. 74, n. 2, p. 187-194.

RIPLEY, L.E.; BOYLE, W.C.; CONVERSE, J.C. (1986). Improved alkalimetric monitoring for anaerobic digestion of high-strength wastes. Journal WPCF, 58: 406411.

RODRÍGUEZ, J. A. (2006). Filtro biológico aeróbio/anóxico para remoção de Nitrogênio de efluentes de reatores UASB. Tese (Doutorado) - Escola de Engenharia de São Carlos, Universidade de São Paulo.

ROJAS, M. del P. A.; de OLIVEIRA NETTO, A. P.; ZAIAT, M. (2008). Actividad metanogénica específica en un reactor anaerobio - aerobio aplicado al tratamiento de agua residual doméstica. Interciência, 33 (4): 284 - 289.

SANEPAR - Companhia de Saneamento do Paraná, (1997). Disponível em: <http://site.sanepar.com.br/>.

SANTOS, A. V.; CYBIS, L.F. e GEHLING, G. R. (2003). Eficiência do reator seqüencial em batelada (RSB) na remoção de nitrogênio no tratamento de esgoto 
doméstico com DQO baixa. In: XXII Congresso brasileiro de engenharia sanitária e ambiental, Anais, Joinville, CD ROM.

SANTOS, P. I. A. (2004). Remoção de DQO e de Nitrogênio, e estudo dos consórcios microbianos em sistema com três reatores sobrepostos, em série, alimentado com esgoto sanitário. Tese (Doutorado) - Escola de Engenharia de São Carlos, Universidade de São Paulo.

SCHMIDT, I.; SLIEKERS, O.; SCHMID, M.; BOCK, E.; FUERST J.; KUENEN, J.G.; JETTEN, M.S.M.; STROUS, M. (2003). New concepts of microbial treatment processes for the nitrogen removal in wastewater. FEMS Microbiology Reviews, 27, 481-492.

SEDLAK, R. (1991). Phosphorus and nitrogen from municipal wastewater: principles and practice. Chelsea: Lewis Publisher.

SILVA G. H. R.; NOUR E. A. A. (2004). Reator compartimentado anaeróbio/aeróbio: Sistema de baixo custo para tratamento de esgotos de pequenas comunidades. Revista Brasileira de Engenharia Agrícola e Ambiental, v. 9, n.2, p. 268-275.

SONOBE H. G.; OLIVEIRA NETTO A. P.; ZAIAT M. (2010). Influência da carga orgânica no desempenho de reator anaeróbio-aeróbio de leito fixo aplicado ao tratamento de esgoto sanitário. Anais do IV seminário do projeto temático. São Carlos/SP.

SURAMPALli, R. Y.;TYAGI, R. D.; SCHEIBLE, O. K.; HEIDMAN, J. A. (1997). Nitrification, denitrification and phosphorus removal in sequential batch reactors. Bioresource Technology, v.61, p.151-7.

TANDUKAR, M.; MACHDAR, I.; UEMURA, S.; OHASHI, A.; HARADA, H. (2006a). Potential of a combination of UASB and DHS reactor as a novel sewage treatment system for developing countries: Long-term evaluation. Journal of Environmental 
Engineering, 132(2): 166-172.

Van LOOSDRECHT, M. C. M.; JETTEN, M. S. (1998). Microbiological conversions in nitrogen removal. Water science and technology. v. 38, n.1, p.1-7.

Von SPERLING, M. (1996). Introdução à qualidade das águas e ao tratamento de esgotos. 2. ed. rev. Belo Horizonte: DESA/UFMG. v. 1.

VIEIRA, L.G.T. (2000). Desenvolvimento de sistema misto (aeróbio/anaeróbio) de leito fixo para remoção de nitrogênio de esgoto sanitário pré-tratado em reator anaeróbio. São Carlos. 144p. Tese (Doutorado) - Escola de Engenharia de São Carlos, USP.

WETZEL, R.G. (1975). Limnology. WB saunders Company, p.186-214.

XIE, S. G.; ZHANG X. J.; WANG Z. S. (2003). Temperature effect on aerobic denitrification and nitrification. Journal of Environmental Sciences, 15(5): 669 - 673.

YE, R.W.; THOMAS, S.M. (2001). Microbial nitrogen cycles: physiology, genomics and application. Current Opinion in Microbiology, 4 pp. 307-312.

YILMAZ, G. (2008). Two stage biological treatment of domestic sewage. Fresenius Environmental Bulletin, 17(2): 240-244.

YOUNG, J.C. (1990). Factors affecting the design and performance of upflow anaerobic filters. Fayetteville University of Arkansas. In: SEMINÁRIO INTERNACIONAL SOBRE DESENVOLVIMENTO DE REATORES ANAERÓBIOS. São Carlos, julho de 1990. 33p.

ZAIAT, M. (1996). Desenvolvimento de reator anaeróbio horizontal de leito fixo (RAHLF) para tratamento de águas residuárias. Tese (Doutorado) - Escola de Engenharia de São Carlos, USP. 
ZAIAT, M.; PASSIG, F.H.; FORESTI, E. (2000). Treatment of Domestic Sewage in Horizontal-Flow Anaerobic Immobilized Biomass (HAIB) Reactor. Environmental Technology, v. 21, p. 1139-1145. 